\title{
RELIABILITY ANALYSIS OF COMMON HAZARDOUS WASTE TREATMENT PROCESSES
}

By

\author{
Robert D. Waters
}

Dissertation

submitted to the Faculty of the

Graduate School of Vanderbilt University

in partial fulfillment of the requirements

for the degree of

DOCTOR OF PHILOSOPHY

in

Environmental and Water Resources Engineering May, 1993

Nashville, Tennessee

\section{Approved:}

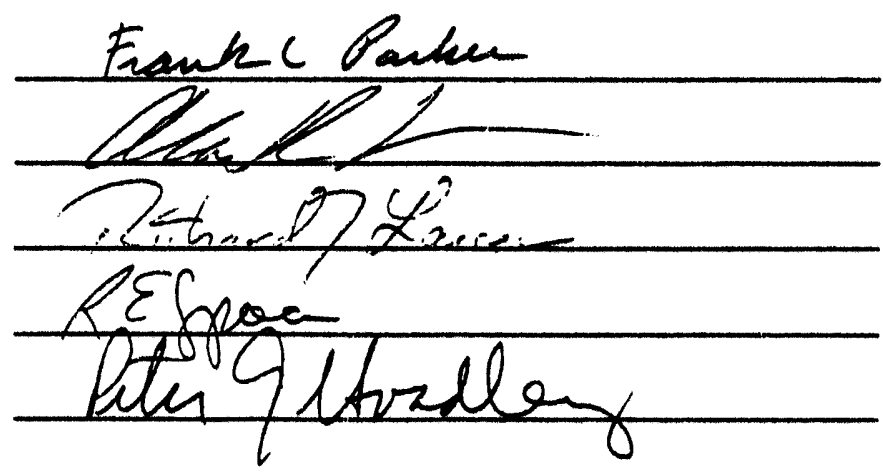

Date:

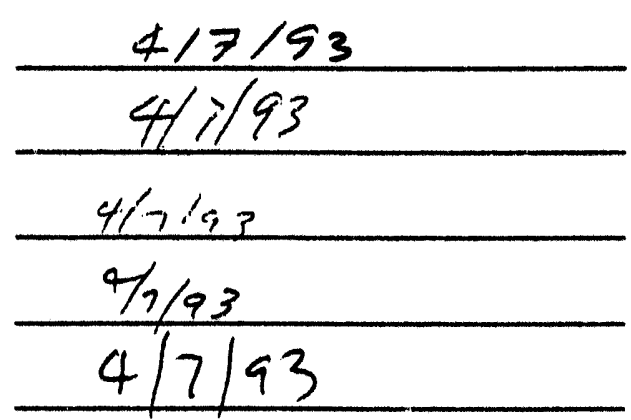




\section{- Copyright by Robert D. Waters 1993 \\ All Rights Reserved}

The Government reserves for itself and others acting on its behalf a royalty free, nonexclusive, irrevocable, world-wide license for governmental purposes to publish, distribute, translate, duplicate, exhibit, and perform any such data copyrighted by the contractor.

\section{DISCLAIMER}

This report was prepared as an account of work sponsored by an agency of the United States Government. Neither the United States Government nor any agency thereof, nor any of their employees, makes any warranty, express or implied, or assumes any legal liability or responsibility for the accuracy, completeness, or usefulness of any information, apparatus, product, or process disclosed, or represents that its use would not infringe privately owned rights. Reference herein to any specific commercial product, process, or service by trade name, trademark, manufacturer, or otherwise does not necessarily constitute or imply its endorsement, recommendation, or favoring by the United States Government or any agency thereof. The views and opinions of authors expressed herein do not necessarily state or reflect those of the United States Government or any agency thereof. 
ENVIRONMENTAL AND WATER RESOURCES ENGINEERING

\author{
RELIABILITY ANALYSIS OF COMMON \\ HAZARDOUS WASTE TREATMENT PROCESSES
}

\title{
ROBERT DAVID WATERS
}

\section{Dissertation under the direction of Professor Frank Parker}

Five hazardous waste treatment processes are analyzed probabilistically using Monte Carlo simulation to elucidate the relationships between process safety factors and reliability levels. The treatment processes evaluated are packed tower aeration, reverse osmosis, activated sludge, upflow anaerobic sludge blanket, and activated carbon adsorption.

The mathematical models used to evaluated each process are the simplest validated deterministic models available in the literature that provide realistic results. Using simple models which require the fewest data inputs increases the likelihood of locating adequate data to generate probability distributions for the model input parameters without sacrificing the integrity of the process model.

Probability distributions for the model parameters are based on data located through extensive literature searches. When sufficient data points for a particular parameter are available, the Kolmogorov-Smirnov goodness-of-fit test is used to determine the appropriate probability distribution. When only a few data points or a data range for a parameter 
are available, the probability distribution is assumed and sensitivity analyses are performed to evaluate the effects of the assumption.

Safety factors, defined as the ratio of an effluent standard to the median design effluent concentration, are determined for each process. Reliability, defined as the frequency that the effluent concentration is lower than the effluent standard, is also determined.

Relationships between treatment costs and reliability levels provide information to decision makers about the tradeoffs of increasing costs with increasing reliability levels. Treatment costs are based on generic designs and are intended for relative comparison only.

The conservatism provided by conventional deterministic designs for the five treatment processes does not always provide high reliability for specific pollutant removal. The degree of reliability required of a treatment process is ultimately a social decision. Relationships between cost and reliability have been determined for each process to aid these decisions.

Approved FrankC Datee Date apmil, 1993 


\section{ACKNOWLEDGMENTS}

I would like to thank the members of my dissertation committee for their guidance throughout this research project, particularly Dr. Frank Parker, who as a friend and advisor, has made my return to academia both challenging and fun.

Special thanks to all the librarians at the science Library and at the Interlibrary Loan office who graciously helped me locate all the data requared to complete this work.

A very special thanks to my wife, Sandy, for supporting and assisting my work, for enduring a summer apart and for always being there for me. I can never thank you enough for the love and support you've given me.

This work was supported in part by a Department of Energy Environmental Restoration/ Waste Management (ER/WM) Fellowship administered by the oak Ridge Institute for Science and Engineering (ORISE). 
TABLE OF CONTENTS

LIST OF TABLES . . . . . . . . . . . . . . . v vii

LIST OF FIGURES . . . . . . . . . . . . . . . . . . . ix

Chapter

I. INTRODUCTION . . . . . . . . . . . . . . . . . 1

Hazardous Chemicals . . . . . . . . . 1

Risks of Hazardous Wastes. . . . . . . . . 3

Federal Environmental Laws . . . . . . . . 10

Present Research . . . . . . . . . 15

II. QUANTIFYING UNCERTAINTY . . . . . . . . . . . . 22

Introduction . . . . . . . . . . . . . 22

Model Uncertainty . . . . . . . . . 23

Parameter Uncertainty . . . . . . . . . 26

Output Uncertainty . . . . . . . . . . 30

Statistical Techniques . . . . . . . 30

Probabilistic Techniques . . . . . . 31

Monte Carlo Simulation . . . . . . 32

Reliability Index Method . . . . 33

Comparison of Monte Carlo

Reliability Index . . . . . 36

Applications ......... . 37

III. PACKED TOWER AERATION . . . . . . . . . . . . . 40

Literature Review . . . . . . . . . . . 40

Research Approach . . . . . . . . . . . . 45

Model Description . . . . . . . . . . 45

Selected Pollutants . . . . . . . . . 46

Results . . . . . . . . . . . . 46

Safety Factor Versus Reliability . . . 46

Sensitivity Analysis ...... . . . 54

Cost Versus Rellability ....... . 55

Comparisons with Conventional Designs. . . . 55

Summary . . . . . . . . . . . . . . . . 58

IV. REVERSE OSMOSIS TREATMENT . . . . . . . . . . . . 61

Literature Review . . . . . . . . . . . 61

Research Approach . . . . . . . . . . . . . . 68

Model Description . . . . . . . . 68

Selected pollutants . . . . . . . 69 
Results. . . . . . . . . . . . . . 72

Safety Factor Versus Reliability . . . . 72

Sensitivity Analyses . . . . . . . . . 79

Treatment Costs . . . . . . . . . . 82

Comparisons with Deterministic Designs : . : 82

Summary . . . . . . . . . . . . . . . 84

V. ACTIVATED SLUDGE TREATMENT . . . . . . . . . 86

Literature Review . . . . . . . . . . 86

Research Approach . . . . . . . . . . . 95

Model Description . . . . . . . . . 95

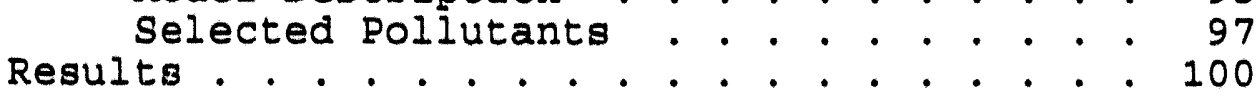

Safety Factor Versus Reliability. . . 100

Sensitivity Analyses.. . . . . . . 108

Cost Versus Reliability . . . . . . . 110

Comparisons with Deterministic Designs . . 110

Summary . . . . . . . . . . . . . . . 114

VI. ANAEROBIC TREATMENT . . . . . . . . . . . . 116

Literature Review . . . . . . . . . 116

Research Approach . . . . . . . . . . . 122

Model Description . . . . . . . . 122

Selected Poliutants . . . . . . . 124

Results . . . . . . . . . . . . . . . 128

Safety Factor Versus Reliability . . . 128

Sensitivity Analyses . . . . . . . . 135

Cost Versus Reliability . . . . . . 136

Comparisons with Deterministic Designs . . 139

Summary . . . . . . . . . . . . . 139

VII. ACTIVATED CARBON ADSORPTION . . . . . . . . . . 141

Literature Review . . . . . . . . . . . . 141

Uniqueness of the Activated Carbon Adsorp-

tion Treatment . . . . . . . . . . . 149

Research Approach . . . . . . . . . 150

Model Description . . . . . . . . . 150

Selected Poliutants and Activated Carbon 151
Results........... . . . . . . 154

Safety Factor Versus Reliability . . . . 154

Sensitivity Analyses....... . . . 161

Cost Versus Reliability . . . . . . . . 162

Deterministic Designs. . . . . . . . . . 166

Summary . . . . . . . . . . . . . . 167

VIII. CONCLUSIONS AND RECOMENDATIONS . . . . . . . . 170

Introduction . . . . . . . . . . . . . 170

Conclusions . . . . . . . . . . . 171 


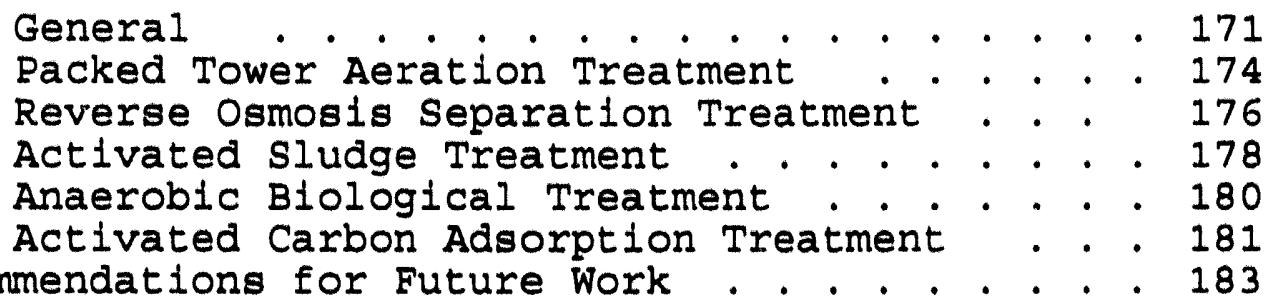

APPENDIX . . . . . . . . . . . . . . . . . . 186

REFERENCES . . . . . . . . . . . . . . . 207 


\section{LIST OF TABLES}

Table

Page

1. Annual Individual Risk of Death Due to Several Common Activities . . . . . . . . . . . . . . 6

2. Major U.S. Environmental Laws . . . . . . . . . 11

3. Sample Activated Sludge Treatment Efficlency Medians and Ranges for Several Hazardous Wastes . 17

4. Common Probability Distributions and Their Parameters . . . . . . . . . . . . . . .

5. Chemical and Physical Properties of Benzene and Trichloroethylene for Packed Tower Aeration Treatment

6. Probability Distribution Parameters of Benzene and Trichloroethylene for Packed Tower Aeration . .

7. Properties of Reverse Osmosis Membranes . . .

8. Chemical and Physical Properties of Cadmium and Lead for Reverse Osmosis Treatment . . . . . .

9. Summary Statistics for Reverse Osmosis Treatment of Cadmium and Lead . . . . . . . . . . . . .

10. Examples of Operating Pressures and Flux Rates for Cellulose Acetate Reverse Osmosis Membranes .

11. Chemical and Physical Properties of Phenol and Chloroform for Activated Sludge Treatment . . .

12. Probability Distribution Parameters for Phenol and Chloroform................

13. Some Compounds Shown to Degrade Anaeroblcally . . 117

14. Chemlcal and Physical Properties of Phenol and 2,4-Dichlorophenol . . . . . . . . . . . . 125

15. Probability Distribution Parameters for Phenol and 2,4-Dichlorophenol. . . . . . . . . . . . . . 
16. Parameters for Numerical Solution of the MADAM Activated Carbon Adsorption Model . . . . . . . . 152

17. Chemical and Physical Properties of Benzene and Carbon Tetrachloride for Activated Carbon

Adsorption Treatment . . . . . . . . . . . . . .

18. Summary Statistics for Activated Carbon Adsorption Treatment of Benzene and Carbon Tetrachloride . . 156

19. Summary of Safety Factor, Cost and Reliability Results . . . . . . . . . . . . . . . 175

20. Packed Tower Aeration; Henry's Constant, $K_{H}$. . . 187

21. Packed Tower Aeration; Gas Diffusivity, $D_{G}$. . . 190

22. Packed Tower Aeration; IIquid Diffusivity, $D_{L}$. . 191

23. Reverse Osmosis Separation; Cellulose Acetate Membranes . . . . . . . . . . . . . . . . .

24. Activated Sludge/Anaerobic Treatment; Henry's

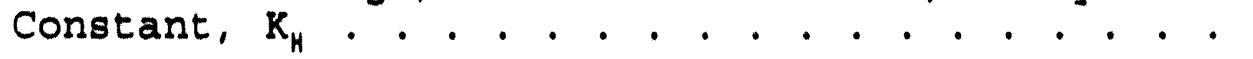

25. Activated Sludge/Anaerobic Treatment; Log Octanol - Water Partition Coefficient, $\log \mathrm{K}_{\mathrm{ow}} . .$. . .

26. Anaerobic Treatment; First Order Degradation Rate, $\mathrm{K}_{\mathrm{b}}$

27. Activated Sludge Treatment; First Order Degradation Rate, $\mathrm{K}_{b}$

28. Activated Carbon Adsorption; Filtrasorb 400 Parameters

29. Activated Carbon Adsorption; Freundlich Adsorption Constant, $\mathrm{K}$. . . . . . . . . . . . . . . . . . .

30. Activated Carbon Adsorption; Freundlich Adsorption Exponent, $(1 / n)$

31. Activated Carbon Adsorption; Surface Diffusion Coefficient, $D_{S}$. . . . . . . . . . . . . . . . 204

32. Activated Carbon Adsorption; F1lm Diffusion Coefficient, $\mathrm{K}_{f}$. . . . . . . . . . . . . . 205

33. Kolmogorov-Smirnov Test Statistics . . . . . . 206 


\section{LIST OF FIGURES}

Figure

Page

1. Probability Distributions of Supply and Demand Functions in Reliability Analysis . . . . . . . . 35

2. Schematic Diagram of the Air Stripping Process . 42

3. Relation Between Safety Factors and Reliability Levels . . . . . . . . . . . . . . . .

4. Cumulative Probability Density Function (CDF) of Packed Tower Aeration Effluent Concentrations for TCE

5. Safety Factor Versus Reliabllity for Air stripping Treatment of Benzene . . . . . . . . . . . . .

6. Safety Factor Versus Reliability for Air stripping Treatment of Trichloroethylene (TCE) A

7. Treatment Cost Versus Reliability for Air Stripping Treatment of Benzene . . . . . . . .

8. Treatment Cost Versus Reliability for Air stripping Treatment of Trichloroethylene (TCE)

9. Comparison of the Packing Heights Calculated with the Deterministic Design and the Packing Heights Associated with Probabilistic safety Factors. . . 59

10. Schematic Diagram of the Reverse Osmosis Process . 62

11. Alpha Versus $x_{v}$ for Reverse Osmosis Treatment of Cadmium

12. Alpha Versus $x_{v}$ for Reverse Osmosis Treatment of Lead . . . . . . . . . . . . . . . . . . .

13. Cumulative Probability Density Function (CDF) of Reverse Osmosis Treatment Ratios for Cadmium . . . 75

14. Safety Factor Versus Reliability for Reverse Osmosis Treatment of Cadmium . . . . . . . . . .

15. Safety Factor Versus Reliability for Reverse Osmosis Treatment of Lead 
16. Reverse Osmosis Treatment Capital Cost Versus Feed Rate ...................... 83

17. Schematic Diagram of the Activated sludge

Treatment Process ................ . 88

18. Comparison of Monod and Haldane Kinetic Models.. 90

19. Example of Uncertainty Associated with

Experimental Data and Attempt at Best-Fit Haldane

Kinetic Model . . . . . . . . . . . . . .

20. Cumulative Probability Density Function (CDF) of

Activated sludge Effluent Concentrations for

Phenol................. . . . . 102

21. Safety Factor Versus Reliability for Activated

Sludge Treatment of Phenol... . . . . . . 103

22. Safety Factor Versus Reliability for Activated

Sludge Treatment of Chloroform . . . . . . . . 104

23. Phenol Fraction Removed Versus Safety Factor. . . 105

24. Chloroform Fraction Removed Versus Safety Factor. 107

25. Cost Versus Reliability for Activated sludge

Treatment of Phenol . . . . . . . . . . . . 111

26. Cost Versus Reliability for Activated sludge 112

27. Interdependencies of Anaerobic Treatment Bacteria 119

28. Anaerobic Wastewater Treatment Processes . . . . 123

29. Cumulative Probability Density Function (CDF) of UASB Effluent Concentrations for Phenol . . . . . 129

30. Safety Factor Versus Reliability for UASB

Treatment of Phenol . . . . . . . . . . . . .

31. Safety Factor Versus Reliability for UASB Treatment of 2,4-Dichlorophenol . . . . . . . . 132

32. Phenol Fraction Removed Versus Safety Factor . . 133

33. 2,4-Dichlorophenol Fraction Removed Versus Safety Factor . . . . . . . . . . . . . . . . .

34. Cost Versus Reliability for UASB Treatment of Phenol 
35. Cost Versus Reliability for UASB Treatment of 2,4Dichlorophenol . . . . . . . . . . . . . .

36. Schematic Diagram of the Activated Carbon Adsorption Process . . . . . . . . . . . . .

37. Cumulative Probability Density Function (CDF) of Activated Carbon Adsorption Breakthrough Time for Benzrile . . . . . . . . . . . . . . . . .

38. Safety Factor Versus Reliability for Activated Carbon Adsorption Treatnient of Benzene . . . .

39. Safety Factor Versus Reliability for Activated Carbon Adsorption Treatment of Carbon Tetrachloride . . . . . . . . . . . . . . . . 160

40. Treatment Cost Versus Reliability for Activated Carbon Adsorption Treatment of Benzene . . . .

41. Treatment Cost Versus Reliability for Activated Carbon Adsorption Treatment of Carbon

42. Activated Carbon Adsorption Treatment Cost Versus Breakthrough Time . . . . . . . . . . . . . 165 


\section{CHAPTER I}

\section{INTRODUCTION}

\section{Hazardous Chemicals}

All things are poisons, only the dose differentiates the effects.

Paracelsus 1530 AD

Several researchers have reported on the effects of natural toxins in the environment. Ames et al. (1987) write that "... no human diet can be entirely free of mutagens or agents that can be carcinogenic in rodent systems." Mold toxins are common pollutants in human foods, especially in the tropics, and over 300 mold toxins have been described. Aflatoxin is a common mold toxin present in peanut butter, wheat, corn and a variety of stored carbohydrates; its toxicity is estimated to be 150 times that of PCBs.

It has been estimated that we ingest at least 10,000 times more by weight of natural toxins, which can amount to five co ten percent of a plant's dry weight, than of man-made pesticide residues (Ames et al. 1987). Oniy a few dozen of the thousands of natural toxins present in the human diet have been tested in animal bioassays and a sizable portion of those tested are carcinogens, many others are mutagens. While these natural toxins are frequently as toxic or more 
toxic than many man-made chemicals, modern America is transfixed by the risks associated with man-made hazards.

Large strides in waste management have occurred in the late nineteenth and twentieth centuries, mostly related to sanitation improvement, and life expectancy has increased as infectious diseases are eradicated. Our attention has shifted in the late twentieth century to chronic illnesses such as cancer and neurological disease and the relation between industrial waste and disease has been questioned (NRC 1991). The rapid development of the chemical industry after World War II brought many benefits to American society without regard for the possible adverse health consequences (Portney 1991). Due to this initial lack of regard for the ultimate fate of the by-products and wastes of the chemical revolution, hazardous waste management has now become a major polttical and social issue of our time.

The Resource Conservation and Recovery Act (RCRA) (U.S. Congress 1976a) defines hazardous waste as a waste (42 USC $1004[5]):$

... which because of its quantity, concentration, or physical, chemical, or infectious attributes, may: (a) cause, or significantly contribute to an irreversible, or incapacitating reversible, illness; or (b) pose a substantial present or potential hazard to human health or the environment when improperly treated, stored, transported, or disposed of, or otherwise managed.

Under this broad definition, the volume of hazardous waste in the United States is staggering and the generating sources diverse. One congressional study estimated that 255 
to 275 million metric tons of hazardous waste are generated each year (U.S. Congress 1983) and another study confirmed this range (NRC 1985).

The cost of hazardous waste management is also staggering. An estimated $\$ 4.2$ billion/year was spent on hazardous waste sites in the U.S. throughout the 1980 s (U.S. Congress 1989). Compliance with the Federal clean air and water regulations has cost an estimated $\$ 640$ billion (Portney 1991). The Department of Energy (DOE) profects that more than $\$ 30$ billion will be required for environmental restoration and waste management activities between 1992 and 1996 and this may be fust for the discovery phase of a program that could cost hundreds of billions of dollars (U.S. Congress 1991) to over one trillion dollars (Russell et al. 1991). DOE has estimated that $\$ 91$ billion may be required just for RCRA and CERCLA compliance.

\section{Risks of Hazardous Wastes}

Public opinion polls consistently rank hazardous waste sites as the most serious environmental risks (Portney 1991) with the underlying fear being their connection with cancer. Yet, while the age-adjusted cancer mortality rate has increased by $6 \%$ between 1950 and 1987, mortality due to heart disease over the same period has decreased by $55 \%$ (Henderson et al. 1991). These figures show that even with no hazardous waste, the risk of dying from cancer must increase in our 
aging population simply due to the reduction or elimination of other fatal diseases. Advances in medical detection and diagnostics also contribute to the increased percentages of deaths attributable tn cancer (Henderson et al. 1991).

Doll and Peto (1981) estimate that 75 to 80 of all cancers are avoldable and are due to lifestyle and environmental factors. Henderson et al. (1991) agree and show that only 1 to 5 t of avoldable cancers are attributed to pollution, and only 1 to 2 to industrial products. These facts lead the researchers to conclude:

The widespread public perception that environmental pollution is a major cancer hazard is incorrect.

Yet, fear of hazardous wastes continues to be a major issue. Another indicator of the public's concern with hazardous wastes is 1llustrated by a comparison of the values-of-ilfe implicit in U.S. regulatory agency risk abatement programs. While explicitly placing a value on a human life is rarely done, each regulation concerned with public safety inherently does so simply because money is spent and an estimated number of accidents or illnesses are prevented.

Morgan (1981) and the Council on Environmental Quality (CEQ) (1990) both show that regulations dealing with familiar accidents or illnesses such as those related to highway safety, Department of Health and Human Services programs and Consumer Product Safety Commission programs implicitly value life generally in the hundreds of thousands of dollars while, 
in general, EPA and OSHA regulations dealing with hazardous substances implicitly value life at greater than $\$ 3$ mililon. One estimate at a superfund cleanup site reported an implicit value-of-life at $\$ 15$ billion (Abelson 1992).

Why are we spending so much money and effort on hazardous waste management when the real risks to 11 fe are elsewhere? One reason is the misunderstanding of the concept of safety. Adequate safety is a social decision and cannot explicitly be determined by scientists or engineers. No human activity is totally without risk and society has generally placed restraints on riskier activities (e.g., lifejackets in boats, seat belts in automobiles, building codes, limits to occupational exposures). Some risk pathways are obvious and solutions apparent (e.g., drowning and lifejackets) while other risk pathways are more subtle (e.g., exposures to hazardous waste).

The need to compare relative risks has been realized in the 11terature (Travis and Cook 1990, NRC 1977) and the federal regulations deem activities presenting lifethreatening risks to Individuals below $10^{\circ 6}$ per lifetime (one in a milifon) as de minimis (de minimis non curat lex - the law does not concern itself with trifles). An enormous amount of data has been collected on the risk of various human activities and the range of risks is impressive. Table 1 lists the risk of several common activities. Yet, while the risks associated with hazardous waste are far 
Table 1. Annual Individual Risk of Death Due to Several Common Activities.

\begin{tabular}{|c|c|}
\hline $\begin{array}{l}\text { Coal Mining } \\
\text { Accident }\end{array}$ & $1.3(10)^{-3}$ \\
\hline Black Lung & $8.0(10)^{.3}$ \\
\hline Firefighting & $8.0(10)^{-3}$ \\
\hline Motor Vehicle & $2.2(10)^{-4}$ \\
\hline Truck Driving & $1.0(10)^{-4}$ \\
\hline Falls & $7.7(10)^{-5}$ \\
\hline Football & $4.5(10)^{-5}$ \\
\hline Home Accidents & $1.2(10)^{-5}$ \\
\hline BIcycling & $1.0(10)^{.5}$ \\
\hline Alr travel & $2.0(10)^{-6}$ \\
\hline Regulated Hazardous Waste & $1.0(10)^{.6}$ \\
\hline $\begin{array}{l}\text { Hazardous waste is regulated } \\
\text { based on theoretical consider } \\
\text { actual individual risk of deat } \\
\text { wastes is probably much lower. }\end{array}$ & $\begin{array}{l}\text { to this risk level } \\
\text { rations only. The } \\
\text { th due to hazardous }\end{array}$ \\
\hline
\end{tabular}

Source: Rodericks and Taylor 1990 
smaller than other, more common activities, the fear of these wastes persists.

Risk perceptions have been studied extensively by sociologists and psychologisto and several factors have been identified as contributing to the increased fear of hazardous wastes, nuclear power and risks of other "new" technologies. slovic et al. (1979) ldentified elght characteristics that tend to alter the perception of rigk. The amount of control an individual exerts over a situation and whether the risk is voluntary or involuntary are two major contributors to ribk perception. People feel in control while driving their car yet feel this control has been lost as a passenger in a jet; thus, while the statistics indicate air travel to be far safer than automoblie travel, perceptions are different. Routine medical x-rays are voluntary while exposure to the emissions of the near-by nuclear power plant are less so; thus, the risk from the nucleax plant is perceived to be higher.

of course, the effects of commercial and political motivations for blurring the risks are also present. Moghissi (1987) compares the effects of "low-level misinformation" with that of low-level exposure to toxins and asserts that the consequences of this exposure are the misallocation of time, effort, money, and concern.

Many of these issues associated with the risk of hazardous waste can be stated in scientific terms but are in 
principle beyond the competency of science to answer. Alvin Welnberg (1972) has called these 18вues trans-sclence.

Risk is commonly defined by sctentists and engineers as the product of the probability and consequence (to whom and the quality of the consequence) of an event. Risk assessment has been developed as a technique to quantify the risks associated with a particular activity. With risk assessment, low probability-high consequence events are given similar welght to events of medium probablitty and consequence. Probabiliotic risk assessments, develcped to atudy nuclear reactor safety (U.S. NRC 1975), are commonly used to quantify the risks of low probability-high ccnsequence events.

Risk assessments are generally divided into three components: hazard ldentification, exposure assessment and hazard assessment (Travis and Cook 1990) and uncertainties abound in every step of the process.

Hazard 1dentiflcations are based on epidemiological studies, long-and short-term animal tests or comparisons of molecular structure. The uncertainty associated with epldemlological studies has prompted one researcher to jest that the definition of a catastrophe $1 \mathrm{~s}$ that "... the effect is large enough that even an epidemlological study can detect 1t" (Hatt1s and Kennedy 1986).

Animal studies have the distinct problem of extrapolation from high doses in animals to low doses in humans. Ames er al. (1987) have stated that the effect of 
high doses on experimental animals may contribute more to the cause of the resulting tumors than the specific chemicals.

The preferred method of the U.S. EPA for designating a new substance as hazardous under the Toxic Substances Control Act (TSCA) (U.S. Congress 1976b) is by comparing oimilarities of Its molecular eructure with previously ldentified hazardous substances. This method 1s popular under TSCA due to the ease of application and low cost of ldentifying new substances as hazardous yet carries all the uncertainty associated with ldentifying the original substance as hazardous in addition to the uncertainty due to extrapolation.

Exposure assessments are the most resource demanding portion of the evaluation and the weakest liak in risk assessments. Mathematical models describing environmental transport are, at best, gross aimplifications of the true exposure phenomenon and provide only crude estimations regardlese of model sophistication.

Hazard assessments are based on mathematical models that attempt to explain the effect of chemicals in the human body. Travis and Cook (1990) present a good summary of these models and the linear, no-threshold model used by the EPA is fust one example of the many available dose-response models. The major uncertainties in this area are the dose and inter. species extrapolations including differences in iffe spans, body size, genetic varlability, presence of disease, and 
metabolism (Travis and Cook 1990, NRC 1977).

Risk assessments are full of uncertainty and the federal regulations concerning hazardous and toxic wastes deal with each of these uncertainties differently. A short discussion of how the major federal hazardous and toxic waste regulations deal with uncertainty will 11lustrate this point.

\section{Faderal Environmental Lawe}

The major federal laws dealing with hazardous and toxic substances are 11sted in Table 2. The statutory purpose, definttions of harmeul substances, descriptions of harm, types of riok considered, and other characteristics of the major federal environmental laws have been tabulated elsewhere (Martin and Johnson 1987).

Most federal environmental laws cite protection of human health as the primary basis for standards although the methods of attaining this protection vary widely. Three general methods are used for setting regulatory levels: health-based standards, rlsk-based standards and technologybased standards.

Health-based standards assume that for certain chemicals there is a concentration below which no adverse health effects occur and these threshold limits are generally based on protection of the most sensitive individuals. These atandards somewhat oimplistically imply that there is zero risk below the threshold concentration. 
Table 2. Mafor U.S. Environmental Laws.

Statue

Agency

Coverage

DOT- Water shipment

USCG of toxic

matertals

Clean Air Act (1970), amended 1977)

Comprehensive Environmental

Response, Compensation, and

Liability Act (1972)

Consumer Product safety Act

(1972)

Dangerous Cargo Act (1952)

EPA Air pollutanto

EPA Hazardous

substances, pollutants, contaminants

CPSA Dangerous consumer products

DOT. Water shipment

USCG of toxic materials

Federal Hazardous Substances

Amendment Act (1976)

CPSC Toxic household producta

Federal Insecticide, Funglcide, and Rodenticide Act (1948), amended 1972)

Federal Water Pollution

Control Act (1972, amended 1977, 1978)

Food, Drug, and Cosmeric Act (1932)

Color-Additive Amend. (1960)

Food Additives Amend. (1958)

Medical Devices Amendment

New Animal Drug Amend. (1968)

New Drug Amend. (1962)

Hazardous Macerials

EPA Pesticides

EPA Water

pollutants

EDA Food, Drugs,

Cosmetics,

Color

additives, Food

additiver,

Medical

devices, Animal

druga, Feed

additives,

New Drugs

Transportation Act

DOT Transportation

of hazardous

materialo 
Table 2. (Cont.) Major U.S. Environmental Laws.

\begin{tabular}{|c|c|c|}
\hline statue & Agency & Coverage \\
\hline $\begin{array}{l}\text { Lead-Based Paint Poison } \\
\text { Prevention Act (1973, } \\
\text { amended 1976) }\end{array}$ & CPSC & $\begin{array}{l}\text { Lead Paint in } \\
\text { federaliy } \\
\text { assisted housing }\end{array}$ \\
\hline $\begin{array}{l}\text { Marine Protection, Research, } \\
\text { and Sanctuaries Act }(1972)\end{array}$ & EPA & Ocean dumping \\
\hline $\begin{array}{l}\text { Occupational Safety and } \\
\text { Health Act }(1970)\end{array}$ & OSHA & $\begin{array}{l}\text { Workplace } \\
\text { exposures }\end{array}$ \\
\hline $\begin{array}{l}\text { Pesticide Residues Amendment } \\
(1954 \text {, amended 1972) }\end{array}$ & EPA & $\begin{array}{l}\text { Pesticide } \\
\text { residues in food }\end{array}$ \\
\hline $\begin{array}{l}\text { Polson Prevention Packaging } \\
\text { Act }(1970)\end{array}$ & CPSA & $\begin{array}{l}\text { Packaging of } \\
\text { dangerous } \\
\text { products }\end{array}$ \\
\hline $\begin{array}{l}\text { Ports and Waterways Safety } \\
\text { Act }(1972)\end{array}$ & $\begin{array}{l}\text { DOT. } \\
\text { USCG }\end{array}$ & $\begin{array}{l}\text { Water shipment of } \\
\text { toxic materials }\end{array}$ \\
\hline $\begin{array}{l}\text { Resource Conversion and } \\
\text { Recovery Act (1976) }\end{array}$ & EPA & Hazardous wastes \\
\hline $\begin{array}{l}\text { Safe Drinking water Act } \\
(1974 \text {, amended } 1977)\end{array}$ & EPA & $\begin{array}{l}\text { Drinking-water } \\
\text { contaminants }\end{array}$ \\
\hline $\begin{array}{l}\text { Toxic Substances Control } \\
\text { Act }(1976)\end{array}$ & EPA & $\begin{array}{l}\text { Chemical hazards } \\
\text { not covered by } \\
\text { other laws }\end{array}$ \\
\hline $\begin{array}{l}\text { Hazardous and Sol1d Waste } \\
\text { Amendments }(1984)\end{array}$ & EPA & Hazardous wastes \\
\hline $\begin{array}{l}\text { Superfund Amendments and } \\
\text { Reauthorization Act }(1986)\end{array}$ & EPA & Hazardous wastes \\
\hline
\end{tabular}

After: Martin and Johnson 1987 
The National Ambient Air Quality Standarda (NAAQS) for existing sources under the Clean Air Act (U.S. Congress 1970) were set to prevent health risks to the most sensitive individuals and prevent further deterioration of ambient air qual1ty. Standards for contaminant concentrations under the Safe Drinking Water Act (U.S. Congress 1974) were also based on maximum contaminant levels which produce no adverse health effects although the requirement to use best treatment technology also makes the act technology-based. When threshold limite can not be established, for example for carcinogens, other approaches must be developed.

Risk-based standards have been developed, based on a more sophisticated understanding of health risks, to fill the gap created by health-based standards for chemicals for which no thresholds could be established. All regulations dealing with carcinogens fall into this category by definition since a zero threshold is assumed. The allowable concentrations for carcinogens are based on a $10^{\circ}$ individual lifetime risk of cancer. These standards explicitly realize the risk inherent in all human activi=ies.

The Comprehensive Environmental Response, Compensation, and Liability ACt (CERCLA) (U.S. Congress 1980) and Resource Conservation and Recovery Act (RCRA) (U.S. Congress 1976a) are two examples of acts with risk-based standards.

Technology-based standards are used when the methods of obtaining the desired risk levels have not been adequately 
developed or additional control is desired. These "commandand-control" regulations provide little leeway for alternative designs and the advantage of consistency is frequently outweighed by disadvantages which include the lack of an unambiguously best technology, assumptions that benefits are worth the costs and the designation of specific control technologies even if better technologies become available (Portney 1991).

RCRA hazardous waste landfill design is an example of a technology-based, command-and-control regulation. The "bestavailable" technology requirements of the Clean water Act (CWA) (U.S. Congress 1977) are another example of a technology-based standard.

Surprisingly, the federal hazardous waste regulations sometime present an impediment to treatment although treatment is the preferred method of the 1984 solid waste amendments to RCRA (U.S. Congress 1976a). RCRA states that the residuals from treatment of listed hazardous waste are also hazardous by definition. Therefore, even if listed wastes are rendered harmless by treatment, the residuals must still be managed as hazardous waste. The de-listing process is long and complicated, further reducing the incentive to treat.

The diversity and inconsistency of the environmental regulations makes the determination that a chemical is hazardous or toxic relatively difficult. The definition 
depends on the particular regulation and even the particular use of the material. There are also no standard procedures to describe the hazard level for physically and chemically complex wastes (Travis and Cook 1990).

\section{Present Research}

In the best of all worlds, once treatment standards are set, treatment processes would be designed to guarantee the necessary level of treatment. Yet, even steady-state processes exhibit output variability due to the variability and uncertainty associated with the inputs and process parameters.

The traditional response to uncertainty is increased conservatism resulting in increased cost. Engineers, attempting to guarantee the high reliability of their designs in the face of uncertainty, sometime produce exceedingly conservative designs. But, as Freudenthal (1947) writes:

... without complete information, it is not feasible (practically or economically) to assure absolute safety or performance of engineered systems.

P.'gsley (1966) adds that:

... a profession that never has accidents is unlikely to be serving its country efficiently.

While performance data on gross parameters (e.g. TOC, BOD, SS) are documented for several treatment processes, little long-term data on removal of specific hazardous wastes are available. Additionally, Martin and Johnson (1987) note that many times, removal of specific toxics appears to be 
incldental rather than intentional.

Median removal efficiencies and efficiency ranges for specific toxics or classes of toxics have been complied by the EPA (U.S. EPA 1983, U.S. EPA 1992) for several treatment processes and an example is shown in Table 3. Unfortunately, little work has been done to quantify the distribution of treatment efficiencies for specific toxics and treatment processes or to determine what factors are causing the variations in the output.

Probablity theory provides a means for quantifying the uncertalnty in a process and predicting the variability of the outcomes. Monte Carlo simulation is used in this research to relate safety factors (degree of conservatism) to specific reliability levels for five common hazardous waste treatment processes: packed tower aeration, reverse osmosis separation, aerobic and anaerobic blological oxidation, and activated carbon adsorption.

The five treatment processes investigated in this research have been selected for their diversity, long history of successful treatment of conventional wastes, availability of validated mathematical models and the growing body of research indicating their abllity to successfully treat hazardous wastes. These attributes increase the probability of locating data required to perform Monte Carlo simulation.

These processes can be designed to essentially any, frequently very high, mean treatment efficlency. However, 


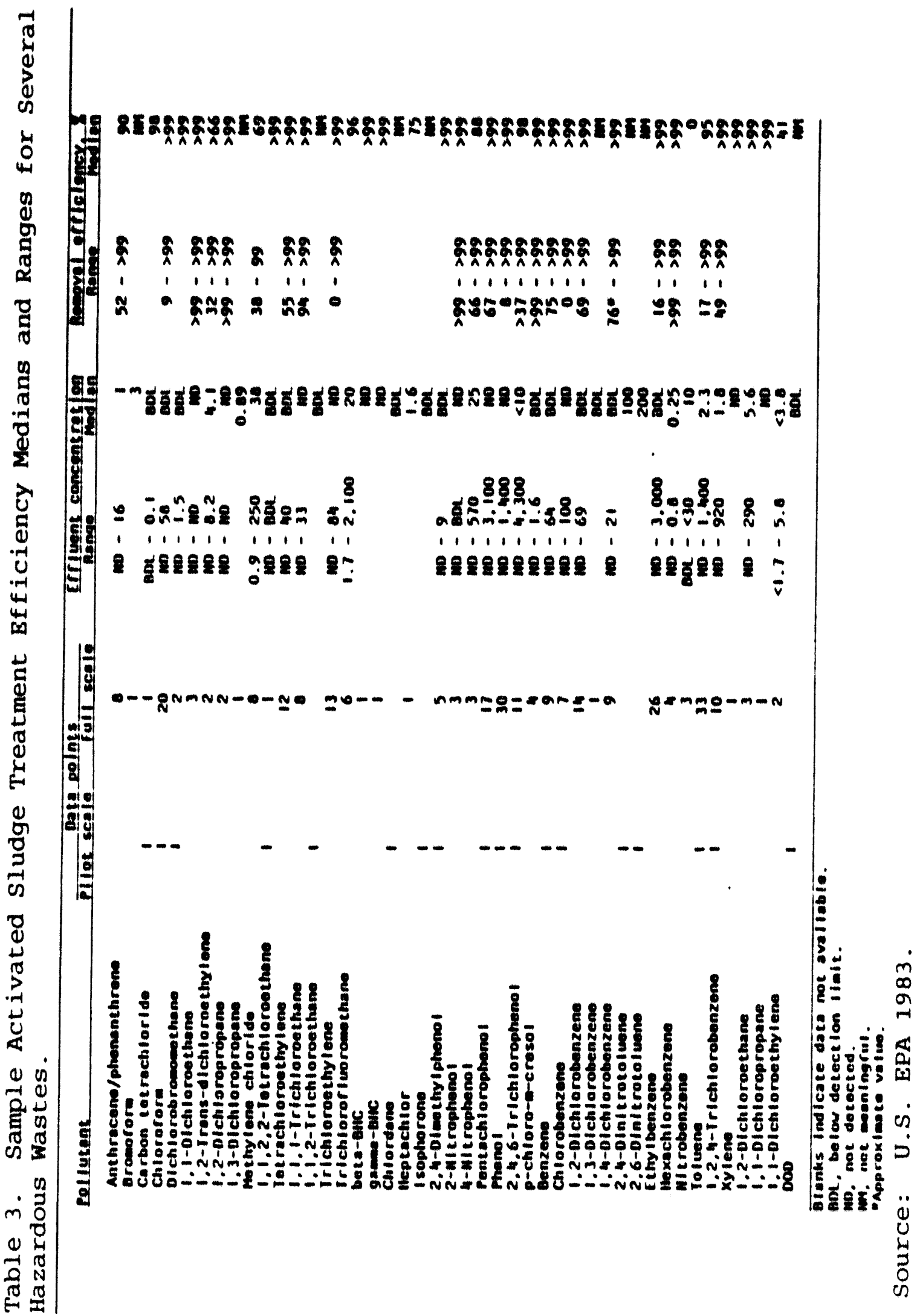


concentrations of the spesific processes treating specific very little is known about the distribution of the effluenthazardous wastes. Probabilistic methods provide a means of elucidating the uncertainty of treatment process performance based on the uncertainty and variability of the input variables and model parameters.

Yet, to improve the design practice currently based on determiniatic analyeis, more 1s required than developing an understanding of the uncertainty associated with the hazardous waste treatment processes. Determining process reliability by linking the uncertainty revealed through probabilistic analysis to the safety factors used in deterministic designs will provide a theoretical basis for the practical design of these treatment processes.

Design standards based on probabilistic methods are not new. A similar approach has resulted in the Load and Resistance Factor Design (LFRD) method for reinforced concrete and steel structures (ACI 1981, AISC 1986). As stated in the AISC code (AISC 1986), the use of a probabilistic mathematical model made it possible to:

... give proper weight to the degree of accuracy with which the various loads and resistances are determined ... and ... provide a rational method for transference of test results into design provision... resulting in ... a more rational design procedure leading to more uniform reliability...

Probabilistic methods have quietly revolutionized structural design because the changes have been internal to 
the process. The practicing engineer is not required to learn more reliablitty theory or understand Mnnte Carlo simulation to benefit from the results of probabilistic analyots. Instead, the safety factors and the method of applying them have been fine-tuned to specific reliability levels, resulting in continued ease of use of deterministic designs coupled with increased uniformity of design reliability.

The application of probabilistic methods to structural design has not dramatically altered the resulting structures because for the most part, the previous designs had evolved over years of trial and error and were reasonable. Such may be the case with the safety factors currently being employed in the design of hazardous waste treatment processes. If the current design practices were inadequate, we would see either no fallures (overly-conservative designs) or very many failures (non-conservative designs). The probabilistic safety factors determined in this research have better theoretical foundations than the conventional safety factors currently in use.

The general research approach consists of five steps:

1. Frobability distributions are fitted to model parameters for specific wastes based on literature reviews.

2. Appropriate effluent standards are selected. Monte Carlo simulations are performed at several mean effluent concentrations less than the standard and a plot of the safety factor versus reliability is generated.

3. Sensitivity analyses are performed to verify all 
assumptions and all results are analyzed statistically.

4. Treatment costs are related to reliablifty levels to provide information on the monetary tradeoff required for high rellability processes.

5. Treatment processes are designed with conventional methods and compared with the probablilstic designs to determine the patterns of conservatism in the conventional designs.

While it would be ldeal to use the same two pollutants to analyze all treatment processes, the nature of the processes are such that they take advantage of specific physical or chemlcal properties of the pollutants le.g., volat1lity, adsorbab1lityl. No pollutants lend themselves to efficlent treatment by all processes and forcing the issue is counter-productive. The next best alternative is to analyze two pollutants that have olgniflcantly different chemical and physical properties and are amenable to treatment by each process. This approach has been adopted in this research.

The two pollutants are evaluated for each treatment process at high and low influent concentrations relative to the specific pollutant and process. Effluent concentrations are set at the Maximum Contaminant Level (MCL) specified under the Safe Drinking Water Act for those pollutants which are so regulated. The selected pollutants and concentration levels for each treatment process have been selected a priori to be amenable to the particular treatment process.

The remainder of this dissertation consists of a review of the methods of quantifying uncertainty, literature reviews 
pertalning to each of the five treatment processes and the results of the research. Conclusions are summarized and areas for additional research are identifled. 
Craprer :I

\section{QOANTIFXINO DICERTAINXY}

\section{Introduction}

Determinietic mathematical models predict the mean behavior of aystems based on mean inputs and model parameters. Bounding variability with deterministic models can only be attempted through worst case scenario analyses and these analyses provide no information about the probability of the workt case.

Alternatively, probabilistic methods seek to provide information on the variability of the outcome based on the varlability or uncertainty of the inputs and model parameters. While deterministic models are limited to prediction of mean values, probabllistic models provide full probability dietributions of the process outputa.

Thomann (1982) has emphasized the need to quantify the uncertainty assoclated with modeling, realizing that decisions are being made based on complex deterministic models with little knowledge of the uncertainty assoclated with the model-generated numbers. Wlthout the quantiflcation of model uncertainty, decision makers may fudge the model output to be completely certain. Gass (1977, Gass and Joel 1981) presents several methods to ensure that a model is 
properly designed, documented and verteled.

At a more eundamental level, otway and von winterfeldt (1992) strese that value fudgements underl le the deciolons to use specific modelo and analytic forms (deterministic versus probabiliatic) and these decisions affect the cope of the analyos and the torm of 1to renults. For example, probabilistic analyses can reveal information that determinietic analyses, by their very nature, will never reveal. But the decinion to use a probabilistic or determiniatic analyois is equenty based on personal or political motivations instead of technical considerations.

While probabiliatic modela are becoming more common, they are not used as erequently as their deterministic counterparts. This lack of commonality is due to several reasons including their increased complexity and need for additional data and many engineers' lack of tamiliarity with probabilistic methods. Penzlas (1989) attributes the scarcity of probabilistic design to the lack of a strong statistical background of most engineers.

\section{Model Oncertalnty}

Model uncertainty arises from tour sources (Lund 1991):

- Uncertainties in model parameters and constants,

- Uncertainties in the true values of the input data,

- Errors introduced by numerical solution techniques,

- Differences in model equations and reality. 
Uncertainty resulting from the elrat two sources is generaliy quantified through sensitivity analysis or etochastic modeling. Uncertainty due to the third wource is guantified by comparing analytical eolutione of elmple problems with their numerlcal solutions. Uncertainty due to the fourth source (erequently required to make the mathematice tractable) is handled through verification and validation studies. The uncertalnty due to model errors are frequently lumped in with the uncertainty of the model parametere (Dettinger and W11son 1981). Konikow (1986) argues that it is imposelble to truly validate certain types of model. For example, three dimenalonal groundwater transport models that require a prohibitive amount of daca. This discussion assumes that the magnitude and time scale of the model is such that the model can be compared with tield data. Some modele by their very nature, preclude compartoon with lield data. An example of this altuation is a ground-water model used to predict the transport of radionuclides erom a deep geologic repository over a ten thousand year time trame.

Two distinct classes of uncertainty exist in all modelo (Lund 1991, Dettinger and W1loon 1981): Intrinsic and information uncertainty and the difference in their meanings goes right to the definttion of probablitty.

Intrinsic uncertainty describes the variability of certain natural phenomena which is irreducible and inherent. 
Intrinsic uncertainty is characterized by random patterns of constantly tluctuating values and is dealt with through random value theory. The common definition of probability as a relative trequency describes these stuations well when meticlent observation are avallable to develop a erequency distribution. Once an adequate number of observations have been made, additional observatione will not greatly affect the relative erequencies or probabilitien.

An example of intringic uncertainty is ten year'a worth of dally flow rate measurement erom a mountain etream. The erequency dietribution of the flow values w111 probably form a log-normal distribution but the etream flow values are random euch that twenty years of data will give eseentially the same dietribution. The intrinelc uncertainty is not decreased through additional measurements.

On the other hand, information uncertainty becomes important when an invueficient number of observation preclude development of a defintelve frequency distribution. Intormation uncertainty is based on the definition of probablitty as the degree of bellef. Probability-as-relative erequency 18 a subset of the more general probability.as. degree of belief definition and 1 applicable only when sufficlent observations allow determination of relative Erequencies.

The defintition of probability as degree of belief is not new (Savage 1954 ) but practitloners are in the minority, 
though they are galning otrength (Jaynes 1986). So-called "Bayesian" probability 18 particularly amenable to evaluation of low-probability events, such as nuclear power plant accidents, where Insueficlent observations render relative Erequency distribution essentially meaningless.

Information uncertainty also applies to aituations of nolsy or incomplete data whose uncertainty can be reduced by further measurement and analysis. Thus, the otandard deviation of the estimate for a single-valued parameter whose true value 1. unknown decreases as additlonal samples are taken. Measurement errors fall into this category. For example, meavuring the concentration of a poliutant in the groundwater will give an ldea of the true value of the concentration but measuring ten times provides much better Information. Additionally, repeated measurements with more precise equipment will give even more confidence in the true value and provide a sharper probability distribution.

As these simple examples 1llustrate, intrinsic uncertainty is independent of information uncertainty but the reverse is not true. Regardless of whether intrinsic or information uncertainty provides the variability, some basic probability diatributions (Table 4) can be utilized to model the resulting variability.

\section{Parameter Uncertainty}

When adequate data are available, frequency distribution 
Table 4. Common Probability Distributions and Their Parameters.

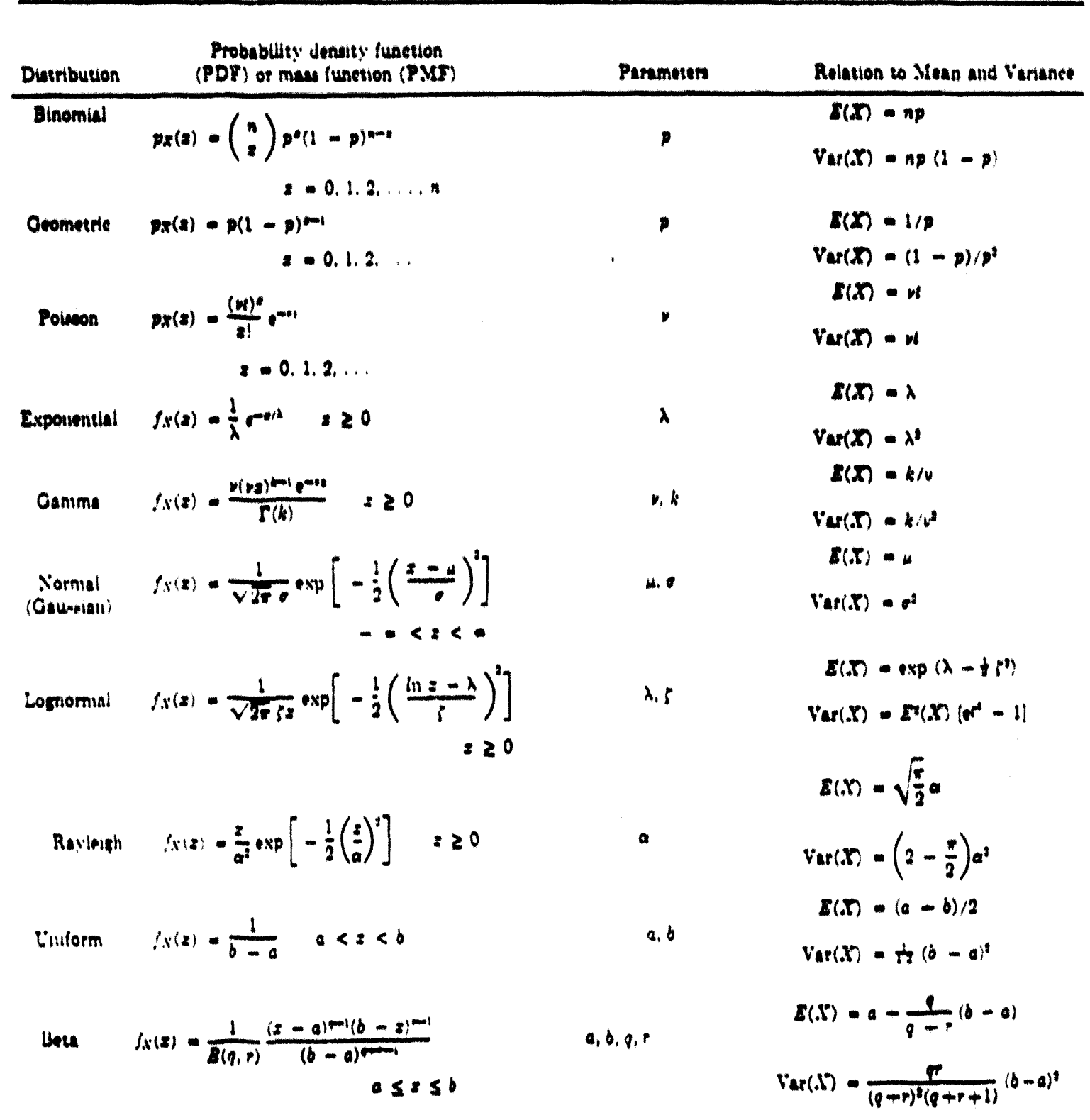

Source: Ang and Tang 1975 
plots will indicate the shape of the underlying probability distribution. Once the probability distribution is determined, common statistical techniques can be used to determine the distribution parameters.

Frequently, only a few data points or the range of a parameter is known and the shape of the distribution must be assumed. Engineering juagement or expert opinion is required to determine the shape of the distribution. Two concerns arise: the use of subjective expert opinion and the fitting of distribution parameters.

Expert opinion has been found to be an effective method of determining the shape of a probability distribution and fairly reliable results may normally be expected from experienced analysts (Hauptmanns and Hömke 1989). While experts tend to estimate the mode and median fairly accurately, estimates of the mean (in skewed distributions) tend to be biased toward the median. Therefore, central tendency estimates received from engineers should be used as medians (Apostolakis 1980).

Assumptions about the shape of the distributions must be verified through sensitivity analyses. In this research, when a normal or log-normal distribution is assumed for a parameter based on lack of data, the model results are compared with the sensitivity of assuming the uniform distribution fit for the parameter. If the model results are not significantly different under these extremely different 
distribution assumptions then the model is robust to the shape of the parameter's distribution and the assumption is not invalidated. If the model results are significanty different, then an area of additional research is 1dentified.

The normal distribution has strong basis in measurement theory through the Central Limit Theorem. This symmetrical distribution frequently models parameters that range less than one order of magnitude. Some parameters can range over several orders of magnitude and exhibit skewness (e.g., lowlevel pollutant concentrations). The log-normal probability distribution is commonly used to describe such parameters.

Engineers have long recognized that the log-normal distribution will generally fit extremely skewed data ranging over several orders of magnitude and Chow (1954) has provided a theoretical basis for this relationship. The log-normal distribution reduces to the normal distribution when the logs of the data are plotted.

In this research, distributions of parameters with very few data points are fitted by calculating the sample mean and standard deviation. Distributions are fitted to parameter ranges by assuming the range corresponds to the two-sided $90 \%$ confidence interval. In both cases, the normal distribution is assumed if the resulting two-sided $90 \%$ confidence interval is less than one order of magnitude. Otherwise, the lognormal distribution is assumed. Broshears (1986) presents a detailed discussion of the method of fitting distributions to 
parameter ranges.

\section{Output Uncertainty}

\section{Statiot 1cal Techniques}

When sufficient data are available on the variablitty of the inputs, parameters and outputs of a process, statistical analysis can be performed to quantify the variability contributed by each input and process parameter. Regression analyses are used to quantify the variability due to individual parameters and a range of statistical tests are avaliable to quantify the confidence in the estimations. Further information on these statistical procedures can be found in many texts on statistical analysis, for example Larsen and Marx (1986).

Niku et al. (1981) used statistical techniques to study the reliability, stability and variability of several secondary municipal waste treatment plants. Gross parameters (e.g., biochemical oxygen demand (BOD), total organic carbon (TOC), suspended solids (SS)), input loadings and process and environmental parameters were evaluated.

The most interesting result of their research is that the combination of all studied input variations explained only 13-61\% of the effluent $B O D$ and 5-52\% of the suspended solids fluctuations. The remaining fluctuations were either inherent in the system or due to other unmeasured factors.

A major problem when dealing with actual operating data 
is that all input variability cannot be controlled or quantified. Plant operators make mistakes and process upsets occur and these gross varlations frequently overshadow the inherent system variability. The cost of collecting data for all variables of interest is also daunting.

Another problem with statistical analysis of data from several treatment plants is the nature of the resulting summary statistics. These summary statistics really describe the differences in plant performances and not necessarily the true treatment statistics. Well designed, well run plants may show up as outliers on the upper tall of the plant performance distribution when they should really be used as the target for performance for the other plants. Large differences in operating parameters between plants also make comparisons difficult.

The data required to perform statistical analyses are frequently lacking (always lacking when the plant is on the drawing board) and other methods must be developed to quantify the remaining uncertainty. Probabilistic methods are used to predict the variability in just such cases.

\section{Probabilistic Technigues}

Two general techniques are available for performing probabilistic uncertainty analysis: full distribution analysis and first and second moment methods (Dettinger and Wilson 1981). 
Full distribution methods use the complete specification of the probabilistic properties of the non-deterministic inputs to specify the complete probability density function (pdf) of the output. Monte Carlo simulation is the most frequently used full distributjon method.

\section{Monte Carle simulation}

Named for the city in Monaco famous for roulette wheels (Marr and Canale 1988), Monte Carlo simulation involves numerous replications of deterministic system simulations with input parameters selected at random from their probability density functions (pdfs). For a continuous variable, the pde is defined such that if $f_{x}(x)$ is the pdf of $x$, the probability of $x$ in the interval $(a, b)$ is

$$
P(a<X \leq b)=\int_{a}^{b} f_{X}(x) d x
$$

The output from many realizations of the stochastic inputs are statistically analyzed to yield estimates of the mean and variance of the stochastic processes. Monte Carlo simulation is straightforward in its application and can be applied to simple or complex systems involving numerical or analytical solutions (Sitar et al. 1987). Complex geometry and boundary conditions can be included.

The process is essentially computer experimentation because the resulting data are subject to the same analyses as other experimental data including parameter estimation, 
inference and sampling errors (Ang and Tang 1984). High. speed computers perform complex Monte Carlo simulations in a very short amount of time.

The generation of random numbers from the pdf of a given input palameter is a major task of Monte Carlo simidation and while algortthms for generating these random variables can be written (Ang and Tang 1984), the IMSL library (IMSL 1986) contains well-tested routines for generating random variables from all standard distributions. The major disadvantage of Monte Carlo simulation is the number of lterations required to provide results with sufficient statistical significance (Marr and Canale 1988, Scavia et al. 1981).

Variance reduction techniques are frequently used with Monte Carlo simulation to reduce the number of simulations required to obtain the desired accuracy. Several methods have been used with success including correlated sampling, Latin hypercube and antithetic variates (Ang and Tang 1984). Monte Carlo simulation using antithetic variates is used in this research.

\section{Reliability Index Method}

The reliabllity index method uses the means and variances of model input parameters to determine the reliability of a design. Reliability can be viewed as a problem of supply and demand although neither is generally simple to evaluate considering its probabilistic aspects (Ang 
and Tang 1984). As shown in Figure 1, the convolution of the supply, $f_{x}(x)$, and demand, $f_{y}(y)$, pdfa gives the probability of fallure as

$$
p_{F}=\int_{0}^{\infty}\left[1-F_{y}(x)\right] f_{X}(x) d x
$$

The amount of overlap (1.e. probability of fallure) depends on the dispersion of the data about their means as well as the distance between the means.

Reliability theory depends on the generation of a performance function $z=g(x)$ where $x=\left(x_{1}, x_{2}, \ldots, x_{n}\right)$ is a vector of random variables describing the uncertainty in the problem. The fallure state is defined as $g(X) \leq 0$ and the corresponding $z$ is interpreted as a safety margin against fallure. Fallure in this sense means that the system enters an arbitrarily defined state such as exceeding a regulatory concentration standard.

Hasofer and Lind (1974) have developed this technique which enjoys wide use in structural engineering. Its extension to environmental engineering has recently been suggested (Jacobs and Vesilind 1992).

The reliablitity index method has several advantages including applicability to numerical and analytical solutions of large problems with many variables, the ability to use minimal distribution information and direct sensitivity analysis (Song and Lee 1989). Its major advantage over Monte 


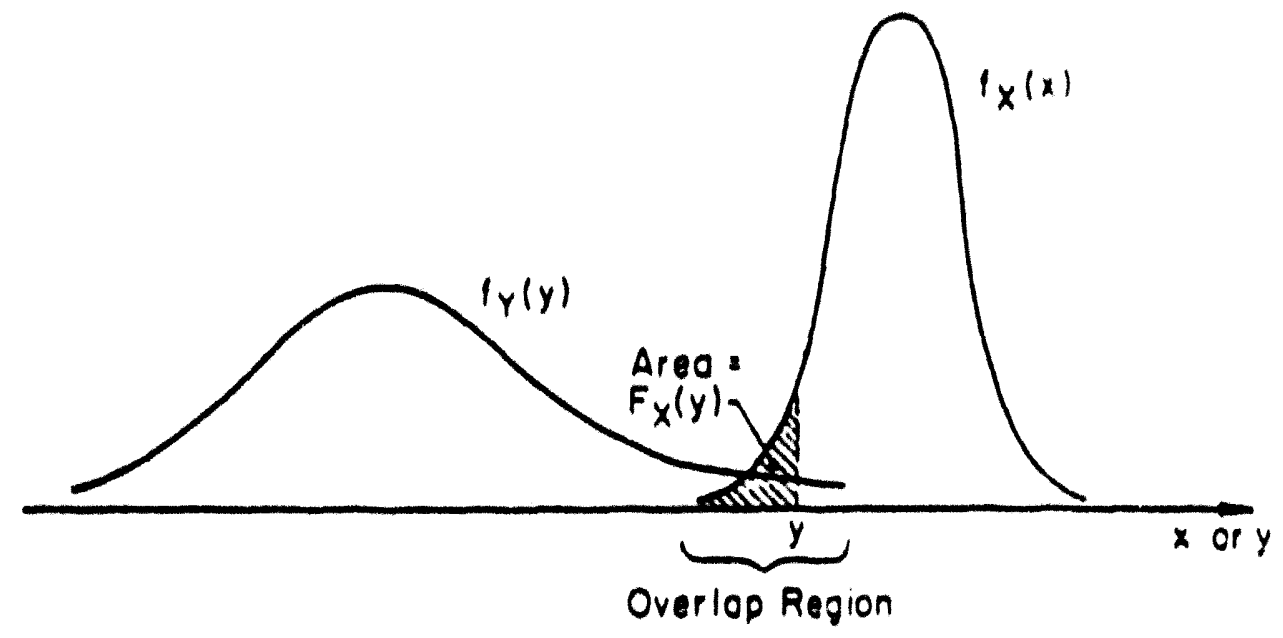

Figure 1. Probability Distributions of Supply and Demand Functions in Reliability Analysis.

Source: Ang and Tang 1984. 
Carlo gimulation, the ability to calculate results for low probability events without excessive repetition, diminishes as computers become faster.

\section{Compartaon of Monte carle and Rellabld1ty index}

The mafor result of interest in probab1listic assessment 1s the determination of the shape of the output distribution. Monte Carlo simulation provides such a distribution from which the oummary statistica are readily calculated. The reliability index, on the other hand, is mainly concerned with determining the design point for a system and the output varlances calculated from this method can be quite different from those generated by Monte Carlo analyois (Scavia et al. 19811 .

Monte Carlo almulation provides information concerning the variability about the population. Reliablitty methods provide error estimates that reflect the variability about typlcal components of the modeled population and do not necessarily represent the dynamics of the total population (Scavia et al. 1981).

Sensitivity analyses are treated differentiy by the two methods. Monte Carlo sensitivity analyses are generally performed by varying one parameter at a time which tends to Ignore the potential higher order effects of two or more parameters. On the other hand, since the method is only valid for small parameter perturbations, the reliablilty 
Index method 1gnorea the higher order effects that are manifest through large parameter errors (Scavia et al, 1981).

\section{Apeltcat tone}

Both Monte Carlo simulation and relfablitty methods have been used in everal clelds of engineering although few applications to hazardous waste treatment are documented. Of those applicatione to hazardous waste treatment, about half are attempte at optimization clearly indicating that the Investigatora' atrengthe were in optimization rather than environmental englneering.

El11. et al. (1985) used a moditied Monte Carlo simulation to attempt to optimize iminimize cost to meet eftluent $11 \mathrm{mits}$ a proposed centralized 11quid industrial waste treatment facility. The model considered waste types and volumes, specific contaminants within each waste, contaminant specific strength distributions, unit treatment process efficiencies and costs, and individual effluent standards. Instead of evaluating the variability of the treatment processes, the researchers used Monte Carlo simulation in confunction with an optimization routine in an attempt to select and order the unit treatment processes to provide minimum cost. Unfortunately, no single treatment train consistently provided the least cost option.

Warwlck and Cale (1987) present one of several probabilistic assessments (Chadderton et al. 1982, Dewey 
1984) of the tam111ar streeter phelpe disolved oxygen model in which they illuatrate the likelihood of obtaining a rellable model based on uncertainty of the model parameters. Normal distributione were chosen for the oxygen deflcit, Intial diseolved oxygen, Inttial ultimate COD and otream velocity. Standard deviation for these parametere were based on the uncertainty aseoclaced with the standard methods for determining these parameters.

The model was callbrated to actual etream data and Monte Carlo imulatione were used to determine the extent of parameter uncertainty which 111 allowed the model to return resulte within prescribed accuracy 1imite. Wastewater treatment plant performance and outflow were just two of many uncertainties modeled in this research.

Warwick and cale demonstrated the inability of even a "pertect" model to reliably achleve high accuracy in the presence of commonly encountered data uncertainty. They etress that disputes over amall differences should not be argued on the basis of predictive model outputa unless the data uncertainties are small.

Rogers and Flering (1986), comparing the uses of systems analysis and optimjzation in major water resources projects. reached a aimilar conclusion from a different perapective. They argue that system redundancy and parameter uncertainty result in an objective function that is relatively flat in the region of many optima so that the search for an optimum 
solution does not improve the result algnificantly. Conversely, the existence of geveral sightly sub-optimal solutione provides the basio for negotiation of the einal coneiguration where previously unstated land frequently unquantiflable) concerne can receive coneideration. 
CERPIER III

\section{PACKID TOWE ABRATION}

\section{Itterature Reviow}

Packed tower aeration (a1r stripping) is a common chemical engineering process and design equations can be found in most mass transfer textbooks (Sherwood et al. 1975, Treybal 1980). As practiced in water treatment air stripping is essentialiy desorption from a dilute solution and when highly volatile compounds are present the gas-phase resistance is relatively minor. This simplifying assumption has been made in many studies (Siungley et al. 1980, Umphres et al. 1983, Ball et al. 1984). Air stripping is effective for volatile and semivolatile organics with Henry's constants in the range of 0.001 to 0.1 atmospheres (atm) (K1ttikul et a). 1990, Patterson and Kodukala 1981, Petrasek et al. 1983, McCarty 1980). For the aimple case of a dilute, volatile solute, the packed height, $z$, required to achleve the desired separation is given as

$$
z \cdot H T U \times N T U
$$

In which HTU - helght of the transfer unit and NTU = number of transfer units. HTU is the ratio of the superficial velocity, $u_{0}$ to the transfer rate constant, $K_{L} a$ : 


$$
H T U=\frac{u_{0}}{K_{L^{a}}}=\frac{L_{m}}{\rho_{L} K_{L^{a}}}
$$

where $L_{m}=11$ quid mass flux; $\rho_{L}$ - 11quid density; and $K_{L} a$ overall transfer rate constant. The transfer rate constant, $K_{L} a$, is the product of the overall coefflcient, $K_{L}$ and the specific interfaclal area, a.

NTU is defined as

$$
N T U=\frac{s}{s-1} \ln \left[\frac{\left(C_{L, 2}-C_{Q, 1} / K_{H}\right)(s-1)+1}{\left(C_{L, 1}-C_{Q, 1} / K_{H}\right) S}\right]
$$

In which $C_{l, 2}$ and $C_{l, 1}$ - influent and effluent liquid solute concentrations, respectively; $C_{0,1}$ - influent gas solute concentration (which is usually assumed equal to zero); $K_{H}=$ Henry's constant (dimensionless ratio of concentration in air to concentration in water); and $S=\left(Q_{0} K_{H}\right) / Q_{l}$ where $Q_{0}$ and $Q_{l}$ - volumetric flow rates of the gas and 1 iquid, respectively. A schematic of an air stripping tower is given in Figure 2 . Incorporating (4) and (5) into (3) and assuming $C_{0,1}=0$, (3) aimplifies to

$$
z=\left(\frac{L_{m}}{\rho_{L} K_{L} a}\right)\left(\frac{S}{S-1}\right) \ln \left[\frac{\left(C_{L_{, 2}} / C_{L, L}\right)(S-1)+1}{S}\right]
$$

The stripping factor, $S$, is an important parameter for stripping tower design. When $S>1$, there is theoretically sufficlent. gas-phase capacity to convey away all the solute in the entering fluid. Given an infinitely tall column, 


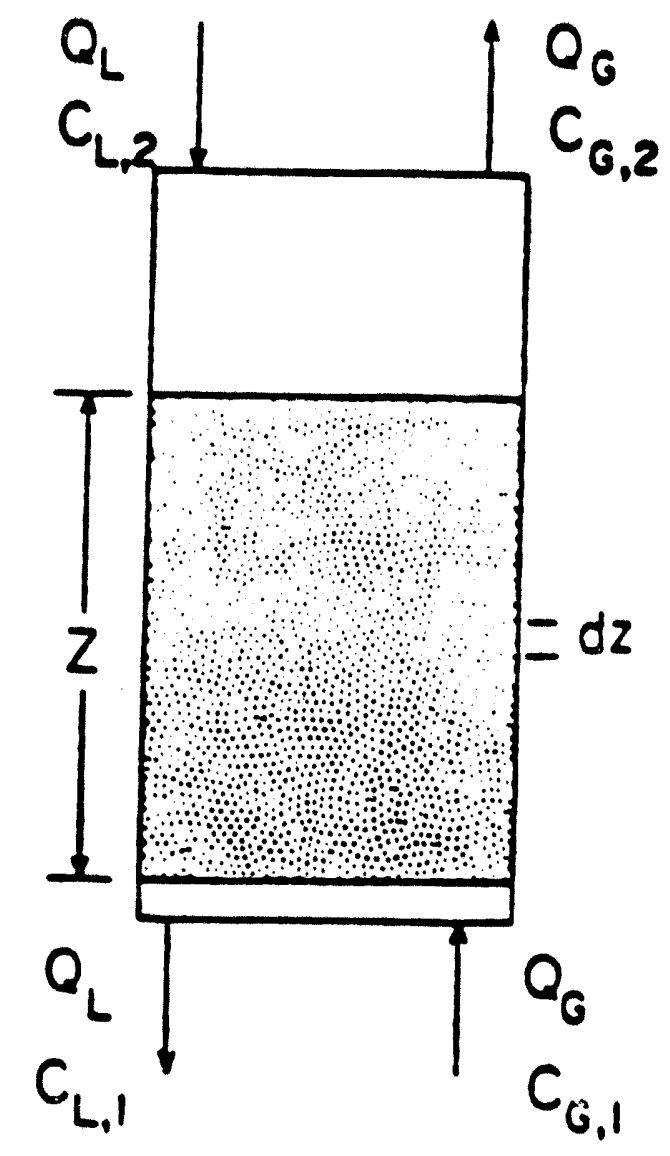

Figure 2. Schematic Diagram of the Air stripping Process. 
complete removal is theoretically possible. Economic considerations will factor strongly in the ultimate degree of removal. When $S<1$, the stripping performance is limited by equilibrium conditions and as the tower height, $\mathrm{Z} \rightarrow \infty,(1-$ $\left.C_{L, 1} / C_{L, 2}\right) \rightarrow S$. The effect of $S$ on the effluent quality and tower height has been demonstrated elsewhere (Roberts and Levy 1985).

Two-film resistance theory is stated as

$$
R_{T}=R_{L}+R_{G}
$$

where the subscripts $T, L$ and $G$ refer to the total, liquidphase and gas-phase resistances, respectively. These resistances are usually defined as the reciprocal of the respective rate constants assuming phase equilibrium is controlled by Henry's law at the interface such that

$$
\left(K_{L} a\right)^{-1}=\left(k_{L} a\right)^{-1}+\left(K_{H} k_{G} a\right)^{-1}
$$

where $\mathrm{K}=$ overall coefficient and $\mathrm{k}=$ coefficient for an individual phase. While the two-resistance model enjoys wide use, it has been questioned on fundamental grounds by King $(1964)$ who warns of the likelihood of significant deviations resulting from local differences in hydrodynamic conditions in the stripping tower.

$\mathrm{K}_{\mathrm{L}}$ a can be determined from several different equations based on correlations of experimental data. Roberts et al. (1985) compared three models and found the Onda model (Onda et al. 1968) provides the best correlation to observed data 
with an accuracy of $\pm 21 \%$. Lamarche and Droste (1989) have confirmed Roberts' findings. The Onda model is recommended by the Chemical Engineer's Handbook (Fair et al. 1973).

Kittikul et al. (1990) evaluated the effect of water temperature on air stripping of fifteen volatile and slightly-volatile organic compounds using the onda correlation and another model. They found that slightlyvolatile compounds gain the most benefit from the temperature rise and that onda's model provides the best correlation, giving a $\pm 21 \%$ accuracy when considering isothermal stripping of volatiles. Nirmalakhandan et al. (1987) show that a specific stripping efficiency can be obtained through several designs and present a cost-optimization method based on the specific problem variables.

Speece et al. (1987) present a nomograph based on a computer model incorporating Roberts et al. (1985) design considerations as an utilitarian resource that can be used to visually indicate sensitivities and provide insight to the air stripping design process.

Air stripping has been studied as a method for removing VoCs from contaminated groundwater (Kavanaugh and Trussell 1980, Mumford and Schnoor 1982 and 1985, Amy and Cooper 1986) and a related method, in situ air stripping, is also finding use as a treatment process (Anastos et al. 1988).

No probabilistic assessments of the uncertainty associated with the air stripping process have been located. 


\section{Research Approach}

\section{Model Description}

Monte Carlo simulation of the deterministic EPA Air Stripping model (Clark and Adams 1991) is performed to ascertain the process reliablitty related to probabilistic safety factors. Probabilistic model parameters include the pollutants' Henry's constant and liquid and gas diffusivities. The EPA Air stripping model is based on the onda correlation for $\mathrm{K}_{\mathrm{L}} \mathrm{a}$ as are most air stripping models and the design equations are summarized in (3) through (8) above.

The model has been modified slightly to calculate the probabilistic effluent concentration resulting from the specific tower height required to achieve a median design effluent concentration. This has been achieved by rearranging (6) to solve for the effluent concentration

$$
C_{L, 1}=\left[\exp \left[z\left(\frac{\rho_{L} K_{L} a}{L_{M}}\right)\left(\frac{S-1}{S}\right)\right] S-1\right]^{-1} \frac{C_{L, 2}}{(S-1)}
$$

Another modification of the model accounts for the $21 \%$ error between the observed mass transfer coefficient and that calculated with the onda equation. This has been accomplished by assuming that the $21 \%$ error is normally distributed with mean equal to the calculated $\mathrm{K}_{\mathrm{L}} \mathrm{a}$ and standard deviation sized such that the $21 \%$ error is equal to the $90 \%$ confidence limit of the mean. 


\section{Selected Pollutants}

Benzene and trichloroethylene (TCE) are the pollutants utilized to evaluate the reliability of the air stripping process. Both are listed RCRA hazardous wastes, priority pollutants, common industrial pollutants, and amenable to air stripping. Benzene and TCE have significantly different chemical and physical properties as shown in Table 5 .

Probability distributions for the Henry's constant, $k_{H}$ and gas and liquid diffusivity, $D_{G}$ and $D_{L}$, have been generated after extensive literature reviews. Table 6 provides the summary statistics of parameter distributions and the appendix contains the specific data values used to generate these distributions.

\section{Results}

\section{Safety Factor Versus Reliability}

Reliability is defined as the frequency that the effluent concentration is below a predetermined effluent standard. As shown in Figure 3, the reliability of a process increases as the median design effluent concentration is reduced. In these terms, the process safety factor is defined as the ratio of the effluent standard to the median design effluent concentration. The effluent standards for benzene and TCE are $5 \mu \mathrm{g} / 1$, their maximum contaminant level (MCL) specified in the Clean water Act.

Monte Carlo simulation of the modified EPA Air stripping 
Table 5. Chemical and Physical properties of Benzene and Trichloroethylene for Packed Tower Aeration Treatment.

\begin{tabular}{|c|c|c|}
\hline Compound Name & Benzene & $\begin{array}{l}\text { Trichloro- } \\
\text { ethylene (TCE) }\end{array}$ \\
\hline CAS Number & $73-43-2$ & $79-01-6$ \\
\hline Compound Type & Aromat 1c & Hydrocarbon \\
\hline Formula & $\mathrm{C}_{6} \mathrm{H}_{6}$ & $\mathrm{C}_{2} \mathrm{HCl}_{3}$ \\
\hline $\mathrm{MW}(\mathrm{g} / \mathrm{mol})$ & 78.11 & 131.4 \\
\hline Melting Point $\left({ }^{\circ} \mathrm{C}\right)$ & 5.5 & -84.8 \\
\hline Boiling Point $\left({ }^{\circ} \mathrm{C}\right)$ & 80.1 & 86.7 \\
\hline $\begin{array}{l}\text { Vapor Pressure } \\
\left.\text { (Torr }{ }^{\circ} \mathrm{C}\right)\end{array}$ & 95 (25 & $77 \odot 53$ \\
\hline $\begin{array}{l}\text { Solubility } \\
\left.\text { (mg/l }{ }^{\circ} \mathrm{C}\right)\end{array}$ & $1780 @ 20$ & $1100 @ 25$ \\
\hline $\log K_{\mathrm{OW}}(\mathrm{dim})$ & 2.13 & 2.53 \\
\hline $\begin{array}{l}\text { Henry's Constant } \\
\left(\mathrm{atm}-\mathrm{m}^{3} / \mathrm{mol}\right)\end{array}$ & $5.5(10)^{-3} \otimes 25$ & $1.17(10)^{-2}$ (ख) 25 \\
\hline
\end{tabular}

Source: US EPA 1992 
Table 6. Probability Distribution Parameters of Benzene and Trichloroethylene for Packed Tower Aeration.

\begin{tabular}{|c|c|c|}
\hline Parameter & Benzene & Trichloroethylene \\
\hline 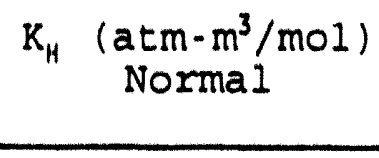 & $\begin{array}{l}m=0.1952 \\
\mathbf{s}=0.0636 \\
n=16\end{array}$ & $\begin{array}{l}m=0.2990 \\
s=0.1582 \\
n=30\end{array}$ \\
\hline$D_{0} \underset{\text { Normal }}{\left(\mathrm{cm}^{2} / \mathrm{sec}\right)}$ & $\begin{array}{l}m=0.08667 \\
s=0.01665 \\
n=3\end{array}$ & $\begin{array}{l}m=0.07775 \\
\mathbf{s}=0.01315 \\
n=4\end{array}$ \\
\hline$D_{L} \underset{\substack{\text { Normal } \\
\left(\mathrm{cm}^{2} / \mathrm{sec}\right)}}{ }$ & $\begin{array}{l}m=9.275(10)^{-6} \\
s=1.773(10)^{-6} \\
n=4\end{array}$ & $\begin{array}{l}m=8.400(10)^{-6} \\
s=1.751(10)^{-6} \\
n=4\end{array}$ \\
\hline
\end{tabular}




\section{SAFETY FACTOR $=\mathrm{ES} / \mathrm{m}_{1}$ RELIABILITY $=1-\mathrm{p}_{\mathrm{Fi}}$}

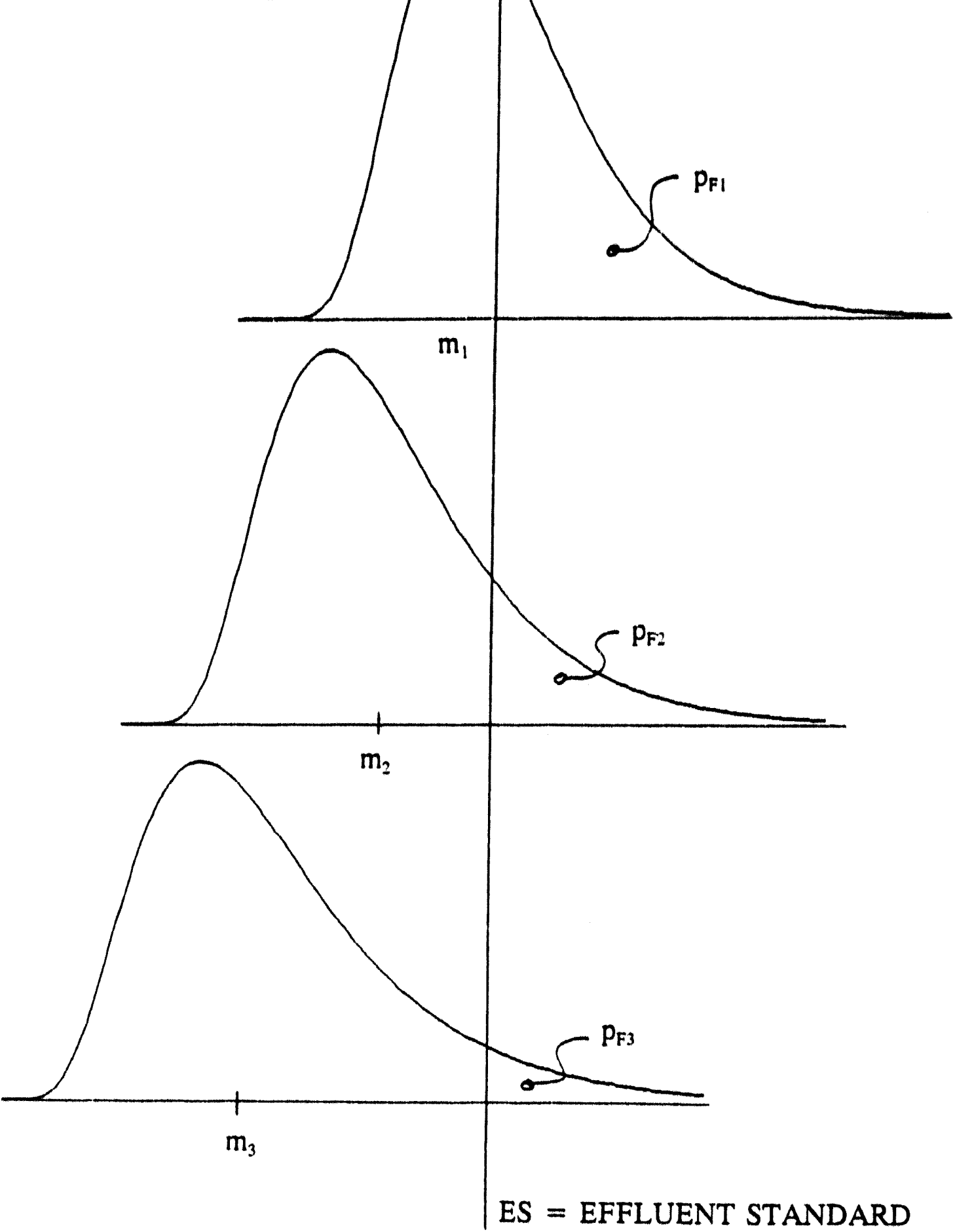

Figure 3. Relation Between Safety Factors and Reliability Levels. 
model is used to generate one thousand realizations of the effluent concentration for each of the two pollutants at two influent concentrations for two stripping factors and 20 safety factors. The resulting cumulative density functions (CDFs) relate the safety factors to reliability levels as 111ustrated in Figure 4. For example, for a safety factor of 2.5, a TCE influent concentration, Co, of $100 \mu \mathrm{g} / 1$, an effluent standard, $C e$, of $5 \mu \mathrm{g} / \mathrm{l}$ and a stripping factor, $s$, of 2 , the reliablitty of the treatment process 1s 97 determined by prcfecting a line upward from the effluent concentration axis at $5 \mu \mathrm{g} / 1$ to the 2.5 safety factor curve and then profecting the line horizontally to the probability axis. Reliability equals the cumulative probabilily at that point.

Plots of safety factor versus rellabllity for stripping factors of 2 and 10 are shown in Figure 5 and Figure 6 for benzene and TCE, respectively. As rellability increases toward one, the safety factors increase asymptotically toward infinity. The $1000 \mu \mathrm{g} / 1$ influent concentration curve is higher than the $100 \mu \mathrm{g} / 1$ curve in both figures indicating that higher safety factors are required for higher treatment efficiencies for all reliability levels. The range of safety factors required to achieve 958 reliablitty are 2 to 5 for benzene and 2 to 6 for TCE. At low influent concentrations, over $99 \%$ reliability is achieved with safety factors of approximately 4 while safety factors in excess of 10 are required to attain 978 reliability for high influent concentrations. 


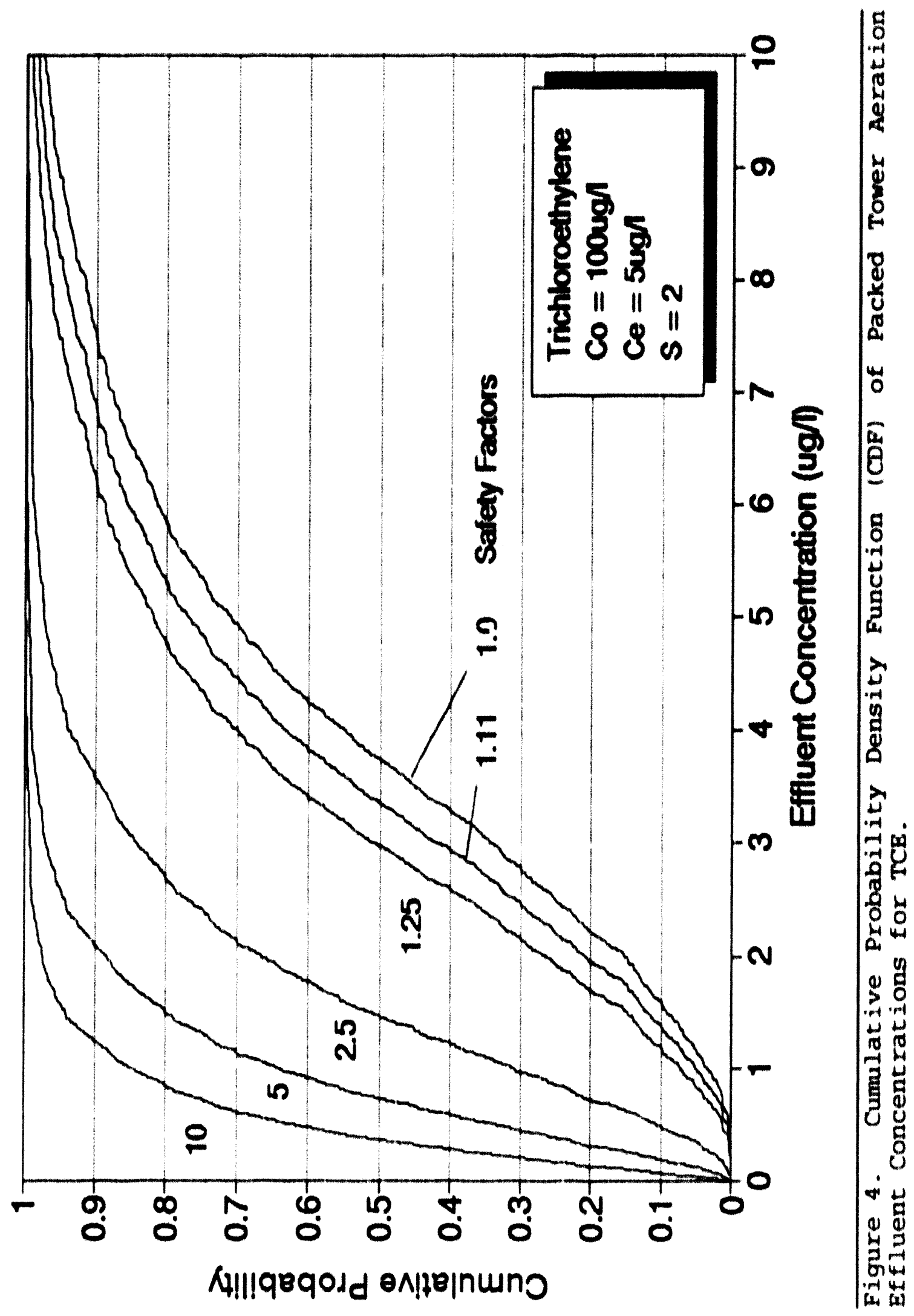




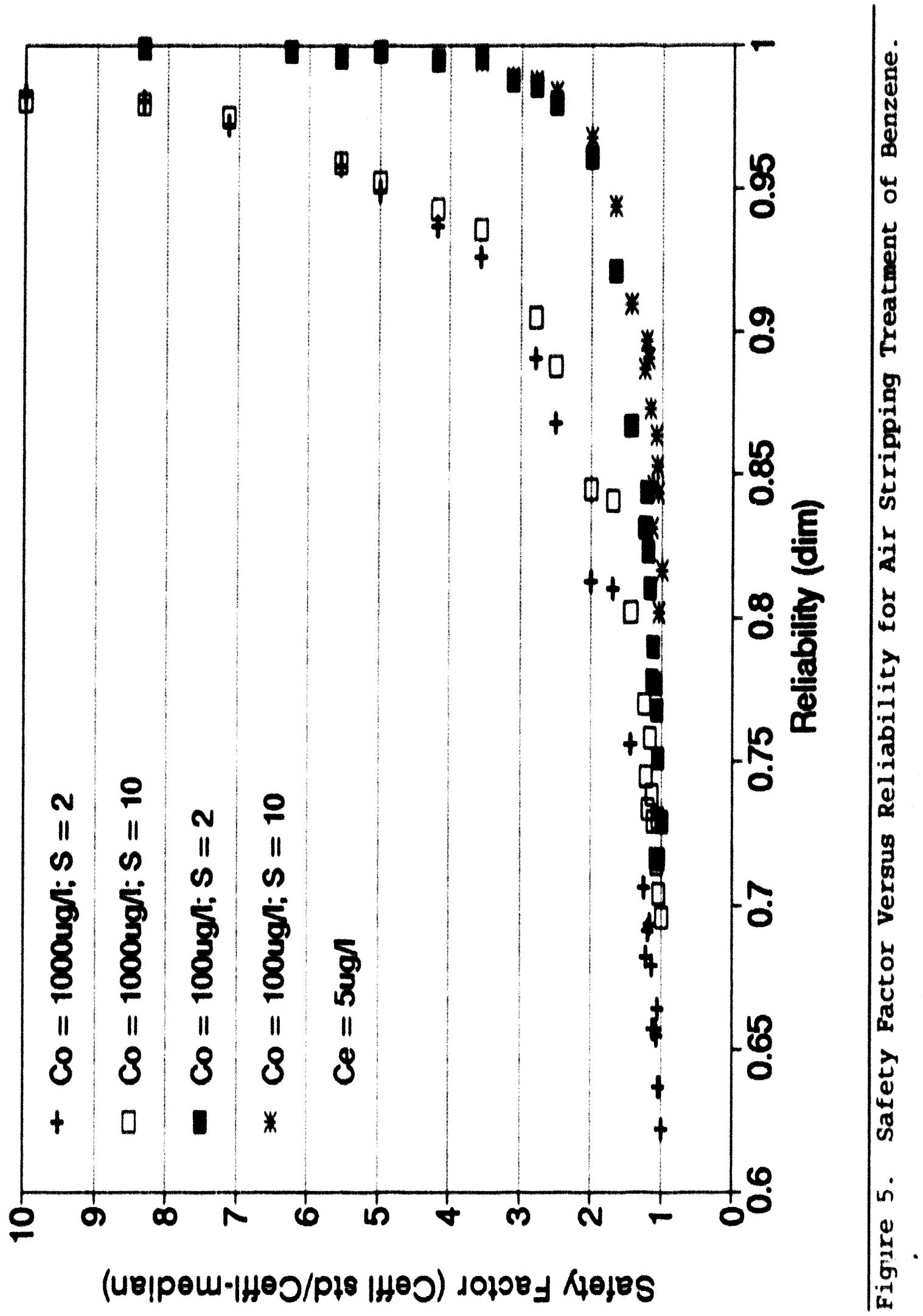




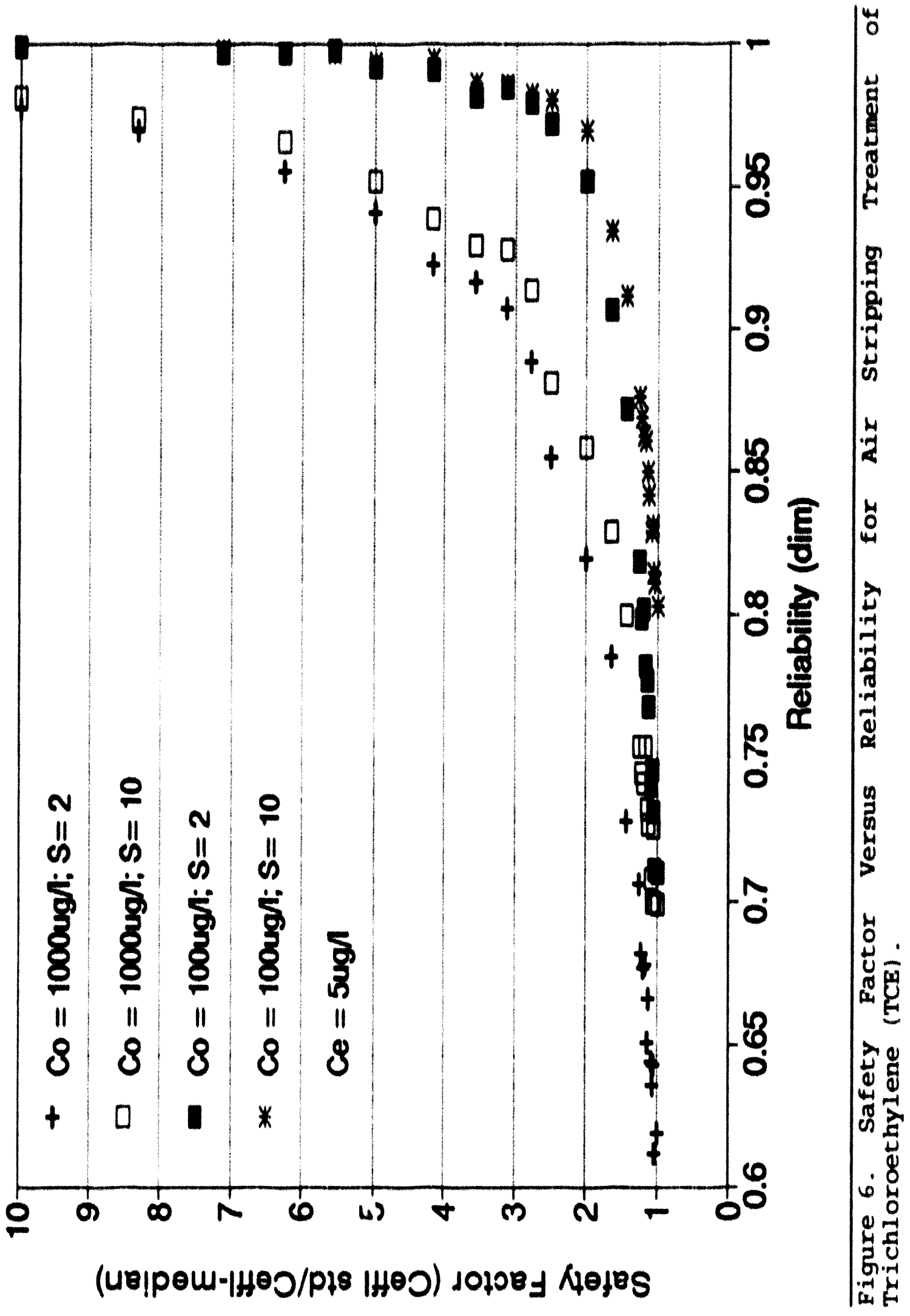




\section{Seneitivity Analysis}

Eftuent concentration distributions resulting from parameter distributions based on few data points or data ranges must be analyzed to determine the effects of these assumptions. The distriburions of Henry's constant, $K_{H}$, of both pollutants are based on the one-sample kolmogorovSmirnov goodnesg-of-tit test with sixteen or more data points. The data fit the normal distribution at the 0.05 level of ignificance so that no sensitivity analysis is required. The distributions of the surface diffusion coefficlents, $D_{1}$, and the flim diffusion coefficients, $K_{1}$, for both pollutants are based on three or four data points and the assumption of the normal distribution to these parameters must be verified.

The parameter distribution assumptions are verified by comparing the model results based on the assumed normal distribution for $D_{8}$ and $k_{f}$ with model results based on the unfform diatribution it to these parameters. The uniform distribution is assumed to span the two-sided 90 confldence interval of the mean. The unfform distribution is chosen because its shape is vastly different than the normal distribution so that parameters passing this sensitivity are robust to the assumption of probability distribution. The sensitivity analyses are performed at low, medium and high safety factors to ascertain the effects resulting from the cholce of safety factor. 
In all sensitivities for both pollutants, the model results were not statistically different at the 0.05 level of significance fustifying the normal distribution assumption.

\section{Cost Vergue Rellablitity}

Cost versus reliablitty plot. for stripping factors of 2 and 10 are shown in Figure 7 for benzene and Figure 8 for TCE. These costs are based on the cost estimating method packaged with the EPA Air stripping model (Clark and Adams 1991a) and are intended to provide relative comparisons only. As expected, treatment costs increase with increasing rellablity. Treatment cost are not greatly affected by stripping factor for a given influent concentration except for TCE at high influent concentration where the higher stripping factor provides slightly lower treatment costs.

Treatment costs do not increase dramatically with increasing reliablitity due mainly to the fixed costs associated with the tower construction. The incremental cost. of increasing the tower helght to ensure greater reliablitty is small in comparison with the overall treatment cost.

\section{Comparisons with Conventional Dealgne}

Conservatism is incorporated into conventional designs by reducing the calculated mass transfer coefficient, $K_{L} a$. Reductions in the range of 17 to 23 are common (Clark and Adams 1991a). The rellability of the conventional design is evaluated by comparing the packing height calculated with the 


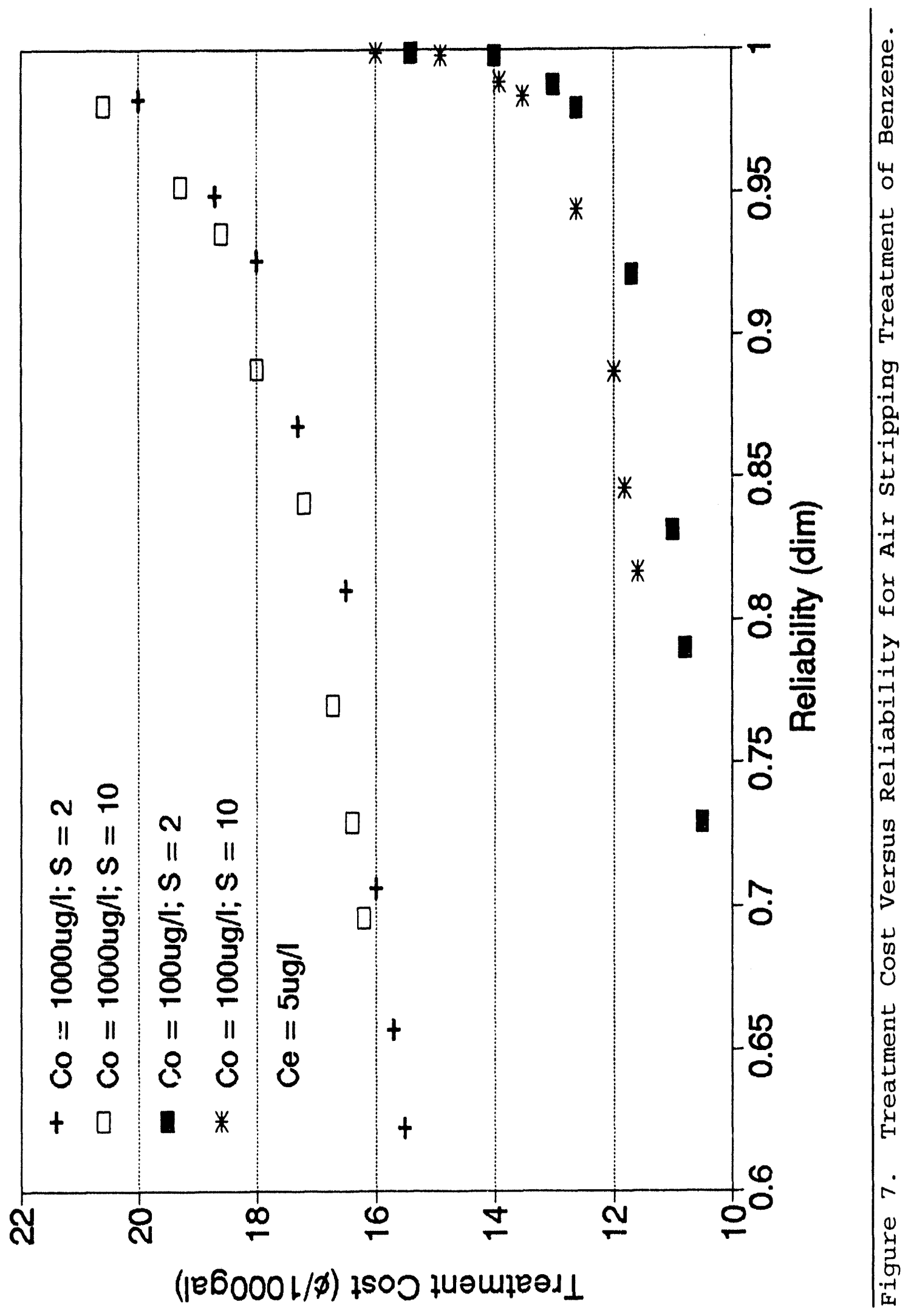




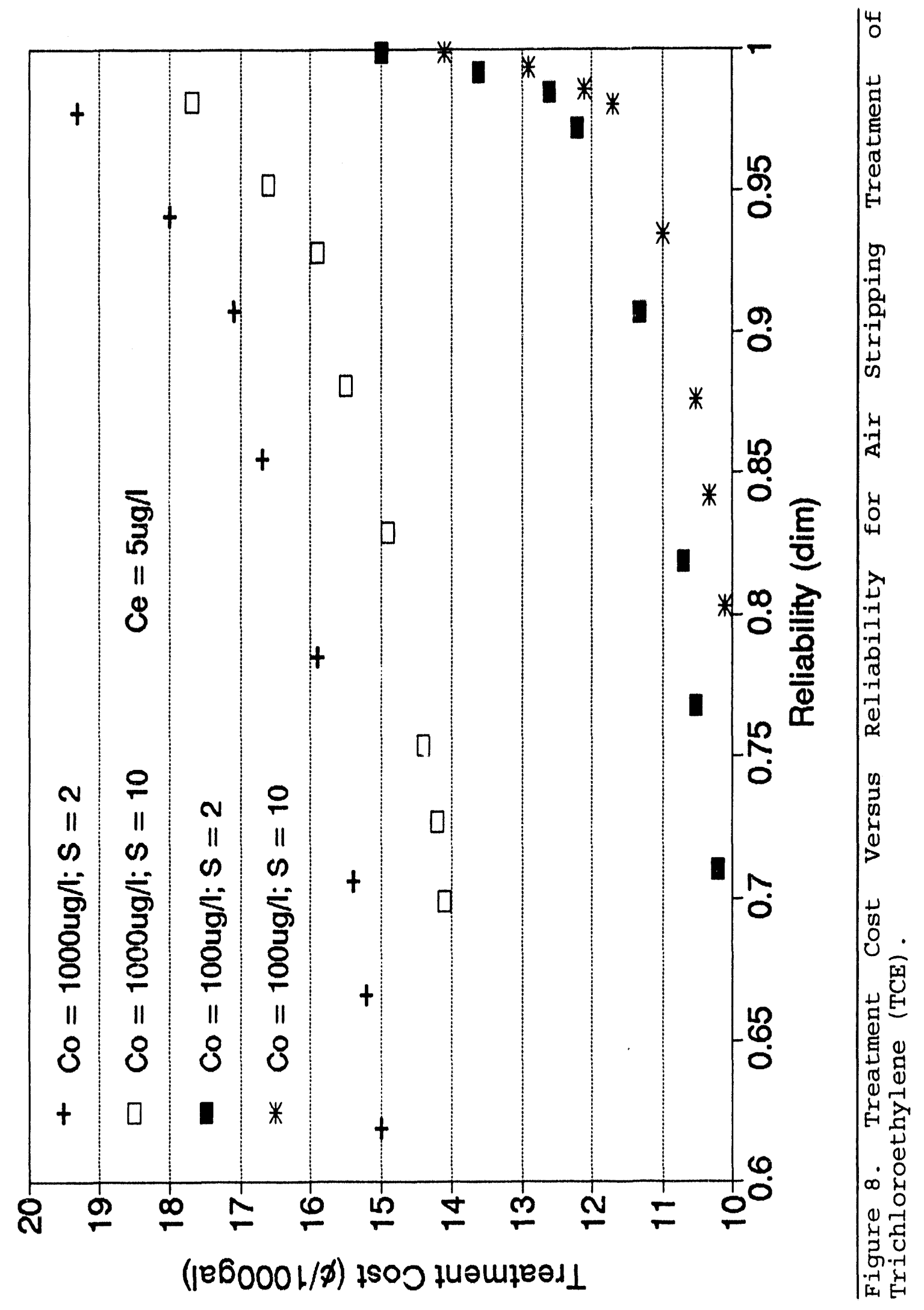


deterministic method and the packing heights associated with probabilistic safety factors.

Figure 9 illustrates that for TCE at $100 \mu \mathrm{g} / 1$ influent concentration, the conventional deterministic designs require packing heights of 19 and 31 feet for stripping factors of 10 and 2 , respectively, which is equivalent to a probabilistic safety factor of approximately 1.8. As Figure 6 shows, this safety factor corresponds to reliability levels of 92 to $94 \%$. Similar analysis for benzene indicates the conventional deterministic designs provide approximately $95 \%$ reliability for both stripping factors.

Conventional designs for influent concentrations of $1000 \mu \mathrm{g} / 1$ result in towers providing reliability levels of 82 to $84 \frac{\%}{6}$ for benzene as shown in Figure 5 and 80 to $84 \%$ for TCE as shown in Figure 6 . The mass transfer coefficient must be reduced further to ensure the deterministic design process provides higher reliability levels.

\section{Summary}

Monte Carlo simulation is performed on the packed tower aeration treatment of benzene and TCE based on probabilistic estimation of their Henry's constants and gas and liquid diffusivities. Safety factors of 2 to 6 are required to achieve $95 \%$ process reliability for both pollutants.

Sensitivity analyses indicate that the model results are robust to the assumption of the distributions of the surface 


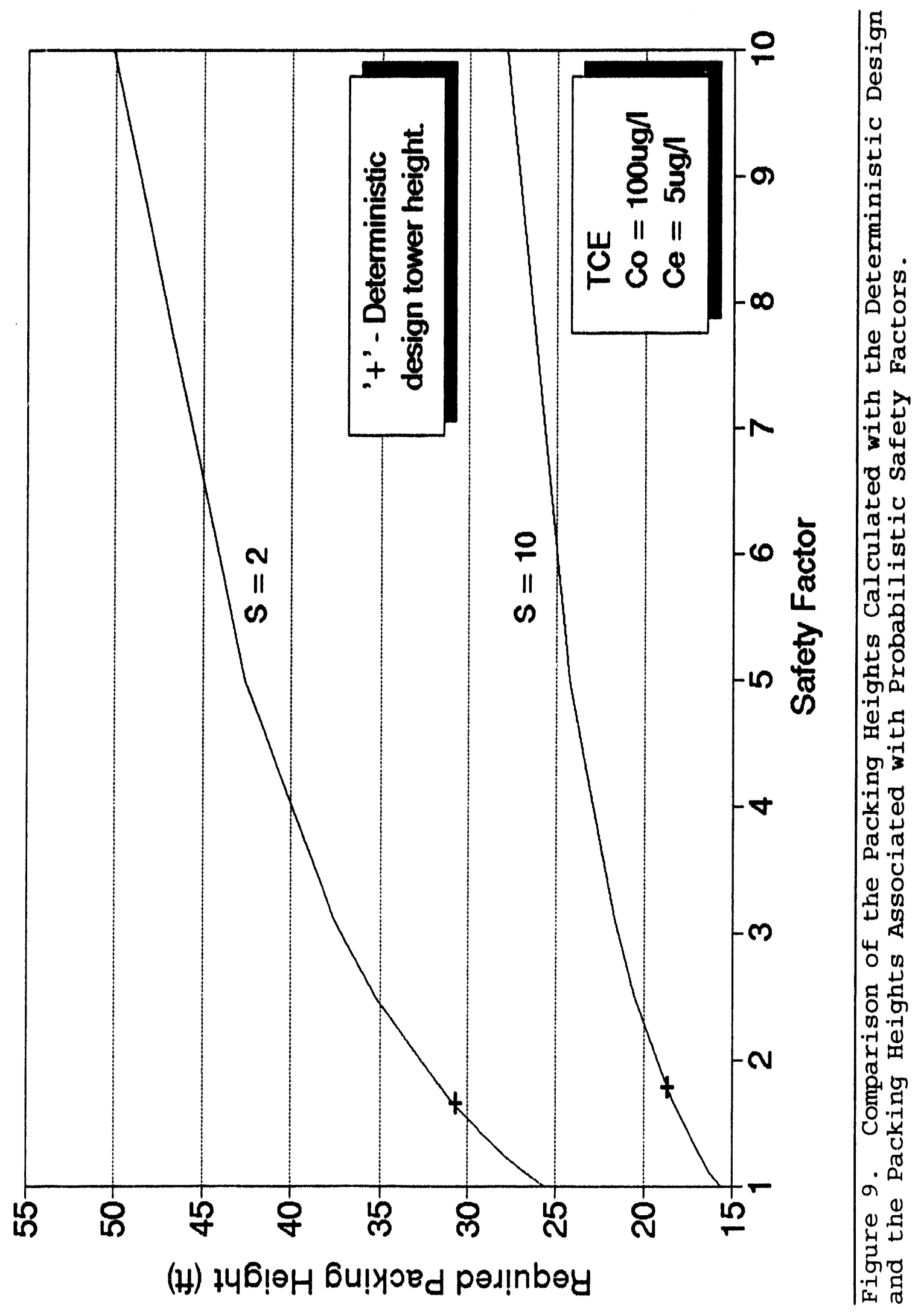


diffusion coefficient, $D_{s}$, and the film transfer coefficient, $k_{f}$, justifying the normal distribution assumption for both. Conventional deterministic designs are based on a $17 \%$ decrease in the calculated mass transfer coefficient. This conservatism results in process reliablitty levels of 92 to $95 \%$ at influent concentrations of $100 \mu \mathrm{g} / 1$ and 80 to $84 \%$ at influent concentrations of $1000 \mu \mathrm{g} / 1$ for both pollutants. Additional reduction (increased conservatism) in the calculated mass transfer coefficient is required to achieve 95\% or greater reliability levels with conventional design methods for both pollutants at high influent concentration levels regardless of stripping factors. 
CEAPTER IV

\section{REVERSE OSMOSIS TREATMENT}

\section{Ilterature Review}

The reverse osmosis process was developed in the $1950 \mathrm{~s}$ for desalination of brackish water in arid regions and only within the last 2 years has the process been used for treating hazardous wastes (MacNeil 1988). Reverse osmosis depends on a thin membrane which acts as a barrier to flow of ionic or nolecular solute species while allowing easy passage of the solvent. The membrane must be highly perm-selective to be effective.

The basis for the process is the phenomenon of osmosis involving spontaneous transport of a solvent from a diluted to a concentrated solution across an ideal, semi-permeable membrane which impedes passage of solute but allows solvent flow. The solvent flows until the osmotic pressures have equilibrated. Osmotic pressure is a property of the solution only and increasing the hydrostatic pressure above the osmotic pressure on the high solute concentration side reverses the flow resulting in reverse osmosis. A schematic diagram of the process is given in Figure 10.

Osmotic pressure is a function of concentration and temperature related as 


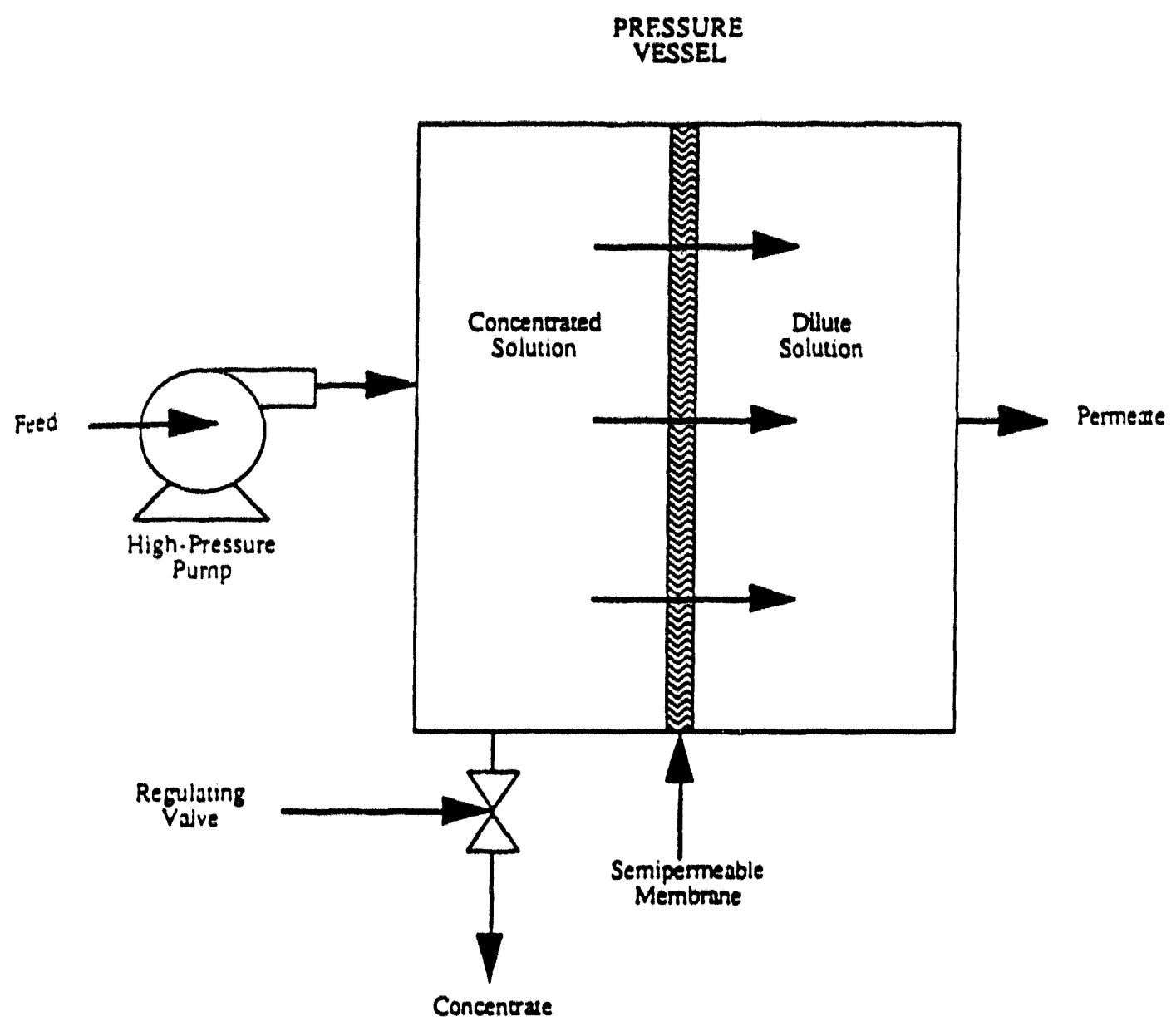

Figure 10. Schematic Diagram of the Reverse Osmosis Process. 


$$
\pi^{0}=\phi_{c} \frac{\bar{n}}{V_{m}} R T
$$

in which $\pi^{0}=$ osmotic pressure; $\phi_{c}=$ osmotic pressure coefficient; $\bar{n}=$ number of moles of solute; $V_{m}=$ molar volume of water; $R=$ universal gas law constant; and $T=$ absolute temperature. Reverse osmosis processes are commonly operated in the 400 to 1500 psi range (MacNeil 1988).

Reverse osmosis removes inorganics (metals, metalcyantde complexes and other lonic species) (MacNell 1988) and organics with molecular weight greater than $50 \mathrm{~g} / \mathrm{mol}$ (Lyandres et al. 1989). Waste streams with total dissolved solids less than $50,000 \mathrm{mg} / \mathrm{l}$ are amenable to treatment with this limit based on operating pressure required to overcome osmotic pressure (MacNeil 1988).

Weber (.1972) summarizes trends in solute rejection as:

- Multi-valent ions are rejected more effectively than univalent ions

- un- or partially-dissociated substances are poorly rejected

- acids and bases are rejected to lesser extent than salts

- co-ions affect rejection of particular ions, and

- Low molecular weight, water soluble organics are poorly rejected.

Reverse osmosis processes are designed based on flux, conversion or rejection. Rejection, defined as 


$$
C=1-\frac{C_{p}}{C_{l}}
$$

where $C_{p}$ and $C_{f}=$ product and feed stream solute concentration, respectively, is the most common parameter used in hazardous waste applications.

Through use, salt concentration bulld-up at the membrane surface causes detrimental effects including elevated local osmotic pressure which decreases the driving force and precipitation of sparingly soluble salts on the membrane which clogs the pores and accelerates membrane deterioration. The silt density index (SDI) and permanganate demand test have been developed to measure fouling potential of feed streams but fall to accurately predict flux decline (KInman et al. 1985). Pretreatment including filtration, $\mathrm{pH}$ adjustment, carbon adsorption, chlorination and coagulation and membrane cleaning are commonly used to minimize deterioration to the membrane.

Three types of membranes are commonly used in reverse osmosis: cellulose acetate, aromatic polyamide and thin film composites. Properties of these membranes are listed in Table 7. Four types of process modules are avallable: tubular, hollow fiber, splral wound, and plate and frame. Tubular modules are the simplest design and turbulent flow provides membrane cleaning. Hollow fiber modules, which contain up to 4.5 milijon hair-like fibers bundled together 


\begin{tabular}{|c|c|c|c|}
\hline $\begin{array}{l}\text { Membrane } \\
\text { materlal }\end{array}$ & pHimits & $\begin{array}{l}\text { Maximum } \\
\text { temperatures }\end{array}$ & $\begin{array}{c}\text { other } \\
\text { Imitations }\end{array}$ \\
\hline $\begin{array}{l}\text { Cellulose } \\
\text { acetate }\end{array}$ & $2.5 \cdot 7$ & $29 \cdot 50^{\circ} \mathrm{C}$ & $\begin{array}{l}\text { Blologically } \\
\text { degradable }\end{array}$ \\
\hline $\begin{array}{l}\text { Aromatic } \\
\text { polyamides }\end{array}$ & $4 \cdot 11$ & $35 \cdot 46^{\circ} \mathrm{C}$ & $\begin{array}{l}\text { Cannot toler } \\
\text { ate chloride }\end{array}$ \\
\hline $\begin{array}{l}\text { Thin film } \\
\text { composites }\end{array}$ & $<1 \cdot 13$ & $46-79^{\circ} \mathrm{C}$ & $\begin{array}{l}\text { Can tolerate } \\
\text { moderate } \\
\text { chloride }\end{array}$ \\
\hline
\end{tabular}

Source: MacNe11 1988 
to provide a large aurface area, are auseptible to fouling and difficult to clean. Splral wound modules sandwich a membrane between two supporting matts wrapped around a permeable tube and are also auceptible to clogging. Plate and frame module membianes are attached to both sides of several circular rigid porous plates and the plates provide the rigidity required to keep the membrane from deforming under pressure.

Reverse osmosie processes were traditionally designod through a cumbersome, 1terative, numerical technique based on pllot testing. Several researchere (Evangelista 1987, Palanki and Gupta 1987 ) have recently developed olmplified numerical and analytical models which have been validated to the previous models as well as experimental results.

The most promising models have been developed by Muldowney and Punzi (1988) based separately on diffusive and advective flow. Signiflcant technical debate concerns which mechanism controls transport, so both mechanlsms were modeled to ascertain which mechanism agreed beat with experimental data. Surprisingly, both methods agreed exceedingly well.

Muldowney and Punzi based their designs on a separation factor, $\alpha$, equal to the ratio of the feed and product solute concentrations. The separation factor, $\alpha$, is a function of pressure, flow rate, temperature, and system specific parameters. The advective flow model corrected for non-ideal membrane performance is 


$$
\alpha-\frac{\epsilon}{K_{2}^{\prime}}\left[1-\exp \left(-\frac{V^{\prime \prime}}{A} \leq \frac{\lambda}{D_{21}}\right)\right]+\frac{K_{2}^{\prime \prime}}{K_{2}^{\prime}} \exp \left(-\frac{V^{\prime \prime}}{A} \div \frac{\lambda}{D_{21}}\right)
$$

where $K_{2}^{\prime \prime}$ and $K_{2}^{\prime}$ - distribution coefficlent of solute at feed- and permeate-side of the membrane, respectively; membrane porosity; $V^{\prime \prime}$ - permeate-elde volumetrlc flow rate; A - membrane crose-nectional area; $t$ - membrane pore tortuosity; $\lambda$ - membrane thickness; and $D_{21}$ - diffusivity of solute in solvent. Many of the parameters in (12) are available from process data $(\alpha$, and $v ")$ measured experimentally, oolvent-solute data $\left(D_{21}\right)$ and membrane otructural data ( $A, \lambda, T$, and $C$ ) gleaned from the literature. The only parameters required to $t$ it the model are the $\left(\epsilon / K_{2}^{\prime}\right)$ and $\left(K_{2} " / K_{2}^{\prime}\right)$ ratios. MacNe1l (1988) reporta that reverse osmosis has been used to treat hazardous metals waste in the plating industry, hazardous leachate and organics contaminated groundwater. Walker et al. (1990) report on the application of reverse osmosis to chromilim plating waste following an intensive waste reduction campaign. Over 984 refection of chromium in the permeate was obtained in pilot and full scale studies. The permeate flux decreased with time and was restored after cleaning with a phosphoric acid mixture.

Connell and Dlckson (1988) studied a toluene-water. cellulose acetate system. W1lliams et al. (1990) studied trichlorophenol and a mixture of organics and found 96 and 
978 refections, respectively for a cellulose acetate membrane. They found that organics tend to adsorb on the membrane and reduce the permeate flux.

Lyandres et al. (1989) show that pH changes from 2.7 to 11.1 changed the acetic acid rejection trom 66 to 99 with a minimum around pH 5 due to water of hydration surrounding the 10n. They developed IInear and polynomial correlation between permeate TOC and $\mathrm{pH}$, leed TOC and volume percent recovery.

No probabilistic aseessments of the reverse osmosis process have been located.

\section{Researob Approach}

\section{Model Description}

Monte Carlo aimulation of the Muldowney and Punzl (1988) reverse osmosis model 1 s performed to ascertain the probability density function of the effluent concentration. Probabilistic model parameters include the pollutants' diffusivity, $D_{21}$, and distribution coefficients, $K_{2}^{\prime}$ and $K_{2} "$, and the membrane's porosity, $\epsilon$, tortuosity, $T$, and thickness, $\lambda$. Literature reviews define the variablitty and uncertainty of the pollutants' diffusivities and the membrane parameters. Mean values of the distribution coefflclents are determined as described by Muldowney and Punzl (1988) by calculating the best-fit straight line to the linearized form of (12) 


$$
\alpha=\left(\frac{\epsilon}{K_{2}^{\prime}}-\frac{K_{2}^{\prime \prime}}{K_{2}^{\prime}}\right) x_{v}+\left(\frac{\epsilon}{K_{2}^{\prime}}\right)
$$

where $x_{v}$ is predominately a eunction of elux (V"/A)

$$
x_{V}=-\exp \left(-\frac{V^{\prime \prime}}{A} \frac{\tau}{\epsilon} \frac{\lambda}{D_{21}}\right)
$$

The variance of the diatribution coefficlents is determined through the method of propagation-of-error (Topping 1955) after determining the variance of the flt between $\alpha$ and $x_{v}$. The general form of the propagation-of-error equation where $x=E\left(m_{1}\right) \quad 1$.

$$
\operatorname{Var} x+\sum_{i=1}^{n}\left(\frac{\partial x}{\partial m_{1}}\right)^{2} \operatorname{Var} m_{1}
$$

\section{Selected Poldutante}

Cadmium and lead are the pollutante utilized to evaluate the rellabllity of the reverse osmosis process. Both are listed RCRA hazardous wastes, priority pollutants, common industrial pollutants, and amenable to reverse osmosis treatment. The chemical and physical properties of cadmium and lead are listed in Table 8 .

An extensive ilterature review was conducted to determine the probability distributions for the probabilistic parameters of the selected model and Table 9 provides the summary statistics of these distributions. The appendix 
Table 8. Chemical and Physical Properties of Cadmium and Lead for Reverse Osmosis Treatment.

\begin{tabular}{||l|l|l|}
\hline Compound Name & Cadmium & Lead \\
\hline \hline CAS Number & $7440-43-9$ & $7440-47-3$ \\
\hline Compound Type & Inorganic & Inorganic \\
\hline Formula & Cd & Pb \\
\hline Mw (g/mol) & 112.4 & 207.2 \\
\hline Melting Point ( $\left.{ }^{\circ} \mathrm{C}\right)$ & 320.9 & 327. \\
\hline Boiling Point ( $\left.{ }^{\circ} \mathrm{C}\right)$ & 765. & 1740. \\
\hline $\begin{array}{l}\text { Vapor Pressure } \\
\left.\text { (Torr @ }{ }^{\circ} \mathrm{C}\right)\end{array}$ & 1 @ 393 & 1 @ 1616 \\
\hline $\begin{array}{l}\text { Solubility } \\
\left.\text { (mg/l @ }{ }^{\circ} \mathrm{C}\right)\end{array}$ & Insoluble & Insoluble \\
\hline
\end{tabular}

Source: US EPA 1992 
Table 9. Summary Statistics for Reverse Osmosis Treatment of Cadmium and Lead.

\begin{tabular}{|c||c|c|}
\hline Parameter & Cadmium & Lead \\
\hline \hline$K_{2}^{\prime}$ (dim) & $\mathrm{m}=6.341(10)^{-4}$ & $\mathrm{~m}=6.322(10)^{-4}$ \\
Normal & $\mathrm{s}=1.681(10)^{-4}$ & $\mathrm{~s}=1.837(10)^{-4}$ \\
& $\mathrm{n}=18$ & $\mathrm{n}=11$ \\
\hline $\mathrm{K}_{2}^{\prime \prime}$ (dim) & Not applicable & $\begin{array}{l}\lambda=-11.72 \\
\zeta=2.792 \\
\mathrm{n}=11\end{array}$ \\
\hline
\end{tabular}

\begin{tabular}{|c|c|}
\hline Parameter & Cellulose Acetate \\
\hline Porosity, $\epsilon(\%)$ & $\mathrm{m}=4.05$ \\
Normal & $\mathrm{s}=0.699$ \\
\hline Tortuosity, $\tau(\%)$ & $\mathrm{m}=2.50$ \\
Normal & $\mathrm{s}=0.304$ \\
\hline Thickness, $\lambda(\mu \mathrm{m})$ & $\mathrm{m}=0.375$ \\
Normal & $\mathrm{s}=0.0760$ \\
\hline
\end{tabular}

$\mathrm{m}=$ sample mean, $\mathbf{s}=$ sample standard deviation, $\mathrm{n}=$ number of data points in the sample population, $\lambda=$ sample mean of the logs of the data, $\zeta$ = sample standard deviation of the logs of the data. 
contains the specific data values used to generate the distributions.

Literature data of the flux and separation ability of cellulose acetate membranes are used to generate Figure 11 for cadmium and Figure 12 for lead. The distribution coefficients are determined from the slope and intercept of the of the best fit curve in these two figures.

\section{Results}

\section{Safety Factor Versus Reliability}

The process safety factor is defined as the ratio of the effluent standard to the mean design effluent concentration which is equivalent to the ratio of the median $\alpha$ to the mean treatment standard $\alpha$ when left in dimensionless terms. As with packed tower aeration, the effluent standard is set equal to the Clean water Act MCL of $5 \mu \mathrm{g} / 1$ for cadmium and lead. Reliability is defined as the frequency that the effluent concentration is below the effluent standard. Monte Carlo simulation of the reverse osmosis model is used to generate one thousand realizations of the effluent concentration for each of the two pollutants at two influent concentrations and 10 safety factors.

The resulting cumulative density functions (CDFs) relate the safety factors to reliability levels in terms of $\alpha s$ as illustrated in Figure 13 for cadmium. For example, a $120 \mu \mathrm{g} / \mathrm{l}$ influent concentration and $5 \mu \mathrm{g} / 1$ effluent standard provides 


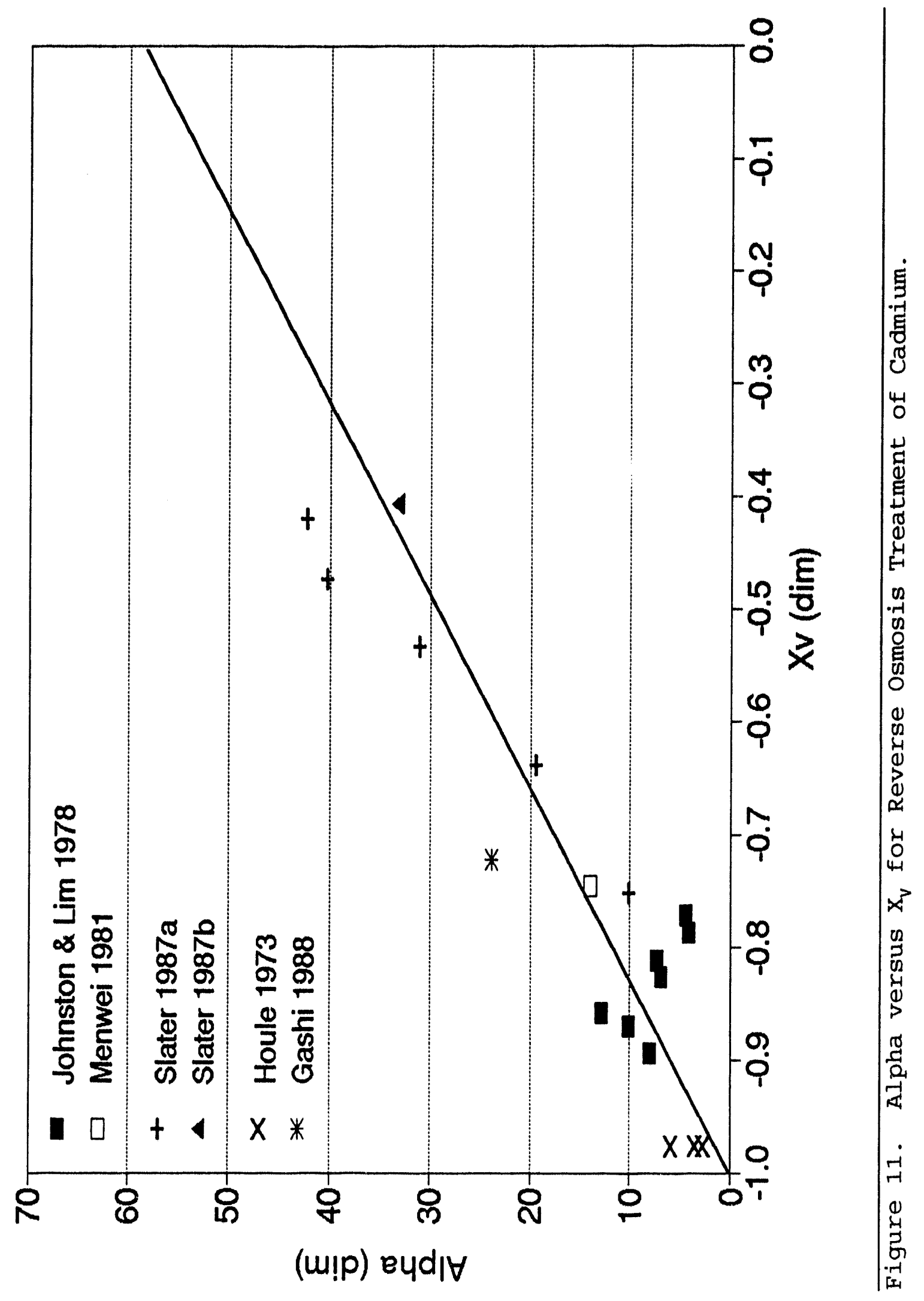




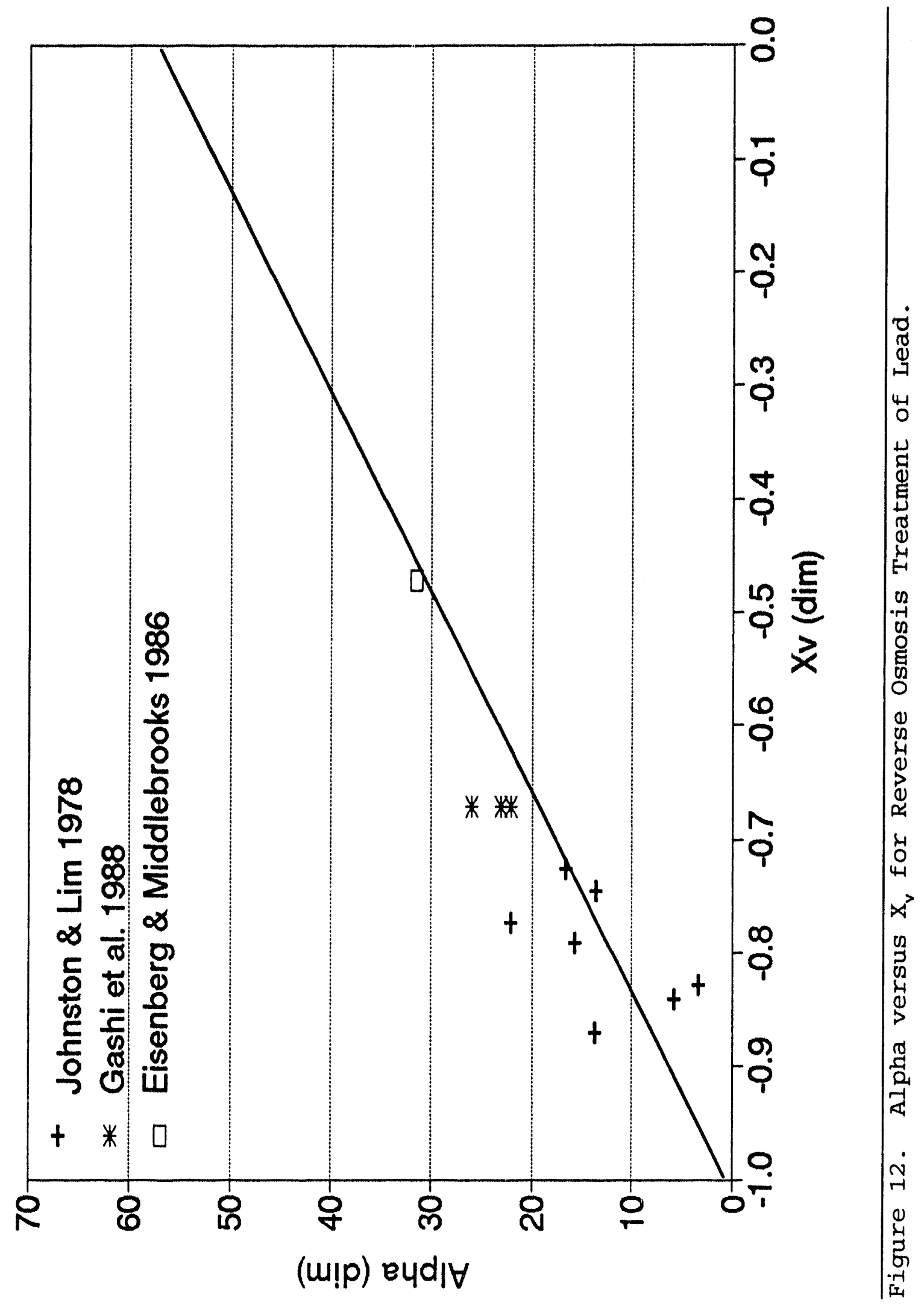




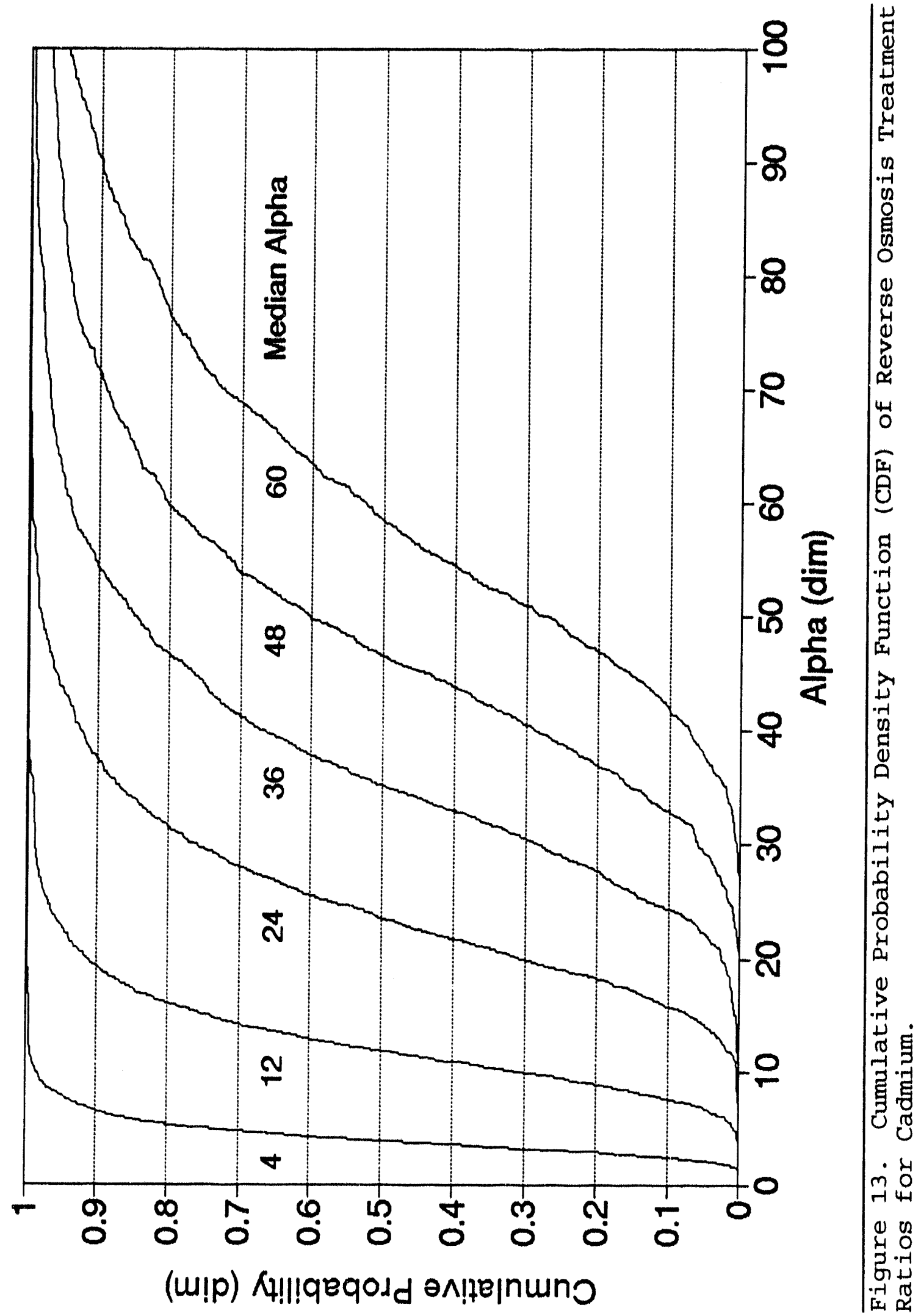


a an $\alpha$ of $24(120 / 5)$. For a safety factor of 1.5 $(\alpha=36 / \alpha=24)$, the treatment process reliability is $89 \%$ determined by projecting a line upward from the $\alpha$ axis at 24 to the median $\alpha$ curve of 36 (safety factor of 1.5 ) and then projecting the line horizontally to the probability axis. Reliability equals one minus the cumulative probability at that point. Reliability levels for other safety factors are determined in a similar fashion.

Plots of safety factors versus reliability for the reverse osmosis process are shown in Figure 14 for cadmium and Figure 15 for lead. As reliability increases toward one, the safety factors increase asymptotically toward infinity. The $20 \mu \mathrm{g} / 1$ influent concentration curve is higher than the $120 \mu \mathrm{g} / 1$ curve indicating higher safety factors are required for lower treatment efficiency at all reliability levels. This seemingly contradictory result is understood in the context of the process application.

Reverse osmosis is based on the principle of unequal fluxes of solvent and solute. The membrane is designed to transmit large quantities of water (solvent) while allowing only small quantities of solute to pass. Both solvent and solute fluxes increase with increasing total flux at higher operating pressures but the solvent flux increases much more dramatically than the solute flux causing a more dilute solute concentration on the permeate side of the membrane.

In the context of this research, increased safety 


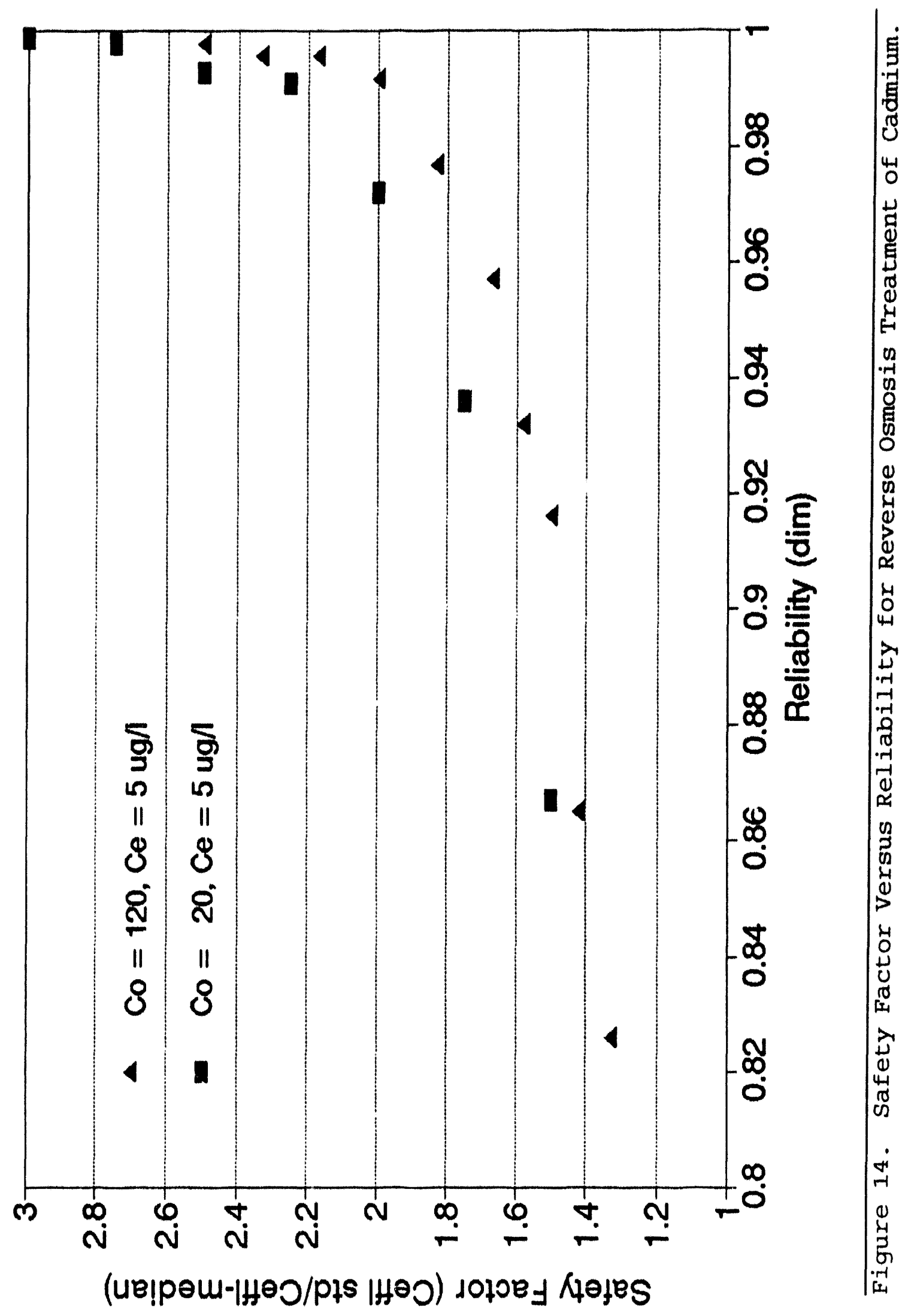




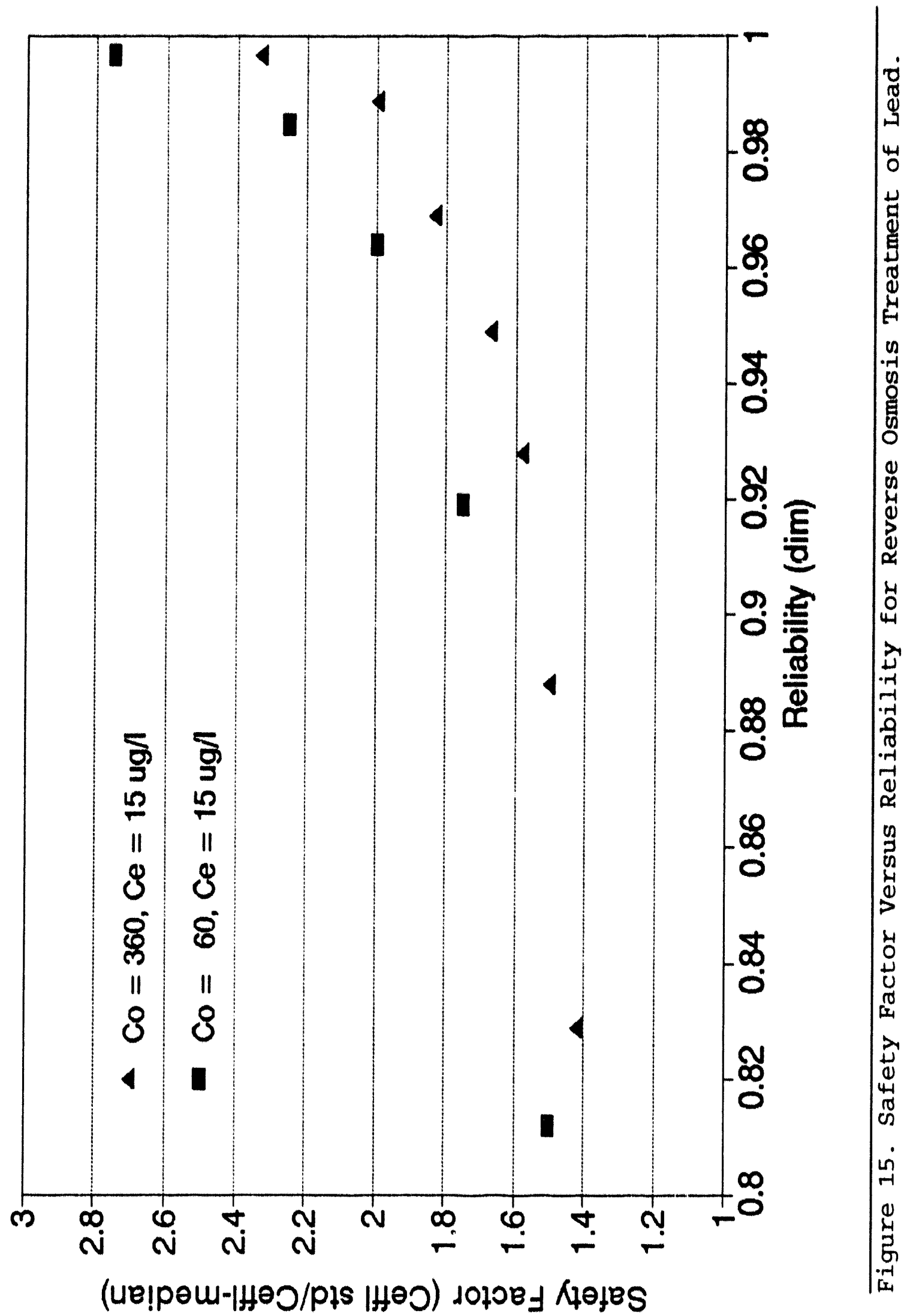


factors provide increased membrane surface area resulting in lower fluxes. As Figure 12 and Figure 11 show, lower fluxes (more negative $x_{v}$ ) result in lower treatment efficiencies. Therefore, to achieve the highest separation efficiency, membranes are operated at their maximum operating pressure and flux rate. Operating pressures and resulting fluxes for several cellulose acetate membranes are listed in Table 10.

A safety factor of approximately 1.6 is required to achieve 95 reliability for cadmium and lead at high treatment efficiency. At high treatment efficiency, over 998 reliability is achleved with safety factors of approximately 2.5 while slightly higher safety factors are required to attain the same reliability for lower influent concentrations. This phenomenon dramatically illustrates the pitfall of over-designing the reverse osmosis treatment process.

\section{Sensitivity Analyses}

Model results based on parameter distributions resulting from few data points or data ranges must be analyzed to determine the effect of the assumptions on the model results. The normal distribution is assumed for the nembrane thickness, $\lambda$, porosity, $\epsilon$, and pore torluosity, $\tau$, based on ranges of these parameters and must be verified through sensitivity analysis. The normal distribution is assumed for the feed-side distribution coefficient, $\mathrm{K}_{2}{ }^{\prime}$ and the log-normal 
distribution is assumed for the permeate-side distribution coefficlent, $\mathrm{K}_{2}$ " based on the results of the propagation of error procedure.

Distribution assumptions are verffled by comparing the model results based on the assumed normal and log-normal distributions with model results based on the uniform distribution fitted to these parameters where the uniform distribution is assumed to span the given data range. The uniform distribution is chosen because its shape is vastly different than the normal distribution so that parameters that pass this sensitivity test are robust to the probability distribution assumption.

The model results are compared with the two-sample Kolmogorov-Smirnov goodness-of-fit test based on 1000 simulations. In all but one sensitivity ( $k_{2} "$ for lead) the model results are not statistically different at the 0.05 level of significance which fustifies the parameter distribution assumptions for both pollutants. The model results are significantly different for the uniform distribution sensitivity of $\mathrm{K}_{2}$ " for lead. In this case, the normal distribution is used to compare the sensitivity of the model to fairly similar parameter distributions.

The normal " log-normal sensitivity analysis indicates significantly different results only at low treatment efficlency and not at medium and high treatment efficiency. As discussed earlier, reverse osmosis processes are designed 
Table 10. Examples of Operating Pressures and Flux Rates for Cellulose Acetate Reverse Osmosis Membranes.

\begin{tabular}{|c|c|}
\hline Operating Pressure (bar) & Flux $\left(\mathrm{m}^{3} / \mathrm{m}^{2}\right.$-day) \\
\hline 140 & 0.54 \\
\hline 105 & $0.81 \cdot 0.94$ \\
\hline 70 & $0.71 \cdot 0.76$ \\
\hline 42 & 0.48 \\
\hline 105 & 0.40 \\
\hline 105 & 0.46 \\
\hline 105 & 0.44 \\
\hline
\end{tabular}

Source: Sammon 1984. 
for high separation efficlency at high flux rates. Therefore, the model results are insensitive to the assumption of the normal or log-normal alstribution of $k_{2}$ " at high flux rates fustifying the assumption.

\section{Treatment ceste}

Reverse osmosis is designed based on the maximum operating pressure and flux of the membrane. The maximum flux rate is usually determined through pllot studies and is a function of the membrane properties, the concentration of poliutants in the waste stream and the desired effl:ar. concentration. Cartwright (1987) provides an estimate of the capital cost of uningtalled reverse osmosis equipment as a function of feed rate (Figure 16).

\section{Comparisone with Deterministic Designe}

Conventional deterministic designs attempt to achieve the maximum possible reduction of pollutant by operating the membrane at maximum operating pressures and fluxes. Extensive pilot testing of specific wastewater is generally performed to design pretreatment processes to protect the membranes. The extent of design conservatiom is specific to the particular design consultant and application. Effluent (permeate) concentration safety factors of three to five are common according to one local consultant (Alley and Associates). Since this safety factor is defined similarly to those in this research (effluent standard divided by 


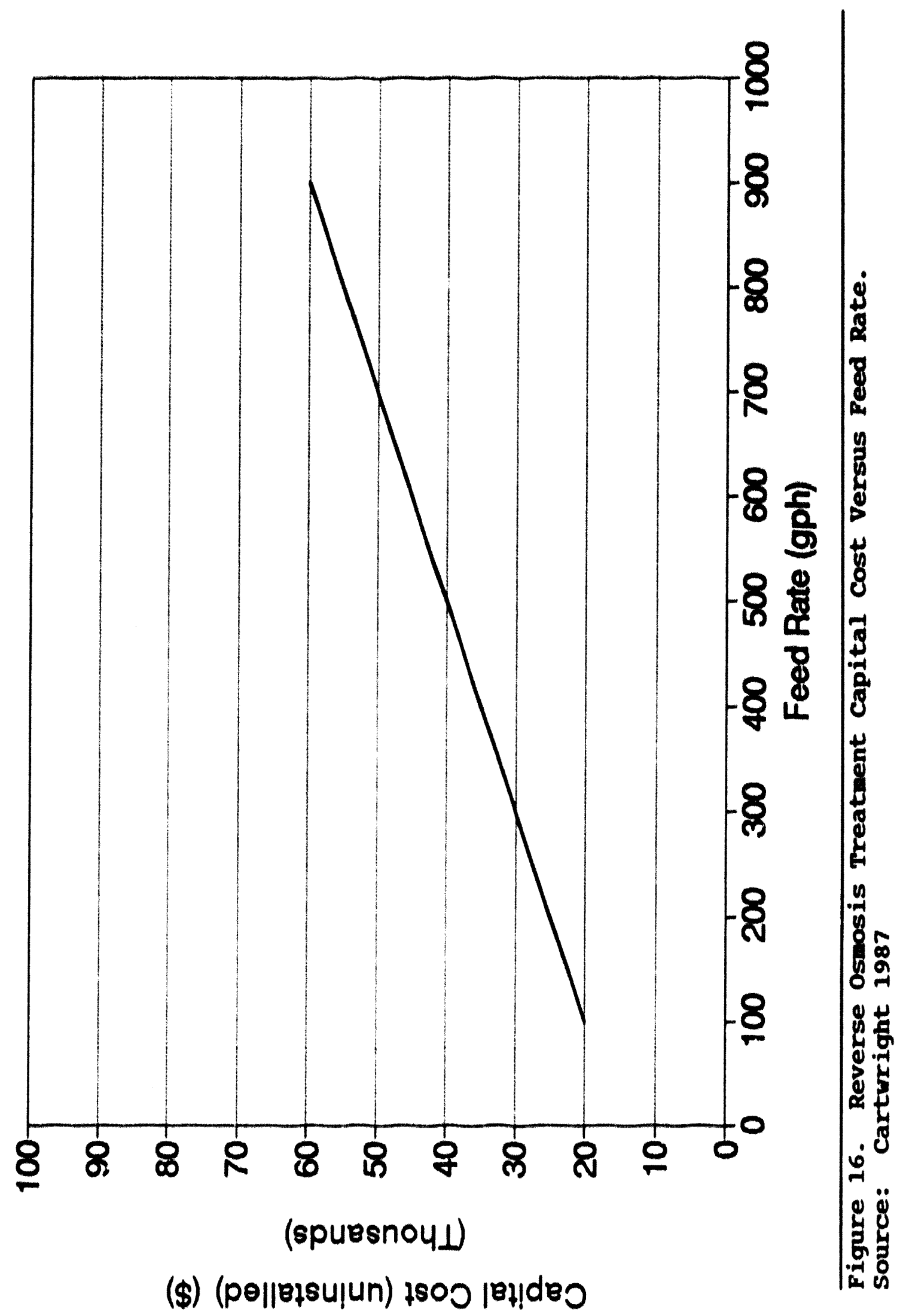


median effluent concentration), a direct prediction of the reliability of the deterministic designs can be made. Figure 14 and Figure 15 show that for a safety factor of three, reliability levels of greater than 99\% are realized for cadmium and lead, respectively. Higher safety factors appear not to be warranted for single pollutant waste streams.

\section{Summary}

Monte Carlo simulation is performed on the reverse osmosis treatment of cadmium and lead based on the probabilistic estimation of their distribution coefficients and the membrane's porosity, tortuosity and thickness. Safety factors of approximately 1.6 are required to achieve 95\% process reliability for both pollutants at the high treatment efficiencies associated with the membrane's maximum operating pressure.

Sensitivity analyses indicate that the model results are robust to the selection of distributions for parameters that lack data to statistically specify a distribution.

Reliability levels are of interest only at high treatment efficiencies, since due to the nature of the reverse osmosis process, the maximum efficiencies are achieved with the maximum flux rates corresponding to the membrane's maximum operating pressure. Costs are presented as a function of flow rate. 
Deterministic designs incorporate conservatism by designing for lower effluent (permeate) concentrations than required. Safety factors of three to five are common. A safety factor of three results in reliability leveis of greater than $99 \%$ based on the results of this research. Higher safety factors appear not to be warranted for single pollutant systems but may be required for more complex waste streams. 


\section{CEAPTER V}

\section{ACTIVATED SLUDGE TREATMEHNT}

\section{Literature Review}

Aerobic microorganisms have been widely studied for their potential in degrading hazardous and toxic substances. Tabak et al. (1981) studied 96 priority pollutants in static beaker flasks mixed with domestic sludge and found many of them biodegradable though flaws in the study cast doubt on the applicability of all the results. The EPA has been active in determining the extent of priority pollutants in publicly owned treatment works (POTWs) and in a pilot study found from 33 to 52 organic priority pollutants in POTWs (U.S. EPA 1979).

While the influent concentrations of priority pollutants in POTWs is usually low, reported removal efficiencies tend to be highly variable (Monteith 1987, Melcer et al. 1989). Significant correlation exists between influent and effluent variability (Melcer et al. 1989) though not all effluent variability is due to influent variability (Mackey and Grady 1988).

Information uncertainty contributes to the variability of the effluent due to the precision and accuracy on the measurement methodologies (Kleopfer et al. 1980). Eckenfelder and Roth (1976) show that variations in the 
influent strength, ambient temperature and the effluent particle flux affect the effluent variability. Ford (1976) adds that changes in $\mathrm{pH}$, nutrient deficiency, loss of dissolved oxygen, presence of toxics or inhibitors, and data artifacts from sampling error contribute to the variability of the effluent.

Pöpel (1976) shows that the gross effluent parameters $B O D$, suspended solids, ammonia, nitrite and flow rate have log-normal distributions. Researchers have found that varlability is increased (Pöpel 1976), unaffected (Ford 1976, Melcer and Bedford 1988, Melcer and Bedford 1987) or reduced (Monteith 1987) by the treatment process leaving one to wonder what is really happening.

Grady (1990) stresses the need to perform more simulation studies as a fast and cheap method of allowing us to focus our efforts where they can be best utilized.

The Monod and Haldane models are frequently used to represent the kinetics of activated sludge process (Figure 17). The Monod model is given by

$$
\mu=\frac{\mu_{m} S}{K_{m}+S}
$$

in which $\mu=$ specific growth rate of microorganisms; $\mu_{\mathrm{m}}=$ maximum growth rate of microorganisms; $S=$ substrate concentration; and $\mathrm{K}_{\mathrm{m}}=$ half-saturation constant. With respect to substrate concentration, the Monod model exhibits 


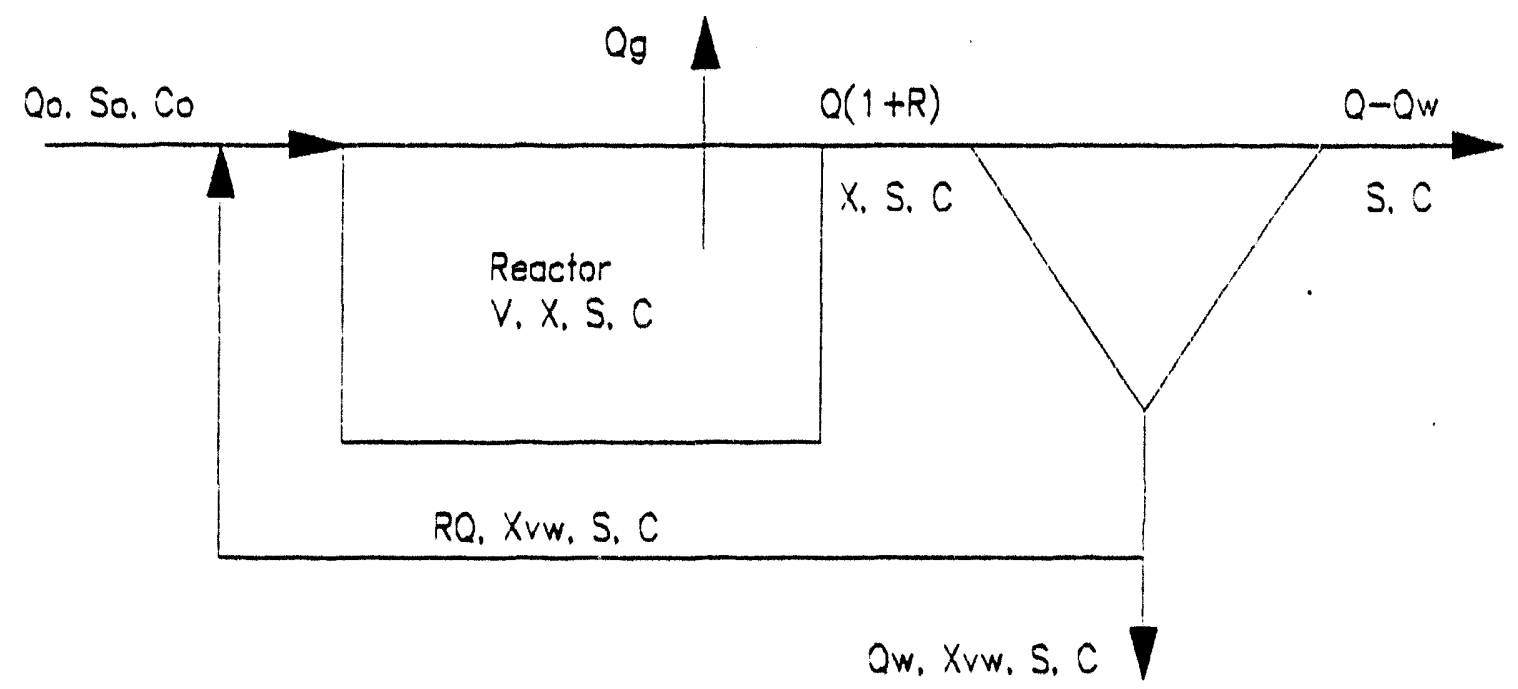

Figure 17. Schematic Diagram of the Activated Sludge Treatment Process. 
first-order kinetics at low substrate concentrations and zero-order kinetics at high substrate concentrations.

The Haldane model reflects high concentration substrate inhibition and is expressed as

$$
\mu=\frac{\mu_{m} S}{K_{m}+S+\frac{S^{2}}{K_{i}}}
$$

in which $\mathrm{K}_{i}=$ Haldane inhibition constant and the other terms are as defined in (16). As shown in Figure 18, the two models match quite well at low substrate concentrations though they diverge at higher concentrations.

Gaudy et al. (1986) have attempted to determine which of several inhibition kinetics models provides the best fit for phenol growth data based on optical techniques from batch and continuous flow experiments. They found the Haldane equation fit the data best but that there was a sufficient degree of data scatter to state statistically that the superiority was due to chance. The best-fit curve js plotted with the experimental data in Figure 19 illustrating the uncertainty of the fit. A method for determining Haldane kinetics based on respirometric techniques has been developed which appears to give much more reliable data (Gaudy et al. 1989, Tabak et al. 1990, Gaudy et al. 1987). Fitting the Haldane equation to the data with non-linear regression still poses some problems.

Ong and Bowers (1990) used Haldane kinetics for phenol 


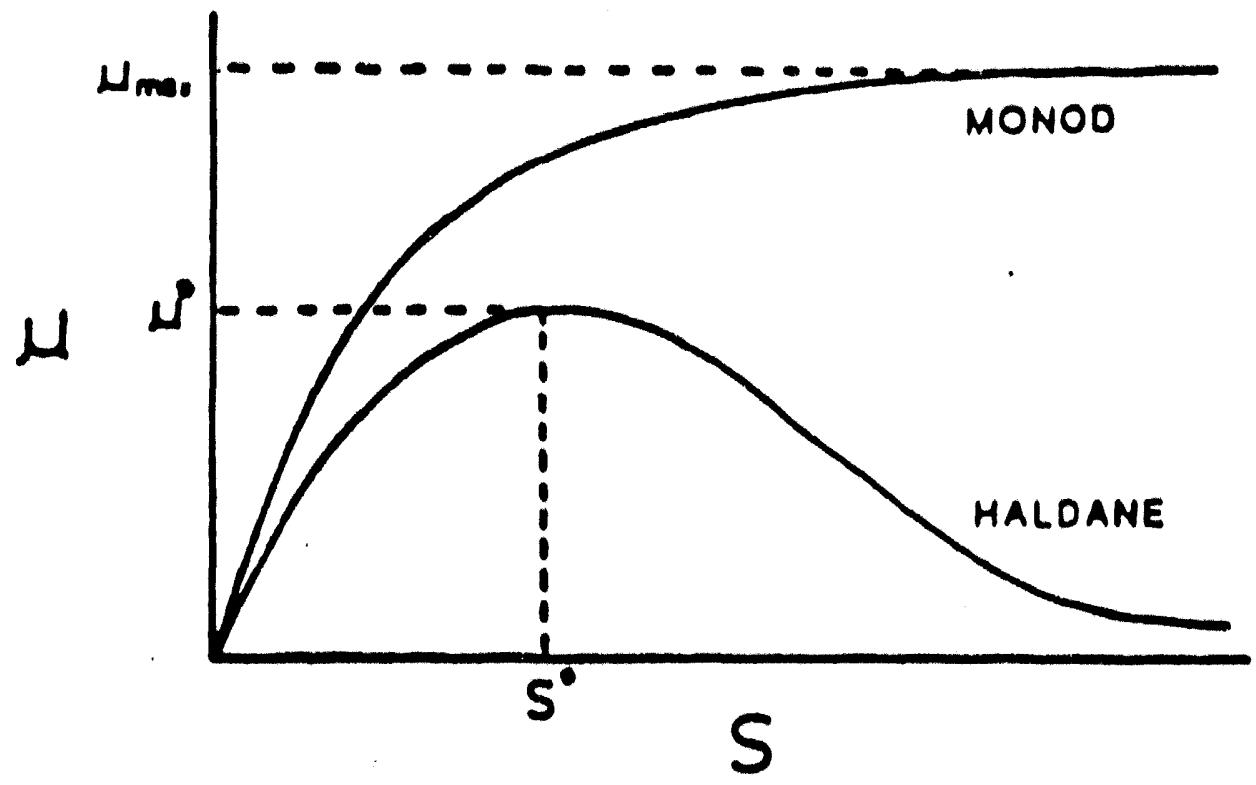

Figure 18. Comparison of Monod and Haldane Kinetic Models. 


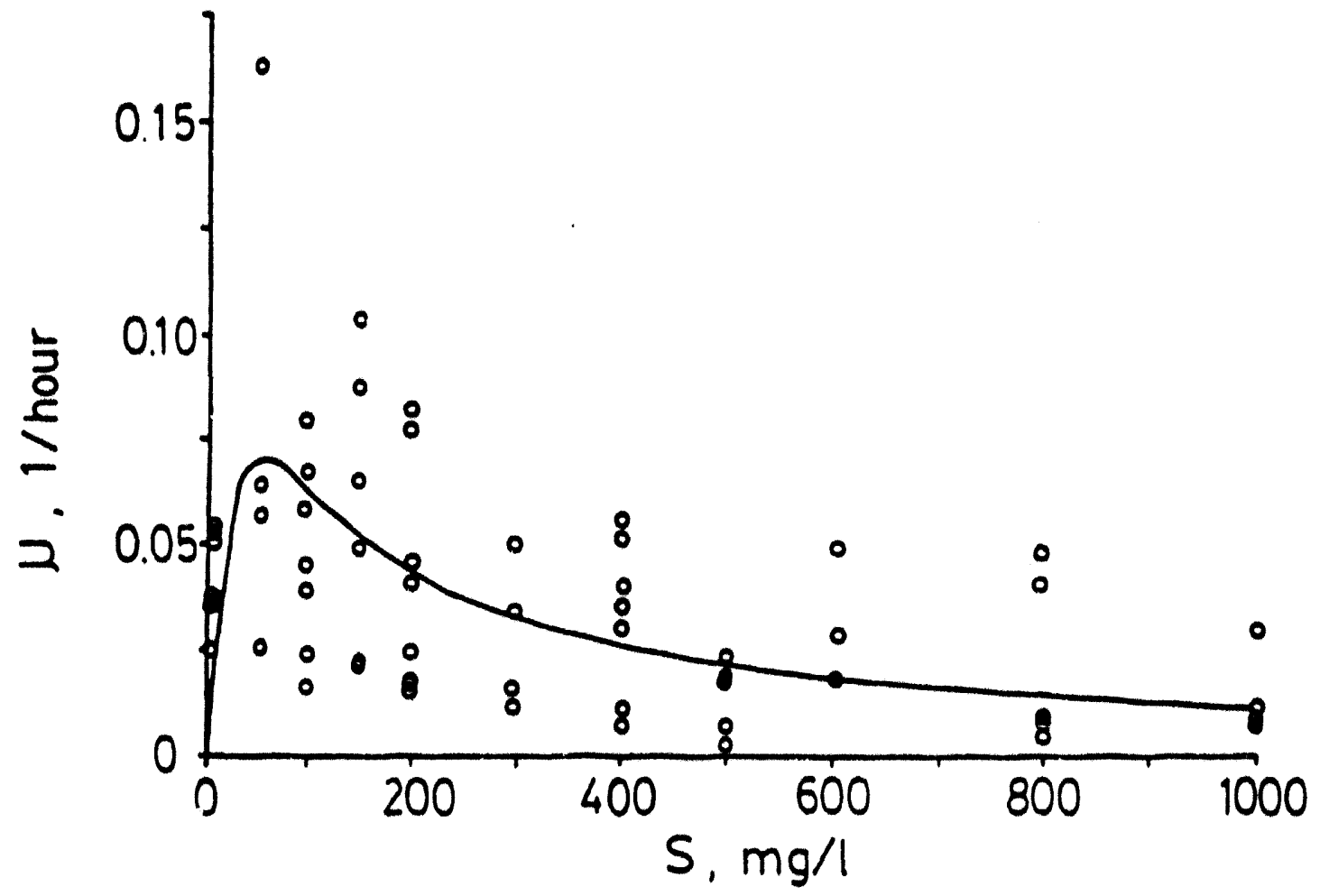

Figure 19. Example of Uncertainty Associated with Experimental Data and Attempt at Best-Fit Haldane Kinetic Model.

Source: Gaudy et al. 1986. 
and a log-normal distribution of the critical solids retention time, $\theta_{c}^{*}$, to demonstrate design of activated sludge systems that meet any specified level of reliability against washout fallure due to inhibition. While $\theta_{c}^{*}$ was the only parameter fit with a probability distribution in this evaluation, the work is a significant step from standard deterministic calculations toward probabilistic assessments.

Since the Monod and Haldane models match well at low concentration and the Haldane model requires three coefficients to the Monod model's two, many researchers have suggested using Monod kinetics even when modeling compounds known to exhibit inhibition tendencies. Most engineers simplify the biokinetics even further by assuming first-order rates with respect to substrate concentration, especially when other removal mechanlsms are considered. This assumption is generally valid for low substrate concentrations found in completely mixed reactors.

stripping and sorption on the mixed liquor are additional removal mechanisms of activated sludge that have received considerable attention recently. Several researchers (Govind et al. 1991, Bell et al. 1991, Namkung and Rittmann 1987, Watkins 1984) have developed models for fate of organics in activated sludge where stripping is primarily related to Henry's constant, $\mathrm{K}_{H}$; sorption is related to the octanol-water coefficient, $\mathrm{K}_{\mathrm{ow}} ;$ and, due to low concentrations and ease of computation, the biodegradation 
rate is assumed first order with respect to substrate concentration.

Most models assume that sorptionidesorption is an instantaneous and reversible process and stripping and blodegradation compete to remove the compound of concern. Namkung and Rittmann (1987) found that for volatile organic compounds (VOCs), when biodegradation occurs, volatilization and adsorption are not important and when biodegradation does not occur, volatilization is the main removal mechanism. These findings are consistent with findings of other researchers (Kincannon et al. 1983a, Weber and Jones 1984, Blackburn et al. 1985). Dobbs et al. (1988) show that pesticides, phthalates and polynuclear aromatics are highly sorbable with concentration factors ranging from 13 to 13,000 due to their high $k_{\text {ow }}$.

Grady (1990) provides an excellent summary article concerning biodegradation of coxic organics and makes two Important points. Simultaneous substrate removal occurs when multiple substrates are present more frequently than sequential substrate removal since the metabolic control mechanisms that cause sequential substrate removal are not operative in carbon limited environments. The use of single substrate removal rates (how tests are generally performed) in multiple substrate environments is therefore conservative and will over-predict effluent concentrations.

Another important point concerns partitioning of the 
microbial mass capable of degrading specific compounds in the waste. Grady indicates that the fraction of the microbial community capable of degrading specific compounds is roughly proportional to the contribution of the specific compounds to the feed COD. Of course, this assumes that the yields of the respective microbes are equal.

statistical modeling of the activated sludge process was performed by Niku et al. (1981) as discussed earlier. This major work was concerned only with gross parameters (e.g., $B O D, T O C)$ and specific compounds were not considered. As previously mentioned, the major drawback to this type of statistical analysis is that much of the performance of the well-designed and operated plants is lost in the averaging with less well designed and operated plants. Additionally, hazardous wastes generally comprise only a small fraction of the municipal waste load calculated with gross parameters such as BOD and TOC.

Debelak and Sims (1981) developed a Box-Jenkins time series transfer function model of the effluent COD from an activated sludge system and attempted to match the output to an industrial process. They rationalized that since many parameters are unknown or estimated and that the activated sludge process is not stationary, a transfer function would provide the best method of solution. They found that the model based on influent and effluent $B O D$ or COD data alone was inadequate to predict the behavior of the system 
providing further support to the results discussed herein. No probabilistic analyses of specific fate models have been located in the literature.

\section{Research Approach}

\section{Model Description}

Monte Carlo simulation of a modified version of the deterministic EPA FATE model (Govind et al. 1991) is performed to ascertain the rellability of the activated sludge treatment process. The several fate models reviewed are based on the same general considerations and the EPA FATE model has been validated through pilot-scale treatment evaluations of 28 RCRA semi-volatile and volatile compounds and 19 CERCLA semi-volatile compounds. The EPA FATE model contains a parameter database of 120 compounds and considers first-order blodegradation, sorption, stripping due to

surface aeration and bubble diffusion, and volatilization from quiescent tanks as removal mechanisms.

The modified EPA FATE model considers first-order biodegradation with respect to substrate, sorption on the wasted solids, and stripping due to fine bubble aeration as pollutant removal processes in a steady-state, completely mixed reactor (CSTR) with a micropollutant mass balance for the aeration tank as 


$$
\begin{aligned}
& Q_{L}\left(C_{0}-C\right) \\
& =V_{L} K_{b} X_{V} C \\
& +Q_{w} K_{p} X_{v, w} C \\
& +\varrho_{G} K_{H}\left[1-\exp \left(-\frac{K_{L}^{b u b} a V_{L}}{K_{H} Q_{G}}\right)\right] C \text { (Stripping) }
\end{aligned}
$$

where $Q_{L}=$ flow rate into the aeration tank; $C_{0}=$ influent substrate concentration; $C=$ substrate concentration; $V_{L}=$ volume of aeration tank; $K_{b}=$ biodegradation rate constant; $X_{v}=$ volatile solids concentration; $Q_{w}=$ waste sludge flow rate; $\mathrm{K}_{\mathrm{p}}=$ solid/Iiquid partition coefficient; $Q_{G}=$ gas flow rate; $K_{H}=$ dimensionless Henry's constant (concentratior in air divided by concentration in water) $\mathrm{K}_{\mathrm{L}}^{\text {bub }} \mathrm{a}=$ mass transfer coefficient by diffused aeration.

The biomass concentration is related through the yield coefficient as

$$
X_{V}=X_{V, w}\left(\frac{r}{I+I}\right)+\frac{V_{L}}{Q_{L}} K_{b} Y X_{v} C
$$

and the volatile solids in the waste sludge

$$
X_{V, w}=\frac{V_{L} / Q_{L} K_{b} Y X_{V} C}{X_{V} / X_{V, w}-I /(1+I)}
$$

where $r=$ recycle ratio.

The treatment process is designed for a typical municipal waste with a $5.7 \mathrm{MGD}\left(0.25 \mathrm{~m}^{3} / \mathrm{sec}\right)$ flow rate and a COD load of $200 \mathrm{mg} / \mathrm{l}$ after primary settling. Biomass yields, wastage rates, aeration tank gas rates, hydraulic and solids retention times are based on the domestic waste. 


\section{Selected pollutants}

Phenol and chloroform are the pollutants utilized to evaluate the reliability of the activated sludge process. Both are listed RCRA hazardous wastes, priority pollutants and common industrial pollutants. Phenol is readily degradable aerobically and is one of the most studied industrial pollutants. Chloroform is not degradable aerobically, has a high Henry's constant and has significantly different chemical and physical properties than phenol (Table 11).

Summary statistics for the probability distributions of the first-order degradation rate, $k_{b}$ i Henry's constant, $k_{H}$; and log octanol-water partition coefficient, log $\mathrm{K}_{\mathrm{ow}}$, for both pollutants are presented in Table 12. The statistics are based on extensive literature reviews and the appendix contains the specific data values used to generate these distributions.

Each pollutant is assumed to enter the process at less than $400 \mu \mathrm{g} / \mathrm{l}$ based on maximum concentrations in POTWs as reported by Russell et al. (1983). At these concentrations, the pollutants exert little effect on the overall process and micropollutant mass balance is used to determine the effluent concentration of the pollutants. 
Table 11. Chemical and Physical Properties of Phenol and Chloroform for Activated Sludge Treatment.

\begin{tabular}{|c|c|c|}
\hline Compound Name & Phenol & Chloroform \\
\hline CAS Number & $108-95-2$ & $67-66-3$ \\
\hline Compound Type & Phenolic & Hycirocarbon \\
\hline Formula & $\mathrm{C}_{6} \mathrm{H}_{6} \mathrm{O}$ & $\mathrm{CHOl}_{3}$ \\
\hline MW $(\mathrm{g} / \mathrm{mol})$ & 94.11 & 11.9 .38 \\
\hline Melting Point $\left({ }^{\circ} \mathrm{C}\right)$ & 43 & -153.5 \\
\hline Bolling Point $\left({ }^{\circ} \mathrm{C}\right)$ & 181.7 & 61.7 \\
\hline $\begin{array}{l}\text { Vapor Pressure } \\
\left.\text { (Torr @ }{ }^{\circ} \mathrm{C}\right)\end{array}$ & $0.35 @ 25$ & $1.60 @ 20$ \\
\hline $\begin{array}{l}\text { Solubility } \\
\left(\mathrm{mg} / 1 @{ }^{\circ} \mathrm{C}\right)\end{array}$ & $8(10)^{\prime} @ 25$ & $9300 @ 25$ \\
\hline $\log k_{\text {ow }}(\mathrm{dim})$ & 1.46 & 1.97 \\
\hline $\begin{array}{l}\text { Henry's Constant } \\
\left(\mathrm{atm}-\mathrm{m}^{3} / \mathrm{mol}\right)\end{array}$ & $1.3(10)^{-6} @ 25$ & $3.39(10)^{-3}$ \\
\hline
\end{tabular}

Source: US EPA 1992 
Table 12. Probability Distribution Parameters for Phenol and Chloroform.

\begin{tabular}{|c|c|c|}
\hline Parameter & Phenol & Chloroform \\
\hline $\begin{array}{c}\mathrm{K}_{\mathrm{b}}(\mathrm{l} / \mathrm{mg} \text {-day }) \\
\text { Log-normal }\end{array}$ & $\begin{array}{l}\lambda=-1.360 \\
\zeta=1.903 \\
n=38 \\
\lambda=-1.595 \\
\zeta=1.963 \\
n=10\end{array}$ & not degradable \\
\hline $\begin{array}{c}\mathrm{K}_{\mathrm{H}}\left(\mathrm{atm}-\mathrm{m}^{3} / \mathrm{mol}\right) \\
\text { Log-normal }\end{array}$ & $\begin{array}{l}\lambda=-5.55 \\
\zeta=1.04 \\
n=5\end{array}$ & $\begin{array}{l}\lambda=-2.00 \\
\zeta=0.416 \\
n=4\end{array}$ \\
\hline $\log \mathrm{K}_{\text {Now }}(\mathrm{dim})$ & $\begin{array}{l}m=1.50 \\
s=0.484 \\
n=18\end{array}$ & $\begin{array}{l}m=1.96 \\
s=0.005 \\
n=4\end{array}$ \\
\hline
\end{tabular}

$\mathrm{m}=$ sample mean; $\mathrm{s}=$ sample standard deviation; $\mathrm{n}$ = number of data points in the sample population; $\lambda$ - mean of the logs of the data; $\zeta=$ standard deviation of the logs of the data. 


\section{Results}

\section{Safety Factor Versus Reliability}

The process safety factor is defined in two different. ways depending on whether the major micropollutant removal mechanism is biodegradation or stripping. For phenol, which is removed primarily by biodegradation, the process safety factor equals the soluble domestic waste $C O D$ effluent standard divided by the median soluble domestic waste COD effluent concentration. The effluent standard is set at 5 $\mathrm{mg} / \mathrm{l}$ soluble COD since total effluent standards are generally $20 \mathrm{mg} / \mathrm{l} C O D$ and the COD contribution of the solids is generally $15 \mathrm{mg} / \mathrm{l}$.

When the pollutant is removed mainly by stripping, as in the case of chloroform, the process safety factor is applied to the gas flow rate within the aeration tank. In this case, the process safety factor equals the ratio of the given air flow rate to the design air flow rate required to provide the oxygen equivalent of the COD load removed in the aeration tank. Pure oxygen aeration (at greatly reduced flow rates) is also evaluated. In all cases, reliability is defined as the frequency that the micropollutant effluent concentration is below the effluent standard.

Monte Carlo simulation of the EPA Fate Model is used to generate one thousand realizations of the effluent concentration for each of the two micropollutants at 400 and 
$100 \mu \mathrm{g} / 1$ influent concentrations for 15 safety factors. The resulting cumulative density functions (CDFs) relate the safety factors to reliability levels as illustrated in Figure 20. For example, for a safety factor of 1.25 , a phenol influent concentration of $400 \mu \mathrm{g} / 1$ and an effluent target concentration of $10 \mu \mathrm{g} / 1$, the reliability of the treatment process is 72\%. This reliability level is obtained by extending a vertical line upward from the effluent concentration axis at $10 \mu \mathrm{g} / 1$ to the 1.25 safety factor curve and extending the line horizontally to the cumulative probability axis. The cumulative probability equals the reliability at that point.

While the simulations were performed for two distinct micropollutant influent concentrations, the solution of the micropoliutant mass balance is in terms of the influent/effluent concentration ratio, or removal ratio for short. This more general presentation is used for the remainder of the chapter.

Plots of safety factors versus reliability for the activated sludge process are shown in Figure 21 for phenol and Figure 22 for chloroform. The safety factors for phenol removal in Figure 21 are related to domestic waste COD removal. Figure 23 shows that biodegradation is the primary removal mechanism for phenol and approximately $99 \%$ removal is achieved for a broad range of safety factors. Since phenol removal is high even at low safety factors, the increase in 


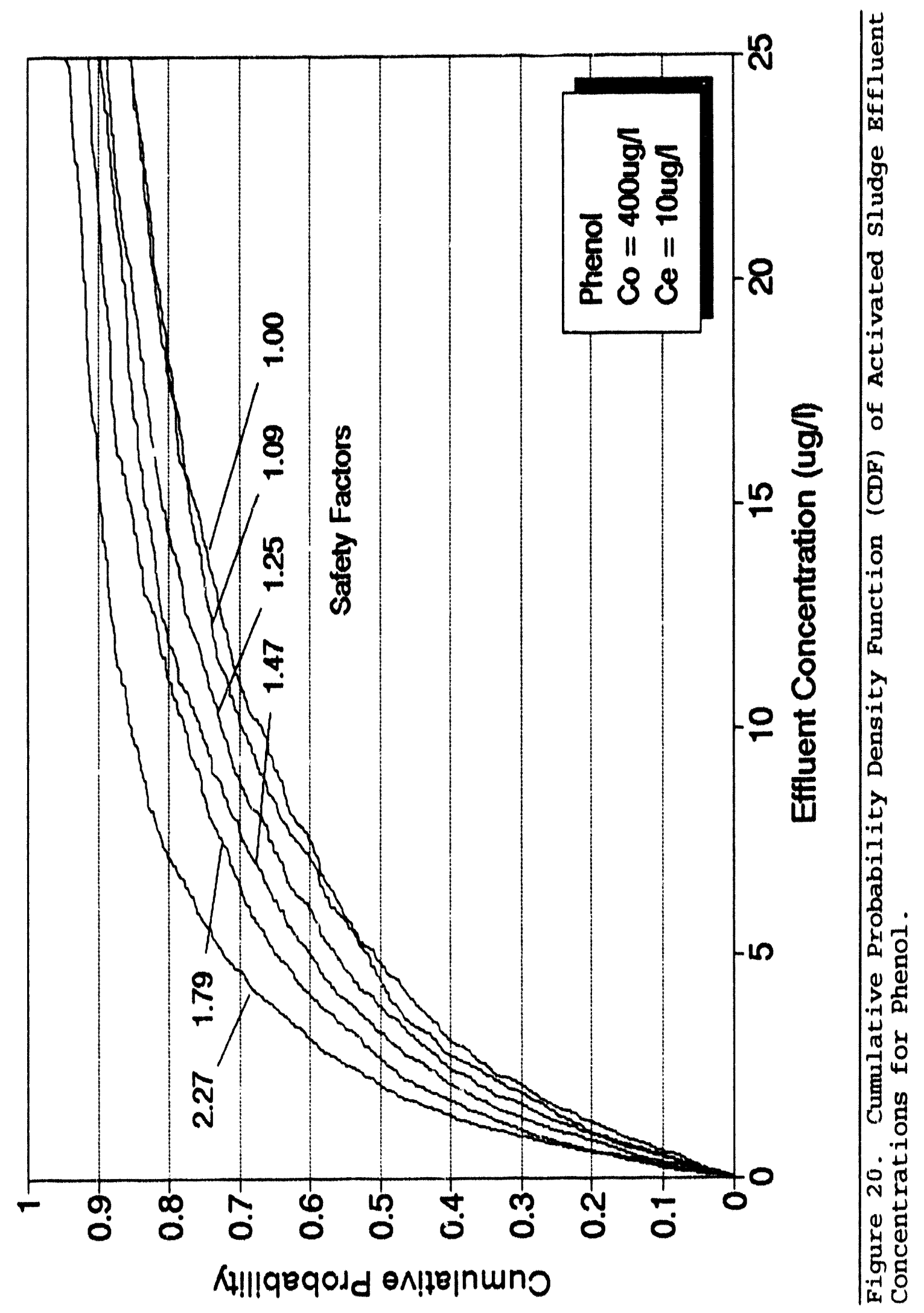




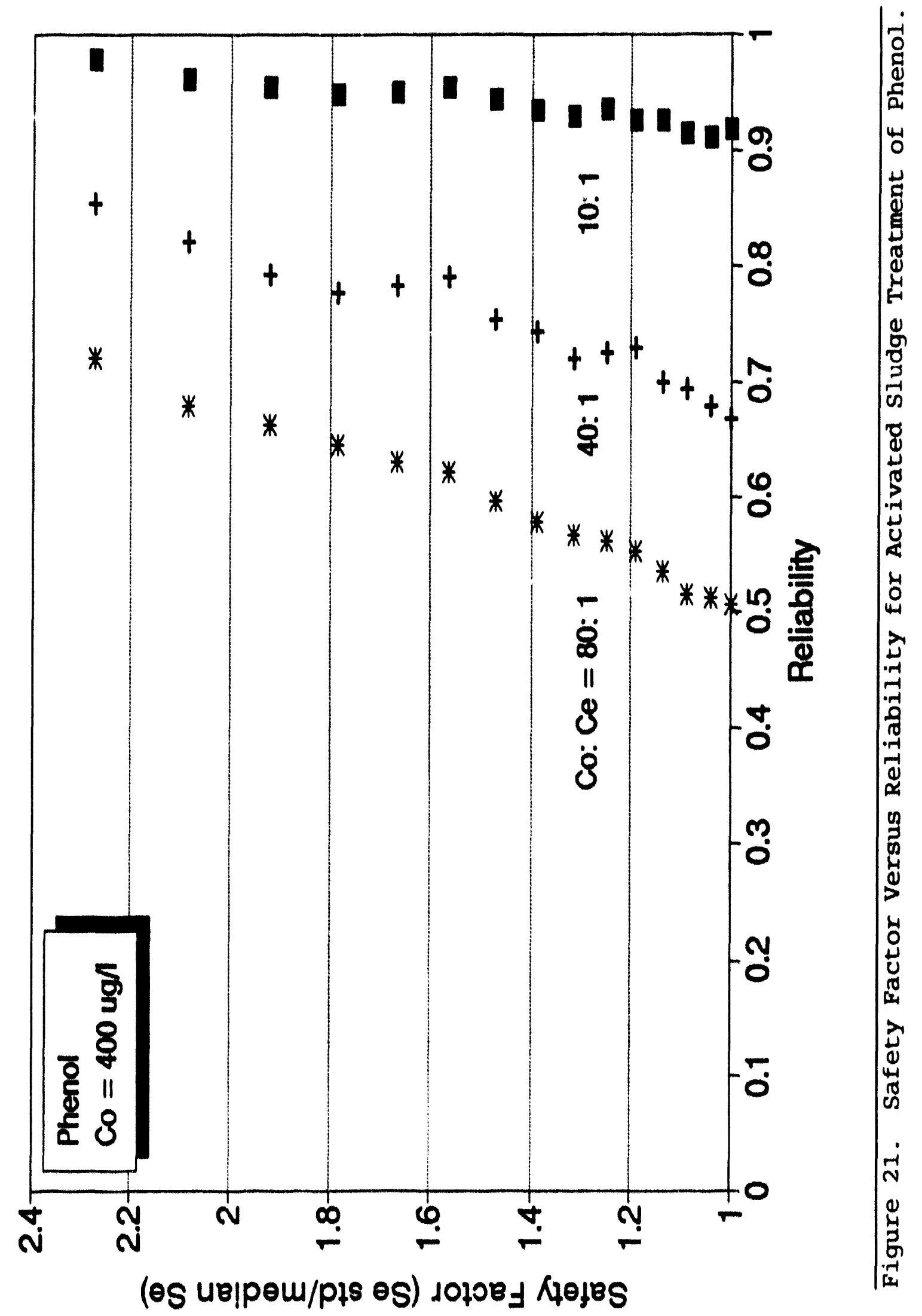




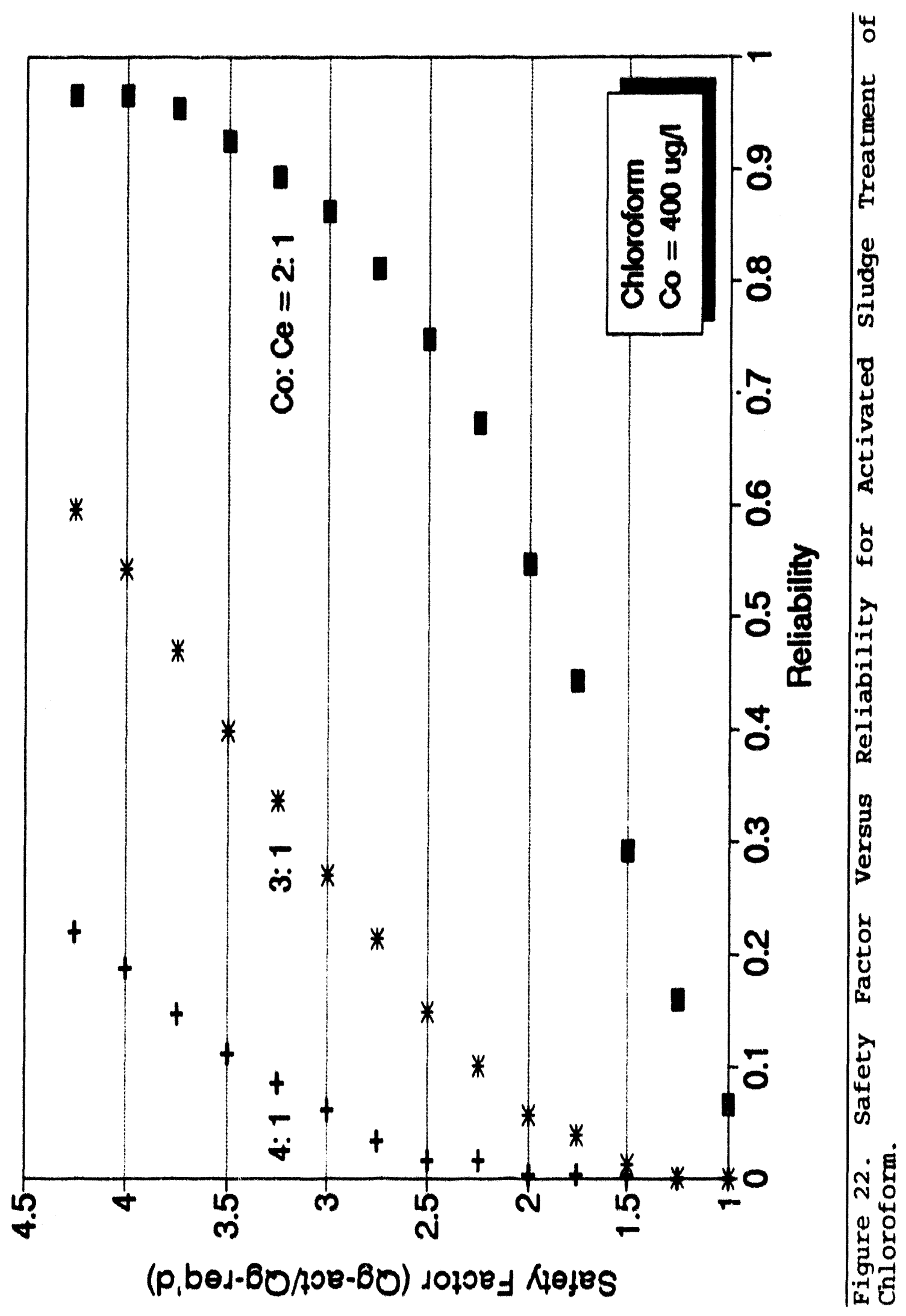




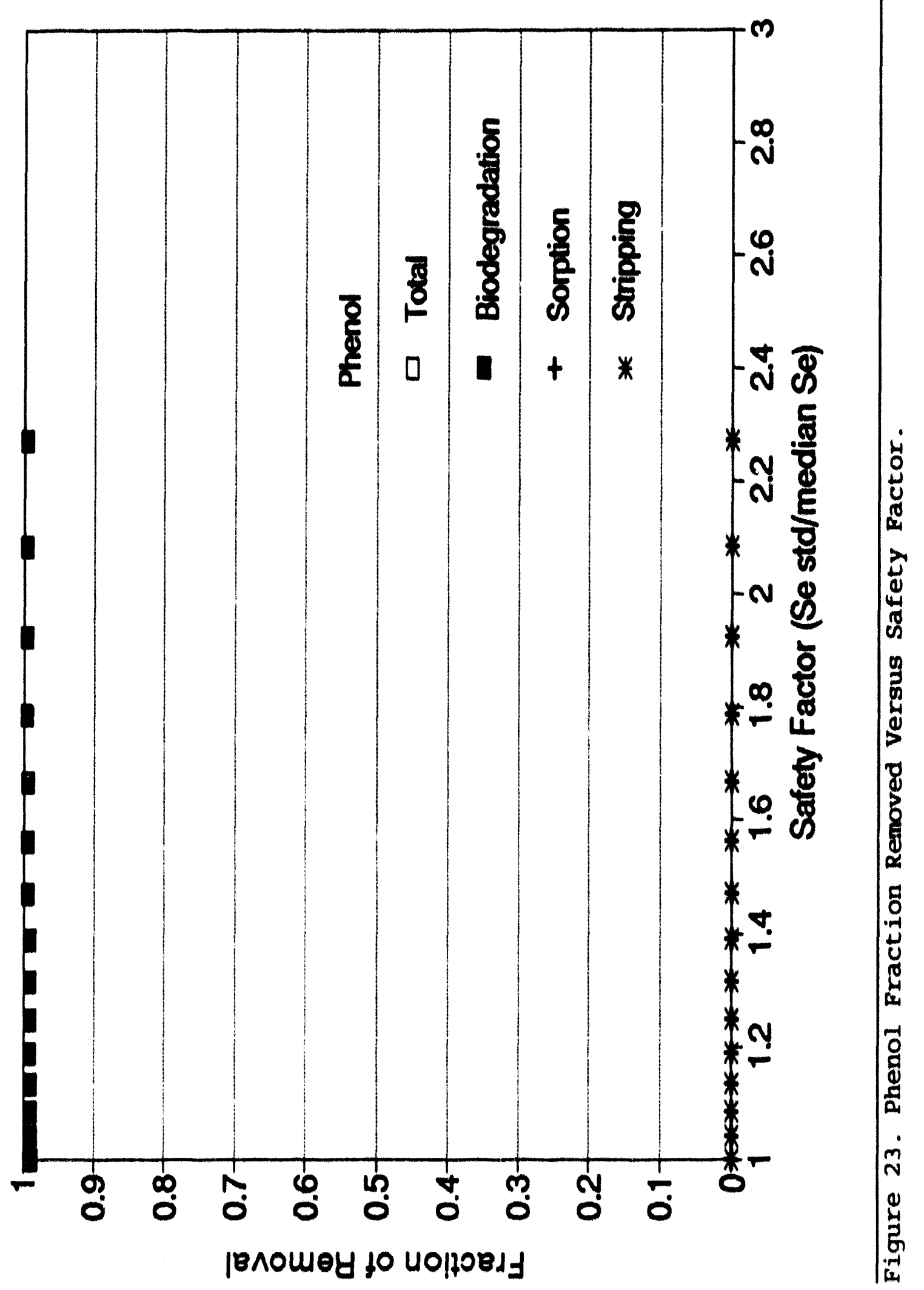


process reliablifty is not greatly improved at higher safety factors as shown in Figure 21 by the very steep curves of safety factor versus reality. As expected, relfablitty levels are lower for the higher removal ratio. Rellability increases are also more pronounced for the higher removal ratios since there 18 more room for improvement in reliablity for these scenarios.

The safety factors in Figure 22 are related to the air flow rate in the aeration tank. The oxygen transfer effictency of 15 for fine bubble diffusion has been assumed. At a safety factor of three, the air flow rate approaches that of coarse bubble diffusion which has 5 t oxygen transfer efficlency, thus both aeration systems are evaluated. The reliability of chloroform removal it distinctly non-linear and great gains in rellability are achleved for low removal ratios with increased safety factors.

Figure 24 shows that stripping it the primary mechanism for chloroform romoval and the total fraction removed increases from $24 t$ for a safety factor of one to over 60t for a safety factor of three. Thus, gains in reliablitity are expected with increasing safecy factors although, since the total chloroform fraction removed is relatively low, high rellability can be expected only for lower removal ratios.

This result is illustrated in figure 22 where high rellability is realized only at high safety factors and low removal ratios. As safety factors increase, the familiar 


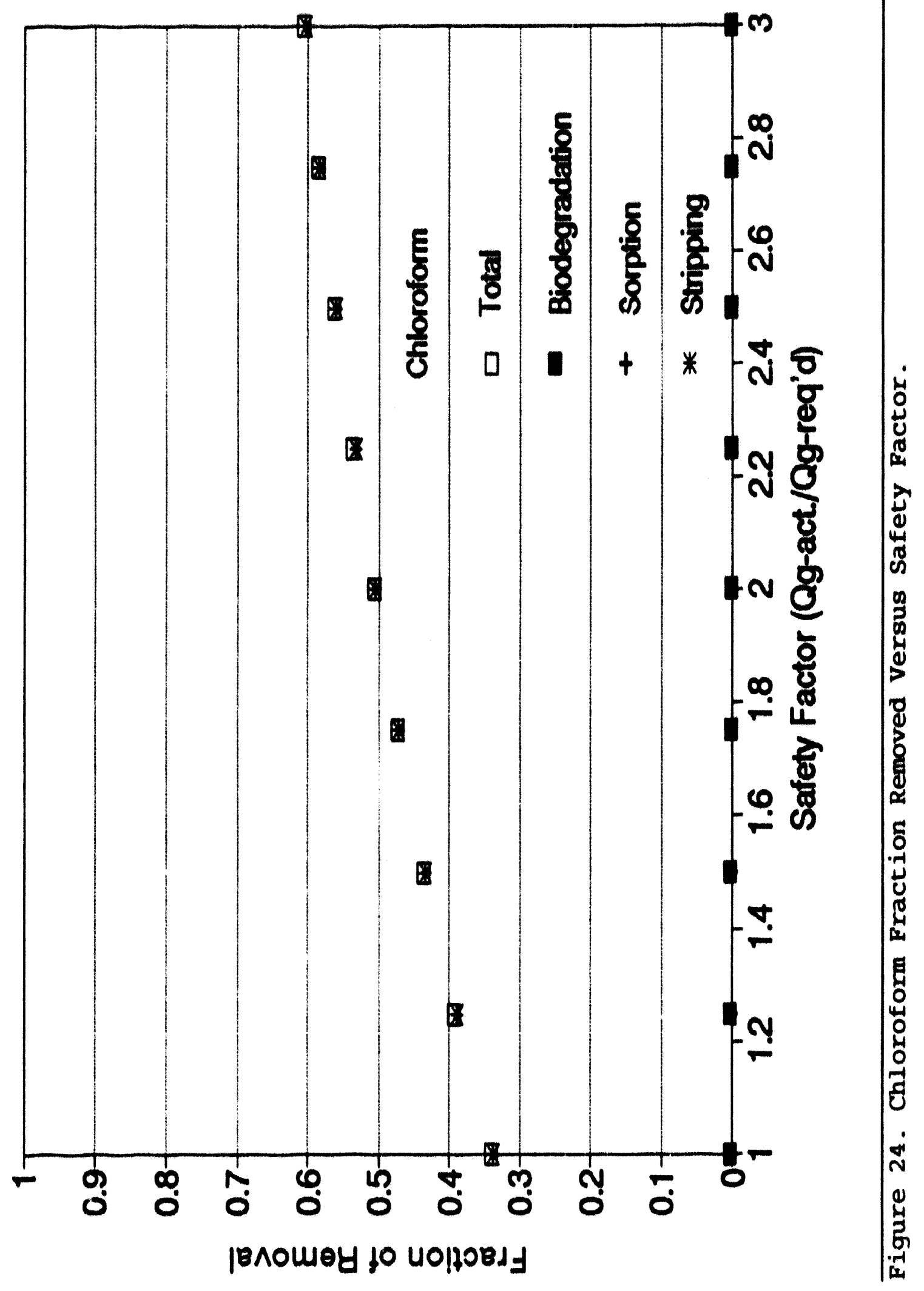


asymptotic approach to 100 reliability is apparent for the 2:1 removal ratio. Increasing rellability is also apparent at the higher removal ratios although at higher safety factors and lower rates.

\section{Sensitivity Analyses}

Effluent concentrations resulting from distributions of parameters based on few data points or data ranges must be analyzed to determine the effects of the assumptions on the model results. For phenol, the degradation rate, $k_{b}$ is the primary variable of interest as shown in Figure 23 . Its distribution is strongly log-normal based on the one-sample Kolmogorov-Smirnov goodness-of-fit test of thirty-eight data points. Therefore no sensitivity analysis is required.

Figure 24 shows that stripping is the major removal mechanism for chloroform. While the chloroform Henry's constant distribution is based on fust four data points, the Henry's constant distributions in the packed tower aeration chapter are strongly log-normal based on several data points. Therefore, the log-normal distribution is fustified and additional sensitivity analyses are not required.

The sensitivity of the activated sludge model to the quantity of data used to generate the probability distribution of the blodegradation rate, $k_{b}$, for phenol is analyzed to indicate the robustness of the model to the number of data points used to generate the probability 
distribution. Most probabilistic parameters in this research are based on approximately ten data points and the phenol $k_{b}$ 1s based on thirty-eight points. To determine the effects of fewer data points, a new distribution for phenol $k_{b}$ is bullt based on ten data points selected at random from the phenol $K_{b}$ database. The results of the model outputs are compared with a two-sample kolmogorov-Smirnov goodness-of-fit test.

As shown in Table 12, the median of the 10 data point distribution is slightly smaller and the variance is slightly larger than their counterpart parameters of the 38 data point distribution. The first result is not surprising since the central limit theorem predicts that the expected value will not shift significantly as the number of data points increases. The second result likewise is not unexpected since the effects of information uncertainty due to fewer data points is expected to increase the parameter standard deviation. This analysis indicates that model results based on parameters with fewer data points should tend to make the resulting safety factors conservative. The model results based on this sensitivity analysis are not significantly different at the 0.05 level of significance based on the twosample Kolmogorov-Smirnov goodness-of-fit test. While this sensitivity analysis cannot be generalized to the other models or pollutants, the effects of the central limit theorem and information uncertainty will tend to give similar trends with other models and pollutants. 


\section{Cost Versus Reliability}

Plots of cost versus reliability for the activated sludge process are shown in Figure 25 and Figure 26 for phenol and chloroform, respectively. As expected, costs increase with increasing reliability and higher removal ratios result in higher costs for a given reliability level. These costs are based on the scoping cost estimating method used by the U.S. EPA (DeWolf et al. 1984) and are intended to provide relative comparisons only.

Figure 25 indicates that for high phenol removal ratios (80:1 and 40:1), treatment costs increase by about $7 \%$ for a reliability increase of $20 \%$. At lower removal ratios 1 10:1 and less), reliability increases less than 10\% for the same cost increase of $7 \%$. Thus, high removal ratio scenarios gain more reliability per dollar spent than do low removal ratio scenarios.

Figure 26 indicates that relative to phenol, chloroform removal ratios are quite small. At $2: 1$ removal ratios, reliability increases from near zero to near $100 \%$ for a treatment cost increase of $27 \%$. Higher removal ratios do not fare nearly as well. In this case, low removal ratio scenarios gain more reliability per dollar spent than do high removal ratio scenarios.

\section{Comparisons with Deterministic Designs}

Conservatism is incorporated into the design of the 


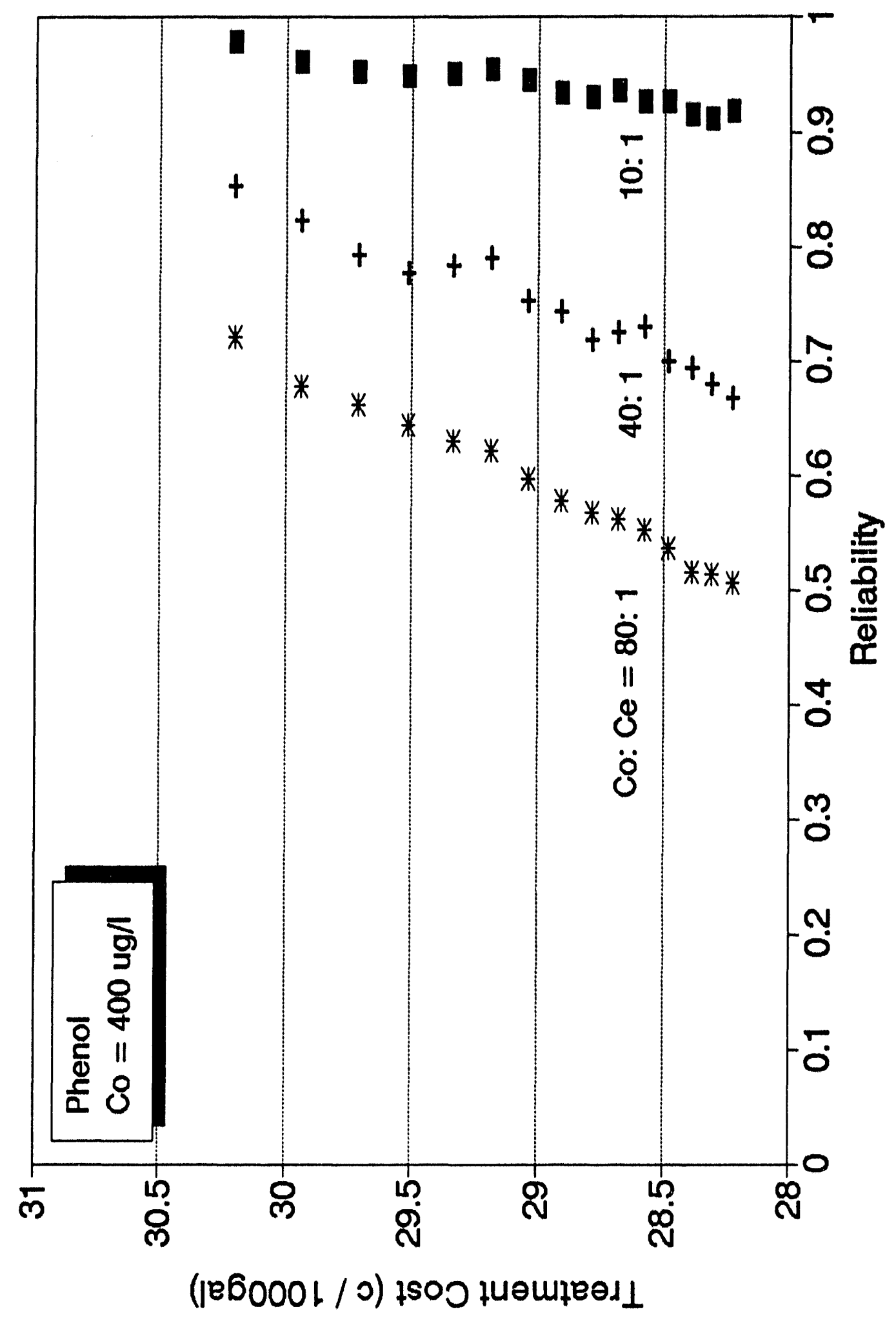




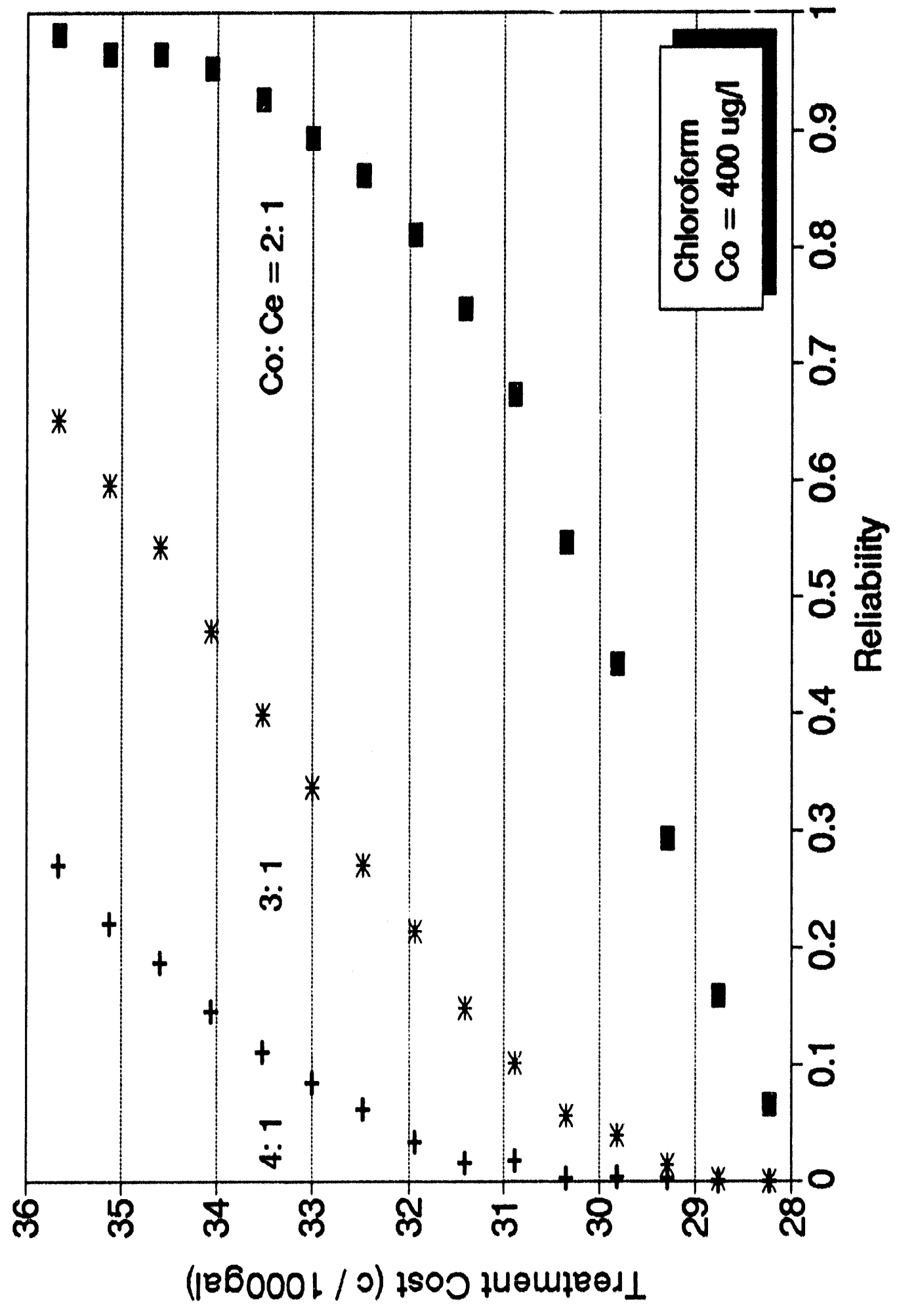


activated sludge process in several ways. Increasing the minimum solids retention time by factors of two to twenty is common for conventional activated sludge treatment (Metcalf and Eddy 1979). Doubling the minimum solids retention time provides a deterministic design which is equivalent to a design based on a probabilistic process safety factor of 1.34. As shown in Figure 21, this safety factor provides a reliability level for phenol removal of approximately 57,73 and 938 for removal ratios of $80: 1,40: 1$ and $10: 1$, respectively. Increased solids retention time does not affect the aeration gas flow rate and, since chloroform is removed by strippling, does not affect chloroform removal reliability.

The goal of this research is to increase the reliability of pollutant removal from the aqueous effluent. The methods of achleving this goal are not always palatable to all interested parties. For example, the health risk due to stripping of volatile organic compounds (VOCs) from the aeration tank, the primary chloroform removal mechanism, is now a major concern at waste treatment plants. Several vocs, which are strippable by definition, are also degradable if held in contact with the biomass sufficiently long. pure oxygen aeration is frequently recommended to reduce the stripping action in the aeration tank.

Pure oxygen transfer efficlency is in the range of $80 \%$ while oxygen transfer efflciency of air is 5 to $15 \%$. 
Considering the difference in transfer efficiencies and recognizing that air is less than 258 oxygen by weight, up to four hundred times more air is required than pure oxygen to transfer the same mass of oxygen. Since stripping is directily rilated to the amount of off-gas, decreasing the aeration gas flow rate by a factor of four hundred greatly decreases the amount of chloroform stripped. Unfortunately, chloroform is not aerobically degradable and the result of pure oxygen aeration, which minimizes stripping, is the retention of chloroform in the aqueous effluent. The resulting reliability of chloroform removal is approximately zero. Pure oxygen aeration is ideal for degradable vocs but ineffective in removing non-degradable voCa. An alternative approach to 1ncreasing the non-degradable voC removal reliability is to capture and treat (degrade, burn and adsorb) all VOCs emitted from the aeration basin.

\section{Summary}

The activated sludge process has been probabilistically analyzed and relations between process safety factors and reliability levels have been determined for phenol and chloroform. Relatively minor gains are realized in reliability of phenol removal for safety factors up to 2.4 while more dramatic reliability increases are realized with chloroform at low removal ratios and safety factors up to 4.5 . 
Relationships between treatment cost and reliability have also been developed to provide information to assist in decisions pertaining to speciflc levels of treatment. As expected, treatment costa Increase with increasing reliability levels although not dramatically.

Conventional deterministic designs provide approximately 57, 73 and 93 reliability for phenol removal ratios of $80: 1$, $40: 1$ and $10: 1$, respectively. Chloroform removal reliability is essentially unchanged by the conservatism of the deterministic designs because the effect of these designs on the aeration gas flow rate is minor.

Since stripping potential is related to the amount of off gas, inefficlent oxygen transfer devices are efficient strippers. Conversely, efficlent oxygen transfer devices are inefficient strippers. When non-degradable vocs (e.g., chloroform) are present, stripping is the primary removal mechanism and efficient strippers, such as coarse bubble diffusers, are required to realize higher treatment process reliability.

Conversely, use of pure oxygen in the aeration tank reduces the reliablitity of chloroform removal to approximately zero as th reduces the amount of chloroform stripped from the aeration tank. Pure oxygen aeration is beneficial when degradable VoCs are present but, as demonstrated here, is ineffective at removing non-degradable VOCs. 
CARPTER VI

\section{ANARROBIC BIOLOCICAL TREAMANT}

\section{Llterature Reviow}

Generally, if a compound is treatable aerobically it is treatable anaeroblcally although there are exceptions (Speece 1983). The reverse is not necessarlly true. The mafor advantage of anaerobic treatment, 1to low synthesis rate, 18 also the mafor disadvantage during startup and recovery of lost blomass. Anaeroblc processes occur in many natural and man-made environments and Hickey and Goodwin (1989) discuss all aspects of on going research in a recent review article. Speece (1983) lists seventy-seven organic compounds shown to degrade anaeroblcally (Table 13). Xylenes, toluene, cresols, phenols and some polynuclear aromatics have been shown to degrade anaeroblcally (Grady 1990). Healy and Young (1978, 1979) were the first to show that catechol was degradable anaeroblcally and demonstrated anaeroblc degradation of eleven simple aromatics derived from heat treated Iignin. When degradation is used in the broad sense, meaning any measurable chemical change in a compound, we can state that chlorinated compounds degrade without implying they are converted completely to inorganic end products.

Chou et al. (1979) state that there may be no relation between a compound's toxicity to unacclimated blomass and its 
Table 13. Some Compounds Shown to Degrade Anaeroblcally.

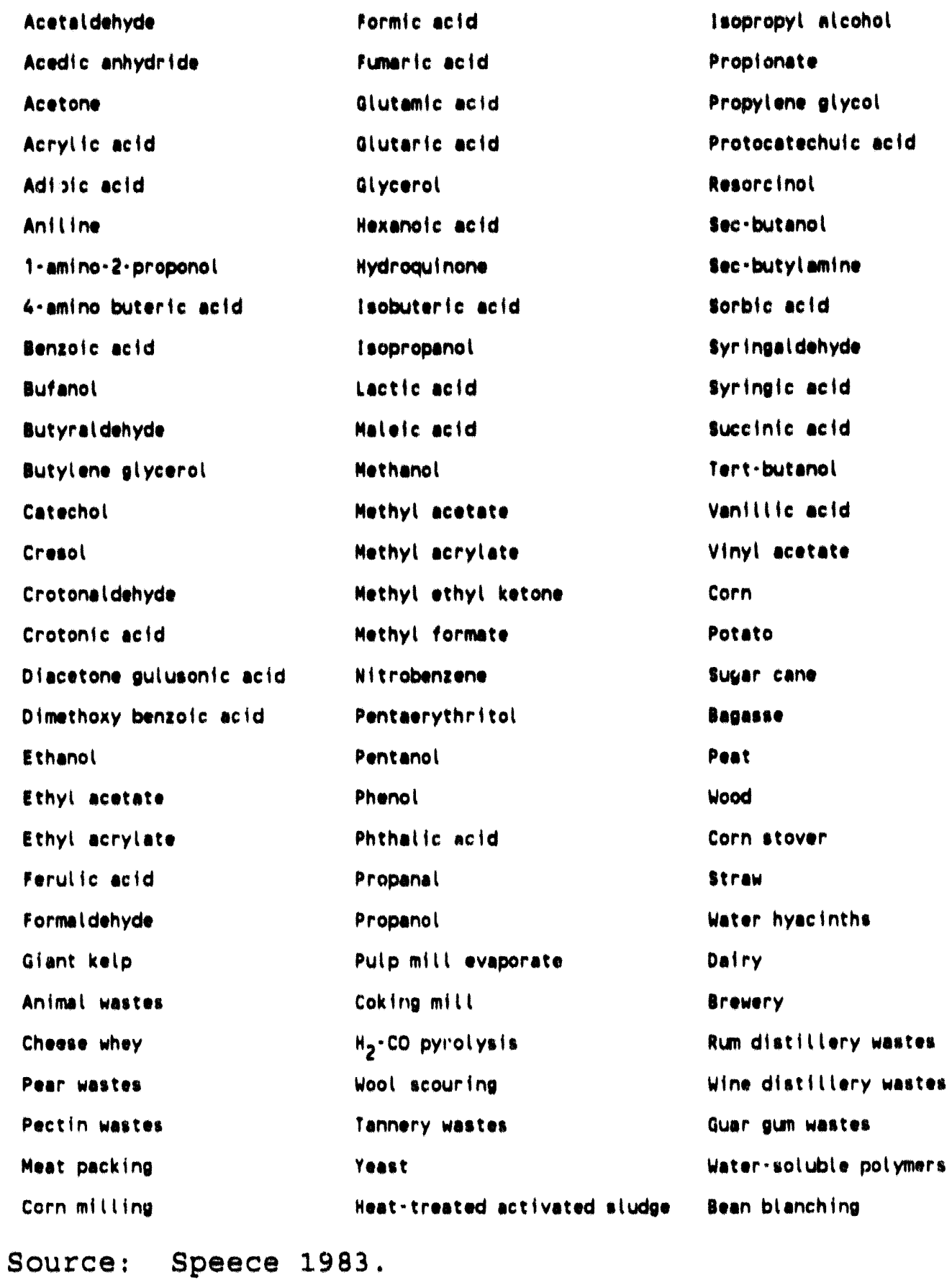


eventual degradation. In addition to controlling toxics, several factors that govern the growth of anaeroblc bacteria must be maintained to ensure degradation. These factors include optimum retention time, adequate mixing, proper $\mathrm{pH}$ and temperature control, adequate concentration of the proper nutrients, and proper feed characteriatics (Parkin and owen 1986).

Anaeroblc degradation 18 belleved to act as a three stage process in which the first stage is hydrolysis, ifquetaction and fermentation; the second otage is hydrogen and acetic acid formation; and the third stage is methane formation (Parkin and Owen 1986). Flgure 27 graphically displays the interactions and interdependence of the different bacterlal cultures in the anaeroblc degradation process. Interruption of any of these process loops can prevent further degradation and not 211 interruptions are due specifically to toxicity.

Mineral deficiency is frequently mitaken for toxicity (Takashima and Speece 1989, Speece 1983). Little difference has been shown between the concentration of a toxic that causes no effect and the concentration that causes complete fallure indicating that toxic response can occur with little warning (Parkin and Owen 1986). However, as Indicated above, acclimation to toxicity and reversibility of toxicity are commonly noted (Parkin et al. 1983).

Toxic compounds are frequently amenable to anaeroblc 


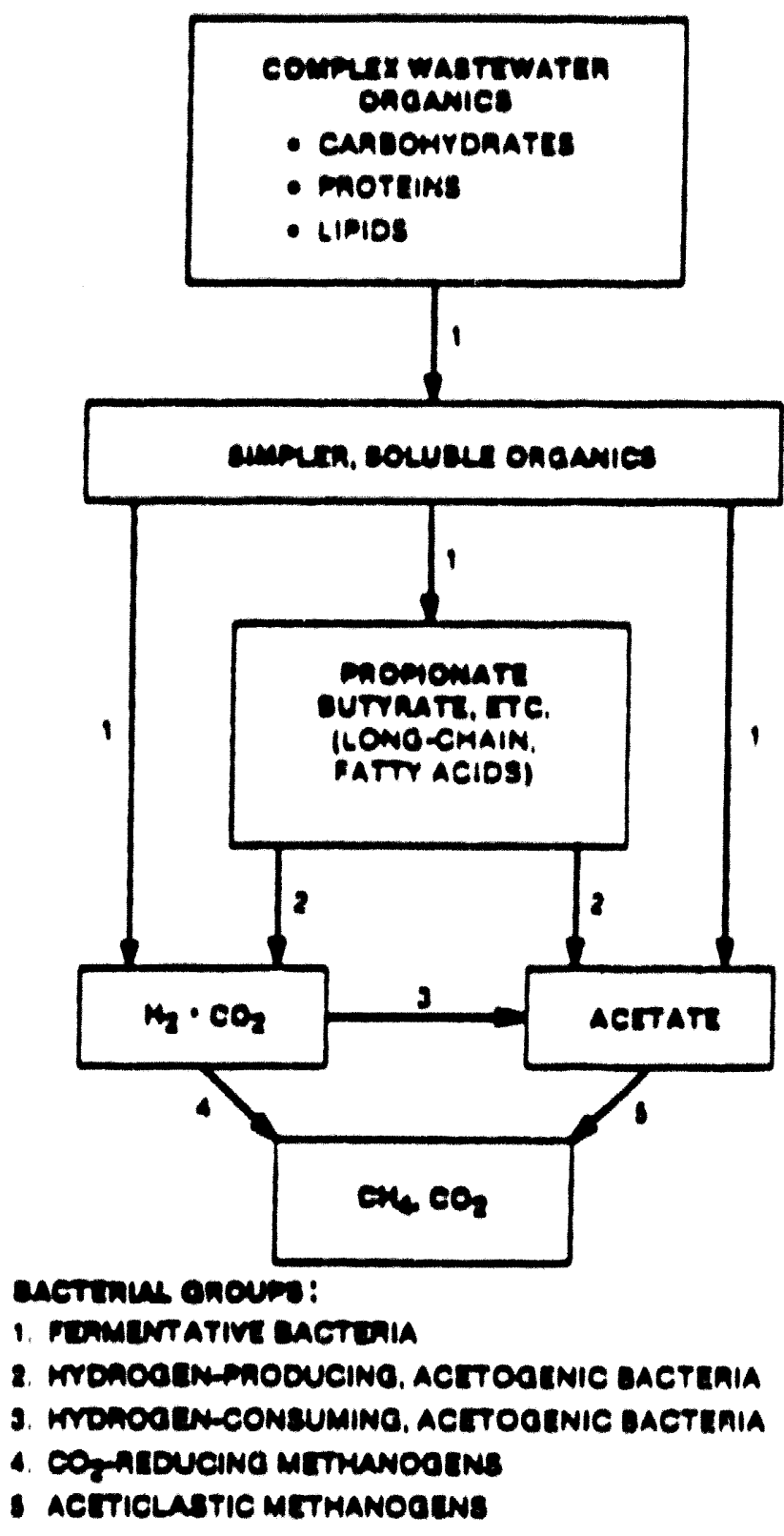

Eigure 27.

Interdependencles

of Anaerobic

Treatment Bacterta.

Source: Parkin and Owen 1986. 
blodegradation at lower concentrations. For example. formaldehyde and phenol are degradable below 400 and 2000 $\mathrm{mg} / \mathrm{l}$ respectively (Speece 1983). The compound must also be soluble to be toxic or blodegradable (Parkin and Owen 1986).

A study of cyanide toxiclty response of anaerobic bacterla (Yang and speece 1985) showe that the longest ooldde retention time (SRT) tolerates highest toxic concentrations but shorter SRTe give facter recovery at lower toxlcant concentratione. This effect la believed to be due to shorter contact time with the toxicant and increased viability of the younger celle at lower SRT. Parkin and Owen (1986) etrese that the key to succese of anaeroblc treatment is the development and maintenance of a large, stable, viable population of nethane-forming bacteria.

Anaeroblc degradation of non-toxic compounde is frequently described by Monod kinetics and response to unacclimated toxice is characterized by an incriase in the minimum yolids retention time (SRT) (Speece, Parkin and Bhattacharya 1986, Parkin and Owen 1986). Monod kinetirs generally do a poor job of describing anaerobic treatment of toxic compounds at high substrate concentrations and Haldane Inhibition kinetics have been found to describe the kinetice much better (Edwarde 1970, Bolle et al. 1986, Hickey and Goodwin 1989, Suldan et al. 1988). Monod and Haldane kinetics and methods of determining the parameters for specific compounds have been discussed in the activated 
sludge chapter.

Haldane kinetic parameter have been reported for several compounds (Suldan et al. 1988, Edwards 1970) and these values are all based on non-linear curve fltting cechniques. The error assoclated with the best-fit equation 1. generally low but does provide some measure of the variability expected of the output due to the uncertainty in model parameter.

Bolle et al. (1986) showed that $K_{1}$ and $\mu_{\max }$ are the most censitive parameters of the Haldane model and that the endogenous decay, $b$, halt velocity conetant, $K_{m}$ and yield, $Y$, are rather insensitive. They therefore, concluded that $K_{1}$ and $\mu_{\max }$ should be determined experimentally and the remaining constante could be gleaned from the literature.

As with activated sludge, assumption of elrst order degradation kinetics with respect to substrate concentration 18 valid tor anaerobic treatment when low substrate concentrations are encountered.

Current effort in anaerobic treatment processes center around determination of degradable compounds and their kinetic parameters as well as methods for making the process more stable. No probabiliatic studies of process performance have been located. 


\section{Research Approach}

\section{Model Description}

Anaerobic treatment processe are designed in several configuration (Figure 28) with the major consideration being the retention of blological solids. The most common configuration presently being designed is the upflow anaerobic sludge blanket (UASB) first evaluated by Lettinga (Lettinga et al. 1980) in which the influent is unfformly distributed acrose the bottom of the reactor and passes upward through a high concentration of anaerobic microorganiams. By maintaining chemical and phyolcal condition favorable to sludge elocculation, supertor settling characteristics are provided. The maintenance of a high concentration of microorganlams without packing material minimizes the likelihood of plugging which is common to packed bed designs. The upper portion of the reactor is equipped with a system for gas, liguid and solids separation.

Due to the need for maintenance of a large active biomass, the UASB is particularly suitable to treatment of high strength industrial waste although several recent applications to domestic waste in tropical countries have been documented (Draalfer et al. 1992; Kiriyama, Tanaka and Mori 1992; Vielra and Garcia 1992; Schellinkhout and Collazos 1992).

The UASB is designed as a completely mixed process 


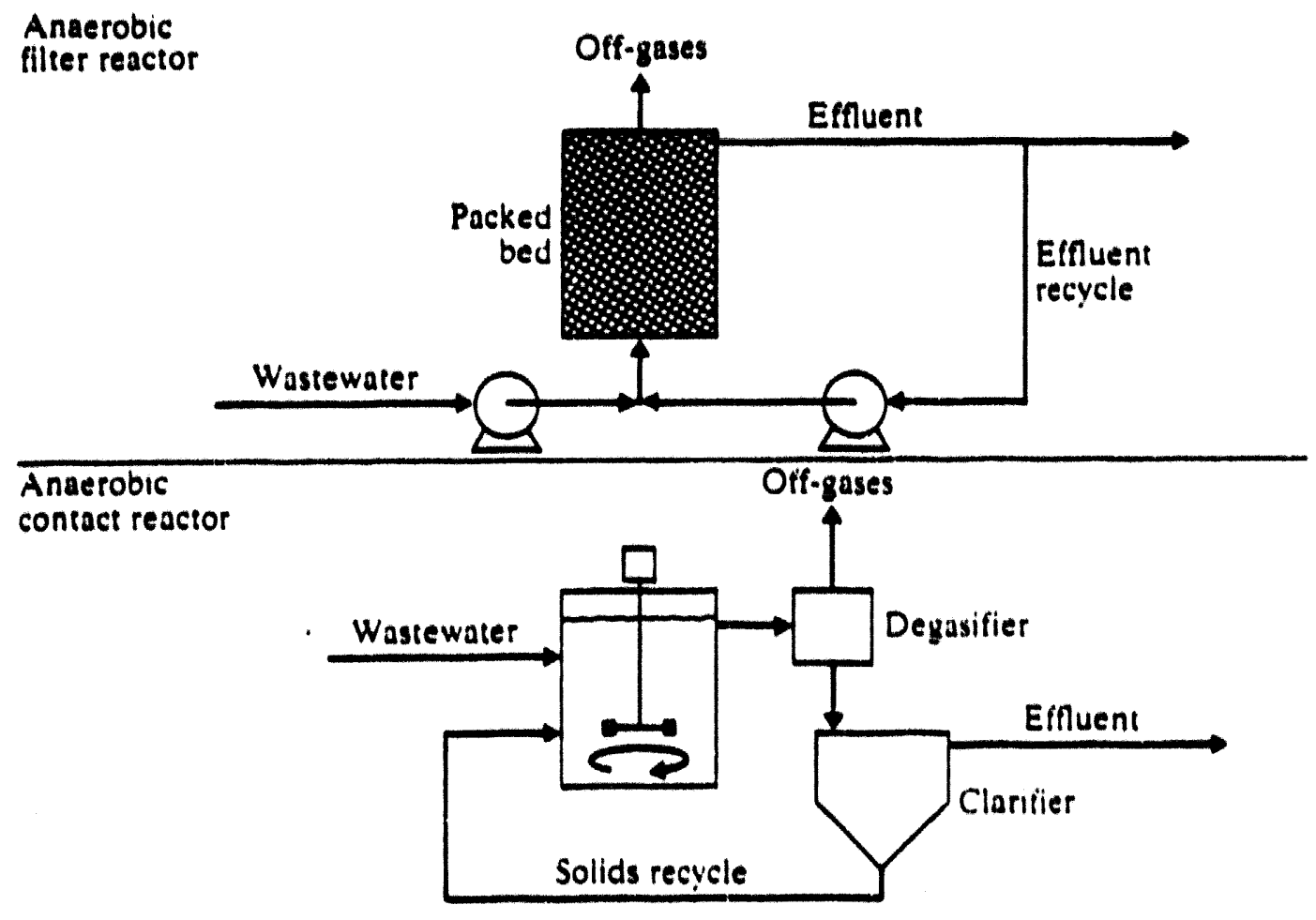

Fluidized-bed reactor

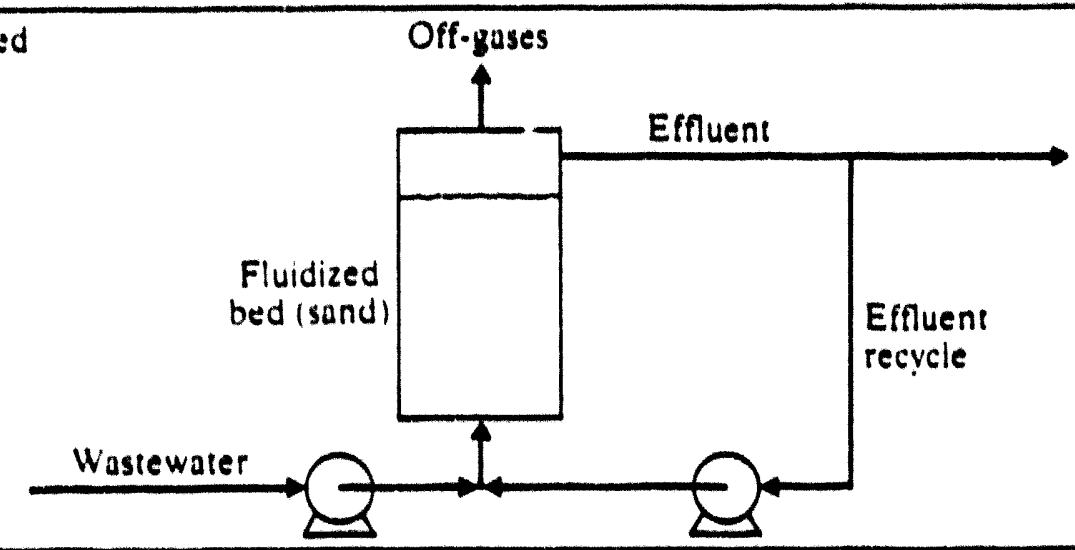

Liprluw anaerobic sludge blankel

(L'ASB)

\section{Oif-yases}

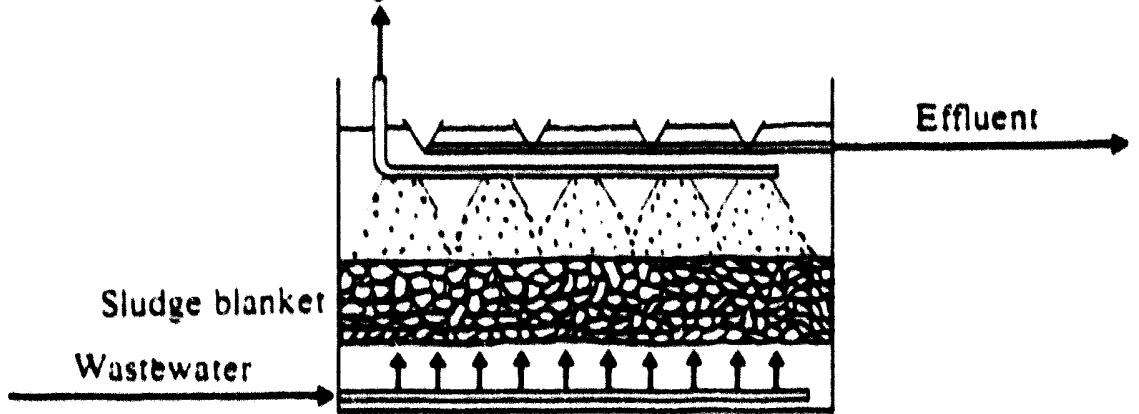

Figure 28. Anaerobic Wastewater Treatment Processes. Source: Eckenfelder 1989. 
(CSTR) which lends itself to design and evaluation by any of a number of fate models. A modified version of the EPA FATE model (Govind, Lai and Dobbs 1991) is used in this research to predict the effluent concentration from the UASB treatment process. Modifications include addition of anaerobic biodegradation kinetic parameters and calculation of the stripping gas flow rate based on the rate of gas generated based on chemical oxygen demand (COD) removal by the biomass. Monte Carlo simulation is used to ascertain the uncertainty of process. The mathematical model and research approach is described in the activated sludge chapter and only the parameter distributions will be different.

\section{Selected poliutants}

Phenol and 2,4-Dichlorophenol (2,4-DCP) are the pollutants utilized to evaluate the reliability of the anaerobic treatment process. Both are listed RCRA hazardous wastes, priority pollutants, common industrial pollutants, and known to degrade anaerobically. The chemical and physical properties of phenol and 2,4-DCP are listed in Table 14 .

Probability distributions for the first-order anaerobic degradation rate, $\mathrm{K}_{b}$; Henry's constant, $\mathrm{K}_{H}$; and octanol-water partition coefficient, $K_{\text {ow' }}$ have been generated after extensive literature reviews. Table 15 provides the summary statistics of these distributions and the appendix contains 
Table 14. Chemical and Physical Properties of Phenol and 2,4-Dichlorophenol.

\begin{tabular}{|c|c|c|}
\hline Compound Name & Phenol & $\begin{array}{l}2,4 \text {-Dichloro- } \\
\text { phenol }\end{array}$ \\
\hline CAS Number & $108-95-2$ & $120-83-2$ \\
\hline Compound Type & Phenolic & Phenolic \\
\hline Formula & $\mathrm{C}_{6} \mathrm{H}_{6} \mathrm{O}$ & $\mathrm{C}_{6} \mathrm{H}_{4} \mathrm{Cl}_{2}$ \\
\hline $\mathrm{MW}(\mathrm{g} / \mathrm{mol})$ & 94.11 & 163.0 \\
\hline Melting Point $\left({ }^{\circ} \mathrm{C}\right)$ & 43 & 45 \\
\hline Boiling Point $\left({ }^{\circ} \mathrm{C}\right)$ & 181.7 & 210 \\
\hline $\begin{array}{l}\text { Vapor Pressure } \\
\text { (Torr @ }{ }^{\circ} \mathrm{C} \text { ) }\end{array}$ & $0.35 @ 25$ & $1 @ 53$ \\
\hline $\begin{array}{l}\text { Solubility } \\
\left(\mathrm{mg} / 1 @ 0^{\circ} \mathrm{C}\right)\end{array}$ & $8(10)^{4} @ 25$ & $4500 @ 25$ \\
\hline $\log K_{0 w}(\mathrm{dim})$ & 1.46 & 2.75 \\
\hline $\begin{array}{l}\text { Henry's Constant } \\
\left(\mathrm{atm}-\mathrm{m}^{3} / \mathrm{mol}\right)\end{array}$ & $1.3(10)^{-6} @ 25$ & $2.8(10)^{-6} @ 20$ \\
\hline
\end{tabular}

Source: US EPA 1992 
Table 15. Probability Distribution Parameters for Phenol and 2,4-Dichlorophenol.

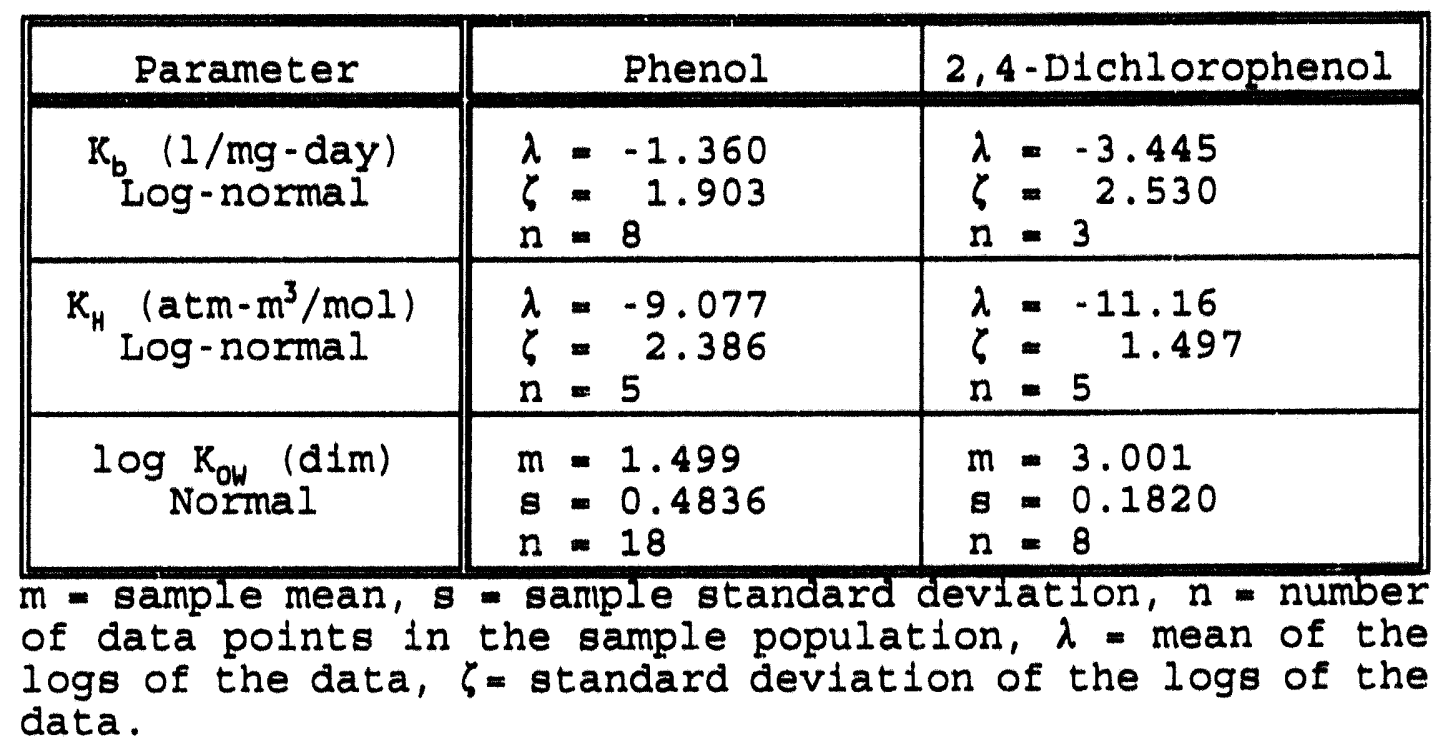


the specific data values used to generate these distributions. The distribution parameters for the biodegradation rates listed in Table 15 reflect biomass specifically acclimated to the substrate of interest. Anaeroblc blodegradation rates for phenol based on digested sludge are also listed in the appendix and are approximately two orders of magnitude lower than the rates based used in this research.

Industrial application of anaerobic treatment processes are common and the wastestream considered in this research is assumed to be associated with a typical pulp and paper mill with a $1.5 \mathrm{MGD}\left(0.064 \mathrm{~m}^{3} / \mathrm{sec}\right)$ flow rate and a COD load of 1000 $\mathrm{mg} / 1$. This waste stream type is chosen due to its high strength and the existence of microconcentrations of phenols and chlorophenols. The design effluent concentration is 250 $\mathrm{mg} / 1$ COD which is assumed to recelve further treatment at the local municipal treatment plant. Biomass and biogas yields, wastage rates, reactor volume, hydraulic and solids retention times are based on pulp and paper mill waste.

Each pollutant is assumed to enter the process at a concentration less than $400 \mu \mathrm{g} / 1$ based on maximum priority pollutant concentrations as reported by Russell, Cain and Jenkins (1983). At these concentrations, the pollutants should exert little effect on the overall process and micropoliutant mass balance is used to determine the effluent concentration of the pollutants. 


\section{Reault:}

\section{Safety Factor Versus Reliability}

Phenol and 2,4-DCP have low Henry's constants indicating that stripping will not be a major removal mechanism. Phenol is readily degradable anaeroblcally and 2,4-DCP is degradable at a much lower rate. In accordance with the convention defined in the activated sludge treatment chapter, the process safety factor equals the soluble domestic waste COD effluent standard divided by the median soluble domestic waste COD effluent concentration. This process safety factor is defined assuming blodegradation is the major removal mechanism. In all cases, reliability is defined as the frequency that the micropollutant effluent concentration is below the effluent standard.

Monte Carlo simulation of the modifled EPA Fate Model is used to generate one thousand realizations of the effluent concentration for each of the two micropollutants at 400 and $100 \mu \mathrm{g} / \mathrm{I}$ influent concentrations for 15 safety factors. The resulting cumulative density functions (CDFs) relate the safety factors to reliability levels as illustrated in Figure 29. For example, for a safety factor of 1.25 , a phenol influent concentration of $400 \mu \mathrm{g} / 1$ and an effluent target concentration of $10 \mu \mathrm{g} / 1$, the reliability of the treatment process is $23 \%$. This reliability level is obtained by extending a vertical line upward from the effluent 


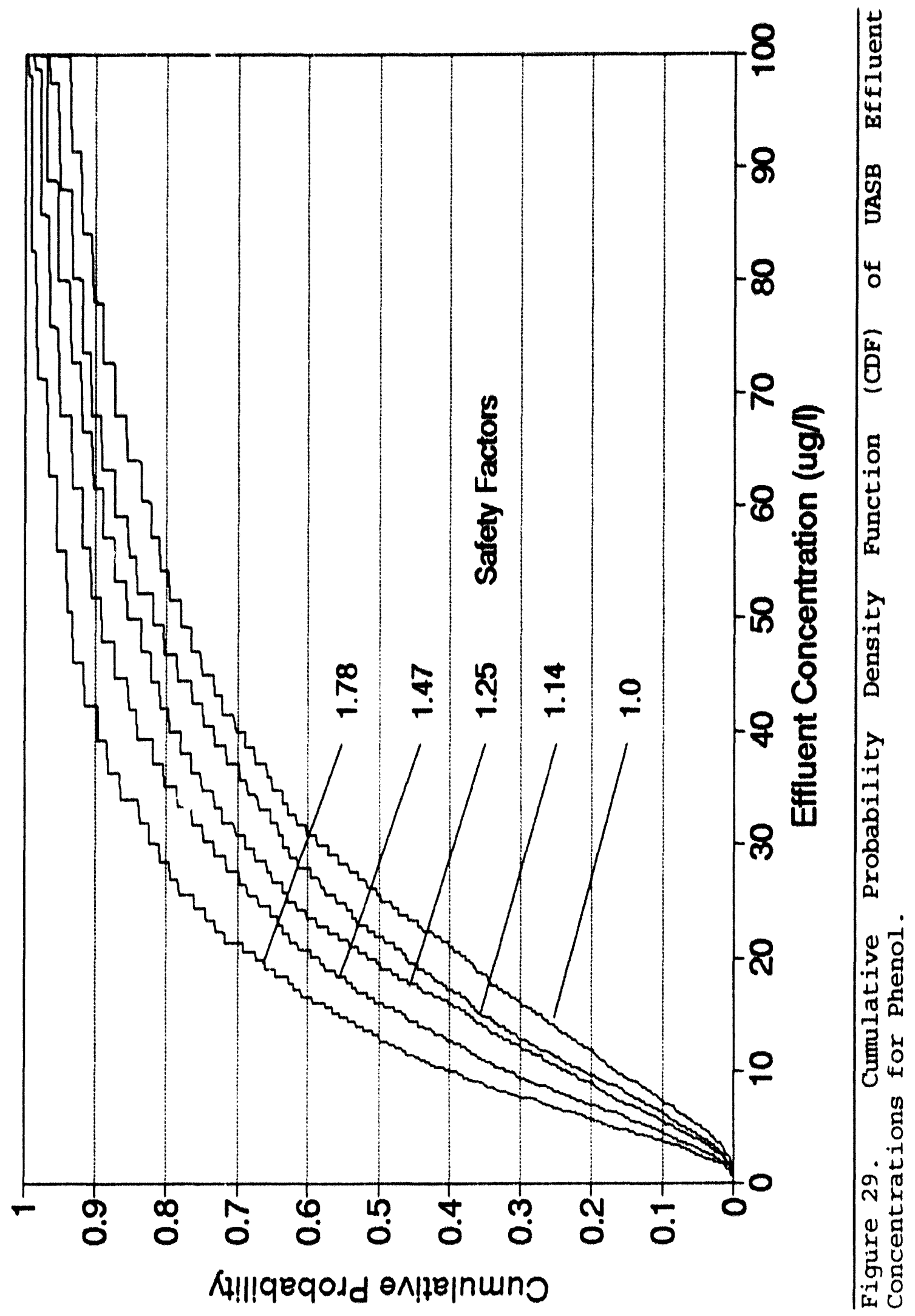


concentration axis at $10 \mu \mathrm{g} / 1$ to the 1.25 safety factor curve and extending the line horizontally to the cumulative probability axis. The cumulative probability equals the reliability at that point.

While the simulations were performed for two distinct micropollutant influent concentrations, the solution of the micropoliutant mass balance is in terms of the influent/ effluent concentration ratio, or removal ratio for short. This more general presentation 1 s used for the remainder of the chapter.

Plots of safety factors versus reliability for the UASB process are shown in Figure 30 for phenol and Figure 31 for 2,4-DCP. Figure 32 shows that biodegradation is the primary removal mechanism for phenol and greater than 93 removal is achieved for a broad range of safety factors. Since phenol removal is relatively high even at low safety factors, the increase in process reliability is only marginally improved at higher safety factors as shown in Figure 30 by the steep curves of safety factor versus reality. As expected, rellability levels are lower for the higher removal ratio. Reliabllity increases are also more pronounced for the higher removal ratios since there is more room for improvement in reliability for these scenarios.

The removal ratios in Figure 31 are very low indicating poor removal of $2,4-D C P$ by the UASB process. Flgure 33 shows that degradation and sorption are the primary mechanisms for 

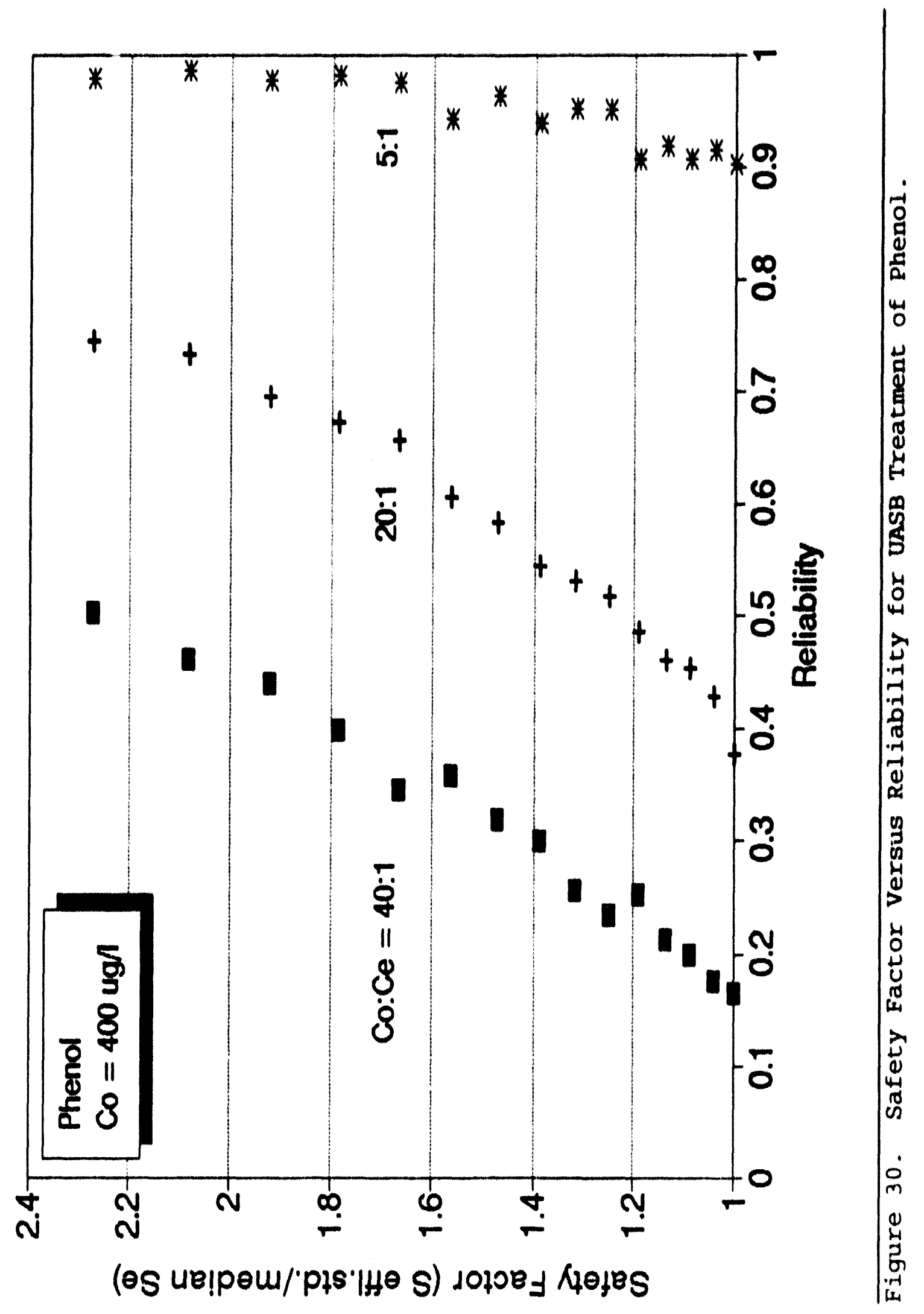


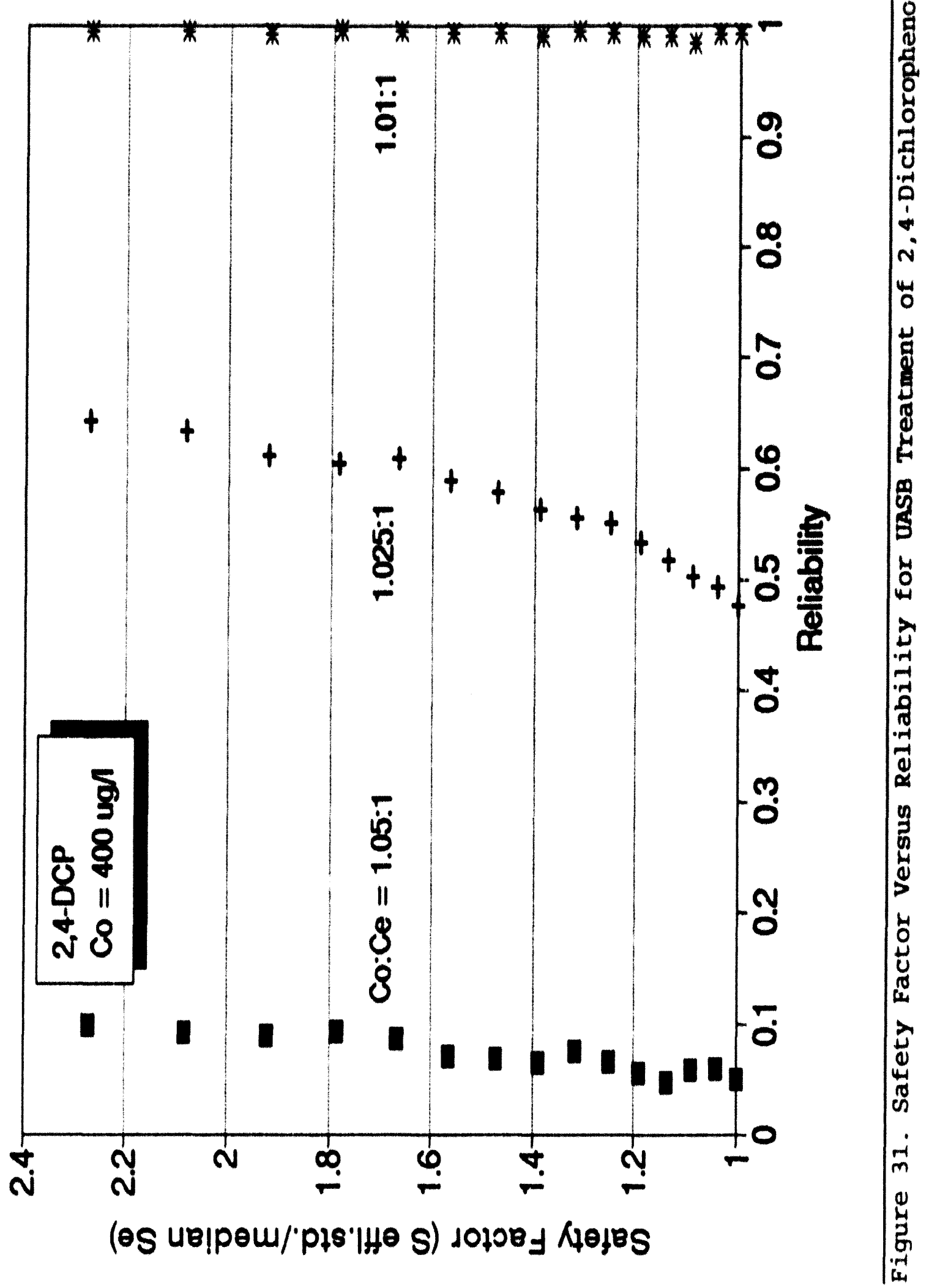




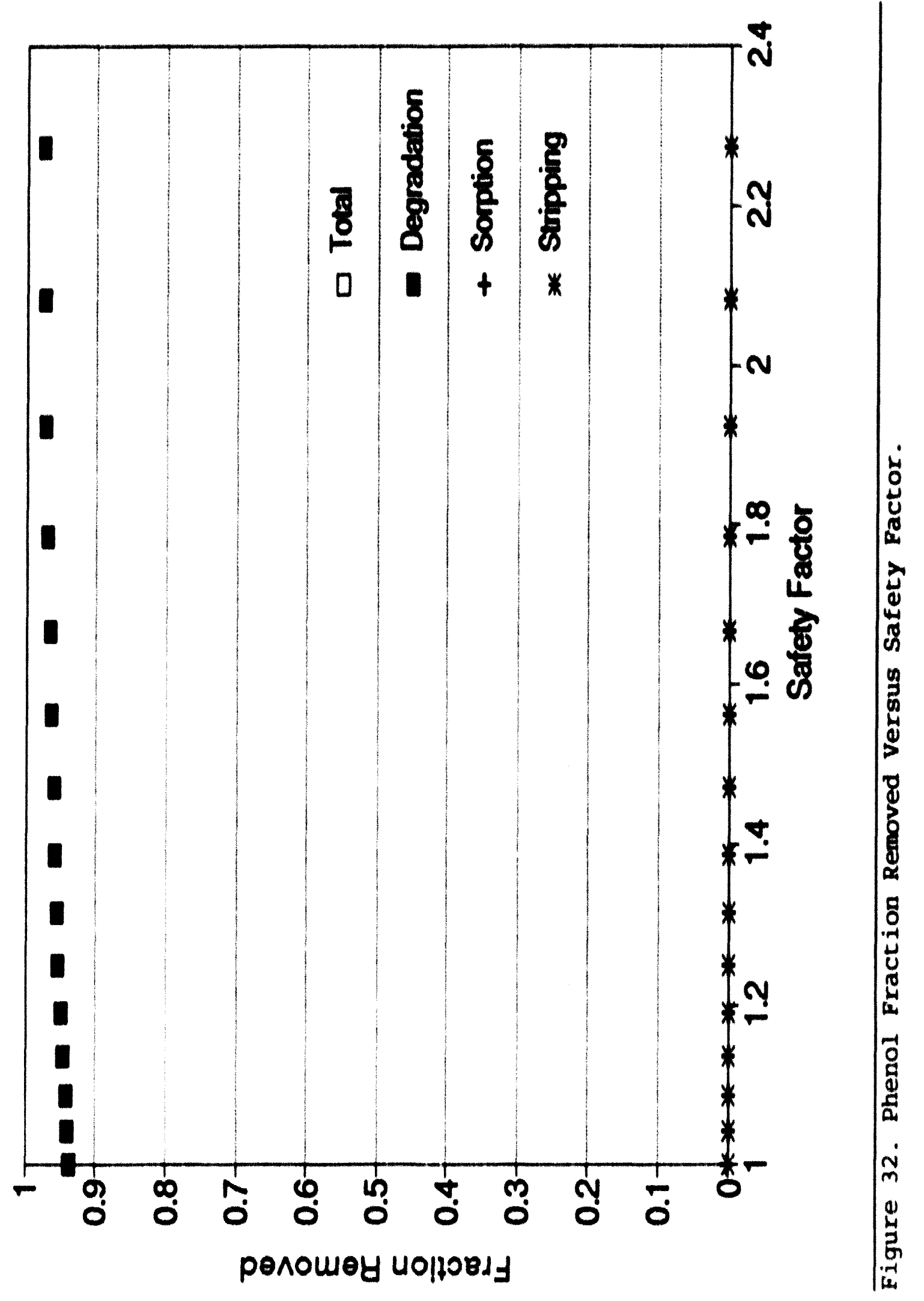




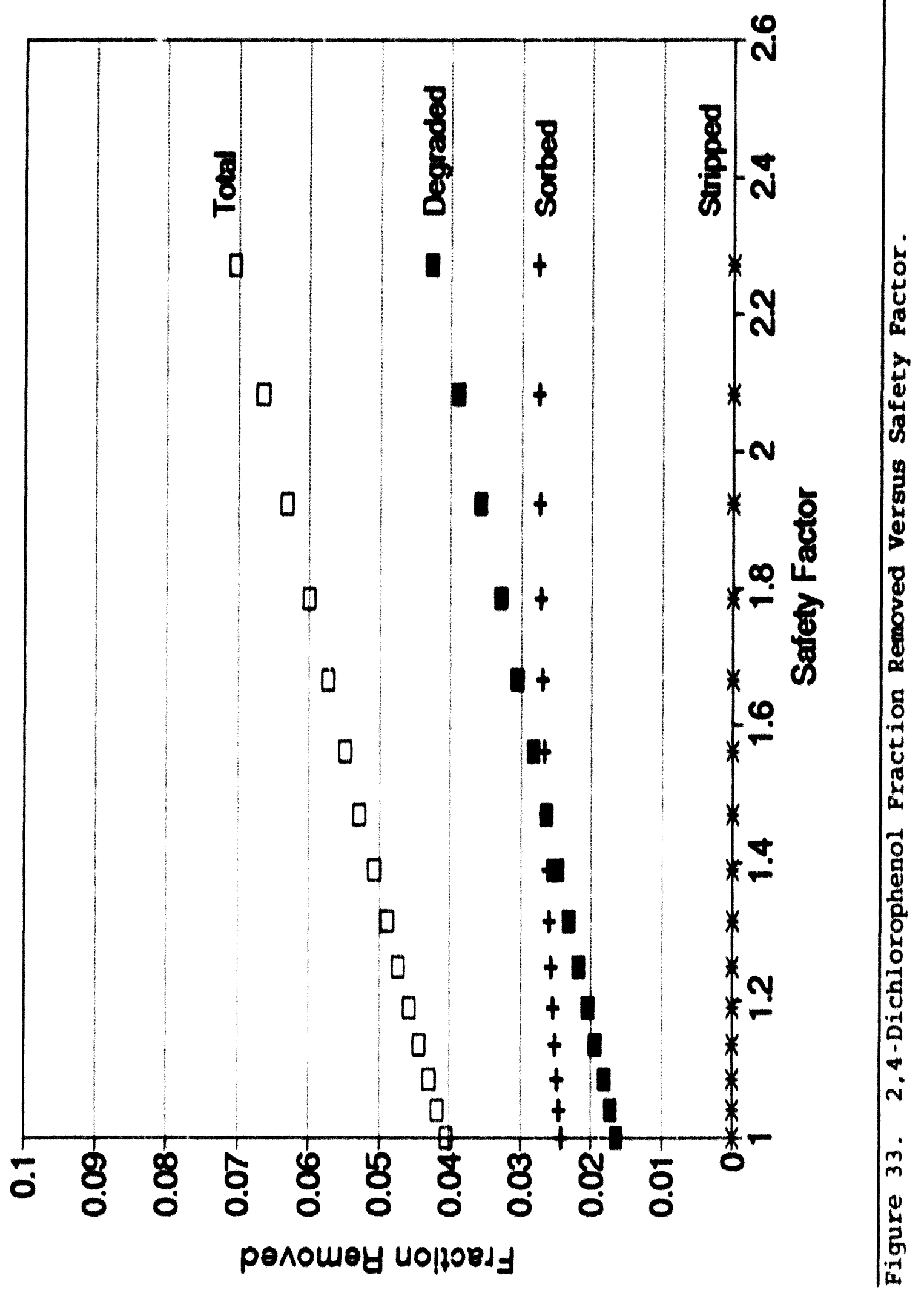


2,4 DCP removal and the total fraction removed increases from 4t for a safety factor of one to over 7 for a safety factor of 2.3, conf $1 \mathrm{rming}$ the poor removal. At low batety factors, sorption provides lightly more removal than degradation while the reverse 1 t true above a safety factor of 1.5 . The increase in degradation 1 expected as the reactor volume Increases and more blomase is avallable to degrade the waste. Figure 31 show very eteep curves of acety tactore verau reliablitty confirming that 11 ttle improvement is realized with increasing afety factore.

The result that a tull range of rellability levela io realized for a emall range of removal ratios $11.01: 1$ to 1.05:1) indicates the certainty of 2,4 .DCP removal level. For example, for an influent concentration of $400 \mu \mathrm{g} / 1$, the effluent concentration w111 range between 396 and $381 \mu \mathrm{g} / \mathrm{l}$ $(400 \mu \mathrm{g} / 1+1.01$ and 1.05 , reapectively).

\section{Senadidyity Anolyae}

Ef luent concentrations resulting from distribut lons of parameters based on tew data point or data ranges must be analyzed to determine the effects of the assumptions on the model regulta. For phenol, the degradation rate, $k_{b}$ is the primary variable of interest as shown in Figure 32 . While its log normal distribution is based on fust elght data points, the distribution of phenol's aerobic degradation rate is strongly log-normal based on the one ample Kolmogorov. 
Smirnov goodness-of-fit test of thirty-eight data points. Therefore, the log-normal distribution 1 g justified and no sensitivity analyois is required.

Degradation and sorption are the primary removal mechanism for $2,4 \cdot D C P$. The log-normal distribution of the anaeroblc degradation rate 1 a justifled based on the phenol discussion and no further analysis is required. The degree of sorption is determined by the pollutant's log octanol. water partition coefficlent, $\log K_{\text {ow }}$ which has a distribution that 18 strongly normal based on elght and elghteen data pointe tor 2,4-DCP and phenol, respectively. Therefore, no further sensitivity analyees are required.

\section{Coft Vergue Reldabldity}

Plots of cost versus reliablilty for the UASB process are shown in Figure 34 for phenol and Figure 35 for 2,4-DCP. As expected, costs increase with increasing reliability and higher removal ratios result in higher costs for a given reliability level. These costs are based on data provided by Schellinkhout and Collazos (1992) and are intended to provided relative comparisons only.

Figure 34 indicates that for high phenol removal ratios (40:1 and $20: 1$ ), treatment costs increase by about 180 for a reliability increase of 35\%. At lower removal ratios 15:1 and less), reliability increases less than 10 for the same cost increase. Thus, high removal ratio scenarios gain more 


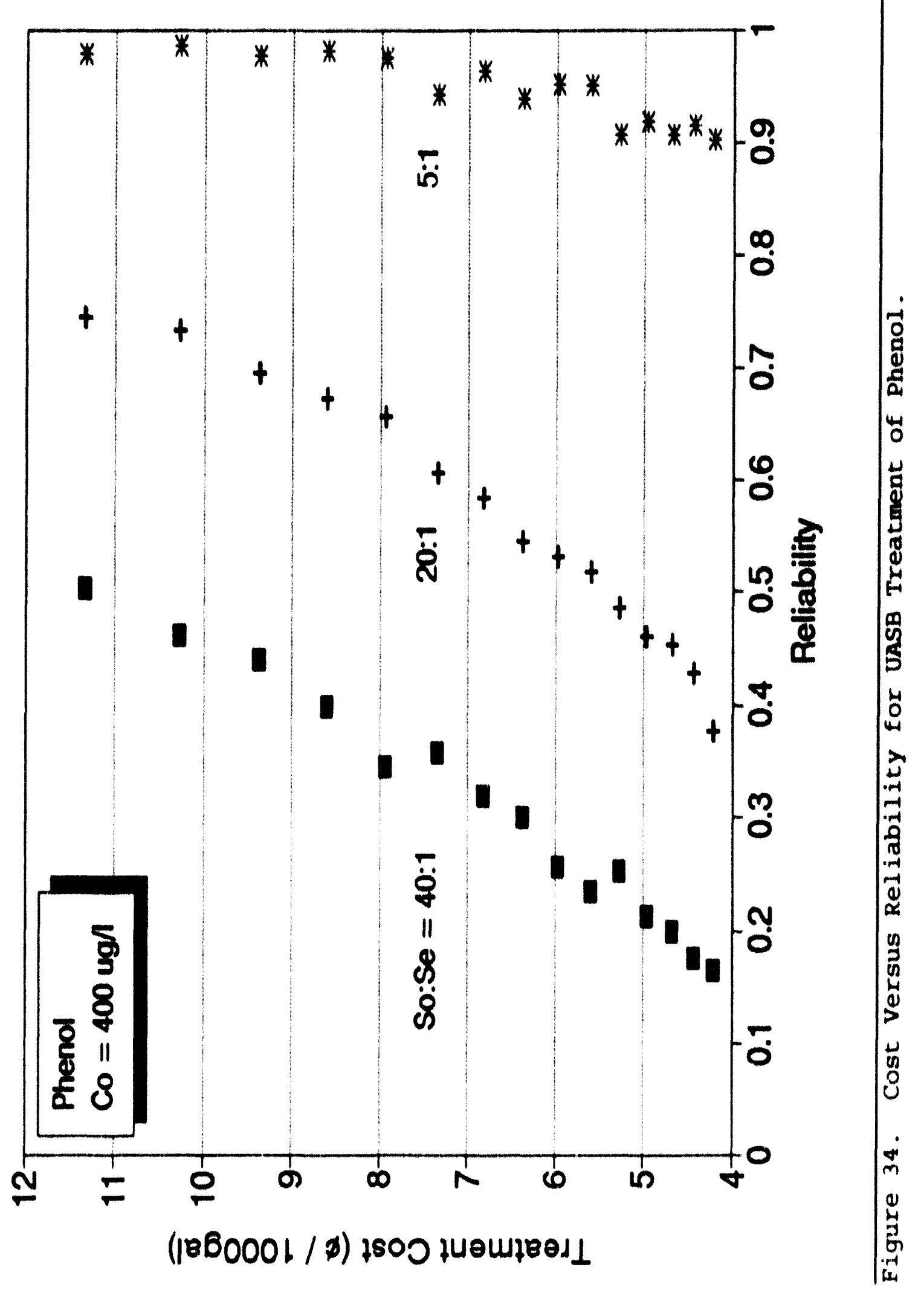




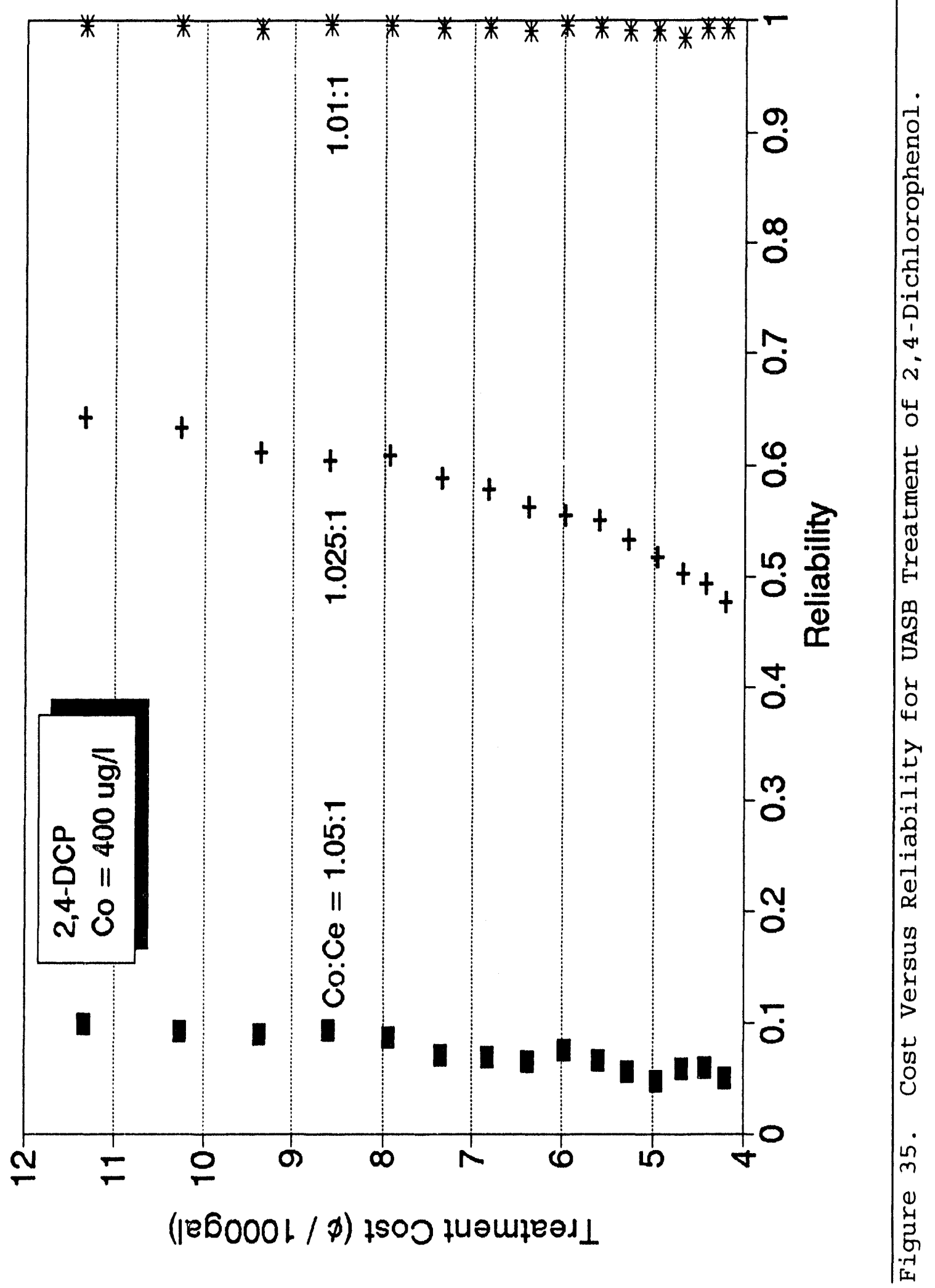


reliability per dollar spent than do low removal ratio scenarios.

Figure 35 indicates that relative to phenol, 2,4-DCP removal ratios are quite small as discussed earlier. Very little 2,4-DCP removal reliability increase is gained for the additional treatment cost for all removal ratios.

\section{Comparisons with Deterministic Designs}

Conservatism is incorporated into the design of the UASB process in several ways. Increasing the minimum solids retention time by factors of two to twenty is common for many biological treatment processes (Metcalf and Eddy 1979). Doubling the minimum solids retention time provides a deterministic design which is equivalent to a design based on a probabilistic process safety factor of 2.0. As shown in Figure 30, this safety factor provides a reliability level for phenol removal of approximately 45,71 and $99 \%$ for removal ratios of $40: 1,20: 1$ and $5: 1$, respectively. Similarly from Figure 31, at a probabilistic process safety factor of 2 , the deterministic design based on twice the minimun SRT provides reliability levels of 10,62 and $99 \%$ for removal ratios of $1.05: 1,1.025: 1$ and $1.01: 1$, respectively.

\section{Summary}

The upflow anaerobic sludge blanket (UASB) process has been probabilistically analyzed and relations between process safety factors and reliability levels have been determined 
for phenol and 2,4-dichlorophenol (2,4-DCP). Substantial gains in reliability of phenol removal are realized for safety factors up to 2.4 at high removal ratios while little increase in reliability is realized at low removal ratios. Little gains in reliability are realized for 2,4-DCP at safety factors up to 2.4 .

Relationships between treatment cost and reliability have also been developed to provide information to assist in decisions pertaining to specific levels of treatment. As expected, treatment costs increase with increasing reliability. 


\section{CEAPTRR VII}

\section{ACTIVATHD CARBON IDSORPTION}

\section{Ilterature Review}

Activated carbon has been used as a polishing process following biological treatment and as a substitute for biological treatment of industrial waste components that pose a problem for the biological degradation process (Metcalf and Eddy 1979). Carbon adsorption of pollutants has been studied for many years and the research efforts of fourteen investigators from 1920 to 1964 have been summarized by Allen et al. (1967).

Carbon adsorption has several advantages over blological treatment including insensitivity to toxics, reduced sensitivity to temperature, low startup time, increased tolerance to concentration and flow rate variations and higher removal of $B O D, C O D$ and TOC for many wastes. Specific classes of adsorbable organic compounds include aromatics, phenolics, chlorinated hydrocarbons, surfactants, organic dyes, unionized organic acids, and high molecular weight alcohols and amines. Inorganic chemicals removed by activated carbon include cyanide, chromium and mercury (U.S. EPA 1983).

The limitations of activated carbon treatment include 
ineffectual removal of low molecular weight or highly soluble organics, a low tolerance for suspended solids and relatively high capital and operating costs (U.S. EPA 1983).

Performance of activated carbon depends on a number of factors related to the compound being adsorbed. In general, molecules, aromatics and large molecules (4 to 20 carbon atoms) are more readily adsorbed than 1ons, aliphatics and small molecules, respectively. The process is considered effective for $65 \%$ of the priority pollutants and reasonably effective for another 228 (U.S. EPA 1983). Waste streams with signiflcant BOD loads can cause blological degradation which tends to regenerate the carbon. BOD loads above 50 $\mathrm{mg} / 1$ will cause blomass to plug the column and produce odors when the biomass becomes anaeroblc (Eckenfelder 1989).

Three activated carbon systems are used in wastewater treatment: granulated and powdered activated carbon (GAC and PAC, respectively) and the PACT process. GAC ranges in size from 0.1 to $1 \mathrm{~mm}$, is used in fixed columns (the most common application (Weber and Smith 1987)) or expanded beds. A schematic diagram of an activated carbon column is given in Figure 36 .

PAC is ground fine enough to pass a 200 mesh screen and is added directly to the influent wastewater to contact with the waste and settle. Coagulation or rapid sand filtration is required to remove the PAC from the waste stream. The PACT process involves adding powdered activated carbon 


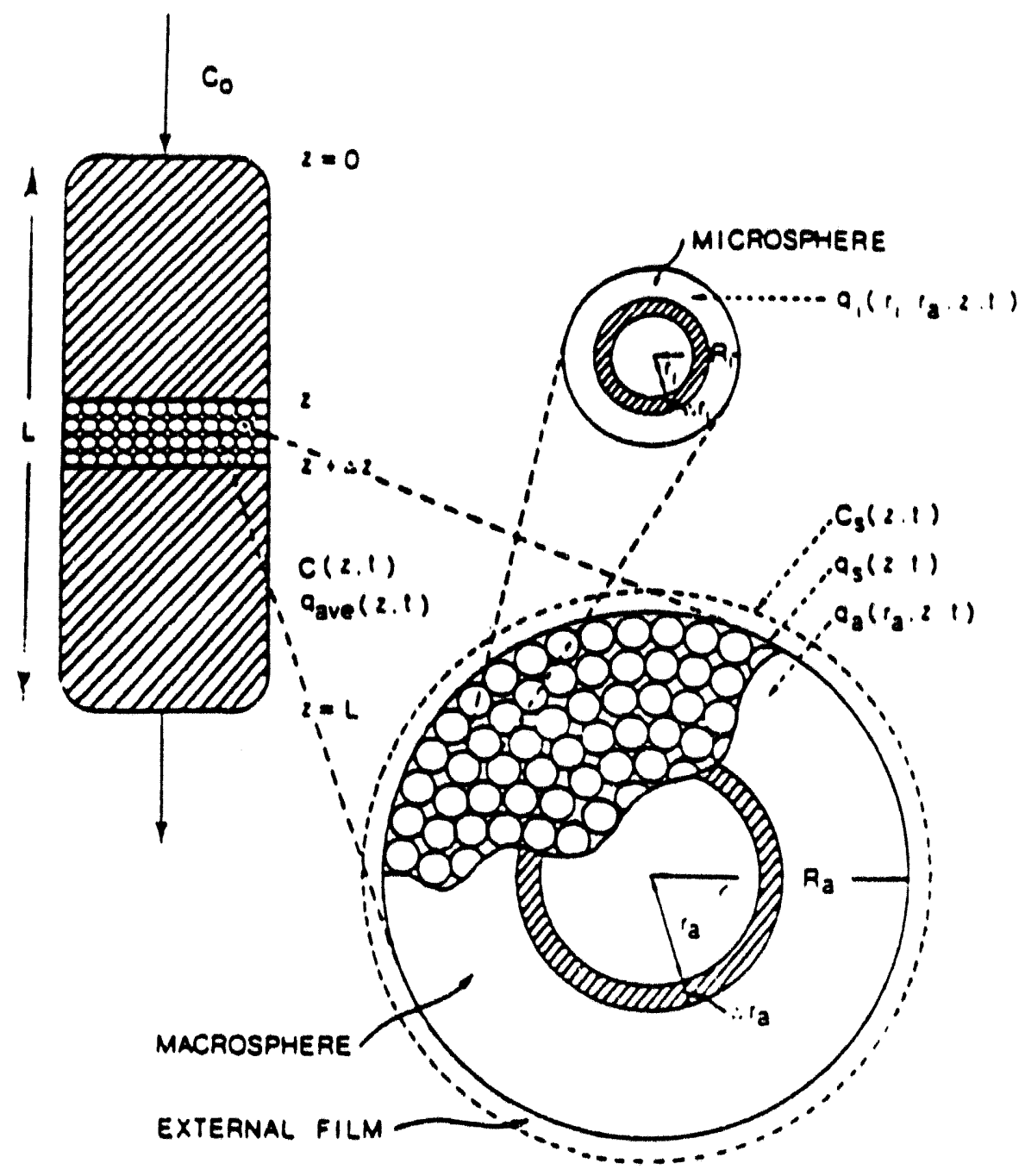

Figure 36. Schematic Diagram of the Activated Carbon Adsorption Process. 
directly to the aeration tank in the activated sludge process to allow more rapid uptake of certain slowly degradable constituents within the biomass and removal of toxics from the blomass (Metcalf and Eddy 1979). Jones (1984) has evaluated the effectiveness of the PACT process.

Activated carbon is made from a variety of materials including wood, lignin, bituminous coal, lignite, coconut shells, and petroleum residues (Metcalf and Eddy 1979, Eckenfelder 1989). Three parameters are used to describe the activated carbon:

Phenol Number, an index of the ability to remove taste and odor

- Iodine Number, an index of the ability to adsorb low molecular welght substances

- Molasses Number, an index of the ability to adsorb high molecular weight substances.

Three major steps of adsorption on activated carbon are

(U.S. EPA 1983, Metcalf and Eddy 1979, Eckenfelder 1989):

1. Transport of the adsorbate through the surface film to the extertor of the carbon. This process is governed by film diffusion.

2. Diffusion of the adsorbate within the pores of the carbon which is governed by pore diffusion.

3. Adsorption of the adsorbate on the interior surfaces of the carbon bounding the pore and capillary spaces.

Step 1 is generally considered rate limiting in continuous flow processes while step 2 is considered rate limiting in batch reactions (Weber 1972 ).

Adsorption is due to either a lyophobic (solvent- 
disliking) characteristic of the solute or high affinity of the solute for the solid (Weber 1972). The solubility of the solute determines the intensity of adsorption for lyophobic solutes and three types of interactions determine adsorption intensity when the solute has a high affinity for the solid. Chemical bonding results in formation of a monomolecular layer of adsorbate on the carbon through forces of residual valence of surface molecules with strong, irreversible bonds. Physical bonding results in adsorbate molecules held by van der Waals forces in weak, reversible bonds. The third type of bonding is due to electrical attraction in an ion exchange type reaction.

Adsorption within an activated carbon column is described graphically by isotherms and Langmuir and Freundich isotherms are commonly used. The rationally derived Langmuir isotherm is based on the assumption that maximum adsorption corresponds to a saturated monolayer of solute molecules, constant energy of adsorption and no transmigration of adsorbate in the plane of the surface (Weber 1972). The isotherm is modeled as

$$
\frac{X}{M}=\frac{a b c}{1+b C}
$$

where $\mathrm{X} / \mathrm{M}=$ amount adsorbed per unit weight adsorbent; ' $\mathrm{a}$ ' and 'b' are empirical constants; and $C=$ equilibrium concentration after adsorption. The Langmuir isotherm has also been extended to competitive adsorption of two or more 
compounds .

The empirically derived Freundlich isotherm is

$$
\frac{x}{M}=K C^{\frac{1}{n}}
$$

where $X / M$ - amount adsorbed per untt weight adsorbent; $C$ equilibrium concentration of adsorbate in solution after adsorption; and ' $K$ ' and ' $1 / n^{\prime}$ ' are emplrical constants. The U.S. EPA (1980) has developed Freundlich 1sotherm parameters for several toxic wastes.

Adamson (1967) shows that the empirically derived Freundith isotherm is really a special case of the Langmuir isotherm for heterogeneous surface energies in which the energy term, $b$, in the Langmuir equation varies as a function of surface coverage strictly due to the variations in heat of adsorption. The Freundich isotherm is not linear at low concentrations as 1.8 the Langmuir 1sotherm and does not compare well to the Langmulr isotherm at high concentrations. Regardless of the 1sotherm used, breakthrough volume is defined as the volume of water passed through the bed before a maximum effluent concentration is reached. Breakthrough time is the time corresponding to the breakthrough volume. The breakthrough volume decreases with decreasing bed height, increasing adsorbent particle size, increasing flow rate, and increasing initial solute concentration (Eckenfelder 1989).

The mafor design parameter for carbon adsorption columns 
is contact or residence time and minor parameters include IInear flow rate, impurity concentration and composition, pH, cemperature, and viscosity. Adsorbent properties of minor importance include particle ize, aduorptive capacity, pore 1ze distribution, and chemical nature of the adsorbent surface (Hutchins 1973). Many of these parameters are controlled through pretreatment and are required for hydraul1c considerations.

Bohart and Adams (Dale et al. 1946) were the elrot to develop an equation, based on urface reaction rate theory, to predict the aervice time of a carbon column. A najor effort underway since the late seventies has developed a mathematical model which accurately predicts tixed-bed adsorber performance (Crittenden and Weber 1978, Weber and Liang 1983). The Michlgan Adsorption Design and Applications Model (MADAM) resulting from this research is based on a dual resistance kinetic model representing film and pore diftusion and 1 lquid and solid mass balance equations for a $f$ lxed bed reactor (Weber and Smith 1987 ).

The model has been successful in oeveral applications (Weber and Smith 1987 ) and analytical solutions for simple systems have been developed (Hand et al. 1984). Model accuracy appears to be $11 \mathrm{~m} 1 \mathrm{ted}$ only by parameter estimation and a method has been developed for placing confidence $11 \mathrm{mit}$ on the model parameters (Olmstead and Weber 1990). The main parameters required by the program are the film and surface 
diffusion coeficient and the appropriate isotherm parameters.

Hutchins (1973) suggest that variatione in the individual treatment parameters have only minor eftect: but some of the parameter are related and could cause longer residence times and higher regeneration rates. He suggest overalzing the yetem for afety but gives no guidance. since many parametere are based on laboratory and pilot scale tests, information uncertainty w111 be present in these parameters which can be reduced with additional testing. Activaced carbon 1s a manufactured materlal and thus abject to irreducible, Inherent variability which should be quantitied by the manufacturer.

Once carbon is exhausted, it can be regenerated through several techniques including thermal, steam or solvent extraction, acid or base treatment, and chemical oxidation. Regenerated carbon 1s generally lower in capacity than virgin carbon due to changes in pore ize and $108 \mathrm{~s}$ of pores by depositional materials. The thermal regeneration process destroys 5 to 10 of the carbon. The number of regeneration cycles is dependent on economics as well as engineering considerations and generally three cycles will define the maximum capacity loss (Eckenfelder 1989). Further discussion of regeneration techniques can be found in Cheremisinoff and Ellerbusch (1978).

No probabilistic assessments of the activated carbon 
process have been found.

\section{Undguenees of the Aot1vated Carbon Adeorption Trentment}

While appearing to be a continuous process, packed column granular activated carbon treatment operates in batch mode based on the total adsorption capacity of the carbon column. Treatment performance reliability is related to the predictablitiy of the designed system' capacity as measured by the breakthrough time. Theretore, the probability density tunctions determined by Monte Carlo simulation will be in terms of the predicted breakthrough time at a apecific concentration. While this approach differs erom that of the previously described treatment processes, it is the best method of defining carbon column reliability.

Safety Eactore developed with this procesa will indicate the reliablitty of predicting the capacity and breakthrough times for a speciflc carbon-pollutant combination in a single column design and are applied to the median breakthrough time. If desired, process reliablitty can be maintalned at high levels without resorting to probabiligtic treatment through diligent monitoring of the effluent concentrations although probabilistic analysis will predict the range of times for expected breakthrough.

This research speciflcally concerno aingle carbon column designs. Columns in series, used for pollshing effluents, provide very high rellability because the second colums has 
aufficlent capacity to adsorb the pollutant when the first columin' capacity is reached and is removed from service. Columns 1.n parallel, frequently used to treat high volumes of water are relatively insensitive to the breakthrough of one column due to the dilution effect provided by the other columns. Both treatment process configurations can benefit from the result of this research on aingle column rellability.

\section{Research Approsoh}

\section{Model Dencribtiton}

Monte Carlo simulation of the U.S. EPA Activated Carbon Adsorption model (Clark and Adams 1991b) is pertormed to ascertain the probability density eunction of the breakthrough $t$ ime, $T_{b r}$. The $\mathrm{EPA}$ model is based on a numerical solution of the MADAM homogeneous surface diffusion model presented by Hand et al. (1984).

probabilistic model parameters include the pollutancs' Freundlich constant, $K$, and exponent, $(1 / n)$, ourface diffusion coefficient, $D_{s}$, and film transfer coefficient, $K_{f} ;$ and the carbon's radius, $R$, porosity, $\epsilon$, and spherlctity, $\phi$. Literature revlews define the varlability and uncertainty of al1 probabilistic parameters.

The general equation for breakthrough time is 


$$
T=A_{0}+A_{1}\left(\frac{C}{C_{0}}\right)^{A_{2}}+\frac{A_{3}}{1.01-\left(\frac{C}{C_{0}}\right)^{A_{1}}}
$$

where $C=$ effluent concentration; $C_{0}$ = Influent concentration; $A_{0}$ through $A_{4}$ are functions of the Freundilch lsotherm exponent, $1 / n$, and the Blot number defined as

$$
B 1=\frac{k_{l} R(1-\epsilon)}{D_{0} D_{0} \epsilon \phi}
$$

$D_{0}$ is defined as

$$
D_{0}=\frac{p_{1} q_{0}(1 \cdot \epsilon)}{\epsilon C_{0}}
$$

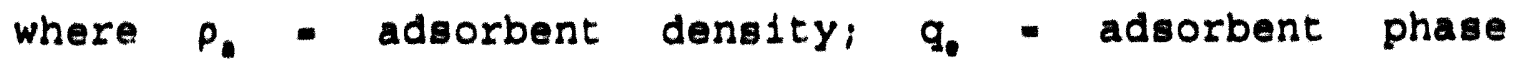
concentration in equilibrium with influent fluid-phase concentration; and $C_{n}$. Influent fluld-phase concentration. The parameters $A_{0}$ through $A_{4}$ are given in Table 16 along with the range of valid concentration ratios, $c / C_{0}$. These parameters are determined by specifying the influent composition, adsorption media and configuration.

\section{Selected Pollutants and Activated Carbon}

Benzene and carbon tetrachloride are the pollutants utilized to evaluate the reliability of the activated carbun adsorption process. Both are listed RCRA hazardous wastes, priority pollutants, common industrial pollutants, and amenable to carbon adsorption. In addition, both pollutants 
Table 16. Parameters for Numerical Solution of the MADAM Activated Carbon Adsorption Model (Hand et al. 1984).

\begin{tabular}{|c|c|c|c|c|c|c|c|c|}
\hline \multirow{2}{*}{$\begin{array}{l}\text { Froundlich } \\
\text { Isotherm } \\
\text { exponent } \\
\text { parameter } \\
(1 / n) \\
\text { (1) }\end{array}$} & \multirow{2}{*}{$\begin{array}{c}\text { Biol } \\
\text { number } \\
\left(B_{1}\right) \\
(2)\end{array}$} & \multicolumn{5}{|c|}{ Empirical Equation } & \multicolumn{2}{|c|}{$\begin{array}{c}\text { Equations Valid } \\
\text { for } C / C_{0} \text { Values } \\
\text { Bonwoen } \\
\text { Following Limns }\end{array}$} \\
\hline & & $\begin{array}{l}A_{0} \\
(3)\end{array}$ & $\begin{array}{l}A_{1} \\
141\end{array}$ & $\begin{array}{l}A_{2} \\
\text { (5) }\end{array}$ & $\begin{array}{l}A_{1} \\
(6)\end{array}$ & $\begin{array}{l}A_{1} \\
(7)\end{array}$ & $\begin{array}{c}\text { Lowor } \\
\text { (8) }\end{array}$ & $\begin{array}{c}\text { Upper } \\
(9)\end{array}$ \\
\hline 0.05 & 0.5 & $-5.44 \pi 14$ & p 5ux509 & 0.026 .569 & 0.019384 & 20.450470 & 001 & 0.99 \\
\hline 0.05 & 2.0 & $-5 .+65811$ & n $342+84$ & 0.004989 & 0.074948 & 0.50 .3250 & 0.01 & 0.99 \\
\hline 0.05 & 4.0 & -3.53115 .5 & h 5 H4S435 & 0.02 .3580 & 0.0 (x) & $0.27 .317 \mathrm{~h}$ & 002 & 0.99 \\
\hline 0.05 & 60 & 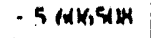 & I TM?IKH & 0.1122144 & $0.111 .312 \mathrm{~h}$ & $11.21424 \mathrm{~h}$ & 11112 & 0.49 \\
\hline 0.05 & 8.0 & $-3 \operatorname{sorswav}$ & 1. S44701 & 0.0201872 & 0.017083 & 0.184537 & 0.02 & 0.99 \\
\hline 0.05 & 10.0 & -5.664173 & $6+56597$ & 0.018157 & 0.019935 & 0.149314 & 0.02 & 0.98 \\
\hline 0.05 & 14.0 & -0.662780 & $1+11252$ & 0.060709 & 0.020229 & 0.143293 & 0.02 & 0.99 \\
\hline 0.05 & 25.0 & -0.662783 & 1.350940 & 0.031070 & 0.020350 & 0.129998 & 0.01 & 0.99 \\
\hline 0.05 & 2100.0 & .0 .665879 & 0.711310 & 2.987309 & 0.016783 & 0.361023 & 0.01 & 0.99 \\
\hline 0.10 & 0.5 & -1.919873 & .7 .055 .768 & 0.055488 & 0.024284 & 15.311766 & 0.02 & 0.99 \\
\hline 0.10 & 2.0 & -2.278950 & $3.34,7925$ & 0.046838 & 0.004751 & 0.384675 & 0.02 & 0.99 \\
\hline 0.10 & 4.0 & -2.3 .37178 & 3.370026 & 0.043994 & 0.008650 & $0.243+12$ & 0.02 & 0.99 \\
\hline 0.10 & 6.0 & -2.107407 & $3.7+131$ & 0.041322 & 0.012552 & $0.1 \% 6565$ & 0.02 & 0.99 \\
\hline 0.10 & 8.0 & -2.477819 & $3.37(1) 54$ & 0.038993 & 0.016275 & $0.176+37$ & 0.02 & 0.99 \\
\hline 0.10 & 10.0 & $-2.5 \times 6414$ & $3.37(1450$ & 0.035003 & 0.019386 & 0.150788 & 0.02 & 0.98 \\
\hline 0.10 & 16.0 & -2.567201 & $3.3(6.2 .41$ & 0.020940 & 0.019483 & 0.136813 & 0.01 & 0.98 \\
\hline 0.10 & 30.0 & -2.568618 & $3.2+1,-83$ & 0.009595 & 0.019610 & 0.121746 & 0.01 & 0.98 \\
\hline 0.10 & $\geq 100.0$ & -2.568 .360 & $.3191+82$ & 0.001555 & 0.019682 & 0.110113 & 0.01 & 0.98 \\
\hline 0.20 & 0.5 & $-1+41000$ & 2569000 & 0.060920 & 0.002333 & 0.371100 & 0.01 & 0.99 \\
\hline 0.20 & 2.0 & $-1.47+313$ & 2558.300 & 0.058480 & 0.005026 & 0.241265 & 0.01 & 0.99 \\
\hline 0.20 & 40 & -1 sunton & 2514259 & 0.1155525 & O (WRTA7 & 0.187510 & 001 & 0.99 \\
\hline 0.20 & 611 & -1017.349 & | ЧHYIIIR & 0 U6928.3 & $00123 \times 12$ & 0.167924 & 0.01 & 0.99 \\
\hline 0.20 & 80 & -0.169192 & $1.0 \pi 521$ & 0.144879 & 0.015500 & 0.168083 & 0.02 & 0.99 \\
\hline 0.20 & 10.0 & -1.402932 & 2.188339 & 0.052191 & 0.018422 & 0.133574 & 0.01 & 0.98 \\
\hline 0.20 & 13.0 & -1.369220 & 2.118545 & 0.039492 & 0.018453 & 0.127565 & 0.01 & 0.98 \\
\hline 0.20 & 25.0 & -1.514159 & 2.2094 .50 & 0.017937 & 0.018510 & 0.118517 & 0.01 & 0.99 \\
\hline 0.20 & $>I(x) n$ & $\|$ A 1412411 & 0 lrikek & 2 571X日月, & 0.1114417 & 0.369418 & 0.101 & 0.99 \\
\hline 0.30 & 11.5 & $17^{\prime}, H_{1}, 46$ & $\therefore x+16.57 h$ & (1) us45.70 & 00031122 & 0.156816 & 0.01 & 0.99 \\
\hline 0.30 & 2.0 & - I nsitht? & $264 \times \times 45$ & $004 \times 4+09$ & 0.005612 & 0.140937 & 0.01 & 0.99 \\
\hline 0.30 & 4.0 & -0 enement & $1937 \times .13$ & $00 \times 4451$ & 0 (X)R8NB & 0.139086 & 0.01 & 0.99 \\
\hline 030 & 60 & $-1119711 \pi$ & $111 \times 6 \times 4$ & $11117 \times 44$ & 0.011527 & 0.135474 & 0.01 & 0.99 \\
\hline 0.30 & 8.0 & -0.1471700 & $|(x, 4)| 0$ & 0119700 & 0.013925 & 0.132691 & 0.01 & 0.99 \\
\hline 030 & 10.0 & -017335. & I mankou & 0.120311 & 0.015940 & 0.133973 & 0.01 & 0.99 \\
\hline 0.30 & 15.0 & $-01: 3350$ & 0 U10i11 & 0071768 & 0.014156 & 0.086270 & 0.01 & 0.98 \\
\hline 0.30 & 35.0 & $0.666+71$ & $0+484570$ & $1.719+40$ & 0.013444 & 0.259545 & 0.02 & 0.99 \\
\hline 0.30 & $\geq 100.0$ & 0696161 & 0516951 & 2.054587 & 0.012961 & 0.303218 & 0.01 & 0.99 \\
\hline $0+0$ & 0.5 & -0.534251 & $18113 \times 34$ & 0094055 & 0.004141 & 0.137797 & 0.01 & 0.99 \\
\hline 0.40 & 2.0 & -0.166270 & 1.190897 & 0.122280 & 0.006261 & 0.134278 & 0.01 & 0.99 \\
\hline 0.40 & 4.0 & -0.166270 & 1.131946 & 0.115513 & 0.008634 & 0.126813 & 0.01 & 0.99 \\
\hline 0.40 & 6.0 & -0.166270 & 1.089789 & 0.112284 & 0.010463 & 0.124307 & 0.01 & 0.99 \\
\hline 0.40 & 9.0 & 0.491912 & 0.491833 & 0.487414 & 0.011371 & 0.147747 & 0.02 & 0.98 \\
\hline 0.40 & 12.0 & 0.564119 & $0 \$ 19196$ & 0.639819 & 0.011543 & 0.149005 & 0.02 & 0.99 \\
\hline 0.40 & 15.0 & 0.640669 & $0.432+66$ & 1.048056 & 0.011616 & 0.212726 & 0.02 & 0.99 \\
\hline 0.40 & 25.0 & 0.672353 & 0.397007 & 1.153169 & 0.011280 & 0.216883 & 0.01 & 0.99 \\
\hline 0.40 & $=100.0$ & 0.741435 & 0.448054 & 1.929879 & 0.010152 & 0.306448 & 0.01 & 0.99 \\
\hline 0.50 & 0.5 & $-0.04(8) 00$ & $1.0 \times 47652$ & 0.158995 & 0.005467 & 0.139116 & 0.01 & 0.99 \\
\hline 0.50 & 4.0 & -0.0410800 & 0 4R2757 & 0.111618 & 0.048072 & 0.1111404 & 0.01 & 0.99 \\
\hline 0.50 & 10.0 & $0.04+602$ & $075+878$ & 0.092059 & 0.019877 & 0.090763 & 0.01 & 0.99 \\
\hline 0.50 & 14.0 & 0.023000 & U. 8 2n68 & 0.057545 & 0.1004652 & 0.084532 & 0.01 & 0.99 \\
\hline 0.50 & 25.0 & 0.023000 & 0.79 .373 & 0.079324 & $0.0(x) 326$ & 0.082751 & 0.01 & 0.99 \\
\hline 0.50 & 2100.0 & 0.529217 & $\|24|k| 1\|$ & O IIR242K & $111 \times 143117$ & 0.075461 & 0.01 & 0.99 \\
\hline
\end{tabular}


Table 16. (Cont.) Parameters for the Numerical solution of the MADAM Activated Carbon Adsorption Model.

\begin{tabular}{|c|c|c|c|c|c|c|c|c|}
\hline (1) & (2) & (3) & (4) & (5) & (6) & (7) & (8) & (9) \\
\hline 0.60 & 0.5 & $0.35 .55 \mathrm{k}$ & $1114: 1114$ & 0.26 .31 .44 & $0.0 \times 15482$ & 0.121775 & 0.01 & 0.9 \\
\hline 0.60 & 2.0 & 0.521979 & 0.504220 & 0.327240 & 0.005612 & 0.128679 & 0.01 & 0.99 \\
\hline 0.60 & 6.0 & 0.676253 & 0.344583 & 0.482297 & 0.005898 & 0.138946 & 0.01 & 0.99 \\
\hline 0.60 & 14.0 & 0.7693 .71 & 11250447 & $117 \pi 1 K R$ & 0.0056001 & 0.16 .5513 & 0.01 & 0.99 \\
\hline 0.60 & 50.0 & 0.849057 & 0.215799 & 1.343183 & 0.004725 & 0.223759 & 0.01 & 0.99 \\
\hline 0.60 & $\geq 100.0$ & 0.831231 & 0.227304 & 1.174756 & $0.004 \% 61$ & 0.212109 & 0.01 & 0.99 \\
\hline 0.70 & 0.5 & 0.575024 & 0.449062 & $\cdot 0.278452$ & 0.004122 & .0 .121682 & 0.01 & 0.99 \\
\hline 0.70 & 4.0 & 0.715269 & 0.307172 & 0.442104 & 0.004371 & 0.138351 & 0.01 & 0.99 \\
\hline 0.70 & 12.0 & 0.787940 & 0.243548 & 0.661599 & 0.004403 & 0.162595 & 0.01 & 0.99 \\
\hline 0.70 & 25.0 & 0.829492 & 0.204078 & 0.784529 & 0.004050 & 0.179003 & 0.01 & 0.99 \\
\hline 0.70 & 2100.0 & 0.847012 & 0.190678 & $: 0.931686$ & 0.003849 & 0.183239 & 0.01 & 0.99 \\
\hline 0.80 & 0.5 & 0.708905 & 0.314101 & 0.357499 & 0.003276 & 0.119300 & 0.01 & 0.99 \\
\hline 0.80 & 4.0 & 0.784576 & 0.239663 & 0.484122 & 0.003206 & 0.134987 & 0.01 & 0.99 \\
\hline 0.80 & 14.0 & 0.839439 & 0.188966 & 0.648124 & 0.003006 & 0.157697 & 0.01 & 0.99 \\
\hline 0.80 & $\geq 100.0$ & 0.882747 & 0.146229 & 0.807987 & 0.002537 & 0.174543 & 0.01 & 0.99 \\
\hline 0.90 & 0.5 & .0 .865453 & $\cdot 0.157618$ & 0.444973 & 0.001650 & 0.148084 & 0.01 & 0.99 \\
\hline 0.90 & 4.0 & 0.854768 & 0.171434 & 0.495042 & 0.001910 & 0.142251 & 0.01 & 0.99 \\
\hline 0.90 & $16 . Q$ & 0.866180 & 0.163992 & 0.573946 & 0.001987 & 0.157594 & 0.01 & 0.99 \\
\hline 0.90 & $\geq 100.0$ & 0.893192 & 0.133039 & 0.624100 & 0.001740 & 0.164248 & 0.01 & 0.99 \\
\hline
\end{tabular}


are resistant to anaerobic biodegradation which frequently occurs in activated carbon columns, thus simplifying the analysis. The chemical and physical properties of benzene and carbon tetrachloride are Iisted in Table 17.

Table 18 provides the summary statistics of the parameter distributions and the appendix contains the specific data values used to generate the distributions.

The activated carbon selected for this research is Calgon Corporation Filtrasorb 400 (F400). F400 is widely used in wastewater treatment and a large body of data is available for determining the probability distributions of the Freundich parameters.

\section{Results}

\section{Safety Factor Versus Reliability}

Safety factors are defined as the ratio of the breakthrough time at the effluent standard to the median design bed replacement time. Reliability is defined as the probability that the effluent concentration is less than the effluent standard at the safety factored bed replacement time. Monte Carlo simulation of the activated carbon model is used to generate one thousand realizations of the effluent concentration for each of the two pollutants at two influent concentrations and 20 safety factored bed replacement times.

The resulting cumulative density functions (CDFs) relate the safety factors to reliability levels as illustrated in 
Table 17. Chemical and Physical properties of Benzene and Carbon Tetrachloride for Activated Carbon Adsorption Treatment.

\begin{tabular}{|c|c|c|}
\hline Compound Name & Benzene & Carbon Tet. \\
\hline CAS Number & $73-43-2$ & $56-23-5$ \\
\hline Compound Type & Aromat1c & Hydrocarbon \\
\hline Formula & $\mathrm{C}_{6} \mathrm{H}_{6}$ & $\mathrm{CCl}_{4}$ \\
\hline $\mathrm{MW}(\mathrm{g} / \mathrm{mol})$ & 78.11 & 153.82 \\
\hline Melting Point $\left({ }^{\circ} \mathrm{C}\right)$ & 5.5 & -23. \\
\hline Boiling Point $\left({ }^{\circ} \mathrm{C}\right)$ & 80.1 & 76.8 \\
\hline $\begin{array}{l}\text { Vapor Pressure } \\
\left.\text { (Torr } \odot{ }^{\circ} \mathrm{C}\right)\end{array}$ & $95 @ 25$ & $113 \bigcirc 25$ \\
\hline $\begin{array}{l}\text { Solubility } \\
\left(\mathrm{mg} / \mathrm{I} \otimes{ }^{\circ} \mathrm{C}\right)\end{array}$ & $1780 @ 20$ & $800 @ 20$ \\
\hline $\log K_{\text {ow }}(\mathrm{dim})$ & 2.13 & 2.73 \\
\hline $\mathrm{K}_{\mathrm{H}}\left(\mathrm{atm}-\mathrm{m}^{3} / \mathrm{mol} \otimes{ }^{\circ} \mathrm{C}\right)$ & $5.5(10)^{-3} @ 25$ & $2.93(10)^{-2} @ 25$ \\
\hline
\end{tabular}

Source: US EPA 1992 
Table 18. Summary Statistics for Activated Carbon Adsorption Treatment of Benzene and Carbon Tetrachloride.

\begin{tabular}{|c|c|c|}
\hline Parameter & Benzene & Carbon Tet. \\
\hline $\begin{array}{c}\text { Freundlich } 1 / n \\
\text { (dim) } \\
\text { Normal }\end{array}$ & $\begin{array}{l}m=0.4879 \\
s=0.0736 \\
n=9\end{array}$ & $\begin{array}{l}\mathrm{m}=0.6004 \\
\mathrm{~g}=0.0983 \\
\mathrm{n}=5\end{array}$ \\
\hline $\begin{array}{l}\text { Freundlich } \mathrm{K} \\
(\mu \mathrm{mol} / \mathrm{g}(1 / \mu \mathrm{mol}) 1 / \mathrm{n} \\
\mathrm{Log} \text {-normal }\end{array}$ & $\begin{array}{l}\lambda=4.719 \\
\zeta=0.2976 \\
n=9\end{array}$ & $\begin{array}{l}\lambda=3.645 \\
\zeta=0.4190 \\
n=6\end{array}$ \\
\hline $\begin{array}{c}D_{\mathrm{s}}\left(\mathrm{cm}^{2} / \mathrm{sec}\right) \\
\text { Log - normal }\end{array}$ & $\begin{array}{l}\lambda=-21.64 \\
\zeta=1.457 \\
n=8\end{array}$ & $\begin{array}{l}\lambda=-21.87 \\
\zeta=0.6834 \\
n=8\end{array}$ \\
\hline $\begin{array}{c}\mathrm{K}_{f}\left(\mathrm{~cm}^{2} / \mathrm{sec}\right) \\
\mathrm{Log}-\mathrm{normal}\end{array}$ & $\begin{array}{l}\lambda=-5.242 \\
\zeta=0.2918 \\
n=6\end{array}$ & $\begin{array}{l}\lambda=-5.535 \\
\zeta=0.2158 \\
n=11\end{array}$ \\
\hline
\end{tabular}

\begin{tabular}{||c||l||}
\hline Parameter & F1ltrasorb 400 \\
\hline Radius, $R(\mathrm{~mm})$ & $\mathrm{m}=0.50$ \\
Normal & $\mathrm{s}=0.0304$ \\
\hline Porosity, $\epsilon(\mathrm{o})$ & $\mathrm{m}=0.59$ \\
Normal & $\mathrm{s}=0.0120$ \\
\hline Sphericity, $\phi(\mathrm{dim})$ & $\mathrm{m}=0.883$ \\
Normal & $\mathrm{s}=0.0505$ \\
\hline
\end{tabular}

$\mathrm{m}=$ sample mean; $\mathbf{s}=$ sample standard deviation; $\mathrm{n}=$ number of data points in the sample population; $\lambda=$ mean of the logs of the data; $\zeta=$ standard deviation of the logs of the data. 
Figure 37. For a benzene breakthrough concentration of $5 \mu \mathrm{g} / \mathrm{l}$ (effluent standard), a safety factor of 2 , and an influent concentration of $500 \mu \mathrm{g} / \mathrm{l}$, the reliability of the treatment process is $84 \%$. This is determined by profecting a line upward from the effluent concentration axis at $5 \mu \mathrm{g} / 1$ to the safety factor of 2 curve and then profecting the line horizontally to the probability axis. Reliability equals the cumulative probability at that point. Reliability levels for other safety factors are determined in a similar fashion.

Plots of safety factors versus reliabllity for the activated carbon process are shown in Figure 38 for benzene and Figure 39 for carbon tetrachloride. As reliability increases toward one, the safety factors increase asymptotically toward infinity.

These curves are interpreted as follows using the benzene influent concentration of $50 \mu \mathrm{g} / 1$ in Figure 38 as an illustration. The median breakthrough time is calculated as 374 days. The reliability is approximately $50 \%$ when the safety factor equals one (374days / 374days). To ensure that $5 \mu \mathrm{g} / 1$ breakthrough concentration occurs less frequently (higher reliability), the carbon column is replaced more frequently than every 374 days. For a safety factor of 2 , the carbon bed would be replaced every 187 days (374days / 2) and the reliability increases to $95 \%$. The $500 \mu \mathrm{g} / \mathrm{l}$ influent concentration curve is higher than the $50 \mu \mathrm{g} / \mathrm{l}$ curve indicating higher safety factors are required for higher 


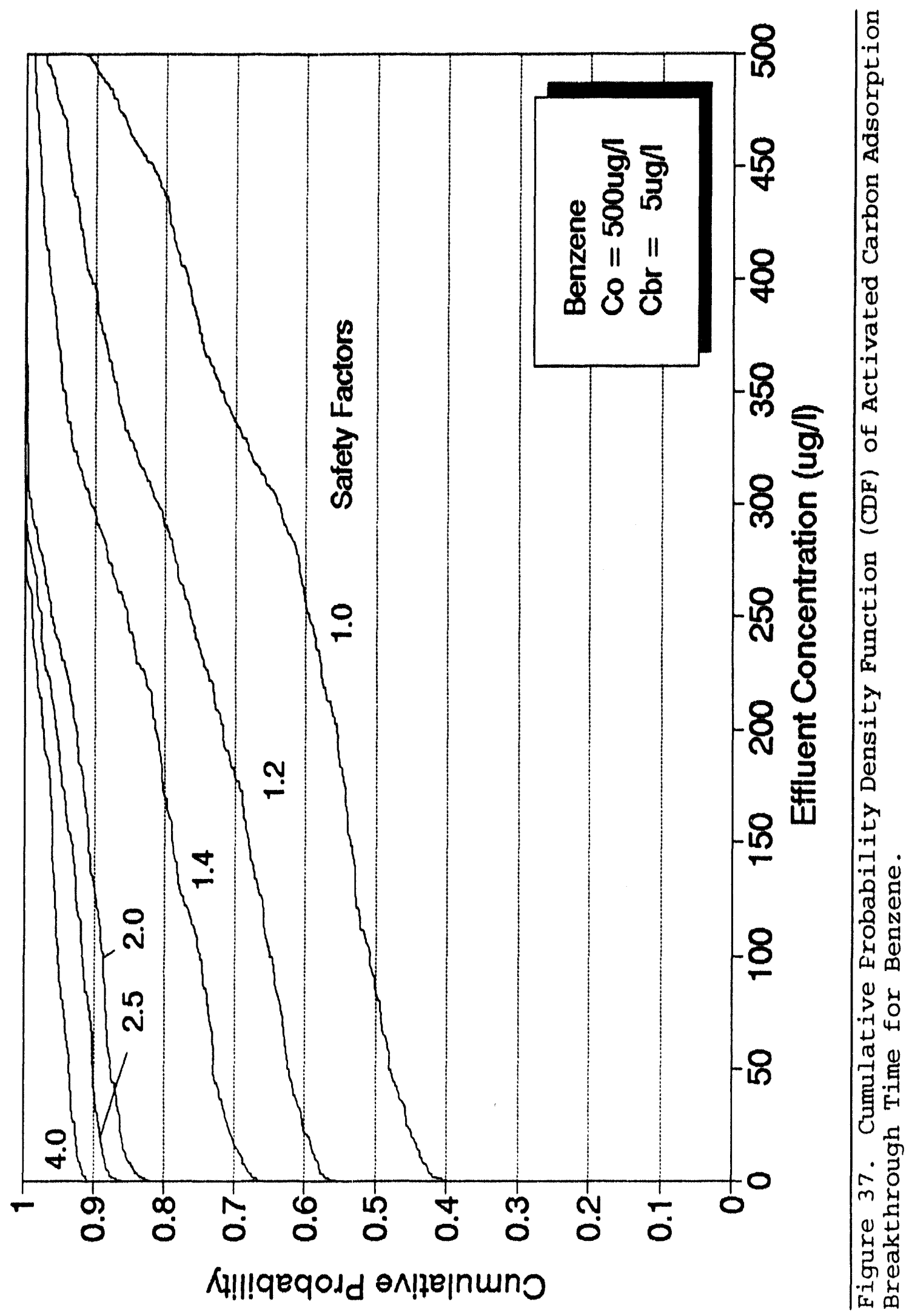




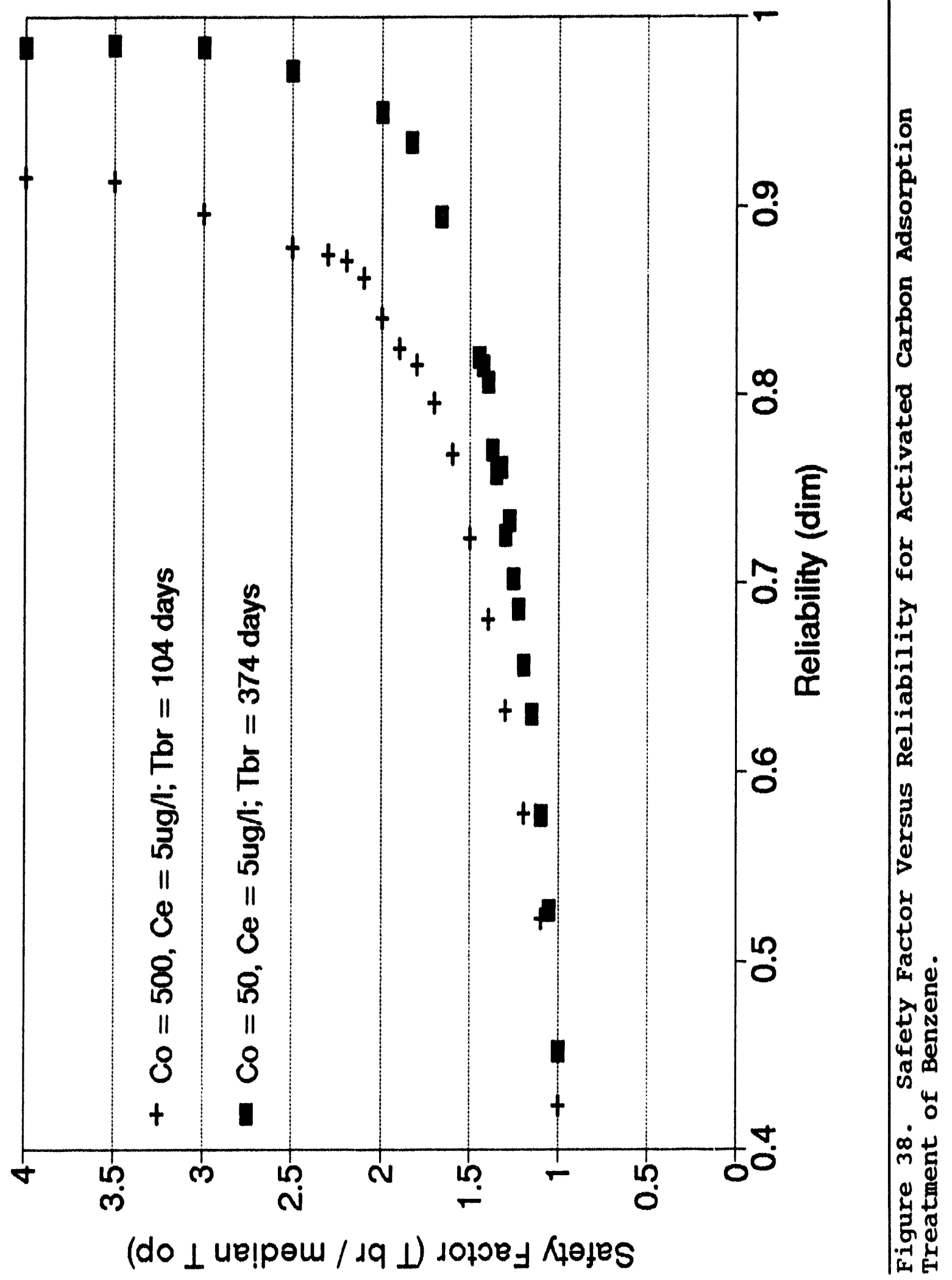




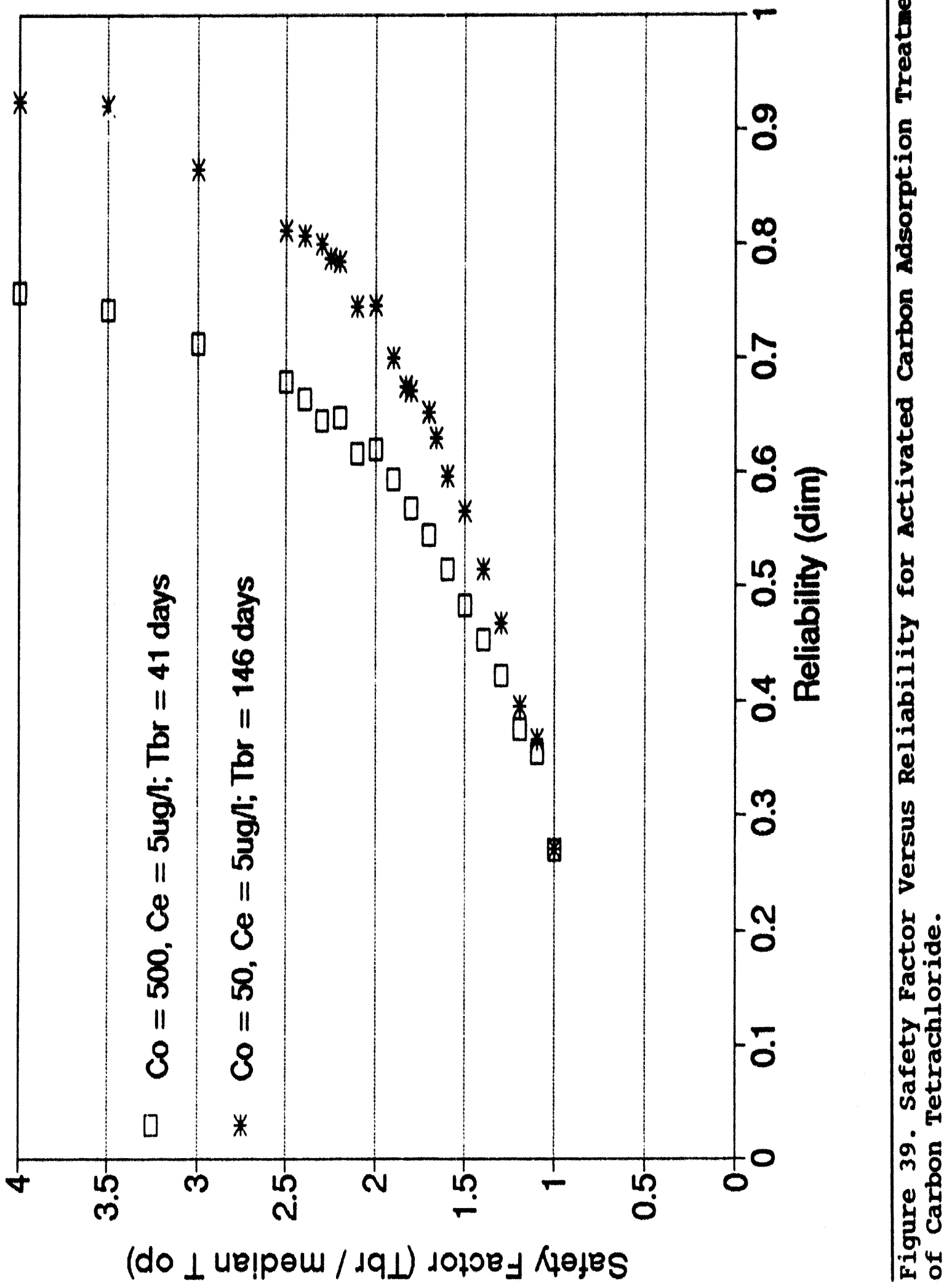


treatment efficiency at all reliability levels.

One of the most interesting result of this research is the inability of the activated carbon process to obtain high rellablity levels with high influent concentrations. The major varlable preventing high reliabllity is the freundlich constant, $K$, which is related to the total adsorption capacity of the carbon column. A wide range of Freundlich constants were found in the literature for the benzene-F400 and carbon tetrachloride-F400 pollutant-carbon systems. The result is a relatively large atandard deviation for $k$ which is reflected in the results of the model. When the total capacity of the carbon column is poorly characterized, the breakthrough time cannot be predicted accurately. This research is concerned with adsorption of single pollutants and cases of multiple poliutants in the waste stream may further increase the uncertainty of the system performance.

The safety factors required to achleve 95 rellability for benzene and carbon tetrachloride at low influent concentrations are 2 and 4 , respectively. At high influent concentrations, maximum reliability levels approach 908 and 75t for benzene and carbon tetrachloride, respectively.

\section{Sensitivity Analysis}

As with the other reviewed treatment processes, model results based on distributions of parameters based on few data points or data ranges must be analyzed to determine the 
effects of the assumptions on the model results. The normal distributions assumed for the three carbon particle physical properties used in the model (radius, $R ;$ bed porosity, $C$; and sphericity, $\phi$ ) are all based on ranges of values found in the 11terature and mut be verifled. The log-normal distributions assumed for the surface diffusion coefficient, $D_{s}$, and $11 \mathrm{~m}$ transer coeffictent, $K_{1}$, must also be verifled. The distribution assumption 18 verified by comparing the model results based on the assumed distribution with model results based on the unfform distribution itted to these parametera. The uniform distribution is chosen because it shape is vastly different than the normal distribution so that parameters that can pass this sensitivity test are robust to the assumption of probability distribution.

The model results are compared with the two-sample Kolmogorov-smirnov goodness-of-fit test based on one thousand simulations at low, medium and high safety factors. In all sensitivities for both pollutants, the model results are not statigtically different at the 0.05 level of significance justifying the distribution assumptions.

\section{Cost Versus Reldabtlity}

Cost versus reliablitty plots are shown in Figure 40 for benzene and Figure 41 for carbon tetrachloride. As expected, costs increase with increasing reliablitty and higher treatment efficiency results in higher costs. These costs 

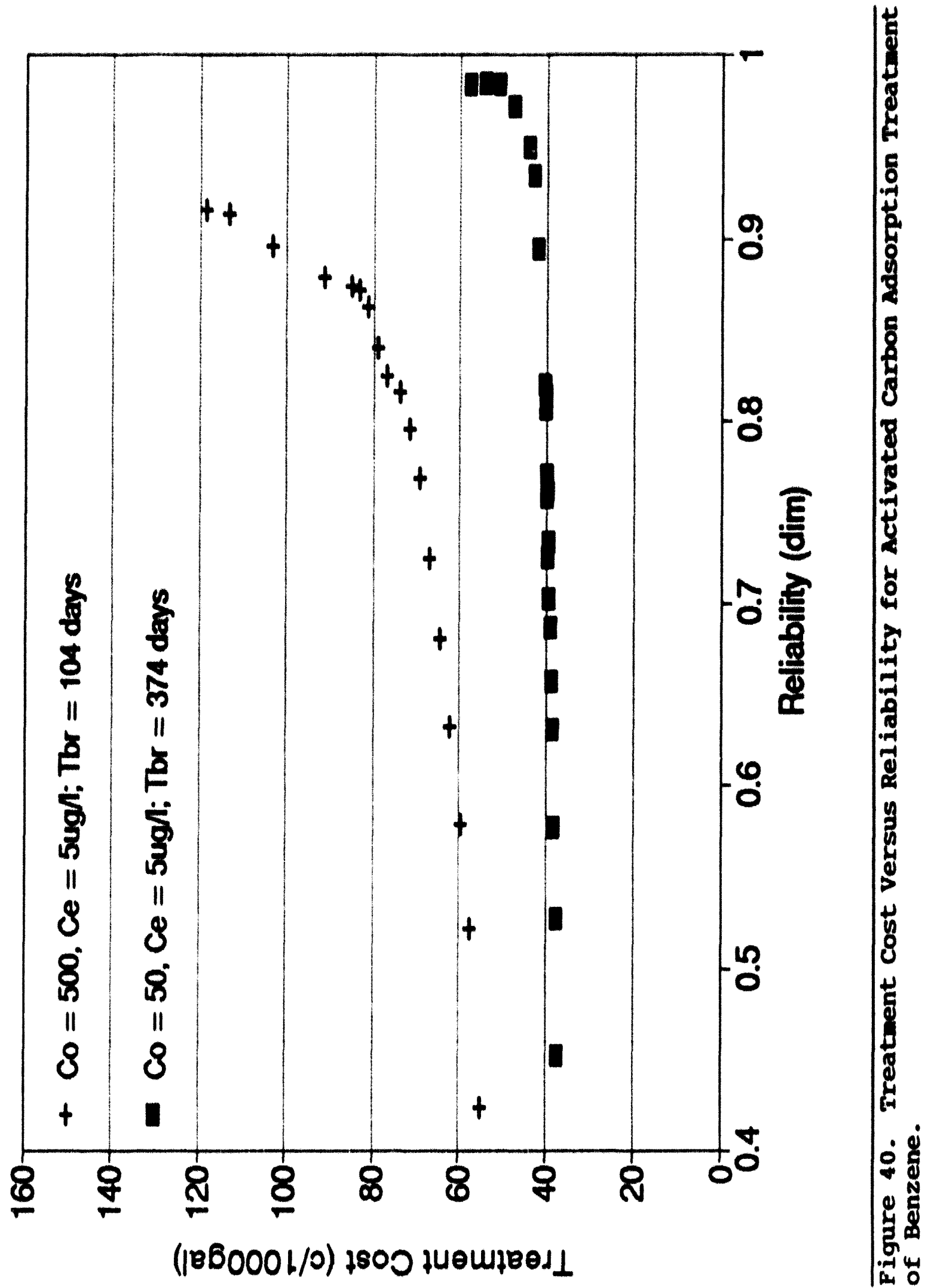


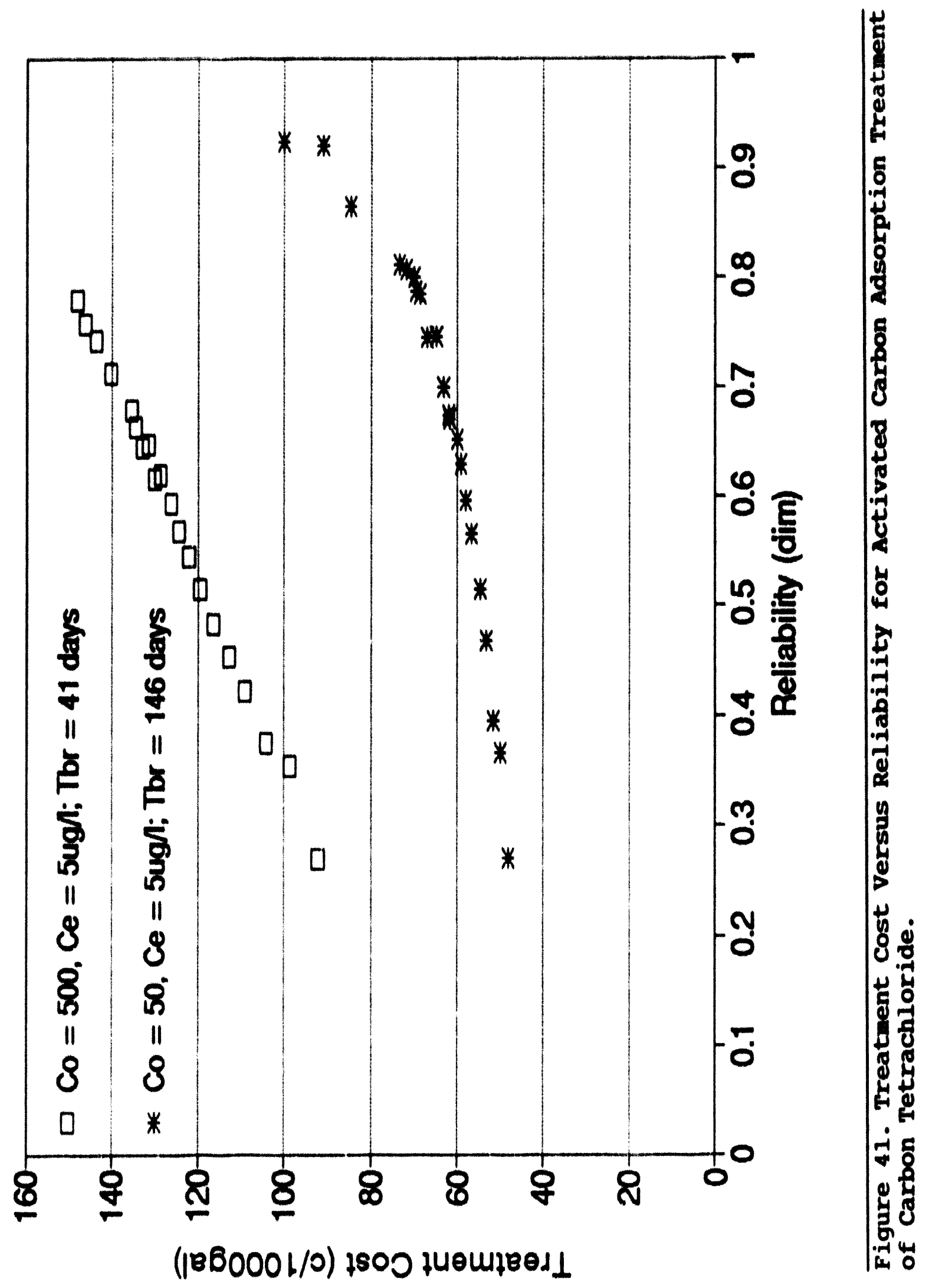




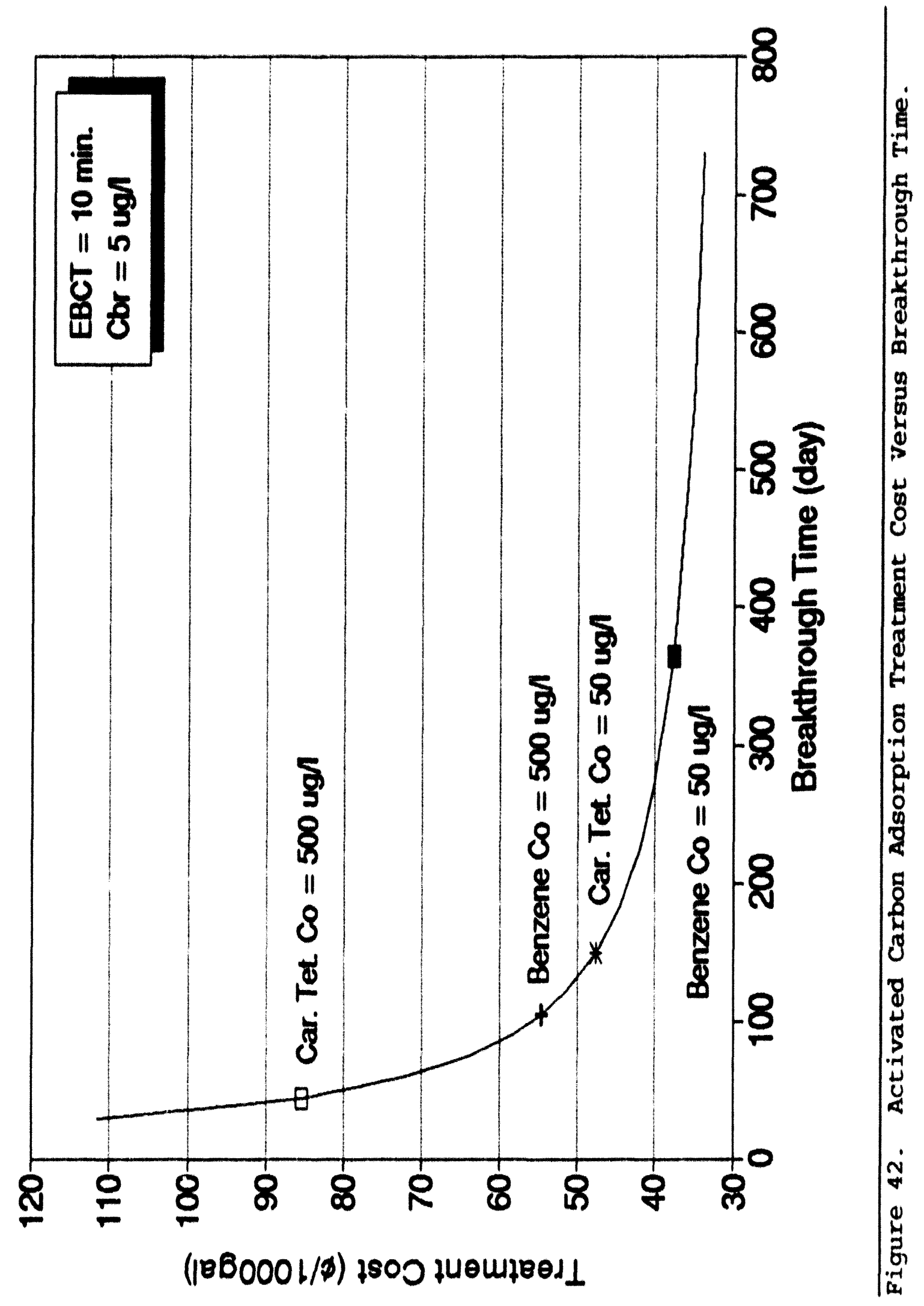


are based on the cost estimating method incorporated into the EPA Activated Carbon Adsorption model (Clark and Adams 1991b) (Figure 42) and are intended to provided relative comparisons only. As illustrated in Figure 42, for a given column size, the largest breakthrough time provides the lowest treatmunt cost. The median breakthrough times for the two influent concentration cases for both pollutants are also shown for empty bed contact times (EBCT) of 10 minutes. Carbon tetrachloride has a much smaller Freundich adsorption constant, $K$, than benzene and attains breakthrough much more quickly. Breakthrough times for high influent concentrations of carbon tetrachloride are very short resulting in very high treatment costs. Conversely, benzene at low influent concentration attains a long breakthrough time and treatment costs are correspondingly lower.

These results are reflected in the treatment costs in Figure 41 where carbon tetrachloride at high influent concentration has the highest cost and Figure 40 where benzene at low influent concentration has the lowest cost. For a given EBCT, the breakthrough time is primarily a function of the pollutant. The breakthrough time of a specific pollutant can be increased by increasing the size of the bed (increasing the EBCT) but the treatment cost will be correspondingly higher.

\section{Deterministic Designs}

Conventional deterministic designs are routinely based 
on pilot testing programs with the specific wastewater. Conservatism is included in various ways including assuming higher flow rates than expected and reducing the estimated adsorption capacity to that of regenerated carbon.

In this research, the deterministic breakthrough times are generated based on the conservatism of assuming regenerated carbon with $80 \%$ of the adsorption capacity of virgin carbon. Results are illustrated in Figure 38 for benzene and Figure 39 for carbon tetrachloride. The deterministic designs provide safety factors of 1.30 and 1.36 for benzene at influent concentrations of 500 and $50 \mu \mathrm{g} / \mathrm{I}$ corresponding to $62 \%$ and $73 \%$ process reliability, respectively. Safety factors of 1.49 and 1.29 for carbon tetrachloride at influent concentrations of 500 and $50 \mu \mathrm{g} / \mathrm{l}$ correspond to $46 \%$ and $48 \%$ process reliability, respectively. As these results demonstrate, the conservatism incorporated into the deterministic designs provide low process reliability with regard to predicting the column breakthrough time.

\section{Summary}

Monte Carlo simulation is performed on activated carbon adsorption of benzene and carbon tetrachloride based on the probabilistic estimation of their Freundlich parameters, surface diffusion coefficients and film transfer coefficients. Probabilistic estimation of Filtrasorb 400 
activated carbon properties: particle radius and sphericity, and bed porosity are also included in the analysis. Safety factors of 2 and 4 are required to achieve $95 \%$ process reliability for benzene and carbon tetrachloride, respectively at influent concentrations of $50 \mu \mathrm{g} / 1$. At $500 \mu \mathrm{g} / 1$ influent concentration, the maximum process reliability achievable is $90 \%$ and $75 \%$ for benzene and carbon tetrachloride, respectively. This relatively low reliability level is due to the significant variability associated with the determination of the Freundich adsorption capacity parameter, $\mathrm{K}$, for both pollutants.

Sensitivity analyses indicate that the model results are robust to the assumption of distribution types for all probabilistic parameters considered. This result indicates that parameters of major importance are sufficiently characterized to ascertain the shapes of their probability distributions while the distribution shape of less wellcharacterized parameters are generally of lesser importance.

Treatment costs decrease with increasing breakthrough time for a given empty bed contact time. Benzene at low influent concentration has the lowest treatment cost while carbon tetrachloride at high influent concentration has the highest treatment cost. The primary variable determining breakthrough time is the Freundich adsorption capacity parameter, $K$.

Deterministic designs based on the conservatism of 
assuming the adsorption capacity of regenerated carbon ( $80 \%$ of virgin carbon) results in reliability level in the range of 60 to $73 \%$ for benzene and 46 to $48 \%$ for carbon tetrachloride. Additional conservatism is required to ensure higher reliability of predicting specific breakthrough times. 


\section{CHAPTER VIII}

\section{CONCLUSIONS AND RECOMMENDATIONS}

\section{Introduction}

Five hazardous waste treatment processes have been analyzed probabilistically using Monte Carlo simulation to elucidate the relationships between process safety factors and reliability levels. Safety factors are defined as the ratio of an effluent standard to the median effluent design concentration. Reliability is defined as the frequency that the effluent concentration is lower than the effluent standard.

The mathematical models used to evaluate each process are the simplest validated deterministic models available in the literature that provide realistic results. Using simple models with few input parameters increases the likelihood of obtaining adequate data from the literature to build probability distributions for these model parameters.

Probability distributions for the probabilistic model parameters are based on data located through extensive literature searches. When sufficient data points for a particular parameter are available, the Kolmogorov-Smirnov goodness-of-fit test is used to determine the appropriate probability distribution. When only a few data points or a 
data range for a parameter are available, the probability distribution is assumed and sensitivity analyses are performed to evaluate the effects of the assumption.

Relationships between treatment costs and reliability levels provide information to decision makers about the tradeoffs of costs and reliability. Treatment costs are based on generic designs and are intended for relative comparison only.

The conservatism commonly incorporated into conventional deterministic designs is evaluated to provide information pertaining to the process reliability related to this conservatism. The degree of reliability required of a treatment process is ultimately a social judgement. Relationships between cost and reliability have been determined for each process to aid these decisions.

The remainder of this chapter is divided into two sections. The first section summarizes the general conclusions of this research and the specific conclusions for each treatment process. Recommendations for future research work are presented in the last section.

\section{Conclusions}

\section{General}

Probabilistic assessments produce outcomes based on the stochastic events in the treatment processes that deterministic assessments based on mean and worst case scenarios are unable to provide. Yet, very few probabilistic 
assessments of hazardous waste treatment processes are available in the literature. Penzias' (1989) proposition that engineers are traditionally weak in probability and statistics is the most likely reason for the lack of probabilistic designs and assessments. While probabilistic assessments are more involved and time consuming than their deterministic counterparts, the insight they provide makes them invaluable in evaluating process reliability.

The use of validated models which require the fewest data inputs capable of realistic predictions increases the likelihood of obtaining sufficient data to develop probability distributions for model parameters. Use of overly complex models containing many parameters for which little data are avallable will reduce the effectiveness of probabilistic designs due to the lack of data on which to base the parameter distributions. Overly simplistic models will not provide reliable results and should not be used. This discussion explicitly emphasizes that the appropriate level of model sophistication is a value judgement based on the context of the problem. An appropriate level of sophistication for one person or context may be overly sophisticated or too simplistic for another person or context.

When using relatively simple models that have enjoyed wide use for several years, sufficient data will gentrally be available in the literature to ascertain the appropriate probability distributions of the most important parameters. 
The probability distributions of model parameters for which little data are avallable in the literature are generally of minor importance as indicated by the robustness of the models to the sensitivity analyses. This conclusion is not unexpected since deterministic sensitivity analyses provide information about the most important model parameters and researchers have generally focused their work in these more productive areas.

Monte Carlo simulation using antithetic variates and 1000 simulations provides sample statistics that approach the population statistics. However, high reliability designs necessarily deal with the upper tails of the distributions where few simulations occur. For example, for a scenario corresponding to $99 \%$ reliability, fust 18 of the simulations provide effluent concentrations that are higher than the effluent standard. This is not an issue when a standard distribution can be fit to the output data based on a goodness-of-fit analysis. The output distributions of the treatment process evaluated in this research cannot be fit to standard distributions with adequate statistical significance so the model output distributions must be used. Since so few data points are available to position the tail of the model output distributions, additional simulations or better variance reduction techniques must be employed for high process reliability analyses.

Table 19, summarizing the results of this research, shows that deterministic safety factors for the different 
treatment processes range from 1.2 to 20 . The reliablitty provided by typlcal safety factors vary from near zero for chloroform removal in activated sludge treatment to over ninety-nine percent for reverse osmosis treatment.

The incremental increase in rellability associated with an incremental cost increase ( $\% / 1000$ gallons) for each process is also given in Table 19 for low and high reliability levels. The greatest increase in reliability per unit cost is attained at lower reliability levels. Above $90 \%$ reliability, further increases in reliability per unit cost are generally an order of magnitude lower. The point of diminishing returns is in the range of 80 to 958 reliability.

\section{Packed Tower Aeration Treatment}

Based on several analyses in the 11terature, the Onda correlation is the best available model for determining the mass transfer coefficient, $K_{L} a$, with a $21 \%$ error between observed and predicted values.

Ninety-five percent reliability for meeting the $5 \mu \mathrm{g} / \mathrm{l}$ MCL for benzene and trichloroethylene (TCE) is realized with safety factors in the range of 2 to 6 for influent concentrations of 100 and $1000 \mu \mathrm{g} / 1$. Varying the stripping factor between two and ten does not appreclably alter the relationship between safety factors and process reliability.

Henry's constant is the most important variable in the evaluation of the packed tower aeration process and several 


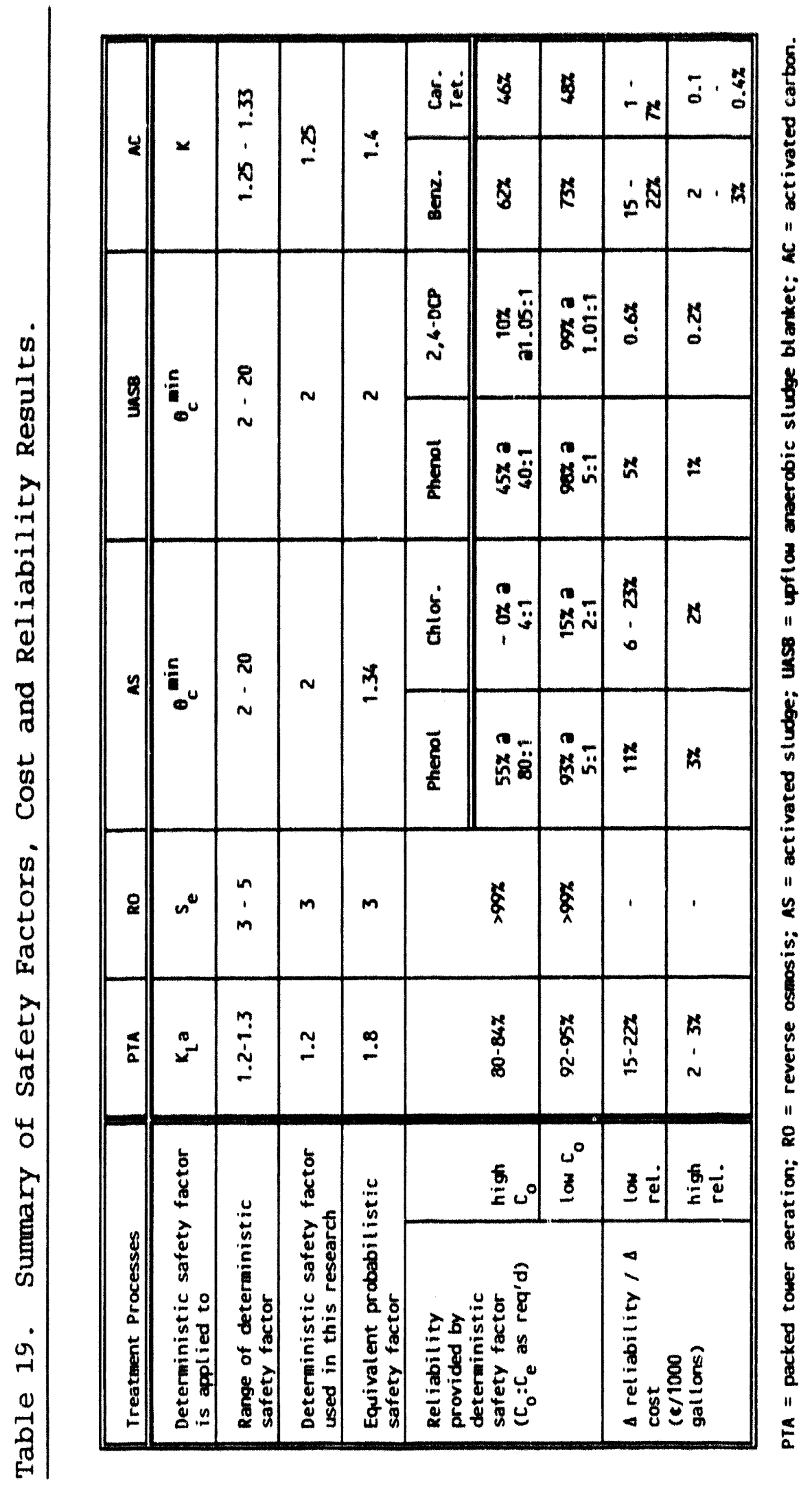


investigators report estimations of Henry's constants for most volatile organic compounds in the literature. The best fit probability distribution for benzene and TCE Henry's constant is the normal distribution.

In conventional deterministic designs, safety factors of 1.2 to 1.3 are applied to the mass transfer coefficient, $K_{h} a$, equivalent to $K_{L}$ a reductiong of 17 to $23 \%$. The conservatism provided by the $K_{L} a$ safety factor of 1.2 results in reliability levels of 92 to 95 for benzene and TCE for influent concentrations of $100 \mu \mathrm{g} / 1$ and 80 to 848 reliablifty for influent concentrations of $1000 \mu \mathrm{g} / \mathrm{l}$. While the conventional conservatism provides appropriate reliability levels for low influent concentrations, additional conservatism is required to realize comparable reliablitty at higher influent concentrations.

Increased reliability is achleved by increasing the tower height and the incremental cost of increasing the tower helght is small relative to the flxed costs associated with packed tower aeration. Fifteen to twenty-ilve percent increase in reliablitty is realized per unit cost $(c / 1000$ gallons) for reliability levels below 908. Above the 908 reliability level, galns in reliablitity per unit cost are approximately an order of magnitude smaller.

\section{Reverse Osmosis Separation Treatment}

The Muldowney and Punzi advective flow model developed 
with sodium chloride data glves reasonable results for cadmium and lead. The model, whlch corrects for the nonldeality of the membrane's ability to refect the solute, produced results aimilar to an ldeal membrane for both pollutants. In terms of model parameters, this result means that the permeate-side distribution coefficient, $K_{2} "$, is essentially zero for cadmium and lead.

Reverse osmogis is most effective when operated at the highest pressure and flux that the membrane can withstand. Both the solute and solvent fluxes increase with increasing pressure but the solvent flux 1ncreases much more dramatically due to the perm-selective nature of the membrane. The increase in solvent flux results in a dilution effect which provides low solute concentration in the permeate.

A safety factor of 1.6 is required for 95 rellability for both cadmium and lead.

Deterministic designs are typically based on extensive pllot testing of specific wastewater-membrane configurations. Safety factors of three to five are common. A safety factor of three provides over 99 reliability for both cadmium and lead.

The distribution of the feed-side distribution parameter, $K_{2}^{\prime}$, is best fit with the log-normal distribution. 


\section{Activated sludge Treatment}

The EPA FATE model is one of several activated sludge models in the 11 terature, all based on imilar formulations. The major differences in the models are the ancillary features provided by each (e.g., databases, graphics, structural activity relationships).

The eirst order degradation rate, $k_{b}$, is log-normally distributed for phenol based on analysis of the literature data. Chloroform is not aeroblcally degradable. Henry's constant, $K_{H}$, 18 log-normally diatributed for phenol ia chloroform and the $\log$ octanol-water partition coefficient, $\log \mathrm{K}_{\mathrm{OW}}$, is normally distributed for phenol and chloroform. Over 99 of phenol, which typlcally enters a typlcal domestic waste treatment plant at a concentration less than $400 \mu \mathrm{g} / 1$, is removed by degradation for the safety factor range of 1 to 2.3 . This safety factor 1 s defined as the soluble COD effluent standard ( $5 \mathrm{mg} / \mathrm{l}$ in this research) divided by the median design soluble effluent concentration. For a safety factor increase of 1 to 2.3 , reliability increases from 50 to 708,67 to 82 and 91 to 98 for removal. ratios (influent concentration divided by effluent concentration) of $80: 1,40: 1$ and $10: 1$, respectively.

Chloroform removal in the activated sludge process increases from thirty to sixty percent for safety factors from 1 to 4.3. Since chloroform is removed primarily by stripping, the safety factor is defined as the ratio of the 
alr low rate in the aeration basin to the alr flow rate required to provide the oxygen equivalent of the COD load. Reliablitty increases from near zero to near 100 for safety factors from 1 to 4.3 at a removal ratio of $2: 1$. Reliability Increases from near zero to 60 and 20 for removal ratios of $3: 1$ and $4: 1$ for the same safety factor increase.

Conventional deterministic designo based on conservatism of a solide retention time (SRT) of twice the minimum required SRT provide a probabiligtic safety factor of 1.34 which corresponds to phenol removal reliability levels of 57 , 73 and 93 for removal ratios of $80: 1,40: 1$ and $10: 1$. Since chloroform is removed by stipping, the increase in SRT does not affect its removal and approximately 35 removal will be realized. High removal efficiency of chloroform cannot be expected with the activated sludge process.

Reliablifty increases per unit cost ( $/ 11000$ gallona) range from 6 to 23 for low rellability levels and fust 2 to 3f for high reliability levels indicating that larger increases in reliablitity for each dollar spent are realized for lower reliability ranges.

Pure oxygen aeration, used to minimize stripping of degradable volatile organic compounde (VOCs), is ineffective in removing non-degradable vOCs such as chloroform. stripping the non-degradable VOCs and treating them separately may be a more effective treatment method. 


\section{Anaerobic Treatment}

The upflow anaerobic sludge blanket (UASB) configuration is one of the most popular configurations for anaerobic treatment today based on the number of articles in the literature. Low capital and operating costs are the primary reason for its popularity.

Over $97 \%$ of the micropollutant phenol is removed from the UASB treatment of a typical pulp and paper mill wastewater by degradation for safety factor ranging from 1 to 2.3. This safety factor is defined as the soluble COD effluent standard $(250 \mathrm{mg} / 1$ in this research) divided by the median design soluble effluent concentration. For the same safety factor increase, reliability increases from 16 to $50 \%$, 38 to $73 \%$ and 90 to $98 \%$ for removal ratios of $40: 1,20: 1$ and $5: 1$, respectively.

The removal of the micropollutant 2,4-Dichlorophenol (2,4-DCP) in the UASB treatment process of typical pulp and paper wastewater ranges from four to seven percent for safety factors of 1 to 2.3. This small fraction of $2,4-D C P$ is removed by a combination of degradation and sorption with degradation predominating above a safety factor of 1.5 . Reliability levels range from 5 to $95 \%$ for the narrow range of small removal ratios of 1.05:1 to 1.01:1 indicating little uncertainty in the treatment process. These data indicate that the UASB treatment process designed to treat typical pulp and paper mill wastewater is ineffective at removing the 
micropollutant $2,4-$ DCP.

Conventional deterministic designs based on conservatism of a solids retention time (SRT) of twice the minimum required SRT provide a probabilistic safety factor of 2.0 which corresponds to phenol removal reliability levels of 45 , 71 and $99 \%$ for removal ratios of $40: 1,20: 1$ and $5: 1$. Deterministic designs provide 2,4-DCP removal reliability levels of 10,62 and $99 \%$ for removal ratios of $1.05: 1$, 1.025:1 and 1.01:1, respectively.

Treatment costs increase by $180 \%$ for the COD-based safety factor increase of 1 to 2.3 resulting in the phenol and 2,4-DCP removal reliability increases of 0.2 to $5 \%$ per unit cost ( $\% / 1000$ gallons). This small gain in reliability per unit cost indicates the large additional cost required to increase micropollutant removal.

\section{Activated Carbon Adsorption Treatment}

The Freundich adsorption constant, $K$, is poorly characterized in the literature for the benzene-Filtrasorb 400 and carbon tetrachloride-Filtrasorb 400 combinations leading to large variability of breakthrough times and low reliability of predicting breakthrough times for high influent concentrations. Safety factors of 2 to 4 are required to realize $95 \%$ reliability of predicting breakthrough time for influent and breakthrough concentrations of $50 \mu \mathrm{g} / 1$ and $5 \mu \mathrm{g} / 1$, respectively. The 
maximum reliability of predicting breakthrough time for an influent concentration of $500 \mu \mathrm{g} / 1$ is 90 and $75 \%$ for benzene and carbon tetrachloride, respectively.

The Freundich adsorption constant, $K$, is log-normally distributed and the Freundilch exponent, $1 / n$, is normally distributed for the two pollutant-carbon combinations considered.

Deterministic designs based on the adsorption capacity of regenerated carbon provide reliability levels of 62 and $73 \%$, and 46 and $48 \%$ for 500 and $50 \mu \mathrm{g} / 1$ influent concentrations for benzene and carbon tetrachloride, respectively.

Treatment costs decrease with increasing breakthrough time for a fixed column size. High influent concentrations and low Freundich adsorption constants shorten the breakthrough time and increase treatment cost. Reliability is related to the prediction of column breakthrough time. Reliability increases of 15 to $22 \%$ and 1 to $7 \%$ per unit cost (c/1000 gallons) are realized for benzene and carbon tetrachloride, respectively at low reliability levels. Reliability increases per unit cost are an order of magnitude lower for higher reliability levels. The maximum reliability of predicting breakthrough times at high influent concentrations is 95 and $70 \%$ for benzene and carbon tetrachloride, respectively.

This research makes the first strides in developing 
probablistically-based safety factors for hazardous waste treatment processes. Although fairly simplistic scenarios have been considered (e.g., steady-state, single pollutants), the results indicate that conventional deterministic designs do not always provide high reliability treatment. Much work remains to be done. The following section outlines the pathway for further research required to bring the fruits of probabilistic analysis of hazardous waste treatment processes to the engineers designing these processes.

\section{Recommendations for Further Work}

This research is the first effort to probabilistically evaluate the reliability of several hazardous waste treatment processes and additional research is required in almost every aspect of the project. Therefore, the first general recommendation for further research work is to evaluate more treatment processes and to evaluate more realistic le.g., nonsteady-state) models of the treatment processes already evaluated. Since this work is the first of its kind in hazardous waste treatment, it is primarily intended to demonstrate a practical method of developing relationships between process reliability and design conservatism. Applying this method to other treatment processes will help bring probabilistic analysis to more areas of hazardous waste treatment.

Nonsteady-state models which consider time varying 
concentrations and flows should be the next level of model complexity to be evaluated. These models will allow more realistic evaluation of the potential process upsets than steady-state models can provide. Realistic combinations of pollutants should also be evaluated to ascertain the effects on treatment process reliability in the presence of synergism or antagonism. Data will probably be lacking for many processes and pollutant combinations so that research into these areas will shed light on the basic research required to evaluate process reliability.

An extensive monitoring program of existing treatment processes to compare the results predicted with the probabilistic methods to actual field data would be valuable research. The link from theoretical models back to actual operating data cannot be overemphasized.

Monte Carlo simulation is a simple and effective method for obtaining probabilistic results. The reliability index method is an alternative method for evaluating reliability. The two methods should be compared by evaluating several hazardous waste treatment processes with both methods to elucidate the differences in the results they provide, their ease of application and their ablitty to generalize results. Lastly, an ambitious project of extensive literature reviews should be undertaken to develop probability distributions for the major physical and chemical properties of the hazardous wastes. This major effort, reminiscent of 
the work by Sax, would result in a volume of data that would prove invaluable to researchers and design engineers involved with probabilistic evaluations of hazardous waste treatment processes. 


\section{APPENDIX}

\section{Sumary Tables of Probability Distributions}

The Kolmogorov-Smirnov one-sample goodness-of-fit test has been used to determine the best fit distribution for the probabilistic parameters. The referenced literature data and summary statistics are contained in this appendix. A table of the Kolmogorov-Smirnov test statistics is also included. The abbreviations listed in the tables are defined as follows:

$\mathrm{m}=$ sample mean, $s$ = sample standard deviation, $\lambda$ = mean of the logs of the data, $\zeta=$ standard deviation of the logs of the data, $n=$ number of data points in the sample population, $D_{n}=$ Kolmogorov-Smirnov test statistic which can be compared to the table at the end of the appendix to determine the goodness of fit to the chosen distribution. 
Table 20. Packed Tower Aeration.

Henry's Constant, $K_{H}\left(a t m-m^{3} / m o l\right)$.

\begin{tabular}{|c|c|c|c|}
\hline \multicolumn{2}{|c|}{ Benzene } & \multicolumn{2}{|l|}{ Reference } \\
\hline \multicolumn{2}{|c|}{$4.6(10)^{-3}$} & \multicolumn{2}{|l|}{ Gross 1985} \\
\hline \multicolumn{2}{|c|}{$5.49(10)^{-3}$} & \multicolumn{2}{|c|}{$\begin{array}{l}\text { Mackay, Shiu and sutherland } \\
1979\end{array}$} \\
\hline \multicolumn{2}{|c|}{$5.55(10)^{-3}$} & \multicolumn{2}{|l|}{$"$} \\
\hline \multicolumn{2}{|c|}{$2.25(10)^{-3}$} & \multicolumn{2}{|l|}{$"$} \\
\hline \multicolumn{2}{|c|}{$1.34(10)^{\cdot 3}$} & \multicolumn{2}{|l|}{ Clark and Adams 1991} \\
\hline \multicolumn{2}{|c|}{$2.37(10)^{-3}$} & \multicolumn{2}{|l|}{$"$} \\
\hline \multicolumn{2}{|c|}{$7.48(10)^{-3}$} & \multicolumn{2}{|l|}{ Yurter1 et al. 1987} \\
\hline \multicolumn{2}{|c|}{$5.46(10)^{-3}$} & \multicolumn{2}{|l|}{$"$} \\
\hline \multicolumn{2}{|c|}{$4.42(10)^{-3}$} & \multicolumn{2}{|l|}{$"$} \\
\hline \multicolumn{2}{|c|}{$5.51(10)^{-3}$} & \multicolumn{2}{|l|}{ Mackay and Shiu 1981} \\
\hline \multicolumn{2}{|c|}{$4.46(10)^{\cdot 3}$} & \multicolumn{2}{|l|}{ Cummins $1985 a$} \\
\hline \multicolumn{2}{|c|}{$5.80(10)^{-3}$} & \multicolumn{2}{|l|}{ Howe et al. 1987} \\
\hline \multicolumn{2}{|c|}{$5.28(10)^{-3}$} & \multicolumn{2}{|l|}{$"$} \\
\hline \multicolumn{2}{|c|}{$5.42(10)^{-3}$} & \multicolumn{2}{|l|}{$"$} \\
\hline \multicolumn{2}{|c|}{$5.47(10)^{-3}$} & \multicolumn{2}{|l|}{$"$} \\
\hline \multicolumn{2}{|c|}{$5.45(10)^{-3}$} & \multicolumn{2}{|l|}{ " } \\
\hline Normal & $m=4.772(10)^{\circ}$ & $s=1.556(10)^{-3}$ & $D_{16}=0.192$ \\
\hline $\begin{array}{l}\text { Log- } \\
\text { normal }\end{array}$ & $\lambda=-5.419$ & $\zeta=0.4454$ & $D_{16}=0.248$ \\
\hline
\end{tabular}


Table 1. (Cont.) Packed Tower Aeration. Henry's Constant, $\mathrm{K}_{\mathrm{H}}\left(\mathrm{atm}-\mathrm{m}^{-3} / \mathrm{mol}\right)$.

\begin{tabular}{|c|c|}
\hline Trichloroethylene & Reference \\
\hline $1.52(10)^{-2}$ & Roberts et al. 1985 \\
\hline $1.22(10)^{-2}$ & $\begin{array}{l}\text { Speece, N1rmalakhandan } \\
\text { and Lee } 1987\end{array}$ \\
\hline $1.0(10)^{-2}$ & Gross 1985 \\
\hline $0.86(10)^{-2}$ & $"$ \\
\hline $0.29(10)^{-2}$ & Ball and Edwards 1992 \\
\hline $1.05(10)^{-2}$ & Yurteri et al. 1987 \\
\hline $0.97(10)^{-2}$ & $"$ \\
\hline $0.73(10)^{-2}$ & $"$ \\
\hline $1.02(10)^{-2}$ & " \\
\hline $0.99(10)^{-2}$ & " \\
\hline $1.00(10)^{\cdot 2}$ & $"$ \\
\hline $0.80(10)^{-2}$ & $"$ \\
\hline $0.93(10)^{-2}$ & $"$ \\
\hline $0.91(10)^{-2}$ & $\begin{array}{l}\text { Govind, Lai and Dobbs } \\
1991\end{array}$ \\
\hline $1.17(10)^{-2}$ & MacKay and ShIu 1981 \\
\hline $1.29(10)^{-2}$ & $"$ \\
\hline $0.93(10)^{-2}$ & $"$ \\
\hline $0.89(10)^{\cdot 2}$ & $"$ \\
\hline $0.29(10)^{-2}$ & Cummins 1982a \\
\hline $0.28(10)^{-2}$ & Clark and Adams 1991 \\
\hline $0.26(10)^{-2}$ & $"$ \\
\hline $1.03(10)^{-2}$ & Howe et al. 1987 \\
\hline $0.32(10)^{-2}$ & Cummins 1982d \\
\hline $0.44(10)^{\cdot 2}$ & $\begin{array}{l}\text { Kavanaugh and Trussel } \\
1980\end{array}$ \\
\hline
\end{tabular}


Table 20. (Cont.) Packed Tower Aeration. Henry's Constant, $\mathrm{K}_{H}\left(\mathrm{~atm}-\mathrm{m}^{3} / \mathrm{mol}\right)$.

\begin{tabular}{|c|c|c|c|c|}
\hline \multicolumn{3}{|c|}{ Trichloroethylene (cont.) } & \multicolumn{2}{|l|}{ Reference } \\
\hline \multicolumn{3}{|c|}{$0.22(10)^{\cdot 2}$} & \multicolumn{2}{|c|}{ Cummins $1982 \mathrm{~g}$} \\
\hline \multicolumn{3}{|c|}{$0.27(10)^{-2}$} & \multicolumn{2}{|l|}{$"$} \\
\hline \multicolumn{3}{|c|}{$0.31(10)^{-2}$} & \multicolumn{2}{|l|}{ Cummins $1982 \mathrm{C}$} \\
\hline \multicolumn{3}{|c|}{$0.18(10)^{-2}$} & \multicolumn{2}{|l|}{ Cummins $1982 \mathrm{e}$} \\
\hline \multicolumn{3}{|c|}{$0.34(10)^{-2}$} & \multicolumn{2}{|c|}{$"$} \\
\hline \multicolumn{3}{|c|}{$0.42(10)^{-2}$} & \multicolumn{2}{|l|}{ Cummins 19821} \\
\hline Normal & $m=7.310(10)^{.3}$ & & $=3.869(10)^{-3}$ & $D_{30}=0.177$ \\
\hline $\begin{array}{l}\text { Log - } \\
\text { normal }\end{array}$ & $\lambda=-5.094$ & & $=0.6445$ & $D_{30}=0.200$ \\
\hline
\end{tabular}


Table 21. Packed Tower Aeration. Gas Diffusivity, $D_{0}\left(\mathrm{~cm}^{2} / \mathrm{sec}\right)$.

\begin{tabular}{|c|c|c|c|}
\hline \multicolumn{2}{|c|}{ Benzene } & \multicolumn{2}{|l|}{ Reference } \\
\hline \multicolumn{2}{|c|}{$9.2(10)^{.2}$} & \multicolumn{2}{|l|}{ Cummins $1985 \mathrm{a}$} \\
\hline \multicolumn{2}{|c|}{$10.0(10)^{-2}$} & \multicolumn{2}{|c|}{ Ball and Edwards 1992} \\
\hline \multicolumn{2}{|c|}{$6.8(10)^{-2}$} & \multicolumn{2}{|l|}{ Treybal 1980} \\
\hline Normal & $q=8.667(10)^{\circ}$ & $\xi=1.665(10)^{\circ}$ & $D_{3}=0.212$ \\
\hline $\begin{array}{l}\text { Log - } \\
\text { normal }\end{array}$ & $\lambda=-2.459$ & $\zeta=0.2029$ & $D_{3}=0.221$ \\
\hline
\end{tabular}

\begin{tabular}{|c|c|c|c|}
\hline \multicolumn{2}{|c|}{ Trichloroethylene } & \multicolumn{2}{|l|}{ Reference } \\
\hline \multicolumn{2}{|c|}{$9.3(10)^{.2}$} & \multicolumn{2}{|c|}{ Ball and Edward 1992} \\
\hline \multicolumn{2}{|c|}{$8.0(10)^{-2}$} & \multicolumn{2}{|l|}{ Cummins 1985d } \\
\hline \multicolumn{2}{|c|}{$7.7(10)^{-2}$} & \multicolumn{2}{|c|}{ Roberts et al. 1985} \\
\hline \multicolumn{2}{|c|}{$6.1(10)^{\cdot 2}$} & \multicolumn{2}{|l|}{ Treybal 1980} \\
\hline Normal & $m=7.775(10)^{-2}$ & $=1.315(10)^{-2}$ & $D_{4}=0.182$ \\
\hline $\begin{array}{l}\text { Log - } \\
\text { normal }\end{array}$ & $\lambda=-2565$ & $=0.1745$ & $D_{4}=0.160$ \\
\hline
\end{tabular}


Table 22. Packed Tower Aeration. Liquid Diffusivity, $D_{L}\left(\mathrm{~cm}^{2} / \mathrm{sec}\right)$.

\begin{tabular}{|c|c|c|c|c|}
\hline \multicolumn{3}{|c|}{ Benzene } & \multicolumn{2}{|l|}{ Reference } \\
\hline \multicolumn{3}{|c|}{$8.8(10)^{.6}$} & \multicolumn{2}{|l|}{ Cummins 1985a } \\
\hline \multicolumn{3}{|c|}{$7.0(10)^{-6}$} & \multicolumn{2}{|c|}{ Ball and Edwards 1992} \\
\hline \multicolumn{3}{|c|}{$11.0(10)^{.6}$} & \multicolumn{2}{|l|}{ Treybal 1980} \\
\hline \multicolumn{3}{|c|}{$10.3(10)^{.6}$} & \multicolumn{2}{|c|}{ Crittenden et al. 1987} \\
\hline Normal & $m=9.275(10)^{-6}$ & & $=1.773(10)^{.6}$ & $D_{4}=0.165$ \\
\hline $\begin{array}{l}\text { Log - } \\
\text { normal }\end{array}$ & $\lambda=-11.60$ & & $=0.2010$ & $D_{4}=0.178$ \\
\hline
\end{tabular}

\begin{tabular}{|c|c|c|c|}
\hline \multicolumn{2}{|c|}{ Trichloroethylene } & \multicolumn{2}{|l|}{ Reference } \\
\hline \multicolumn{2}{|c|}{$6.8(10)^{-6}$} & \multicolumn{2}{|c|}{ Bal.1 and Edwards 1992} \\
\hline \multicolumn{2}{|c|}{$7.0(10)^{.6}$} & \multicolumn{2}{|l|}{ Cummins $1985 \mathrm{C}$} \\
\hline \multicolumn{2}{|c|}{$10.2(10)^{.6}$} & \multicolumn{2}{|l|}{ Treybal 1980} \\
\hline \multicolumn{2}{|c|}{$9.6(10)^{.6}$} & \multicolumn{2}{|c|}{ Crittenden et al. 1987} \\
\hline Normal & $m=8.400(10)^{-6}$ & $s=1.751(10)^{.6}$ & $D_{4}=0.288$ \\
\hline $\begin{array}{l}\text { Log- } \\
\text { normal }\end{array}$ & $\lambda=-11.70$ & $\zeta=0.2100$ & $D_{4}=0.285$ \\
\hline
\end{tabular}


Table 23. Reverse Osmosis Separation. Cellulose Acetate Membranes.

\begin{tabular}{|l|l|}
\hline $\begin{array}{l}\text { Membrans Activity Layer } \\
\text { Thickness, } \lambda(, \mathrm{m})\end{array}$ & Reference \\
\hline \hline $0.25-0.50$ & Muldowney and Punzi 1988 \\
\hline
\end{tabular}

\begin{tabular}{|l|l|}
\hline $\begin{array}{l}\text { Membrane Activity Layer } \\
\text { Porosity, } \epsilon(\%)\end{array}$ & Reference \\
\hline $2.9-5.2$ & Muldowney and Punzi 1988 \\
\hline
\end{tabular}

\begin{tabular}{||l|l|}
\hline $\begin{array}{l}\text { Membrane Activity Layer } \\
\text { Pore Tortuosity, } \tau \text { (dim) }\end{array}$ & Reference \\
\hline $2-3$ & Muldowney and Punzi 1988 \\
\hline
\end{tabular}


Table 24. Activated Sludge/Anaerobic Treatment. Henry's Constant, $\mathrm{K}_{\mathrm{H}}\left(\mathrm{atm}-\mathrm{m}^{3} / \mathrm{mol}\right)$.

\begin{tabular}{|c|c|c|c|}
\hline \multicolumn{2}{|l|}{ Phenol } & \multicolumn{2}{|l|}{ Reference } \\
\hline \multicolumn{2}{|l|}{$4.54(10)^{-5}$} & \multicolumn{2}{|c|}{ Govind, Lai and Dobbs 1991} \\
\hline \multicolumn{2}{|l|}{$2.7(10)^{-5}$} & \multicolumn{2}{|l|}{ NCASI 1986} \\
\hline \multicolumn{2}{|l|}{$3.97(10)^{-7}$} & \multicolumn{2}{|l|}{ Howard 1989} \\
\hline \multicolumn{2}{|l|}{$2.7(10)^{-7}$} & \multicolumn{2}{|c|}{$\begin{array}{l}\text { Dietrich, Treichler and } \\
\text { Armstrong } 1987\end{array}$} \\
\hline \multicolumn{2}{|l|}{$1.3(10)^{-6}$} & \multicolumn{2}{|c|}{$\begin{array}{l}\text { Convery, Cohen, and Bishop } \\
1980\end{array}$} \\
\hline Normal & $m=1.49(10)^{-5}$ & $s=2.05(10)^{-5}$ & $D_{5}=0.345$ \\
\hline Log - normal & $\lambda=-5.55$ & $\zeta=1.04$ & $D_{5}=0.226$ \\
\hline
\end{tabular}

\begin{tabular}{|c|c|c|c|}
\hline \multicolumn{2}{|c|}{ 2,4-Dichlorophenol } & \multicolumn{2}{|l|}{ Reference } \\
\hline \multicolumn{2}{|l|}{$2.8(10)^{-6}$} & \multicolumn{2}{|c|}{ Mabey et al. 1982} \\
\hline \multicolumn{2}{|l|}{$4.1(10)^{.5}$} & \multicolumn{2}{|c|}{$\begin{array}{l}\text { Buisson, Kirk and Lester } \\
1988\end{array}$} \\
\hline \multicolumn{2}{|l|}{$4.2(10)^{-5}$} & \multicolumn{2}{|c|}{ Kincannon et al. $1983 \mathrm{~b}$} \\
\hline \multicolumn{2}{|l|}{$4.2(10)^{-5}$} & \multicolumn{2}{|c|}{ Nyholm et al. 1992} \\
\hline \multicolumn{2}{|l|}{$2.8(10)^{-6}$} & \multicolumn{2}{|c|}{$\begin{array}{l}\text { Govind, Lai and Dobbs } \\
1991\end{array}$} \\
\hline Normal & $m=2.61(10)^{-5}$ & $s=2.13(10)^{-5}$ & $D_{5}=0.263$ \\
\hline Log - normal & $\lambda=4.85$ & $\zeta=0.642$ & $D_{5}=0.263$ \\
\hline
\end{tabular}


Table 24. (Cont.) Activated Sludge/Anaerobic Treatment. Henry's Constant, $K_{H}\left(a t m-m^{3} / m o l\right)$.

\begin{tabular}{|c|c|c|c|}
\hline \multicolumn{2}{|l|}{ Chloroform } & \multicolumn{2}{|l|}{ Reference } \\
\hline \multicolumn{2}{|l|}{$3.39(10)^{-3}$} & \multicolumn{2}{|c|}{$\begin{array}{l}\text { Convery, Cohen and Bishop } \\
1980\end{array}$} \\
\hline \multicolumn{2}{|l|}{$5.30(10)^{-3}$} & \multicolumn{2}{|l|}{ NACSI 1986} \\
\hline \multicolumn{2}{|l|}{$3.80(10)^{-3}$} & \multicolumn{2}{|c|}{ Cummins and Westrick 1990} \\
\hline \multicolumn{2}{|l|}{$3.06(10)^{-3}$} & \multicolumn{2}{|c|}{$\begin{array}{l}\text { Speece, Nirmalakhandan and } \\
\text { Lee } 1987\end{array}$} \\
\hline \multicolumn{2}{|l|}{$5.29(10)^{-3}$} & \multicolumn{2}{|c|}{ Roberts et al. 1985} \\
\hline \multicolumn{2}{|l|}{$1.44(10)^{-3}$} & \multicolumn{2}{|c|}{ Bell et al. 1991} \\
\hline \multicolumn{2}{|l|}{$2.65(10)^{-3}$} & \multicolumn{2}{|l|}{$"$} \\
\hline \multicolumn{2}{|l|}{$3.4(10)^{-3}$} & \multicolumn{2}{|l|}{ Gross 1985} \\
\hline Normal & $m=3.54(10)^{-3}$ & $s=1.29(10)^{-3}$ & $D_{8}=.171$ \\
\hline Log - normal & $\lambda=-5.71$ & $\zeta=0.416$ & $D_{8}=.128$ \\
\hline
\end{tabular}


Table 25. Activated Sludge/Anaerobic Treatment. Log Octanol - Water Partition Coefficient, $\log \mathrm{K}_{\text {ow }}(\mathrm{d} I \mathrm{~m})$.

\begin{tabular}{|c|c|}
\hline Phenol & Reference \\
\hline 1.49 & EPA 1985 \\
\hline 1.46 & Stover et al. 1983 \\
\hline 1.47 & Govind, La1 and Dobbs 1991 \\
\hline 1.49 & Bodor et al. 1989 \\
\hline 1.36 & $"$ \\
\hline 1.46 & $"$ \\
\hline 1.47 & $"$ \\
\hline 2.3 & Maithot and Peters 1988 \\
\hline 2.6 & $"$ \\
\hline 1.18 & Schmidt-Bleek et al. 1982 \\
\hline 1.46 & Isnard and Lambert 1988 \\
\hline 1.45 & Miller et al. 1985 \\
\hline 1.46 & Banerjee et al. 1980 \\
\hline 2.2 & Briggs 1981 \\
\hline 1.04 & $\begin{array}{l}\text { Yalkowsky, Valvani and } \\
\text { Mackay } 1983\end{array}$ \\
\hline 1.29 & Anliker and Moser 1987 \\
\hline 0.70 & $\begin{array}{l}\text { Chiou, schmedding and } \\
\text { Manes } 1982\end{array}$ \\
\hline 0.72 & Terwarl et al. 1982 \\
\hline Normal & $s=0.4836$ \\
\hline
\end{tabular}


Table 25. (Cont.) Activated Sludge/Anaerobic Treatment. Log Octanol-Water Partition Coefficient, $\log K_{\text {ow }}(\mathrm{d} I \mathrm{~m})$.

\begin{tabular}{|c|c|}
\hline 2,4 - Dichlorophenol & Reference \\
\hline 2.75 & Callahan et al. 1977 \\
\hline 3.08 & $\begin{array}{l}\text { Buisson, Kirk and Lester } \\
1988\end{array}$ \\
\hline 3.23 & Leuenberger et al. 1985 \\
\hline 2.90 & Govind, Lai and Dobbs 1991 \\
\hline 3.06 & Banerjee et al. 1984 \\
\hline 3.07 & $"$ \\
\hline 2.75 & Westall 1985 \\
\hline 3.17 & N1iml 1991 \\
\hline$m=3.001$ & $D_{8}=0.39$ \\
\hline
\end{tabular}

\begin{tabular}{|c|c|c|}
\hline Chloroform & & Reference \\
\hline 1.97 & & Leo, Hansch and Elkins 1971 \\
\hline 1.96 & & Govind, Lal and Dobbs 1991 \\
\hline 1.97 & & NCASI 1986 \\
\hline 1.97 & & Dobbs, Wang and Govind 1989 \\
\hline Normal & $m=1.96$ & $s=0.005$ \\
\hline
\end{tabular}


Table 26. Anaeroblc Treatment.

First Order Degradation Rate, $k_{b}$ ( $1 / \mathrm{mg}$-day).

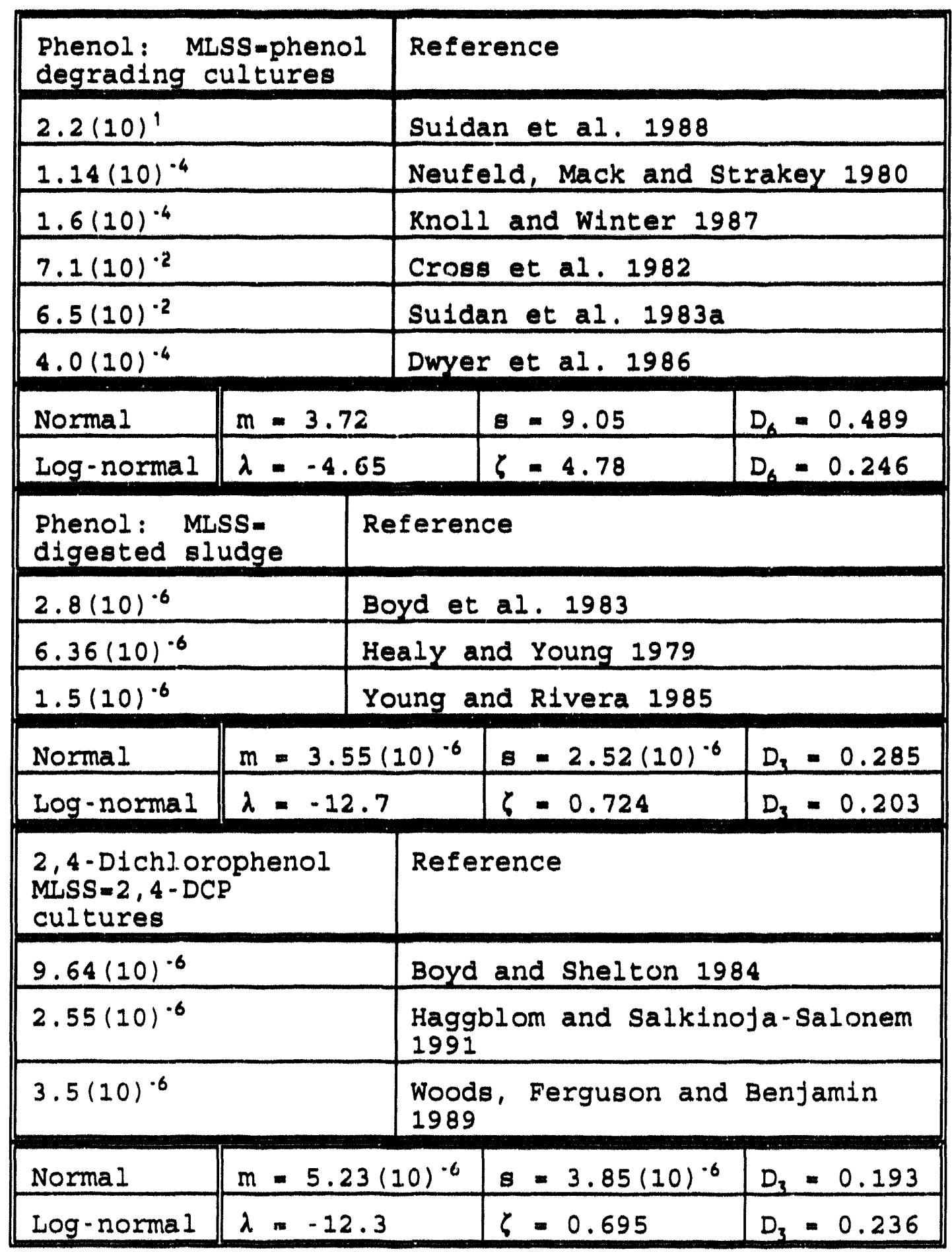


Table 27. Activated sludge Treatment. First Order Degradation Rate, $k_{h}$ ( $1 / \mathrm{mg}$-day).

\begin{tabular}{|c|c|}
\hline Phenol & Reference \\
\hline 6.71 & Yang and Humphrey 1975 \\
\hline 5.72 & $"$ \\
\hline 0.913 & Palowsky and Howell 1973 \\
\hline 0.246 & $"$ \\
\hline 0.130 & Rozich, Gaudy and D'Adamo 1983 \\
\hline 0.0967 & $" 1$ \\
\hline 0.103 & Rozlch and Gaudy 1983 \\
\hline 0.0970 & $" \quad "$ \\
\hline 0.124 & " \\
\hline 0.0701 & " \\
\hline 0.706 & Borlghem and Vereenken 1981 \\
\hline 0.742 & $n$ \\
\hline 0.674 & Howell, Chl and Palowsky 1972 \\
\hline 0.408 & Szetela and Winnicki 1981 \\
\hline 0.0167 & Beltrame et al. $1980 \mathrm{~b}$ \\
\hline 0.254 & Graham 1969 \\
\hline 0.117 & $"$ \\
\hline 0.0337 & $"$ \\
\hline 0.0301 & $"$ \\
\hline 0.204 & $"$ \\
\hline 1.49 & ChI and Howell 1976 \\
\hline 28.0 & Tatsuo et al. 1973 \\
\hline 4.11 & $"$ \\
\hline 0.0925 & Rozlch, Gaudy and D'Adamo 1983 \\
\hline
\end{tabular}


Table 4. (Cont.) Activate sludge Treatment. Firat-Order Degradation Rate, $K_{b}$ ( $1 / \mathrm{mg}$-day).

\begin{tabular}{|c|c|c|}
\hline \multicolumn{2}{|l|}{ Phenol } & Reference \\
\hline 0.107 & & Rozich, Gaudy and D'Adamo 1983 \\
\hline 0.316 & & Palowgky and Howell 1973 \\
\hline 0.191 & & $"$ \\
\hline 0.00754 & & Beltrame et al. $1980 \mathrm{~b}$ \\
\hline 0.0504 & & $\begin{array}{l}\text { Beltrame, Beltrame and Carnit } 1 \\
1984\end{array}$ \\
\hline 1.88 & & Arvin et al. 1990 \\
\hline 1.01 & & Desa1, Govind and Tabak $199 \mathrm{C}$ \\
\hline 0.289 & & $\begin{array}{l}\text { Lewandowsk1, Baltzis and } \\
\text { Varuntanya } 1986\end{array}$ \\
\hline 0.227 & & $"$ \\
\hline 0.255 & & $"$ \\
\hline 0.0137 & & Beltrame et al. 1979 \\
\hline 3.00 & & Govind, Lal and Dobbs 1991 \\
\hline 0.00562 & & Govind, La1 and Dobbs 1991 \\
\hline 0.910 & & stover et al. 1983 \\
\hline Normal & $m=1.562$ & $D_{38}=0.364$ \\
\hline Log - normal & $\lambda=-1.360$ & $D_{38}=0.088$ \\
\hline
\end{tabular}


Table 27. (Cont.) Activated sludge Treatment. First-Order Degradation Rate, $K_{b}$ ( $1 / \mathrm{mg}$-day).

\begin{tabular}{|c|c|c|}
\hline \multicolumn{2}{|l|}{ 2,4-D1chlorophenol } & Reference \\
\hline 2.4 & Gov1: & nd, Lai and Dobbs 1991 \\
\hline 0.336 & $"$ & $"$ \\
\hline 0.211 & Hann & an et al. 1986 \\
\hline 0.0098 & Hann & ah et al. 1988 \\
\hline 0.378 & KInce & innon et al. $1983 \mathrm{~b}$ \\
\hline 0.019 & KInce & annon et al. $1983 \mathrm{a}$ \\
\hline 0.011 & 4 & $"$ \\
\hline 0.007 & $"$ & $"$ \\
\hline 3.44 & Chude & oba et al. 1989 \\
\hline 0.0026 & Bu1s & son, K1rk and Lester 1988 \\
\hline 0.0029 & $"$ & $"$ \\
\hline 0.00091 & $n$ & $"$ \\
\hline 0.0171 & Belt: & came et al. 1982 \\
\hline 0.0194 & Belt: & came et al. $1980 \mathrm{a}$ \\
\hline 0.0050 & Pitte & 1976 \\
\hline Norma 1 & $m-0.457$ & $D_{15}=0.399$ \\
\hline Log - normal & $\lambda=-3.445$ & $D_{15}=0.247$ \\
\hline
\end{tabular}

Chloroform - not degradable aeroblcally 
Table 28. Activated Carbon Adsorption. Filtrasorb 400 parameters.

\begin{tabular}{|l|l|}
\hline Carbon Particle Radius, $r(\mathrm{~mm})$ & Reference \\
\hline $0.45-0.55$ & Calgon 1976 \\
\hline
\end{tabular}

\begin{tabular}{|l|l|}
\hline Bed Porosity, $(\mathrm{d} 1 \mathrm{~m})$ & Reference \\
\hline $0.57-0.61$ & Calgon 1976 \\
\hline
\end{tabular}

\begin{tabular}{||l|l|}
\hline Spherlcity, $\phi(\mathrm{dim})$ & Reference \\
\hline $0.80-1.00$ & Falr, Geyer and Okum 1971 \\
\hline
\end{tabular}


Table 29. Activated Carbon Adsorption. Freundlich Adsorption Constant, $\mathrm{K}\left(\mu \mathrm{mol} / \mathrm{g}(1 / \mu \mathrm{mol})^{1 / \mathrm{n}}\right)$

\begin{tabular}{|c|c|}
\hline Benzene - F400 & Reference \\
\hline 164.6 & Clark and Adame 1991a \\
\hline 82.7 & Crittenden et al. 1987 \\
\hline 78.5 & Weber and Pazar1 1981 \\
\hline 135.5 & E1-Dib and Badeway 1979 \\
\hline 116.0 & Samaneh 1981 \\
\hline 134.0 & $"$ \\
\hline 158.4 & $"$ \\
\hline 100.8 & $"$ \\
\hline 77.1 & $"$ \\
\hline$m=116.5$ & $D_{9}=0.174$ \\
\hline Log-Norma1 $\lambda=4.719$ & $\zeta \cdot 0.2976$ \\
\hline
\end{tabular}

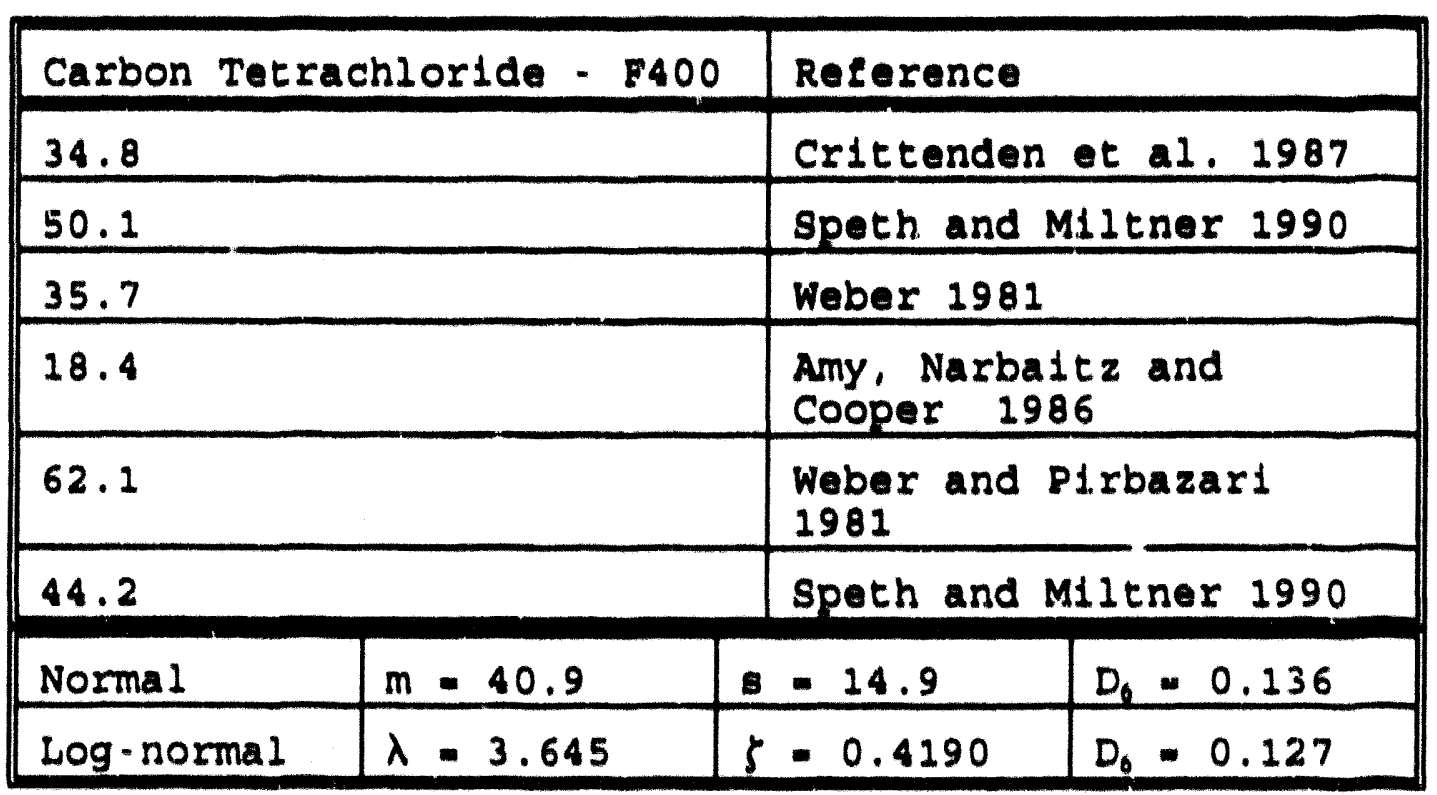


Table 30. Activated Carbon Adsorption. Freundl1ch Adsorption Exponent, $(1 / n)$ (dim).

\begin{tabular}{|c|c|c|}
\hline Benzene - & 100 & Reference \\
\hline 0.39 & & Weber and P1rbazar1 1981 \\
\hline 0.533 & & Speth and Miltner 1990 \\
\hline 0.48 & & E1-D1b and Badaway 1979 \\
\hline 0.398 & & Crittenden et al. 1987 \\
\hline 0.61 & & Samaneh 1981 \\
\hline 0.53 & & $n$ \\
\hline 0.46 & & $n$ \\
\hline 0.44 & & $"$ \\
\hline 0.55 & & $"$ \\
\hline Norma 1 & $m=0.4879$ & $B=0.0736$ \\
\hline Log-normal & $\lambda=-0.7278$ & $\zeta=0.1517$ \\
\hline
\end{tabular}

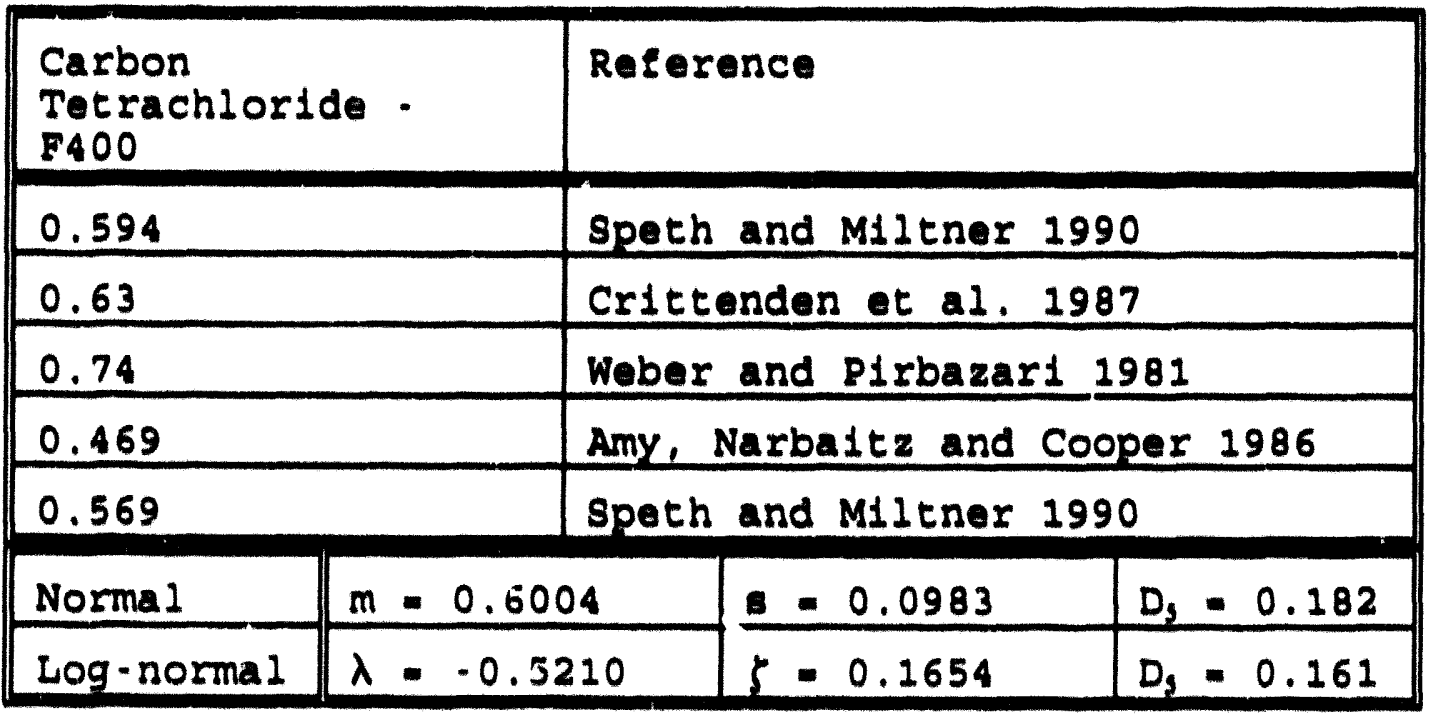


Table 31. Act1vated Carbon Adsorption. Surface Diffusion Coefficient, $D_{s}\left(\mathrm{~cm}^{2} / \mathrm{sec}\right)$.

\begin{tabular}{|c|c|c|c|}
\hline \multicolumn{2}{|c|}{ Benzene - $\$ 400$} & \multicolumn{2}{|l|}{ Reference } \\
\hline \multicolumn{2}{|c|}{$1.30(10)^{\circ}$} & \multicolumn{2}{|c|}{ Weber and P1rbazar1 1981} \\
\hline \multicolumn{2}{|c|}{$1.37(10)^{\circ}$} & \multicolumn{2}{|c|}{$n$} \\
\hline \multicolumn{2}{|c|}{$1.30(10)^{\circ}$} & \multicolumn{2}{|c|}{ Crittenden et al. 1987} \\
\hline \multicolumn{2}{|c|}{$2.63(10) \cdot 10$} & \multicolumn{2}{|l|}{$"$} \\
\hline \multicolumn{2}{|c|}{$9.65(10)^{\cdot 10}$} & \multicolumn{2}{|l|}{$"$} \\
\hline \multicolumn{2}{|c|}{$3.0(10) \cdot 10$} & \multicolumn{2}{|c|}{ Weber and P1rbazar1 1983} \\
\hline \multicolumn{2}{|c|}{$1.9(10) \cdot 10$} & \multicolumn{2}{|c|}{$"$} \\
\hline Normal & $m=7.14(10) \cdot 10$ & $8.5 .75(10)^{.10}$ & $D_{7}=0.279$ \\
\hline $\begin{array}{l}\text { Log- } \\
\text { normal }\end{array}$ & $\lambda=-21.64$ & $\zeta=1.457$ & $D_{7}=0.184$ \\
\hline
\end{tabular}

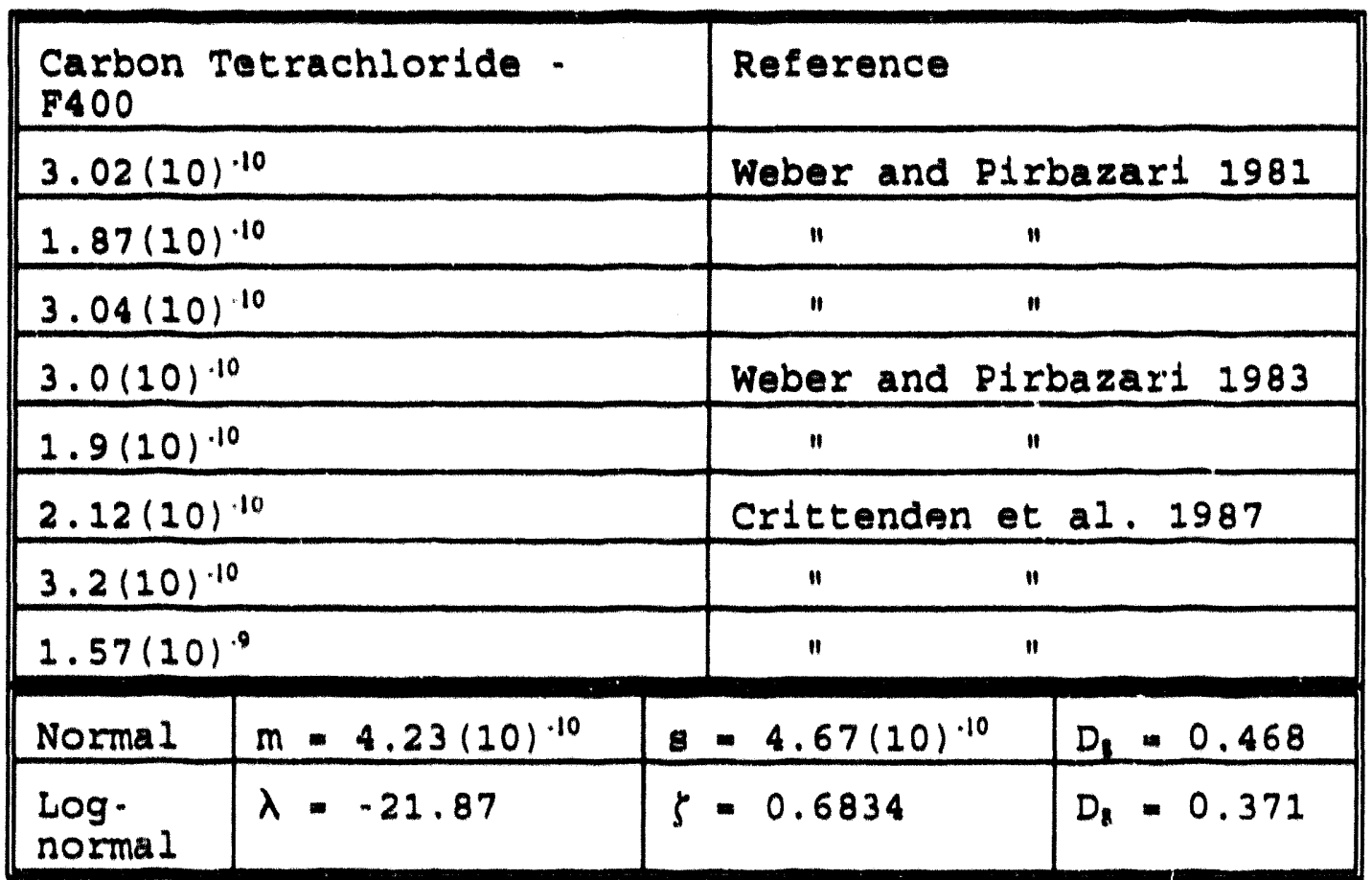


Table 32. Act1vated Carbon Adrorption.

Film Diffusion Coefficient, $K_{f}(\mathrm{~cm} / \mathrm{sec})$.

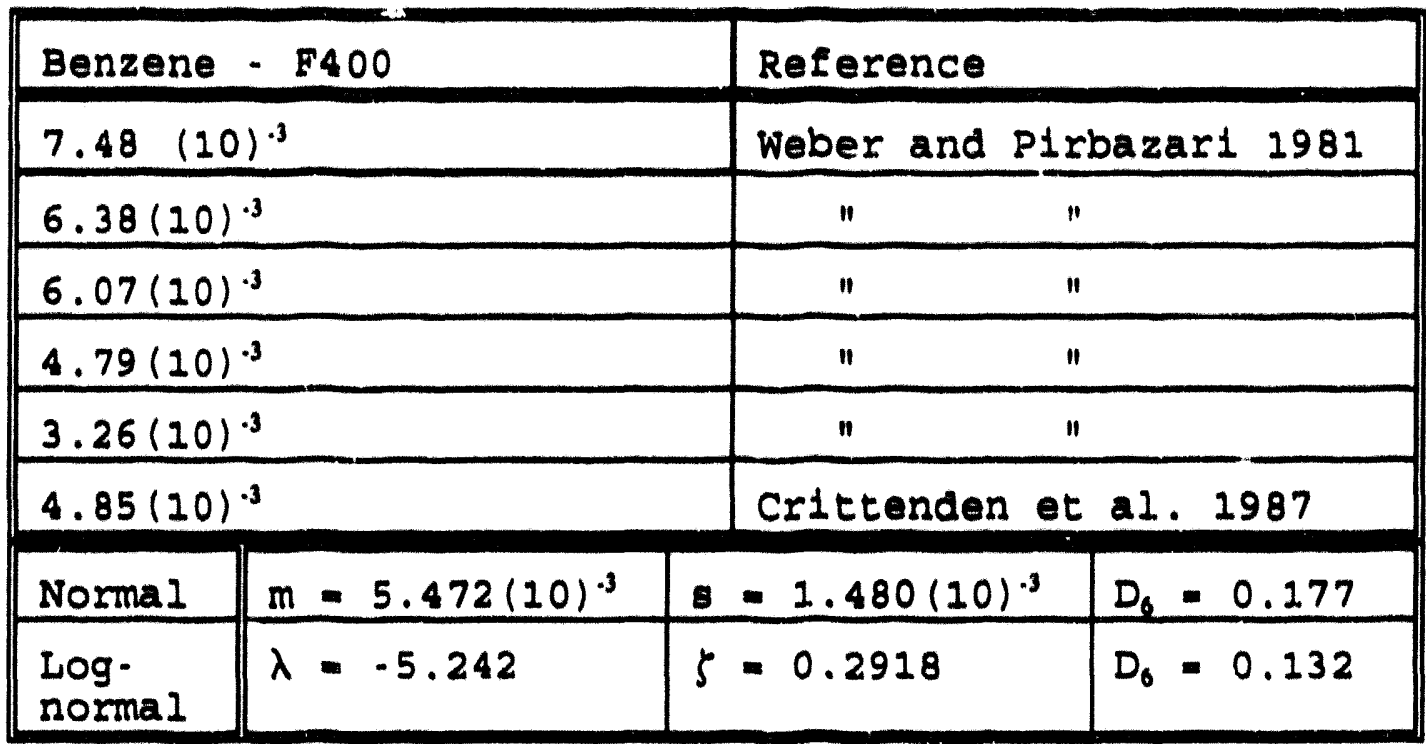

\begin{tabular}{|c|c|c|c|c|}
\hline \multicolumn{3}{|c|}{$\begin{array}{l}\text { Carbon Tetrachloride - } \\
\text { F } 400\end{array}$} & \multicolumn{2}{|l|}{ Reference } \\
\hline \multicolumn{3}{|c|}{$4.07(10)^{.3}$} & \multicolumn{2}{|c|}{ Weber and P1rbazar1 1981} \\
\hline \multicolumn{3}{|c|}{$3.78(10)^{.3}$} & \multicolumn{2}{|c|}{ " } \\
\hline \multicolumn{3}{|c|}{$5.50(10)^{-3}$} & \multicolumn{2}{|r|}{ " } \\
\hline \multicolumn{3}{|c|}{$2.97(10)^{.3}$} & \multicolumn{2}{|r|}{ " } \\
\hline \multicolumn{3}{|c|}{$3.41(10)^{.3}$} & \multicolumn{2}{|l|}{ " } \\
\hline \multicolumn{3}{|c|}{$4.1(10)^{.3}$} & \multicolumn{2}{|l|}{ Weber 1986} \\
\hline \multicolumn{3}{|c|}{$3.8(10)^{.3}$} & \multicolumn{2}{|c|}{$"$} \\
\hline \multicolumn{3}{|c|}{$5.5(10)^{.3}$} & \multicolumn{2}{|c|}{$"$} \\
\hline \multicolumn{3}{|c|}{$3.0(10)^{-3}$} & \multicolumn{2}{|c|}{$"$} \\
\hline \multicolumn{3}{|c|}{$3.4(10)^{-3}$} & \multicolumn{2}{|c|}{$"$} \\
\hline \multicolumn{3}{|c|}{$4.82(10)^{.3}$} & \multicolumn{2}{|c|}{ Crittenden et al. 1987} \\
\hline Normal & $m=4.032(10)^{.3}$ & & $=8.96(10)^{4}$ & $D_{11}=0.195$ \\
\hline $\begin{array}{l}\text { Log - } \\
\text { normal }\end{array}$ & $\lambda=-5.535$ & & $=0.2158$ & $D_{11}=r .154$ \\
\hline
\end{tabular}


Table 33. Kolmogorov-Smirnov Test statistics.

\begin{tabular}{|c|c|c|c|c|c|}
\hline \multirow{2}{*}{$\begin{array}{c}\text { Sample } \\
\text { size } \\
(N)\end{array}$} & \multicolumn{5}{|c|}{ Level of significance for $D=\operatorname{maximum}\left|F_{0}(X)-S_{F}(X)\right|$} \\
\hline & .20 & .15 & .10 & .05 & .01 \\
\hline $\begin{array}{l}1 \\
2 \\
3 \\
4 \\
5\end{array}$ & $\begin{array}{l}.900 \\
.684 \\
.565 \\
.494 \\
.446\end{array}$ & $\begin{array}{l}.925 \\
.726 \\
.597 \\
.525 \\
.474\end{array}$ & $\begin{array}{l}.950 \\
.776 \\
.642 \\
.564 \\
.510\end{array}$ & $\begin{array}{l}.975 \\
.842 \\
.708 \\
.624 \\
.565\end{array}$ & $\begin{array}{l}.995 \\
.929 \\
.828 \\
.733 \\
.669\end{array}$ \\
\hline $\begin{array}{r}6 \\
7 \\
8 \\
9 \\
10\end{array}$ & $\begin{array}{l}.410 \\
.381 \\
.358 \\
.339 \\
.322\end{array}$ & $\begin{array}{l}.436 \\
.405 \\
.381 \\
.360 \\
.342\end{array}$ & $\begin{array}{l}.470 \\
.438 \\
.411 \\
.388 \\
.368\end{array}$ & $\begin{array}{l}.521 \\
.486 \\
.457 \\
.432 \\
.410\end{array}$ & $\begin{array}{l}.618 \\
.577 \\
.543 \\
.514 \\
.490\end{array}$ \\
\hline $\begin{array}{l}11 \\
12 \\
13 \\
14 \\
15\end{array}$ & $\begin{array}{l}.307 \\
.295 \\
.284 \\
.274 \\
.266\end{array}$ & $\begin{array}{l}.326 \\
.313 \\
.302 \\
.292 \\
.283\end{array}$ & $\begin{array}{l}.352 \\
.338 \\
.325 \\
.314 \\
.304\end{array}$ & $\begin{array}{l}.391 \\
.375 \\
.361 \\
.349 \\
.338\end{array}$ & $\begin{array}{l}.468 \\
.450 \\
.433 \\
.418 \\
.404\end{array}$ \\
\hline $\begin{array}{l}16 \\
17 \\
18 \\
19 \\
20\end{array}$ & $\begin{array}{l}.258 \\
.250 \\
.244 \\
.237 \\
.231\end{array}$ & $\begin{array}{l}.274 \\
.266 \\
.259 \\
.252 \\
.246\end{array}$ & $\begin{array}{l}.295 \\
.286 \\
.278 \\
.272 \\
.264\end{array}$ & $\begin{array}{l}.328 \\
.318 \\
.309 \\
.301 \\
.294\end{array}$ & $\begin{array}{l}.392 \\
.381 \\
.371 \\
.363 \\
.356\end{array}$ \\
\hline $\begin{array}{l}25 \\
30 \\
35\end{array}$ & $\begin{array}{l}.21 \\
.19 \\
.18\end{array}$ & $\begin{array}{l}.22 \\
.20 \\
.19\end{array}$ & $\begin{array}{l}.24 \\
.22 \\
.21\end{array}$ & $\begin{array}{l}.27 \\
.24 \\
.23\end{array}$ & $\begin{array}{l}.32 \\
.29 \\
.27\end{array}$ \\
\hline Over 35 & $\frac{1.07}{\sqrt{N}}$ & $\frac{1.14}{\sqrt{N}}$ & $\frac{1.22}{\sqrt{N}}$ & $\frac{1.36}{\sqrt{N}}$ & $\frac{1.63}{\sqrt{N}}$ \\
\hline
\end{tabular}

Source: Kempthorne and Folks 1971 


\section{REFERENCES}

Abelson, P. H. (1992). "Remediation of Hazardous Waste Sites." Science, 255, 901.

Adamson, A. W. (1967). Phystcal Chemistry of surfaces, 2nd Ed. Interscience Publishers, NY.

Anliker, R. and Moser P. (1987). "The Limits of Bioaccumulation of Organic Pigments in Fish: Their Relation to the Partition Coefficient and the Solubility in Water and Octanol." Ecotoxicol. Environ. Safety, 13, $43-52$.

Allen, J. B., Joyce, R. S. and Kasch, R. H. (1967). "Process Design Calculations for Adsorption from Liquids in Fixed Beds of Granular Activated Carbon." J. Water Pollut. Control Fed., 39(2), 217-229.

American Concrete Institute (ACI). (1981). Building Code Requirements for Reinforced Concrete: ACI Standard $318-$ 77, Detroit, Michigan.

American Institute of Steel Construction (AISC). (1986). Manual of Steel Construction. Load and Resistance Factor Design, 1st Ed., Chicago, Illinois.

Ames, B. N., Magaw, R. and Gold, L. S. (1987). "Ranking Possible Carcinogenic Hazards." Science, 236, 271-280.

Amy, G. L. and Cooper, W. J. (1986). "Air stripping of Volatile Organic Compounds Using structured Media." J. Environ. Engrg. Div., 112(4), 729-743.

Amy, G. L., Narbaitz, R. M. and Cooper, W. J. (1986). "Coupled Air Stripping and Activated Carbon Adsorption for the Removal of Volatile Organic Compounds from a Highly Colored Groundwater." Proc. AWWA 1986 Annual Conf., 1743-1754.

Anastos, G. J. et al. (1988). "Innovative Technologies for Hazardous Waste Treatment." Nucl. Chem. Waste Manage., $8,269-281$.

Ang, A. H-S. and Tang, W. H. (1975). Probability Concepts in Engineering Planning and Design: Volume I: Basic Principles, John Wiley and Sons, NY. 
Ang, A. H-S. and Tang, W. H. (1984). Probability concepts in Engineering Planning and Design. Volume II: Decision. Blsk and Reliablility, John Wiley and Sons, NY.

Apostolakis, G. et al. (1980). "Specialfzation for Plant Speclfic Risk Studies." Nucl. Eng. Des., 56, 321-229.

Arvin, E. et al. (1990). "Microblal Degradation of Mixtures of Aromatic Compounds at Low Concentrations Under Aerobic Conditions." Proc. Organic Mircopollutants in the Aquatic Environ., Lisbon, Portugal, 174-183.

Ball, B. R. and Edwards, M. D. (1992). "Air stripping vocs from Groundwater: Process Design Considerations." Environ. Prog., 11(1), 39-48.

Ball, W. P., Jones, M. D. and Kavanaugh, M. C. (1984). "Mass Transfer of Volatile Organic Compounds in Packed Tower Aeration." J. Water Pollut. Control Fed., 56, 127-136.

Banerfee, S. et al. (1984). "Development of a General Kinetic Model for Blodegradation and Its Application to Chlorophenols and Related Compounds." Environ. Sci. Technol., 18(6), 416-422.

Banerjee, S., Yalkowsky, S. H. and Valvanl, S. C. (1980). "Water Solubility and Octanol/water Partition Coefficients of organics. Limitations of the Solubility-Partition Coefficient Coorelations. "Environ. Sc1. Technol., 14, 1227-1229.

Bell, J. P. et al. (1991). "Estimating Treatability Parameters for Predicting the Fate of VoCs in Wastewater Treatment Plants." 84th Annual Air and Waste Management Assoc. Symposium, Vancouver, BC, June 16-21, 1991.

Beltrame, P., Beltrame, P. L. and Carnit1, P. (1984). "Influence of Feed Concentration on the kinetics of Blodegradation of Phenol in a Continuous Stirred Reactor." Water Res., 18(4), 403-407.

Beltrame, P. et al. (1982). "Kinetics of Blodegradation of Mixtures Containing 2,4-Dichlorophenol in a Continuous Stirred Reactor." Water Res., 16(4), 429-433.

Beltrame, P. et al. (1980a). "Kinetics of Biodegradation of Phenol and 2,4-Dichlorophenol in a Continuous Stirred Reactor." Milano Socie'a de Chimica Industriale, 62(9), $659-662$. 
Beltrame, P. et al. (1980b). "Kinetics of Phenol Degradation by Activated Sludge in a Continuous-Stirred Reactor." J. water Pollut. Control Fed., 52(1), 126-133.

Beltrame, P. et al. (1979). "Kinetics of Phenol Degradation by Activated Sludge: Value of Measurements in a Batch Reactor." Water Res., 13, 1305-1309.

Blackburn et al. (1985). Organtc Chemical Fate Predict on in Activated sludge Treatment Rrocesses, EPA-600/2-85/102, Cincinnat1, OH.

Bodor, N., Gabanyi Z. and Wong, C-K. (1989). "A New Method for Estimation of Partition Coefficient." J. Am. Chem. Soc., 111, 3783-3786.

Bollu, W. L. et al. (1986). "Kinetics of Anaeroblc Purification of Industrial Wastewater." Blotech. Bloeng., 28, 542-548.

Borighem, G. and Vereecken J. (1981). "Model of a Chemostat Utilizing Phenol as Inhibitory substrate." Ecol. Model., 12(4), 231-243.

Boyd, S. A. et al. (1983). "Anaerobic Blodegradation of Phenolic Compounds in Digested Sludge." Appl. Environ. Microb., 46 (1), 50-54.

Boyd, S. A. and Shelton, D. R. (1984). "Anaerobic Biodegradation of Chlorophenols in Fresh and Acclimated Sludge." Appl. Environ. Microb., 47(2), 272-277.

Briggs, G. G. (1981). "Theoretical and Experimental Relationships Between Soll Adsorption, Octanol-Water Partition Coefficients, water solubilities, Bioconcentration Factors, and the Parchor." J. Agric. Fd. Chem., 29, 335-346.

Buisson, R. S. K., Kirk, P. W. W. and Lester, J. N. (1988). "The Behavior of Selected Chlorinated Organic Micropollutants in the Activated Sludge Process: A P1lot Plant study." Water, Air and Soll Pollution, 37 , $419-432$.

Calgon Corp. (1976). F1ltrasurb 300 and 400 for Wastewater Treatment, Activated Carbon Product Bulletin, 20-2e.

Callahan, M. A. et al. (1977). Water-Related Environmental Eate of 129 Priority Pollutants, Vol. II, EPA 440/4-79029b, U.S. Environmental Protection Agency, Washington, D.C. 
Cartwright, P. S. (1987). "Economic and Design Factors in the Application of Reverse Osmosis to Metal Finiahing Solute Recovery." Proc. AESF Ann. Tech. Conf., Orlando, FL, 74, 1-16.

Chadderton, R. A., M1ller, A. C. and McDonnell, A. J. (1982). "Uncertainty Analysis of Dissolved Oxygen Model." J. Environ. Engrg. Div., 108(EE5), 1003-1013.

Cheremisinoff, P. N. and Ellerbusch, F., (eds). (1978). Carbon Adserption Handbeok, Ann Arbor Science, Ann Arbor, MI.

Chi, C. T. and Howell, J. A. (1976). "Transient Behavior of Continuous stirred Tank Blological Reactors Utilizing Phenol as an Inhibitory Substrate." Blotech. Bioengrg., $18(1), 63 \cdot 80$.

Chiou, C. T., Schmedding, D. W. and Manes, M. (1982). "Partitioning of Organic Compounds in octanol-Water Systems." Environ. Sc1. Technol., 16, 4-10.

Chou, W. L., speece, R. L. and Siddig1, R. H. (1979). "Acclimation and Degradation of Petrochemical Wastewater Components by Methane Fermentation." Biotechnical and Bloengineering Symposium No. 8, 391-414.

Chow, V. T. (1954). "The Log-Probability Law and Its Engineering Applications." Proc. ASCE 80, 536-1-536-25.

Chudoba, J. et al. (1989). "Blodegradation of 2,4Dichlorophenol by Activated Sludge Microorganisms. "Wat. Res., 23(11), 1439-1442.

Connell, P. J. and Dickson, J. M. (1988). "Modeling Reverse Osmosis Separations with Strong Solute-Membrane Affinity at Different Temperatures Using the Finely Porous Model." J. Appl. Polym. Sci., 35(5), 1129-1148.

Convery, J. J., Cohen, J. M. and Bishop, B. F. (1980). "Occurrence and Removal of Toxics in Municipal Wastewater Treatment Facilities." Seventh Joint United States Japan Conference, Tokoyo, Japan.

Council on Environmental Quality (CEQ) . (1990). Environmental Quality: 218t Annual Report.

Crittenden, J. C. et al. (1987). "Design Considerations for GAC Treatment of Organic Chemicals." J. AWWA, 79(1), 7482 . 
Crittenden, J. C. and Weber, W. J., Jr. (1978). "Predictive Model for Design of Flxed-Bed Adsorbers: Parameter Estimation and Model Development." J. Environ. Engrg. Div., 104 (EE2), 185-197.

Crogs, W. H. et al. (1982). "Anaerobic Blological Treatment of Coal Gasifier Effluent." Blotechnol. Bloengrg. Symp., $12,349-363$.

Cummins, M. D. (1982a). Packed Column Alr stripoing P1lot Test. Brewster. New York, February 10, 1982. EPA Report, Office of Drinking Water, Technical Support Division, Cincinnati, OH.

Cummins, M. D. (1982b). Eleld Evaluation of Tricholorethylene Removal by Packed Column Atr stripoing Landsale PA August $10,1982$. EPA Report, Offlce of Drinking Water, Technical Support Division, Cincinnati, OH.

Cummins, M. D. (1982c). Eleld Evaluation of Packed Column Air stripoing. Glen Cove, NY - August 20 and December 14-16, 1982. EPA Report, Office of Drinking Water, Technical support Division, Cincinnati, OH.

Cummins, M. D. (1982d). Eleld Evaluation of Trichloreethylene Removal by Packed column Alr stripeting, olean, NY - May 25. 1982. EPA Report, Office of Drinking water, Technical Support Division, Cincinnati, OH.

Cummins, M. D. (1982e). Eleld Evaluation of Packed Column Atr stripoing. Rockaway Township, NJ - August $17,1982$. EPA Report, Office of Drinking Water, Technical Support Division, Cincinnati, OH.

Cummins, M. D. (1982f). Fleld Evaluation of 1,1.1Irichloroethane Removal by Packed Column Air stripoing, Dedham, MA - Auguat 24, 1982. EPA Report, Office of Drinking Water, Technical Support Division, Cincinnati, $\mathrm{OH}$.

Cummins, M. D. (1982g). Field Evaluation of Trtchloreethylene Removal by Packed Column Atr stripplng, Delavan, WI October 1 1982. EPA Report, Offlce of Drinking Water, Technical Support Division, Cincinnati, OH.

Cummins, M. D. (1985a). Eleld Evaluation of Packed Column Air Stripoing. Bastrop, LA - February 1984. EPA Report, Office of Drinking Water, Technical support Division, Cincinnati, OH. 
Cummins, M. D. (1985b). Fleld Evaluation of Racked Column Air stripping, Vallay Park, MO - March 1985. ERA Report, offlce of Drinking Water, Technical support Diviaion, Cincinnati, OH.

Cummins, M. D. (1985c). Field Evaluation of Packed column Air stripoting. Palm Beach Gardens. FI- Apr11 1984. EPA Report, Office of Drinking Water, Technical support Division, Cincinnati, OH.

Cummins, M. D. and Westrick, J. J. "Treatment Technologies and Costs for Removing Volatile Organic Compounds from Water: Aeration" in sianificance and Treatment of Volatile organic Compounde in Water suppliten, Lewis Publishers, Chelsea, MI, 1990.

Dale, J., Malcolm, J. and Klotz, I. M. (1946). Ind. Eng. Chem. , 38(1), 289.

Debelak, K. A. and Sims, C. A. (1981). "Stochastic Modeling of an Industrial Activated Sludge Process." Wat. Res., 15, $1173-1183$.

Desal, S., Govind, R. and Tabak, H. (1990). "Determination of Monod KInetics of Toxic Compounds by Resplrometry for Structure-Blodegradability Relationships." Emerging Technologies in Hazardous Waste Management. Tedder, $D$. W. and Pohland, F. G. (eds), Am. Chem. Soc.

Dettinger, M. D. and Wilson, J. L. (1981). "First order Analysis of Uncertainty in Numerical Models of Groundwater Flow; Part 1. Mathematical Development." Water Resour. Res., 17(1), 149-161.

Dewey, R. J. (1984). "Application of Stochastic Dissolved Oxygen Model." J. Environ. Engrg., 110(2), 412-429.

Dewolf, G, et al. (1984). The cest Digest: Cost summartes of Selected Environmental control Technologies, EPA$600 / 8-84-010$.

Dietrich, C., Treichler, D. and Armstrong, J. (1987). An Evaluation of Rotary Atr strloping for Removal of Volatile erganics from Groundwater, ESL-TR-86-46, Final Report. Engineering and Services Laboratory, Air Force Engineering and Services Center, Tyndall Alr Force Base, FL. 
Dobbs, R. A., Jelus, M. and Cheng, K-Y. (1988). "Partitioning of Toxic Organic Compounds on Municipal Wastewater Treatment Plant Sol1ds." In Btotechnology for Degradation of Toxtc Chemicale to Hazardous Wasted, Noyer Data Corp., Park Ridge, NJ, 584-600.

Dobbs, R. A., Wang, L. and Govind, R. (1989). "Sorption of Toxic Organic Compounds on Wastewater Sol1de: Correlation with Fundamental Properties." Environ. Sc1. Technol., 23, 1092-1097.

Doll, R. and Peto, R. (1981). "The Causes of Cancer Quantitative Estimates of Avoldable Risks of Cancer in the United States Today." J. Nat. Cancer Instit., 66, $1191-1309$.

Draaljer, H. et al. (1992). "Performance of the 5 MLD UASB Reactor for sewage Treatment at Kanpur, India." Water Sc1. Technol., 25, 7, 123-133.

Dwyer, D. F. et al. (1986). "Klnetics of Phenol Blodegradation by an Immobilized Methanogenic Consortium." Appl. Environ. Microb., 52(2), 345-351.

Eckenfelder, W. W., Jr. and Roth, J. A. (1976). "Effluent Variability as Related to Developing Performance standards." Prog. Water Technol., 8(1), 1-14.

Eckenfelder, W. W. , Jr. (1989). Induntrial water Poldution Centrol, 2nd Ed., McGraw-H111, NY.

Edwards, V. H. (1970). "The Influence of High substrate Concentrations on Microbial Kinetics." Biotech. Bloeng., 12, 679-712.

El-Dib, M. A. and Badawy, M. I. (1979). "Adsorption of Soluble Aromatic Hydrocarbons on Granular Activated Carbon." Wat. Res., 13, 255-258.

Ellis, J. H., McBean, E. A. and Farquhar, G. J. (1985). "Stochastic Optimization/Simulation of Centralized Liquid Industrial Waste Treatment." J. Environ. Engrg. , $111(6), 804-821$.

Evangelista, F. (1987). "Approximate Design Method for Reverse Osmosis Plants Equipped with Imperfectly Refecting Membranes." Ind. Eng. Chem. Res., 26, 1109 1116. 
Fair, J. R. et al. (1973). Chemtand Englnears Handbook, 5th Ed. Chapter 18, Chilton, C. H. (ed), McGraw-H111, NY, 1973.

Fa1r, G. M. Geyer, J. C. and Okum, D. A. (1986). Water and Watiewater Enatinearing, W1ley, NY.

Ford, D. L. (1976). "Factore Affecting varlability from Waste Water Treatment Plants." Prog. Water Technol., $8(1), 91 \cdot 111$.

Freudenthal, A. M. (1947). "The safety of structures." ASCE Transactions, $112,125-159$.

Gass, S. I. (1977). "Evaluation of Complex Model. " Comput. 4 Ops. Res., 4, 27-35.

Gase, S. I. and Joel, L. S. (1981). "Concepts of Model Conf1dence." Comput. Ops. Res., 8(4), 341-346.

Gaudy, A. F., Jr, Rozich, A. F. and Gaudy, E. T. (1986). "Act Ivated Sludge Process Model for Treatment of Toxic and Non-tox1c Wastes." Water Sc1. Technol., 18, 123-137.

Gaudy, A. F., Jr, et al. (1987). "Methodology for Ut111zing Resplrometric Data to Aseess Blodegradation Kinetics." 42 nd Annual Industrial Waste Conference Proceedings, Purdue University, West Lafayette, IN.

Gaudy, A. E., Ekambaram, A. and Rozlch, A. F. (1989). "A Respirometric Method for Blokinet1c Characterization of Toxic Wastes." 43 rd Purdue Industrial Waste Conterence Proceedings, Lewis Publ., Chelsea, MI, 35-44.

Govind, R., Lal, L. and Dobbs, R. (1991). "Integrated Model for predicting the Fate of Organics in Wastewater Treatment Plants." Environ. Prog., 10(1), 13-23.

Grady, C. P. L., Jr. (1990). "Blodegradation of Toxic Organics: Status and Potential." J. Environ. Engrg. $116(5), 805-828$.

Graham, P. W. (1969). "Kinet1c Aspects of the Treatment of Phenolic Wastes." Advances in Water Pollut. Res., Fourth Int. Conf., Prague, Czechoslovakia.

Gross, R. L. (1985). Development of Packed-Tower Air Strippers for Trichloroethylene Removal at Wurtamith Atr Eerce Base, Michtaan, ESL-TR-85-28, Elnal Report, Engineering and Services Laboratory, Air Force Engineering and Services Center, Tyndali AFB, Flordia. 
Haggblom, M. $M$. and Salkinoja.Salonem, M. (1991). "Blodegradability of Chlorinated Organic Compounde in Pulp Bleaching Efeluents." Water Sc1. Technol., 24(3-4), 161.170.

Hand, D. W., Crittenden, J. C. and Thacker, W. E. (1984). "Simplified Model for Design of F1xed-Bed Adeorption syetems." J. Environ. Engrg., 110(2), 440.456.

Hannah, S. A. et al. (1988). "Removal of Organic Toxic Pollutants by Trickling Filter and Activated sludge." $\mathrm{J}$. Wat. Pollut. Control Fed., 60(7), 1281-1283.

Hannah, 9. A. et al (1986). "Comparative Removal of Toxic Pollutante by $\mathbf{s 1 x}$ Wastewater Treatment Procesees." $\mathrm{J}$. Wat. Pollut. Control Fed., 58(1), 27.34.

Hasoter, A. M. and LInd, N. C. (1974). "Exact and Invariant Second-Moment Code Format." J. Eng. Mech. D1V., 100 (BMI), $111-121$.

Hattis, D. and Kennedy, D. (1986). "Aseeseing Risks exom Health Hazarde: An Imperfect Sclence." Technology Review, $89(4), 60-71$.

Hauptmanns, U, and Hómke, P. (1989). "Bayesian Eet Imation of Fallure Rate Distributions for Components in Procese Plants." Ind. Eng. Chem. Res., 28, 1639.1644.

Healy, J. B., Jr. and Young, L. Y. (1978). "Catechol and Phenol Degradation by a Methanogenic Population of Bacter1a." Appl. Environ. Microb., 35(1), 216-218.

Healy, J. B., Jr. and Young, L. Y. (1979). "Anaeroblc Blodegradation of Eleven Aromat 1c Compounde to Methane." Appl. Environ. Microb., 38(1), 84-89.

Henderson, B. E., Rose, R. K. and P1ke, M. C. (1991). "Toward the Primary Prevention of Cancer." Science, 254, 1131. 1138.

Hickey, R. F. and Goodwin, S. (1989) . "Anaerobic Processer." $J$. Water Pollut. Control Fed., 61(6), 814-821.

Howard, P. H. (1989). Handbook of Envtronmental Face and Expogure Data for Organte Chemicale, Volg, I and II. Lew1s Publ., Chelsea, MI. 
Howe11, J. A., Ch1, C. T. and Paloweky, U. (1972). "gefect of Wall Growth on scale-up Problems and Dynamic Operating Characterietic of Blological Reactor." Blotech. Bloengrg., 14(2), 253-265.

Hutchine, R. A. (1973). "New Method simplifles Design of Act 1vated.Carbon Syetems." Chem. Eng., Auguet 20, 133 . 138.

International Mathematical statietical Llbrary (IMSL). (1987). Reference Manual, Houeton, TX.

Isnard, P. and Lambert, s. (1988). "Betimating Bloconcentration Factore erom Octanol-Water Partition Coeffleient and Aqueous solublilty." Chemosphere, 17. $21 \cdot 34$.

Jacobs, T. and Veollind, A. (1992). "Probab1l1et1c Environmental Rigk of Hazardoue Materials." J. Environ. Engrg., $118(6), 878.889$.

Jaynew, E. T. (2986). "Bayestan Methode: Ceneral Background," in Maximum Bntropy and Bayentan Mathod in Apolited Ptatintice, Justice, J. H. (ed), Cambridge Univereity Preas.

Jones, E. J. (1984). Rate of Toxtc organtc Compound in in Activated sluden and Intearated Act lyated sludan/Carbon Trentment syatem, PhD Diesertation, Univereity of Michigan, Ann Arbor, MI.

Kavanaugh, M. C. and Truese11, R. R. (1980). "Design of Aeration Towers to strip Volatile Contaminants $t r o m$ Drinking Water." J. Am. Water Works Aswoc, $72(12), 684$. 692.

Kempthorne, O. and Folke, L. (1971). Rrobabllity statiftica and Date Analyeta. Iowa state University Prese, Ames, IO.

KIncannon, D. F. et al. (1983a). "Removal Mechantems for Toxic Prlorlty Pollutants." J. Water Pollut. Control Fed., 55(2), 157-163.

Kincannon, D. F. et al. (1983b). "Predicting Treatabl11ty of Multiple organic Priority Pollutant Wastewater from single-Pollutant Treatablilty studies." Proc. $37 \mathrm{th}$ Ind. Waste Conference, Purdue U., Ann Arbor Sc1., 641.650. 
King, C. J. (1964), "The Additivity of Individual phase Resistances in Mass Transfer Operations." AIChE J., 10, 671.677 .

Kinman, R. N., Nutini, D. and stamm, J. W. (1985). "Reverae Omosi. Membrane Pouling, Electrolese Copper Plating Solutione." Matal Finish., 83, 53.

Kiriyama, K., Tanaka, Y. and Mor1, I. (1992). "Fleld Test of a Composite Methane Gas Production Syetem Incorporating a Membrane Module for Munlcipal Sewage." Water Sc1. Technol., 25, 7, 135-141.

Kittlkul, P. ot al, (1990). "study of High water Temperature Etect on Air stripping of volatile and silghtly Volat1le Organice 2 rom Water." $44 \mathrm{th}$ Purdue Induetrial Waste Conterence Proceedings, Lewie Publ., Chelsea, MI, $435 \cdot 452$.

Xleopter, $R$. D. et al. (1980). "Prinrity Pollutant Methodology Quality Assurance Review." Internal Rep., U.s. BPA, Kaneas City, Kaneas.

Knol1, G. et al. (1987), "Anaerobic Degradation of Aromat 1c and Halogenaromatic Compounde in Wastewater." Tech. of Blol. Proc., Safety in Blotech., Appl. Genet ic Engrg.: 5th DECHEMA Canv., Frankfurt, FRG., 409.415.

Knoll, G. and Winter, J. (1987). "Aneroble Degradation of Phenol in Sewage Sludge." Appl. Microblol. Blotechnol.., 25, $384 \cdot 391$.

Lamarche, P. and Droste, R. L. (1989). "Alr Stripping Mass Tranafer Correlation for Volatile Organics." J. Amer. Wat, Worke Assoc., 81(1), 78-89.

Larsen, R. J. and Marx, M. L. (1986). An Introduction to Mathematicel statintias and ter Appltantione, 2nd Ed. Prentice Hall, Englewood Clifts, NJ.

Leo, A., Hansch, C. and Elkins, D. (1971). "Partition Coefficients and Their Uses." Critical Reviews, 71(6), $525 \cdot 616$.

Lettinga, $G$. et al. (1980). "Use of the Uptlow Sludge Blanket (USB) Reactor Concept for Blological Wastewater Treatment Eapecially tor Anaerobic Treatment." Blotech. Bloeng., 22, 699-734. 
Leuenberger, C. et al. (1985). "Peraletent Chemical in Pulp Mili Efeluente; Occurance and Behaviour in an Activated Sludge Treatment Plant." Water Res., 19(7), 885.894.

Lewandowek1, G. Baltzla, B. and Varuntanya, C. P. (1986). "The Use of Pure Cultures as a Means of Understanding the Performance of Mixed Cultures in Blodegradation of Phenol1ce." Blotechnology for Dearadation of Toxis Chemicaln in Harardous Hinte, Scholze, R. J., Jr. (ed), Noyes Data Corp, Park Ridge, NJ.

Lund, J. R. (1991). "Random Variablea versus Uncertain Values: Stochastic Modeling and Design." J. Water Resour. Planning Management, $117(2), 179-194$.

Lyandres, S., Meardon, J. and Rees, J. (1989). "Evaluation of Membrane Processes for the Reduction of Trace Organic Contaminante." Environ. Prog., 8(4), 239-244.

Mabey, W. R. et al. (1982). Bquatle Fate Procene Data for erganic Extority Pellutante, EPA-440/4-81-041, U.S. Environmental Protection Agency.

Mackay, D. and Shiu, W. Y. (1981). "A Critical Review of Henry' Law Constant for Chemical of Environmental Interest." J. Phys. Chem. Ret. Data, 10(4), 1175-1199.

Mackay, D., ShIu, W. $Y$, and sutherland, R. P. (1979). "Determination of Air-Water Henry' Law Conetants for Hydrophoblc Pollutante." Environ. Scl. Tech., 13(3), $333-337$.

Mackey, J. K. and Grady, C. P. L., Jr. (1988). "The Influence of Population Dynamics on the 'steady-state' Blodegradation of 2-Chlorophenol by a Mixed Microbial Communtty." Water Sc1. Technol., 20(11/12), 477-479.

MacNe11, J. C. (1988). "Membrane Separation Technologies for Treatment of Hazardous Wastes." CRC Critlcal Reviews in Environ. Control, 18(2), 91-131.

Mallhot, H. and Peters, R. H. (1988). "Emplrical Relationships Between the 1-Octanol/Water Partition Coefficient and Nine Physicochemical Properties." Environ. Sc1, Tech., 22(12), 1479-1488.

Marr, J. K. and Canale, R. P. (1988). "Load Allocation for Toxics Using Monte Carlo Techniques." J. Water Pollut. Control Fed., 60(5), 659-666. 
Martin, E. J. and Johnson, J. H. (eds). (1987). Hazardous Waste Management Engtneering, Van Nost rand Reinhold Co., NY.

McCarty, P. L. (1980). "Organics in water - An Engineering Challenge." J. Environ. Engrg. Div., Proc. ASCE, EE1, 117.

Melcer, H. and Bedford, W. K. (1987). "The Fate of 4,6. Dinitro-0-Cresol in Municipal Activated Sludge syetems." International Conference on Innovative Blological Tratment of Toxic Wastewaters, Arlington, VA, 532-542.

Melcer, H. and Bedford, W. K. (1988). "Removal of Pentachlorophenol in Municipal Activated Sludge Systems." J. Water Pollut. Control Fed., 60(5), 622-626.

Metcalf and Eddy, Wastewater Englnearing: Treatment. Difperal, Reuse, 2nd Bd. McGraw-H111, NY, 1979.

Miller, M. M. et al. (1985). "Relationships Between Octanol. Water Partition Coefficient and Aqueous Solubility." Environ. Sci. Technol., 19, 522-529.

Monte1th, H. D. (1987). "Fluctuations of Trace Contaminants on Sewage Treatment Plants." Monograph No. 1, Canadian Association on Water Pollution Research and Control, Burlington, Ontario.

Morgan, M. G. (1981). "Choosing and Managing TechnologyInduced Risk." IEEE Spectrum, 18(12), 53-60.

Muldowney, G. P. and Punz1, V. L. (1988). "A Compartson of Solute Rejection Models in Reverse Osmosis Membranes for the System Water-Sodium Chloride-Cellulose Acetate." Ind. Eng. Chem. Res., 27, 2341-2352.

Mumford, R. L. and Schnoor, J. L. (1982). "Alr Stripping of Volatile Organics in Water." Proc. Am. Wat. Works Assoc. Annual Conf., Miami Beach, FL.

Mumford, R. L. and Schnoor, J. L. (1985). "Mass Transfer of Volatile Organics in a Packed Bed Stripper." Proc. Am. Wat. Works Assoc. Annual Conf., Washington, DC.

Namkung, E. and Rittmann, B. E. (1987). "Estimating Volatile Organic Compound Emiseions from Publicly Owned Treatment Works." J. Water Poll. Control Fed. 59(7), 670-678. 
National Council of the Paper Industry for Air and stream Improvement, Inc. (NCASI). (1986). Simulation of Organic Compound Removal in Biolgocial Wastewater Treatment Processes, Technical Bulletin No. 511, New York, NY.

National Research Council (NRC). (1977). Drinking Water and Health, National Academy of Sciences, Washington, DC.

National Research Council (NRC). (1991). Environmental Epidemiology: Volume 1 , Public Health and Hazardous Waste, National Academy Press, Washington, DC.

National Research Council (NRC). (1985). Reducing Hazardous Waste Generation: An Evaluation and a Call for Action, National Academy Press, Washington, DC.

Neufeld, R. D., Mack, J. D. and Strakey, J. P. (1980). "Anaerobic Phenol Biokinetics." J. Wat. Pollut. Control Fed., 52(9), 2367-2377.

Niimi, A. J. (1991). "Solubility of Organic Chemicals in Octanol, Triolein and Cod Liver Oil and Relationships Between Solubility and Partition Coefficients." Wat. Res., 25 (12), 1515-1521.

Niku, S. et al. (1981). Performance of Activated Sludge Processes: Reliability, stability and Variability, EPA$600 / 2-81-227$.

Niku, S., Samaniego, F. and Schroeder, E. (1981). "Discharge Standards Based on Geometric Mean." J. Wat. Pollut. Control Fed., 53(4), 471-473.

Nirmalakhandan, N., Lee, Y. H. and Speece, R. E. (1987). "Designing a Cost-Efficient Air-Stripping Process." J. AWWA Research and Technology, 56-63.

Nyholm, N. et al. (1992). "Removal of Organic Micropollutants at PPB Levels in Laboratory Activated Sludge Reactors Under Various operating Conditions: Biodegradation." Wat. Res., 26(3), 339-353.

Olmstead, K. P. and Weber, W. J., Jr. (1990). "Statistical Analysis of Mass-Transfer Parameters for Sorption Processes and Models." Environ. Sci. Technol., 24(11), $1693-1700$.

Onda, K., Takeuchi, H. and Okumoto, Y. (1968). "Mass Transfer Coefficients Between Gas and Liquid Phases in Packed Columns." J. Chem. Engrg. Japan, 1(1), 56-62. 
Ong, S. K. and Bowers, A. R. (1990). "Steady-State Analysis for Blological Treatment of Inhibitory substrates." J. Environ. Engrg., 116(6), 1013-1028.

Otway, H. and von Winterfeldt, D. (1992). "Expert Judgment in Risk Analysis and Management: Process, Context, and Pitfalls." Risk Analysis, 12(1), 83-97.

Palanki, S. and Gupta, S. K. (1987). "Analytical Design Equations for Multisolute Reverse Osmosis Systems. "Ind. Eng. Chem. Res., 26, 2449-2454.

Palowsky, U., and Howell, J. A. (1973). "Mixed Culture Oxidation of Phenol 1 . Determination of Kinetic Parameters." Biotech. Bloengrg., 15(5) 889-896.

Parkin, G. F. et al. (1983). "Response of Methane Fermentation Systems to Industrial Toxicants." J. Water Pollut. Control Fed., 55(1), 44-53.

Parkin, G. F. and Owen, W. F. (1986). "Fundamental of Anaerobic Digestion of Wastewater Sludges." J. Environ. Engrg., 112(5), 867-920.

Patterson, J. W. and Kodukala, P. S. (1981). "Emission and Effluent Control-Biodegradation of Hazardous Organic Pollutants." Chem. Engrg. Prog., April, 48-55.

Penzias, A. (1989). "Teaching statistics to Engineers." Science, 244,1025 .

Petrasek, A. C. et al. (1983). "Fate of Toxic Organic Compounds in Wastewater Treatment Plants." $\mathrm{J}$. Water Pollut. Control Fed., 55(10), 1286-1296.

Pitter, P. (1976). "Determination of Biological Degradability of Organic Substances." Wat. Res., 10, $231-235$.

Pöpel, H. J. (1976). "A Concept for Realistic Effluent Standards." Prog. Water Technol., 8(1), 69-89.

Portney, P. R., (ed). (1991). Public policies for Environmental protection, Resources for the Future, Washington, DC.

Pugsley, A. G. (1966). The Safety of Structures, E. Arnold Publ. Ltd., London. 
Roberts, P. V. et al. (1985). "Evaluating Two-Resistance Models for Air Stripping of Volatile organic Contaminants in a Countercurrent, Packed Column." Environ. Sci. Tech., 19(2), 164-173.

Roberts, P. V. and Levy, J. A. (1985). "Energy requirements for Air Stripping Trihalomethanes." J. Am. Water Works Assoc., $77(4), 138-146$.

Rodericks, J. and Taylor, M. R. (1983). "Application of Risk Assessment to Food Safety Decision Making." Regul. Tox. \& Pharm., 3, 275-284,302-307.

Rogers, P. P. and Flering, M. B. (1986). "Use of systems Analysis in Water Management." Water Resour. Res., $22(9), 146 \mathrm{~S}-158 \mathrm{~S}$.

Rozich, A. F., Gaudy, A. F., Jr. and D'Adamo, P. D. (1983). "Predictive Model for Treatment of Phenolic Wastes by Activated Sludge." Water Res., 17(10), 1453-1466.

Rozich, A. F., and Gaudy, A. F., Jr. (1983). "Response of Phenol-Acclimated Activated Sludge Process to Quantitative Shock Loading." Proc. of the $38 \mathrm{th}$ Indust. Wast Conf., Prudue Univ., Lafayette, Ind., 725-736.

Russell, L. L., Cain, C. B. and Jenkins, D. I. (1983). "Impact of Priority Pollutants on Publicly Owned Treated Works Processes: A Literature Review." Proc. 37th Ind. Waste Confr., Purdue U., Ann Arbor Scl.

Samaneh, T. S. A. (1981). A Study of Benzene and Toluene Adsorption on Granular Activated Carbon, PhD Dissertation, Washington St. Univ.

Sammon, D. C. (1984). "Hyperfiltration Membranes, Their Stability and Life" in Synthetic Membrane Processes: Fundamentals and Water Applications, Belfort, G. (ed), Academic Press, Orlando.

Savage, L. J. (1954). The Foundations of Statistics, John Wiley and Sons, NY.

Scavia, D. et al. (1981). "Comparison of First-Order Error Analysis and Monte Carlo Simulation in Time-Dependent Lake Eutrophication Models." Water Resour. Res. , $17(4)$, 1051-1059.

Schellinkhout, A. and Collazos, C. J. (1992). "Full-Scale Application of the UASB Technology for Sewage Treatment." water Sci. Technol., 25, 7, 159-166. 
Schmidt-Bleek, F. et al. (1982). "Steps Towards Environmental Hazard Assessment of New Chemicals (Including a Hazard Ranking Scheme Based Upon Directive 79/831/ECC." Chemosphere, 11, 383-415.

Sherwood, T. K. , Pigford, R. I. and Wilke, C. R. (1975). Mase Iransfer, McGraw-Hill, NY.

Sitar, N., Cawlfield, J. D. and Kiureghian, A. D. (1987). "First-Order Reliability Approach to Stochastic Analysis of Subsurface Flow and Contaminant Transport." Water Resour. Res., 23(5), 794-804.

Siungley, J. E. et al. (1980). Irace Organics Remeval by Air Stripoing, Environmental science and Engineering, Gainsvilie, FL.

Slovic, P., Fischhoff, B. and Lichtenstein, S. (1979). "Rating the Risks." Environment, 21(3), 14-20, 36-39.

Song, J. S. and Lee, K. J. (1989). "Stochast1c Analysis of Radioactive Waste Package Performance Using First-Order Reliability Method." Waste Manage., 9, 211-218.

Speece, R. E., Nirmalakhandan, N. and Lee, Y. H. (1987). "Nomograph for Air stripping of VOC from Water." $\mathrm{J}$. Environ. Engrg., $113(2), 434-443$.

Speece, R. E. (1983). "Anaerobic Biotechnology tor Industrial Wastewater Treatment." Environ. Sc1. Tech., $17(9), 416 \mathrm{~A} \cdot 427 \mathrm{~A}$.

Speth, T. F. and Miltner, R. J. (1990). "Technical Note: Adsorption Capacity of GAC for synthetic Organics." $\mathrm{J}$. AWWA, $82(2), 72-75$.

Stover, E. L, et al. (1983). "Variability Analysis During Biological Treatability of Complex Industrial Wastewaters for Design." Proc. 37th Ind. Waste Conf. Purdue U., Ann Arbor Sci.

Suidan, M. T. et al. (1988). "Anaerobic Blodegradation of Phenol: Inhibition Kinetics and system stability." $\mathrm{J}$. Environ. Engrg., 114(6), 1359-1376.

Suidan, M. T. et al. (1983). "Anaerobic Fllters for the Treatment of Coal Gasification Wastewater." Biotech. Bioeng., 25, 1581-1596. 
Szetela, R. W. and Winnick1, T. Z. (1981). "A Novel Method for Determining the Parameter of Microbial Kinetics." Blotech. Bloengrg., 23(7), 1485-1490.

Tabak, H. H. et al. (1981). "Biodegradability studies with Organic Priority Pollutant Compounds." J. Water Pollut. Control Fed., 53(10), 1503-1518.

Tabak, H. H., Desal, S. and Govind, R. (1990). "Determination of Blodegradability Kinetics of RCRA Compounds Using Respirometry for structure-Activity Relationships." 44 th Purdue Industrial Waste Conference Proceedings, Lewis Publ., Chelsea, MI, 405-423.

Takashima, M. and speece, R. E. (1989). "Mineral Nutrient Requirements for High-Rate Methane Fermentation of Acetate at Low SRT." Research J. Water Poll. Control Fed., 61(11/12), 1645-1650.

Tatsuo, S. et al. (1973). "Continuous Treatment of Wastewater Containing Phenol by Candida Troplcalis." J. Ferment. Tech., 51(11), 809-812.

Tewari, Y. B. et al. (1982). "Aqueous Solubility and Octanol/water Partition Coefficient of Organic Chemicals at $25.0^{\circ} \mathrm{C}$." J. Chem. Engrg. Data, 27, 451-454.

Thomann, R. V. (1982). "Verification of Water Quality Models." J. Environ. Engrg. Div., 108(EE5), 923-940.

Topping, J. (1955). Errors of Observation and Their Ireatment, Institute of Physics, London.

Travis, C. C. and Cook, S. C. (1989). Hazardous Waste Incineration and Human Health, CRC Press, Boca Raton, FL.

Treybal, R. (1980). Mass Transfer operations, 3rd Ed., McGraw-Hill, NY.

Umphres, M. D. et al. (1983). "Trihalomethane Removal by Packed-Tower Aeration." J. Amer. Water Works Assoc., 75, $414-418$.

U.S. Congress. (1989). Office of Technology Assessment, Coming Clean: Superfund problems Can Be solved, OTAITE-433, U.S. Government Printing office, washington, DC. 
U.S. Congress. (1991). Offlce of Technology Assessment, comolex cleanup: The Environmental Legacy of Nuclear Weapens Rroduction, OTA-0-484, U.S. Government Printing office, Washington, DC.

U.S. Congress. (1983). Office of Technology Assessment, Technologies and Management strategles for Hazardous Wagte Control, OTA-M-196, U.S. Government Printing office, Washington, DC.

U.S. Congress. (1970). Clean Air Act, Public Law 91-604, Washington, DC.

U.S. Congress. (1977). Clean Water Act, Public Law 95-217, Washington, DC.

U.S. Congress. (1974). Safe Drinking Water Act, Public Law 93-523, Washington, DC.

U.S. Congress. (1976a). Resource Conservation and Recovery Act of 1976 (RCRA), Public Law 94-580, Washington, DC.

U.S. Congress. (1976b). Toxic substances Control Act (TSCA), Public Law 94-4691, Washington, DC.

U.S. Congress. (1980). Comprehensive Environmental Response, Compensation, and Liability Act (CERCLA), Public Jaw 96 510, Washington, DC.

U.S. EPA. (1980). Carbon Adsorption Isotherms for Toxic Qrganics, EPA-600/8-80-023.

U.S. EPA. (1979). Eate of Priority Pollutants in Publicly owned Treatment Works - Pilot Study, EPA-440/1-79-300.

U.S. EPA. (1985). ergantc Chemical Fate prediction in Activated Sludge Treatment Process, project summary, EPA- 600/S2-85-102.

U.S. EPA. (1983). Predicting Preferential Adsorption of organics by Activated Carbon, EPA-600/S2-83-047.

U.S. EPA. (1992). Risk Reduction Engineering Laboratory (RREL) Treatability Database, Version 4.0. Cincinnati, $\mathrm{OH}$.

U.S. EPA. (1983). Treatability Manual, Vol. III: Technology for Control/Removal of Pollutants, EPA-600/2-82-001c.

U.S. Nuclear Regulatory Commission. (1975). Reactor Safety Study, WASH-1400. 
Vieira, S. M. M. and Garcia, A. D., Jr. (1992). "Sewage Treatment by UASB-Reactor. Operation Results and Recommendations for Design and Utilization." Water Sc1. Technol., 25, 7, 143-157.

Walker, J. F., Wilson, J. H. and Brown, C. H., Jr. (1990). "Minimization of Chromium-Contaminated Wastewater at a Plating Facility in the Eastern United States." Environ. Prog., 9(3), 156-160.

Warwick, J. J. and Cale, W. G. (1987). "Determining the Likelihood of Obtaining a Reliable Model." J. Environ. Engrg., $113(5), 1102-1119$.

Watkin, A. T. (1984). Removal Mechantams for Prtortty Rollutants in the Activated Sludge Process, Masters Thesis, Vanderbilt University, Nashville, TN.

Weber, W. J., Jr. (1972). Physicochemical Processes for water Qualtty control, Wiley-Interscience, NY.

Weber, W. J., Jr. and Jones, B. E. (1984). "Toxic substance Removal in Activated Sludge Treatment Processes." Paper presented at the 1984 Annual Conference of the Water pollution Control Fed., New Orleans, LA.

Weber, W. J., Jr. and Liang, S. (1983). "A Dual ParticleDiffusion Model for Porous Adsorbents in Fixed Beds." Environ. Prog., 2(3), 167-175.

Weber, W. J., Jr. and Pirbazari, M. (1983). "Removal of Carbon Tetrachloride from Water by Activated Carbon." in Treatment of Water by Granular Activated Carbon, McGuire, M. J. and suffet, I. H., (eds), Advances in Chemistry Series 202, Am. Chem. Soc.

Weber, W. J., Jr. and Pirbazar1, M. (1981). Effectiveness of Activated Carbon for Removal of Texic and/or Carcinogenic compounds from Water supplieg, ERA 600/281-057, USEPA Office of Research and Development, Cincinnati, $\mathrm{OH}$.

Weber, W. J., Jr. and Smith, E. H. (1987). "Simulation and Design Models for Adsorption Processes." Environ. Sc1. Technol., 21(11), 1040-1050.

Weinberg, A. M. (1972). "Science and Trans-Science." Science, 177, 211. 
Westall, J. C. (1985). "Influence of pH and Ionlc strength on the Aqueous-Nonaqueous Distribution of Chlorinated Phenols." Environ. Sc1. Technol., 19(2), 193-198.

Williams, M., Deshmukh, R. and Bhattacharyya, D. (1990). "Separation of Hazardous Organics by Reverse Osmosis Membranes." Environ. Prog., 9(2), $118-125$.

Woods, S. L., Ferguson, J. F. and Benjamin, M. M. (1989). "Charaterization of Chiorophenol and Chloromethoxybenzene Biodegradation During Anaerobic Treatment." Environ. Sc1. Technol., 23(1), 62-68.

Yalkowsky, S. H., Valvant, S. C. and Mackay D. (1983). "Estimation of the Aqueous Solubility of Some Aromatic Compounds." Residue Rev., 85, 43-55.

Yang, J. and Speece, R. E. (1985). "Effects of Engineering Controls on Methane Fermentation Toxicity Response." $\mathrm{J}$. Water Pollut. Control Fed., 57(12), 1134-1141.

Yang, R. D., and Humphrey, A. E., (1975). "Dynamic and Steady State Studies of Phenol Degradation in Pure and Mixed Cultures." Biotech. Bloengrg., 17(8), 1211-1235.

Young, L. Y. and Rivera, M. D. (1985). "Methanogenic Degradation of Four Phenollc Compounds." Wat. Res., $19(10), 1325-1332$.

Yurteri, C. et al. (1987). "The Effect of Chemical Composition of Water on Henry's Law Constant." J. Wat. poliut. Control Fed., 59(11), 950-956. 

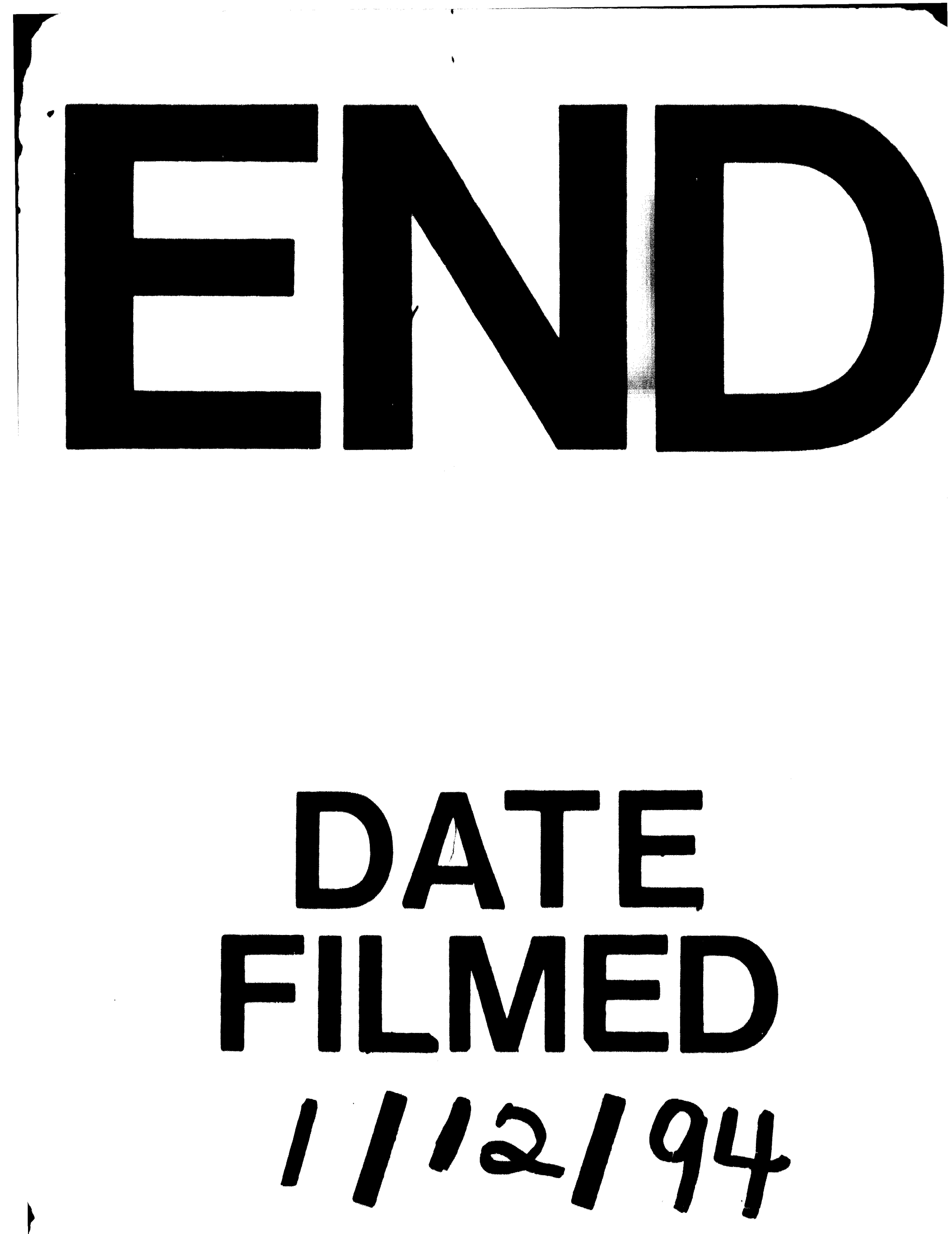
